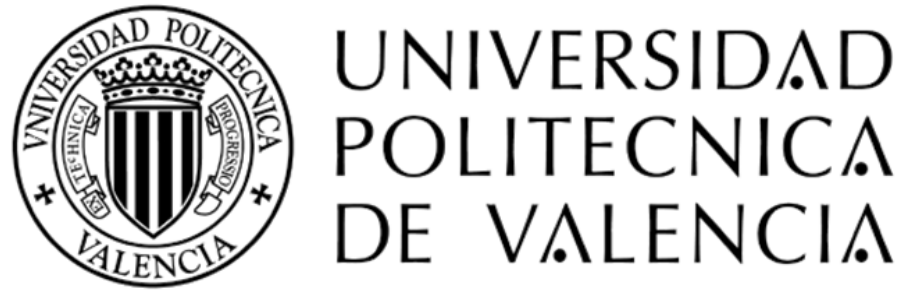

Departamento de Ingeniería de la Construcción y P. I. C.

\title{
Upgrading the push-off test to analyze the contribution of steel fiber on shear
} transfer mechanisms

\section{Javier Echegaray Oviedo}

- PhD thesis -

Supervisors:

Prof. Dr. Pedro Serna Ros

Prof. Dr. Juan Navarro Gregori
Tribunal:

Prof. Dr. Pedro Miguel Sosa

Prof. Dr. Antoni Cladera Bohigas

Prof. Dr. Antoni Marí Bernat 
A mis hermanos

Ana Laura y Rodrigo 



\section{Acknowledgments}

Agradezco especialmente a mi director, D. Pedro Serna Ros, por los conocimientos transmitidos, por su comprensión e interés, por su apoyo. Especialmente por haberme dado, no solo la oportunidad de participar de un proyecto experimental cómo siempre quise, sino también por permitirme estar en el "otro lado del mundo". Muchas gracias Pedro. También a mi co-director, D. Juan Navarro Gregori por darme la posibilidad de trabajar codo a codo, por escucharme y tener siempre esa palabra de aliento para seguir adelante aún cuando no me quedaban energías.

Agradezco de todo corazón a la gente que trabaja en el Departamiento de Ingeniería de la construcción y P. O. C. por el caluroso trato que me han brindado a lo largo de estos años. En particular a Marí José, por todas las risas y los buenos que hemos compartido. No puedo dejar de mencionar a la persona que me abrió las puertas (no sólo de su despacho) aún cuando yo estaba todavía en Argentina, muchas gracias José María Monzó.

Quiero expresar tambiíen mi agradecimiento a la gente responsable del programa EuroTANGO, que dentro del projecto Erasmus Mundus, permitieron mi manuntención en España. En especial quiesiera agradecer a Begoa, Geraldine y Ester, por preocuparse siempre de nosostros sus becarios, y también por hacernos ver que en la vida no todo es estudiar.

Agradezco a los técnicos del laboratorio su apoyo a lo largo de todo el proceso de la fase experimental. En especial a Paco y Jorge, por trabajar codo a codo conmigo en toda la etapa del laboratorio, por su alegría, por hacerme más llevadero los ensayos y por ser grandes amigos. Ha sido un gustazo trabajar con ustedes.

Quiero aprovechar para agradecer muy especialmente a mi gran amiga Estefanía Cuenca. Por todo su apoyo, por hacerme reír cuando quería matar a alguien, por parar dos segundos a escucharme cuando no tenía tiempo ni para ella. En definitiva, gracias por estar siempre que lo necesité, inclusive hoy a la distancia.

No puedo dejar de agradecer a mis compaeros del ICITECH, donde día a día respiramos el hormigón de las maneras más diversas que existen. En especial a Jaime, Javi, Carlos, Alberto, Moisés, Benjamín. A los comenzamos juntos el máster y a pesar de esa dosis seguimos aún acá, Tati, Yasna, Clara. A mis compaeros de la "mesa de materiales" a Juan Ángel y Marta. Hay dos personas que me las llevo en el corazón, gracias Vicente por ser mi hermano espaol y ensearme muchas cosas de la terreta; y muchas gracias Aitor por hacerme ver que los vascos nacemos donde nos da la gana.

A toda la familia de argentinos con quienes compartí y comparto desde un mate hasta una buena charla. Gracias Nahuel, Lucía, Paula (y tú Sergio también), Sergio, Mica, Mecha, a Juan Manuel (Tyson), pero especialmente a la Petisa por su constante apoyo y buena vibra, aún estando al otro lado del mundo.

También quiero agradecer a mis amigos que deje en San Juan, a ellos con los que viví muchas aventuras que hoy forman parte de mi tesoro más preciado, la amistad 
más sincera. Por entenderme y ayudarme a perseguir mis sueños. Porque a pesar de estar muy lejos los siento más cerca que nunca.

Por último y más importante, quiero agradecer a toda mi familia en especial a mis padres y mis hermanos. Porque a pesar de la distancia y la diferencia horaria siempre están ahí para acompaarme en todos los momentos importantes de mi vida. Por transmitirme a lo largo de los aos todos los valores y ayudarme a entender que con sacrificio y trabajo se logran maravillas. En definitiva a ellos les debo todo lo que soy.

Gracias de todo corazón

Javier A. Echegaray Oviedo 


\section{Abstract}

The shear behavior of a specimen made of reinforced concrete is complex. Resisting mechanisms are affected by different factors such as section form, slimness of the specimen, longitudinal and transversal reinforcement arrangement, bond between concrete and steel, among others. The addition of steel fibers to the concrete improves the ductility as well as the traction behavior; providing good control during the cracking process. Fibers also enhance the shear behavior of structural elements, increasing ultimate resistance and ductility.

Push-off tests had been used to study the mechanisms of shear transfer in concrete. Concluding that, shear strength of the specimen depends on the contribution of both concrete and shear reinforcement. Aggregate interlock (framed in crack shear friction theory) has a significant contribution to the concrete shear capacity. In the last decades new kinds of concrete have been developed for industrial use, such as high strength concrete (HSC), self-compacting concrete (SCC) or fiber reinforced concrete (FRC), among others. In these new materials, aggregate interlock phenomenon may be different when compared to conventional concrete (CC). There is a lack of information in literature about the mechanisms of shear transfer in fiber reinforced concrete elements.

Self-compacting concrete (SCC) is which, as a given a studied mixing proportion and by the utilization of superplasticizer additives, compacts by action of its own weight, without the need of vibrational energy or the use if any other compacting method; without segregation, lock of the coarse aggregate, bleeding, nor exudation of the cement grout. On the other hand, the addition of fibers modifies the behavior of fresh concrete, affecting, particularly, the packing density of aggregates.

This document is focused on studying shear behavior of self-compacting concrete reinforced with Steel fibers, but at a crack level. We evaluate crack resistance capacity, using different initial widths.

To assess the latter, we designed a rigid steel frame to confine the specimens, restricting crack width, buy allowing block movement, so as to improve stability and control on crack width. We will verify functioning and sensitivity of this confinement system, so we canto know and assess displacements suffered by the specimen blocks due to manipulation after precracking.

An extensive experimental program is developed for over 60 specimens. The aims of this program are, adjusting the design and calibrate general functioning of the restraint frame; defining in detail essay methodology; and finally, evaluate the possibility to detect and interpret different behaviors related to type of material tested.

It is also described the implementation of methodologies of discreet measurement. Photogrammetry of crack width and triangulation with DEMEC are used. Meaning that, measurements are taken between precracking test and push-off test. The objective is to know the relative movements that suffer the specimen, due to manipulation between tests. 
From the results obtained, it can be analyzed that the developed frame is capable of confining the specimen to effectuate the push-off test, without interfering with the slip displacement. It is evaluated that transmitted shear of the frame due to its vertical stiffness. In average, the frame effect represents $10 \%$ of total tension theoretically calculated. It is defined a basic friction coefficient that presents higher stability during the test. This friction coefficient is affected by maximum aggregate size and aspect ratio. 


\section{Resumen}

El comportamiento de una pieza de hormigón armado cuando se analiza su comportamiento frente a cortante es complejo. En los mecanismos resistentes influyen diversos factores como la forma de la sección, la esbeltez de la pieza, la disposición de las armaduras longitudinales y transversales, la adherencia entre el hormigón y el acero, entre otros. La adición de fibras metálicas al hormigón mejora tanto su ductilidad como su comportamiento a tracción; además proporciona un buen control durante el proceso de fisuración. Las fibras mejoran así el comportamiento frente a cortante de elementos estructurales, incrementando tanto su resistencia última como su ductilidad.

Los ensayos de push-off se han usado para estudiar los mecanismos de transferencia de cortante del hormigón. El engranamiento de áridos (que se enmarca en la teoría de fricción por cortante) tiene una contribución muy significativa para la resistencia del hormigón sin refuerzo. En las últimas décadas nuevos tipos de hormigones se han desarrollado para su uso en la industria, como el hormigón de alta resistencia (HAR), hormigón autocompactante (HAC) o el hormigón reforzado con fibras (HRF), entre otros. En estos nuevos materiales el fenómeno de engranamiento de áridos es diferente si se compara con hormigón tradicional (HT). En la literatura existe un vacío de información en los mecanismos resistentes frente a cortante de los hormigones autocompactantes reforzados con fibras.

El hormigón autocompactante (HAC) es aquel que, como consecuencia de una dosificacin estudiada y del empleo de aditivos superplastificantes, se compacta por la acción de su propio peso; sin necesidad de energía de vibración ni de cualquier otro método de compactación, no presentando segregación, bloqueo de árido grueso, sangrado, ni exudación de la lechada. Además, la adición de fibras modifica el comportamiento del hormigón en estado fresco, y en particular altera la densidad de empaquetamiento de los ridos.

A lo largo de este documento se pretende estudiar el comportamiento frente a cortante del hormigón autocompactante reforzado con fibras metálicas a nivel de la fisura, valorando la capacidad resistente de la fisura bajo distintos anchos iniciales.

Para llegar a ello, se disea un marco metálico con el cual se confina la probeta, restringiendo el ancho de fisura pero permitiendo el deslizamiento entre los bloques y as mejorar la estabilidad y el control del ancho de fisura. Se comprobará el funcionamiento y sensibilidad del marco de confinamiento, con el objetivo de conocer y valorar los desplazamientos que sufren los bloques que conforman la probeta producto de su manipulacin luego de prefisurada.

Se desarrolla un extenso programa experimental compuesto por más de 60 probetas. Los objetivos de este programa son, ajustar el diseo y calibrar funcionamiento general del marco de confinamiento; definir de manera detallada la metodología de ensayo; y finalmente, valorar si es posible detectar e interpretar distintos comportamientos en función del tipo de material ensayado. 
Se describe también la implementacin de metodologías de medicin discreta. Se utiliza la fotogrametría del ancho de la fisura y una triangulación con DEMEC. Es decir, se realizan mediciones entre el ensayo de prefisuración y el ensayo de pushoff. Con el objetivo de conocer los movimientos relativos que sufre la probeta debido a la manipulación entre ambos ensayos.

De los resultados obtenidos se desprende que el marco desarrollado es capaz de confinar a la probeta para realizar el ensayo de push-off, sin interferir con el deslizamiento por cizallamiento. Se valora el cortante que transmite el marco debido a su rigidez vertical. En valor medio, el efecto del marco representa el $10 \%$ del total de la tensión calculada teóricamente. Se define un coeficiente básico de fricción que presenta mayor estabilidad durante el ensayo. Este coeficiente de fricción, se ve afectado por el tamao mximo del árido y la esbeltez de la fibra.

Se presentan conclusiones finales y futuras líneas de investigación necesarias para ampliar el estado del conocimiento del comportamiento frente a cortante en hormigones autocompactantes reforzados con fibras de acero. 


\section{Resum}

El comportament d'un element de formigó armat quan s'analitza la seua resposta baix l'acció de sol-licitacions de tallant és complex. En els mecanismes resistents influeixen diversos factors com la forma de la secció, l'esveltesa de la pea, la disposició de les armadures longitudinals i transversals, l'adherència entre el formigó i l'acer, entre d'altres. L'addició de fibres metàl-liques al formigó millora tant la seva ductilitat com el seu comportament a tracció; ademés proporciona un bon control durant el procés de fissuració. Les fibres milloren així el comportament enfront de tallant d'elements estructurals, incrementant tant la seva resistència última com la seva ductilitat.

Els assaigs de push-off s'han usat per estudiar els mecanismes de transferència de tallant del formigó. El engranament d'àrids (que s'emmarca en la teoria de fricció per tallant) té una contribució molt significativa per a la resistència del formigó sense reforç. En les últimes dècades nous tipus de formigons s'han desenvolupat per al seu ús en la indústria, com el formigó d'alta resistència (HAR), formigó autocompactant (HAC) o el formigó reforçat amb fibres (HRF), entre d'altres. En aquests nous materials el fenomen de engranament d'àrids és diferent si es compara amb formigó tradicional (HT). En la literatura hi ha un buit d'informació en els mecanismes resistents davant tallant dels formigons autocompactants reforçats amb fibres.

El formigó autocompactant (HAC) és aquell que, com a conseqüència d'una dosificació estudiada i de l'ocupació d'additius superplastificant, es compacta per l'acció del seu propi pes; sense necessitat d'energia de vibració ni de qualsevol altre mètode de compactació, no presentant segregació, bloqueig d'àrid gruixut, sagnat, ni exsudació. A ms, l'addició de fibres modifica el comportament del formigó en estat fresc, i en particular altera la densitat d'empaquetament dels àrids.

Al llarg d'aquest document es pretén estudiar el comportament davant tallant del formigó autocompactant reforçat amb fibres metàl-liques a nivell de la fissura, valorant la capacitat resistent de fissures de diferents amplàries inicials.

Per arribar a això, es dissenya un marc metàl-lic amb el qual es confina la proveta, restringint l'ample de fissura però permetent el lliscament entre els blocs i així millorar l'estabilitat i el control de l'ample de fissura. Es comprovarà el funcionament i sensibilitat del marc de confinament, amb l'objectiu de conèixer i valorar els desplaaments entre els blocs que conformen la proveta producte de la seva manipulació desprs de prefissurada.

Es desenvolupa un extens programa experimental compost per més de 60 provetes. Els objectius d'aquest programa són, ajustar el disseny i calibrar el funcionament general del marc de confinament; definir de manera detallada la metodologia d'assaig; i finalment, valorar si és possible detectar i interpretar diferents comportaments en funció del tipus de material assajat.

Es descriu també la implementació de metodologies de mesurament discret. S'utilitza la fotogrametria de l'ample de la fissura i una triangulació amb DEMEC. És 
a dir, es realitzen mesuraments entre l'assaig de prefisuración i l'assaig de push-off. L'objectiu d'açò és conèixer els moviments relatius que pateix la proveta a causa de la manipulació entre tots dos assajos.

Dels resultats obtinguts es desprèn que el marc desenvolupat és capaç de confinar a la proveta per a realitzar l'assaig de push-off, sense interferir amb el lliscament per cisallament. Es valora el tallant que transmet el marc a causa de la seua rigidesa vertical. En valor mitjà, l'efecte del marc representa el $10 \%$ del total de la tensió calculada teòricament. Es defineix un coeficient bàsic de fricció que presenta major estabilitat durant l'assaig. Aquest coeficient de fricció, es veu afectat per la grandària màxima de l'àrid i lèsveltesa la fibra. 


\section{Contents}

Abstract $\quad$ iii

Contents

List of symbols $\quad$ xiii

List of figures $\quad$ xiii

List of tables $\quad$ xx

1 Introduction 1

1.1 Statement of problems ................... 1

1.2 Research aims . . . . . . . . . . . . . . . . 2

1.2.1 Specific objectives ................ 3

1.3 Thesis arrangement . . . . . . . . . . . . . . 4

2 State of the Art 5

2.1 Introduction . . . . . . . . . . . . . . . 5

2.2 Fiber Reinforced Concrete $(\mathrm{FRC}) \ldots \ldots \ldots$. . . . . . . 5

2.2.1 Material properties . . . . . . . . . . 6

2.2.2 Use of steel fibers as shear reinforcement . . . . . . . . . 9 
2.3 Main ideas on shear behavior in cracked concrete . . . . . . . . . 10

2.3.1 Failure modes . . . . . . . . . . . . . . . 12

2.4 Shear transfer mechanisms across crack interfaces . . . . . . . . . . 14

2.4.1 Aggregate interlock . . . . . . . . . . . . . 15

2.4 .2 Dowel action . . . . . . . . . . . . . . . 16

2.4 .3 Influencing factors . . . . . . . . . . . . . 17

2.5 Experimental tests on direct shear . . . . . . . . . . . . . . 18

2.5.1 Definition ....................... 19

2.5.2 Theories on direct shear . . . . . . . . . . . . . 19

2.5.3 Test methodologies . . . . . . . . . . . . . . . 22

2.5.4 Experimental results and mathematical models . . . . . . . 28

2.5.5 Panels test ...................... 42

2.6 Conclusions . . . . . . . . . . . . . . . . . . . 45

3 Design and development of test procedure $\quad 47$

3.1 Introduction . . . . . . . . . . . . . . . . 47

3.2 Concepts and definitions of the test . . . . . . . . . . . . . . 48

3.2.1 Push-off concept . . . . . . . . . . . . . 48

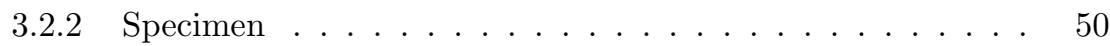

3.2.3 Restraint frame . . . . . . . . . . . . . . . . 54

3.2.4 Ball bearing . . . . . . . . . . . . . 57

3.2.5 Allowed initial crack width $\left(w_{o}\right) \ldots \ldots . \ldots 58$

3.3 Initial design and first approach . . . . . . . . . . . . . . . . 59

3.3.1 First approach to the restraint frame . . . . . . . . 59

3.3 .2 Procedure to set $w_{o} \ldots \ldots \ldots$. . . . . . . . 60

3.3.3 Precraking baseplate . . . . . . . . . . . . 61

3.3.4 Preliminary tests . . . . . . . . . . . . 61

3.3.5 Testing procedure and instrumentation . . . . . . . . 62

3.3.6 Results of the precracking phase . . . . . . . . 66

3.3.7 Results of the push-off phase . . . . . . . . . . . 71

3.3.8 Problems detected and their solutions . . . . . . . . . . . 74

3.4 Second approach to the test methodology . . . . . . . . . . 75 
3.4.1 Testing frame . . . . . . . . . . . . . 75

3.4.2 Restraint frame (Frame 2.0) . . . . . . . . . . . . 75

3.4.3 Numerical behavior of the restraint frame . . . . . . . . 76

3.4.4 Testing procedures and instrumentation used . . . . . . 78

3.4.5 Second preliminaries tests . . . . . . . . . . 80

3.4.6 Final considerations . . . . . . . . . . . . . . 89

3.5 Final test methodology . . . . . . . . . . . . . . . . . . . . 90

3.5.1 Testing frame . . . . . . . . . . . . . . . 90

3.5.2 Sliding baseplates . . . . . . . . . . . . . 91

3.5.3 New restraint frame . . . . . . . . . . . . . . . 93

3.5.4 Crack width photogrametry (optional) . . . . . . . . 97

3.5.5 DEMEC measurements . . . . . . . . . . . . . . 97

3.5.6 Strain gauges on the external restraint bars . . . . . . . . 99

3.5.7 Precracking procedure and instrumentation . . . . . . . 100

3.5.8 Push-off procedure and instrumentation . . . . . . . . . 100

3.5.9 Experimental results obtained . . . . . . . . . . . . 101

4 Experimental program $\quad 103$

4.1 Introduction . . . . . . . . . . . . . . . . 103

4.2 Experimental outline . . . . . . . . . . . . . . . . . . 104

4.2.1 Study parameters . . . . . . . . . . . . 104

4.2.2 Experimental program . . . . . . . . . . . 105

4.2 .3 Test series . . . . . . . . . . . . . . . 106

4.3 Material properties . . . . . . . . . . . . . 109

4.3.1 Mix design . . . . . . . . . . . . . . 109

4.3.2 Concrete mix procedure . . . . . . . . . . . . 109

4.3 .3 Steel fiber . . . . . . . . . . . . . . . . . 111

4.3 .4 Reinforcing steel . . . . . . . . . . . . . . . . 111

4.4 Concrete characterization . . . . . . . . . . . . . 112

4.4.1 Concrete compressive strength . . . . . . . . . . . 112

4.4.2 Concrete tensile strength . . . . . . . . . . . 113 
5 Results, analysis and discussions $\quad 117$

5.1 Introduction . . . . . . . . . . . . . . . . . 117

5.2 Presentation of the experimental results . . . . . . . . . . . . . . 118

5.2.1 Results of the precracking phase . . . . . . . . . 118

5.2.2 Comparison between photogrammetry and DEMEC measurements ..................... 121

5.2.3 Results of the push-off phase . . . . . . . . . . . 123

5.3 Study of the restraint frame behavior . . . . . . . . . . . . . . 126

5.3.1 Real shear stress transmitted by the crack . . . . . . . . 126

5.3.2 Study of horizontal stiffness of the restraint frame . . . . 133

5.3.3 Verification of the ball bearing . . . . . . . . . . 137

5.3.4 Statistical study of plate displacements . . . . . . . . 139

5.4 Analysis and discussion of the experimental program results . . . . 143

5.4 .1 Influence of $w_{o} \ldots \ldots \ldots \ldots$

5.4 .2 Influence of fiber type . . . . . . . . . . . . . . . 145

5.4 .3 Influence on amount of fibers . . . . . . . . . . . . . . 147

5.4 .4 Influence of transverse reinforcement $(\rho$ ratio $) \ldots . . . . .149$

5.4.5 Influence of concrete strength and maximum aggregate size 151

5.4.6 SFRC and RC comparison . . . . . . . . . . . . . . . 154

5.4 .7 Roughness analysis . . . . . . . . . . . 156

6 Conclusions $\quad 163$

6.1 Main conclusions .................... 163

6.1.1 About the test methodology . . . . . . . . . . 163

6.1.2 Studying the parameters in the experimental program . . . 165

6.2 Recommendations for further research . . . . . . . . . . . . 166

6.2.1 About the methodology .............. 166

6.2.2 About cracked concrete behavior . . . . . . . . . . . 166

References 


\section{List of Figures}

2.1 Softening (a) and hardening (b) behavior in axial tension Bulletin

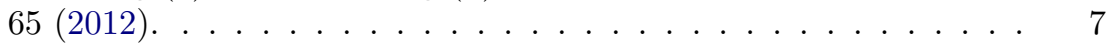

2.2 Test set-up required by EN-14561 (dimension in mm) Bulletin 65

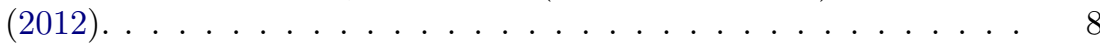

2.3 Typical load F-CMOD curve for plain and FRC Bulletin 65 (2012). 8

2.4 Main differences between plain and fiber reinforced concrete having both normal and high strength under uniaxial compression Bulletin 65 (2012). . . . . . . . . . . . . . . . . . 9

2.5 Concrete beam subjected to a concentrated load. . . . . . . . . . . 11

2.6 Principal compression stress trajectories in an uncrack concrete beam Wright and MacGregor (2009). . . . . . . . . . . . . 11

2.7 Shear-resisting component after formation for diagonal crack Wright and MacGregor (2009). . . . . . . . . . . . . 12

2.8 Shear cracking and shear failure Committee-426 (1973). . . . . . . 13

2.9 Relative contribution from shear resisting components (Committee$426,1973) \ldots \ldots \ldots \ldots \ldots \ldots$

2.10 Local variation of the crack width after a shear displacement Walraven (1978). . . . . . . . . . . . . . . .

2.11 Idealized roughness of the crack plane and definition of the crack displacements Walraven (1978). . . . . . . . . . . . . . 1

2.12 The dowel action mechanism contributing to shear transfer along a crack Walraven (1980). . . . . . . . . . . . . . . 16 
2.13 General concept of the push-off test . . . . . . . . . . . . . 19

2.14 Shear friction hypothesis Birkeland and Birkeland (1966). . . . . . 20

2.15 Contact areas between aggregate and matrix (a) and stress condition (b) Walraven (1981). . . . . . . . . . . . . . . . 21

2.16 Schematic representation of test specimen. . . . . . . . . . . . . 24

2.17 Dimension and reinforcement of test specimens Paulay and Loeber

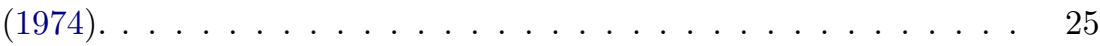

2.18 Schematic representation of confined specimen Walraven, Vos, and Reinhardt (1979). . . . . . . . . . . . . 26

2.19 Adjustment of the crack width by pairs of bolts Walraven (1980). . 26

2.20 Test specimen for evaluating aggregate interlock Kim et al. (2010). 27

2.21 Schematic representation of shear test Mirsayah and Banthia (2002). 28

2.22 Typically load-slip curves Hofbeck, Ibrahim, and Mattock (1969). . 29

2.23 General and local roughness Walraven, Frenay, and Pruijssers (1987). 30

2.24 The mean shear stress-shear displacement relationships for aggregate interlock action Paulay and Loeber (1974). . . . . . . . . . . . 31

2.25 Example of the statistical model of aggregate interlock Walraven

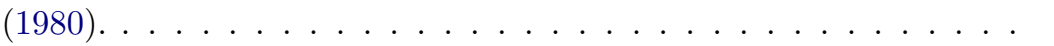

2.26 Comparison of shear transfer strength of initially cracked concrete with strength predicted by design equations Mattock, Li, and Wang (1976) . . . . . . . . . . . . . . .

2.27 Design chart for determining shear friction capacity by taking account the compressive strength of concrete Walraven, Frenay, and Pruijssers (1987). . . . . . . . . . . . . . . 34

2.28 Shear strength of cracked normal weight concrete Mattock (2001). 36

2.29 Trilinear approximation of test data Mansur, Vinayagam, and Tan (2008). . . . . . . . . . . . . . . . . 38

2.30 Plot of mean shear-to-normal stress ratio versus crack width Kim et al. (2010). . . . . . . . . . . . . . . . . 4 41

2.31 Panel test machine: (a) front face and (b) back face Susetyo (2010). 43

2.32 Relationship between shear transmitted across crack and compressive stress on crack Vecchio and Collins (1986). . . . . . . . . . 44

3.1 Schematic representation of displacements and stresses on the crack plane. ........................ 50

3.2 Schematic representation of the test specimen (dimension in $\mathrm{mm}$ ). 51 
3.3 Test specimen: (a) schematic representation, (b) photo of a specimen actually used. . . . . . . . . . . . . . . 51

3.4 Relative position of the specimen faces. . . . . . . . . . . . . 52

3.5 Framework modifications. . . . . . . . . . . . . . . 53

3.6 Arrangement of the additional reinforcement cages and connectors links (dimensions in $\mathrm{mm}$ ). . . . . . . . . . . . . 54

3.7 Definition of the allowed initial crack width. . . . . . . . . . . . . 54

3.8 Relative position of the parts of the restraint frame and specimen. $\quad 55$

3.9 Arrangement of restraint plates, bars and ball bearing on the specimen. . . . . . . . . . . . . . 5 56

3.10 Restraint frame assembly procedure. . . . . . . . . . . 57

3.11 Dimension and details of the ball bearing (dimension in $\mathrm{mm}$ ). . . . 58

3.12 Bowl of the ball bearing with small balls inside. . . . . . . . . . 58

3.13 Definition of the allowed initial crack width. . . . . . . . . . . 59

3.14 Different parts of the restraint frame (dimensions in $\mathrm{mm}$ ). . . . . . 60

3.15 Schematic arrangement of the precracking baseplate (dimensions in

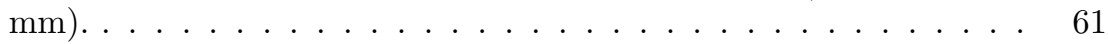

3.16 General arrangement in the precracking phase. . . . . . . . . 64

3.17 Precracking test instrumentation. . . . . . . . . . . . . 64

3.18 Position of the measurement devices in the push-off experiments. . 65

3.19 Schematic representation of vertical stability. . . . . . . . . 66

3.20 First attempt of the precracking phase. . . . . . . . . . 67

3.21 Second attempt of the precracking phase. . . . . . . . . . 68

3.22 Final step of the precracking experiments. . . . . . . . . . . 68

3.23 Load vs. crack width relationship . . . . . . . . . . . . 69

3.24 Movement of Plate A in precracking phase. . . . . . . . . . . . 70

3.25 Shear stress vs. slip relationship. . . . . . . . . . . . . . 72

3.26 Shear stress vs. crack width relationship. . . . . . . . . . 73

3.27 Frontal view of the new testing frame. . . . . . . . . . 76

3.28 Comparison made between both the restraint frame designs. . . . . 76

3.29 Numerical model of the new restraint frame design. . . . . . . . . . 77

3.30 Solution from the FE model. . . . . . . . . . . . . . . . . 77

3.31 Vertical stability of specimen A5/1.0/3a. . . . . . . . . . . 81 
3.32 Vertical stability of specimen A5/3.0/3b. . . . . . . . . . 82

3.33 Restraint force vs crack width differences relationship. . . . . . . 83

3.34 Shear stress vs. slip relationship. . . . . . . . . . . . . . . 84

3.35 Shear stress vs. crack width relationship. . . . . . . . . . . 85

3.36 Crack opening path relationship. . . . . . . . . . . . 86

3.37 Normal stress vs. crack width relationship. . . . . . . . . . 87

3.38 Comparison between the photogrammetry and DEMEC measurements. . . . . . . . . . . . . . . . . 89

3.39 Testing frame modification (dimensions in $\mathrm{mm}$ ). . . . . . . . . 90

3.40 New testing frame. . . . . . . . . . . . . . . . . . 91

3.41 Precracking sliding baseplate (dimensions in $\mathrm{mm}$ ). . . . . . . . . 92

3.42 Positioning the push-off sliding baseplate. . . . . . . . . . . . . 92

3.43 Push-off sliding baseplate (dimensions in $\mathrm{mm}$ ). . . . . . . . . . 93

3.44 New design of the restraint frame parts (dimensions in $\mathrm{mm}$ ). . . . 94

3.45 Picture of the special break on the external nut. . . . . . . . . . . 94

3.46 The final restraint frame assembly procedure. . . . . . . . . . . 95

3.47 Position of the restraint bars and strain gauges.. . . . . . . . . . 95

3.48 Schematic representation of the tightened nuts. . . . . . . . . . 96

3.49 Fixed marks on Plate A and external nut. . . . . . . . . . . . . 97

3.50 Photography target points (dimensions in $\mathrm{mm}$ ) . . . . . . . . . 97

3.51 Photogrammetry sequence. . . . . . . . . . . . . . 98

3.52 DEMEC points on the specimen. . . . . . . . . . . . . 98

3.53 Crack width and slip definition. . . . . . . . . . . . . . . 98

3.54 Strain gauge instrumentation. . . . . . . . . . . . . . . . . 99

3.55 Precracking phase setup. . . . . . . . . . . . . 100

3.56 Push-off phase instrumentation . . . . . . . . . . . . . 101

3.57 Examples of curves of the experimental results obtained with the

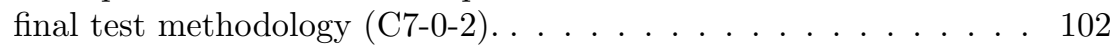

4.1 Slump-flow test of PC-1-2a. . . . . . . . . . . . . . 110

4.2 Dramix ${ }^{\circledR}$ hooked-end steel fibers. . . . . . . . . . . . . . 111

4.3 Cylinder compresion test. . . . . . . . . . . . . . 112

4.4 Crack pattern of the cylinder compression test specimens. . . . . . 113 
4.5 Cylinder splitting test. . . . . . . . . . . . . . 113

4.6 Cylinder surface profile. . . . . . . . . . . . . . . . . . . . . 115

5.1 Schematic position of the LVDTs during the precracking test. . . . 120

5.2 Linear fit of F.end according to the LVDT or DEMEC measurements. 120

5.3 Qualitative information of the picture. . . . . . . . . . . . . 121

5.4 Linear correlation between the photogrammetry and DEMEC measurements. . . . . . . . . . . . . . . . . 123

5.5 Relative position of Plates A, B and the ball bearing respect to the specimen. . . . . . . . . . . . . . 127

5.6 Simplified model to calculate the shear force transmitted by the restraint frame. . . . . . . . . . . . . . . . 127

5.7 Vertical displacement of Plate A during the push-off test. . . . . . 132

5.8 Real shear stress transmitted by the crack (C4-0-2b specimen). . . 133

5.9 Representation of horizontal stiffness. . . . . . . . . . . . . . . 133

5.10 Fitting curves for normal stress in the specimens with $w_{o}=1$. . . 134

5.11 Upside down position of Plate A. . . . . . . . . . . 137

5.12 Vertical displacement of Plates A and B (B4-0-2a specimen). . . . 138

5.13 Shear stresses vs. slip relationship . . . . . . . . . . . . . . 138

5.14 Histogram for PB displacement. . . . . . . . . . . . . . . . . . . 141

5.15 Histogram for PA displacement. . . . . . . . . . . . . . . . . . . . . 142

5.16 Influence of the allowed initial crack width on shear behavior (plain concrete). . . . . . . . . . . . . . . . 144

5.17 Influence of $w_{o}$ on shear behavior for different shear reinforcement. 145

5.18 Influence of fiber type on shear behavior. . . . . . . . . . . . . 146

5.19 Shear behavior for 40 and $50 \mathrm{~kg} / \mathrm{m}^{3}(\mathrm{RC}-65 / 35 \mathrm{BN})$. . . . . . . . 148

5.20 Shear behavior for 40 and $70 \mathrm{~kg} / \mathrm{m}^{3}$ (RC-80/30 BP) . . . . . . . . 149

5.21 Shear behavior for different shear reinforcement ratios (0.44 and $0.77 \%) \ldots \ldots \ldots \ldots \ldots 15 \ldots \ldots \ldots$

5.22 Crushed concrete covering of stirrups. . . . . . . . . . . . 151

5.23 Final aspect of stirrup. . . . . . . . . . . . . . . 151

5.24 Influence of maximum aggregate size on the confined condition. . . 152

5.25 Sample of aggregate slice. . . . . . . . . . . . . . . 153

5.26 Influence of concrete strength on direct shear behavior. . . . . . . . 154 
5.27 General shear behavior of SFRC (A4-0-2a specimen). . . . . . . . . 155

5.28 Shear behavior for high reinforced levels. . . . . . . . . . . . . . . 156

5.29 Hypothesis of the shear friction theory. . . . . . . . . . . . . 157

5.30 Applied force at the crack interface. . . . . . . . . . . 158

5.31 Evolution of the friction coefficient in plane concrete. . . . . . . . 159

A.1 Shear behavior for confined specimens $\left(w_{o}=0\right)$, Material A4-0-2. . 178

A.2 Shear behavior for confined specimens $\left(w_{o}=0\right)$, Material A4-0-2 (continued). . . . . . . . . . . . . . . . 179

A.3 Shear behavior for confined specimens $\left(w_{o}=0\right)$, Material A5-0-2. . 180

A.4 Shear behavior for confined specimens $\left(w_{0}=0\right)$, Material A5-0-2 (continued). . . . . . . . . . . . . . . . . 181

A.5 Shear behavior for confined specimens $\left(w_{o}=0\right)$, Material B4-0-2. . 182

A.6 Shear behavior for confined specimens $\left(w_{o}=0\right)$, Material B4-0-2 (continued). . . . . . . . . . . . . . . 183

A.7 Shear behavior for confined specimens $\left(w_{o}=0\right)$, Material C4-0-2. . 184

A.8 Shear behavior for confined specimens $\left(w_{o}=0\right)$, Material C4-0-2 (continued). . . . . . . . . . . . . . . 185

A.9 Shear behavior for confined specimens $\left(w_{o}=0\right)$, Material C7-0-2. . 186

A.10 Shear behavior for confined specimens $\left(w_{o}=0\right)$, Material C7-0-2 (continued). . . . . . . . . . . . . 187

A.11 Shear behavior for confined specimens $\left(w_{o}=1\right)$, Material A4-1-2. . 188

A.12 Shear behavior for confined specimens $\left(w_{o}=1\right)$, Material A4-1-2 (continued). . . . . . . . . . . . . . . 189

A.13 Shear behavior for confined specimens $\left(w_{o}=1\right)$, Material A5-1-2. . 190

A.14 Shear behavior for confined specimens $\left(w_{o}=1\right)$, Material A5-1-2 (continued). . . . . . . . . . . . . . 191

A.15 Shear behavior for confined specimens $\left(w_{o}=1\right)$, Material A5-1-4. . 192

A.16 Shear behavior for confined specimens $\left(w_{o}=1\right)$, Material A5-1-4 (continued). . . . . . . . . . . . . . 193

A.17 Shear behavior for confined specimens $\left(w_{o}=1\right)$, Material B4-1-2. . 194

A.18 Shear behavior for confined specimens $\left(w_{o}=1\right)$, Material B4-1-2 (continued). . . . . . . . . . . . . . 195

A.19 Shear behavior for confined specimens $\left(w_{o}=1\right)$, Material C4-1-2. . 196 
A.20 Shear behavior for confined specimens $\left(w_{o}=1\right)$, Material C4-1-2 (continued).

A.21 Shear behavior for confined specimens $\left(w_{o}=1\right)$, Material C7-1-2. . 198

A.22 Shear behavior for confined specimens $\left(w_{o}=1\right)$, Material C7-1-2 (continued). . . . . . . . . . . . . . . . 199

A.23 Shear behavior for confined specimens $\left(w_{o}=0\right)$, Material PC-0-2. . 200

A.24 Shear behavior for confined specimens $\left(w_{o}=0\right)$, Material PC-0-2 (continued). . . . . . . . . . . . . . . 201

A.25 Shear behavior for confined specimens $\left(w_{o}=0\right)$, Material PC-0-4. . 202

A.26 Shear behavior for confined specimens $\left(w_{o}=0\right)$, Material PC-0-4 (continued). . . . . . . . . . . . . . . 203

A.27 Shear behavior for confined specimens $\left(w_{o}=0\right)$, Material PC-0-5. . 204

A.28 Shear behavior for confined specimens $\left(w_{o}=0\right)$, Material PC-0-5 (continued). . . . . . . . . . . . . . . 205

A.29 Shear behavior for confined specimens $\left(w_{o}=1\right)$, Material PC-1-1. . 206

A.30 Shear behavior for confined specimens $\left(w_{o}=1\right)$, Material PC-1-1 (continued). . . . . . . . . . . . . 207

A.31 Shear behavior for confined specimens $\left(w_{o}=1\right)$, Material PC-1-2. . 208

A.32 Shear behavior for confined specimens $\left(w_{o}=1\right)$, Material PC-1-2 (continued)....................... 209

A.33 Shear behavior for confined specimens $\left(w_{o}=0\right)$, Material S6-0-1. $\quad 210$

A.34 Shear behavior for confined specimens $\left(w_{0}=0\right)$, Material S6-0-1

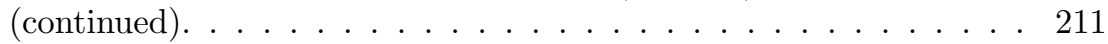

A.35 Shear behavior for confined specimens $\left(w_{o}=1\right)$, Material S6-1-2. . 212

A.36 Shear behavior for confined specimens $\left(w_{o}=1\right)$, Material S6-1-2 (continued). . . . . . . . . . . . . . 213

A.37 Shear behavior for confined specimens $\left(w_{o}=1\right)$, Material S6-1-5. . 214

A.38 Shear behavior for confined specimens $\left(w_{o}=1\right)$, Material S6-1-5 (continued). . . . . . . . . . . . . 215

A.39 Shear behavior for confined specimens $\left(w_{o}=0\right)$, Material S8-0-2. . 216

A.40 Shear behavior for confined specimens $\left(w_{o}=0\right)$, Material S8-0-2 (continued)....................... 217

A.41 Shear behavior for confined specimens $\left(w_{o}=1\right)$, Material S8-1-2. . 218

A.42 Shear behavior for confined specimens $\left(w_{o}=1\right)$, Material S8-1-2 (continued). . . . . . . . . . . . . . . . 219 


\section{List of Tables}

2.1 List of push-off tests. . . . . . . . . . . . . . . . . 23

2.2 Geometrical properties of different specimens. . . . . . . . . . . . . 24

2.3 Specimen and notch differences . . . . . . . . . . . . . . . 28

2.4 Comparison between RC and FRC push-off tests . . . . . . . . 39

3.1 List of specimens . . . . . . . . . . . . . . . . . . 62

3.2 Mix proportion in $\mathrm{kg} / \mathrm{m}^{3}$. . . . . . . . . . . . . . . . . . 63

3.3 Specimens where Plate A was instrumented and the push-off phase was carried out. . . . . . . . . . . . . . . . . 63

3.4 Precracking test results f . . . . . . . . . . . . . . . . 71

3.5 Ultimate push-off test values. . . . . . . . . . . . . . 73

3.6 Experimental length of the seven side of the triangles. . . . . . . . 79

3.7 Statistical parameters. . . . . . . . . . . . . . . . . . 79

3.8 Specimen name and characteristic . . . . . . . . . . . . . 80

3.9 Mix proportion (in $\mathrm{kg} / \mathrm{m}^{3}$ ) and concrete properties. . . . . . . . . 81

3.10 Results of the precracking test. . . . . . . . . . . . . . . 82

3.11 The push-off test results. . . . . . . . . . . . . . . . 87

3.12 Values of the measurements obtained from the photogrammetry and DEMEC techniques. . . . . . . . . . . . . 88 
4.1 The significance of the study parameters and their research range. 104

4.2 Experimental program. . . . . . . . . . . . . . 106

4.3 Identification code used for SFRC . . . . . . . . . . . . . . . 106

4.4 Test specimen details. . . . . . . . . . . . . . . . 108

4.5 The dry composition of concrete used in the research $\left(\mathrm{kg} / \mathrm{m}^{3}\right)$. . 109

4.6 Mechanical properties of steel fibres. . . . . . . . . . . . . . 111

4.7 Mechanical properties of the reinforcement. . . . . . . . . . . . . 112

4.8 Concrete compression strength results. . . . . . . . . . . . . . . . . 114

4.9 Results of the concrete tensile strength. . . . . . . . . . . . . 116

5.1 Results of the precracking phase. . . . . . . . . . . . . 119

5.2 List of the specimens used to make the comparison. . . . . . . . . 121

5.3 Photogrammetry and DEMEC measurements of crack width. . . . 122

5.4 Results of the push-off phase. . . . . . . . . . . . . . . . . 125

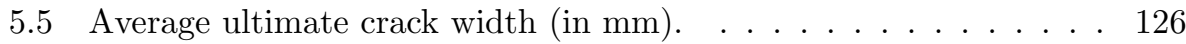

5.6 Ultimate values of shear stresses (first part) . . . . . . . . . . 130

5.7 Ultimate values of shear stresses (second part) . . . . . . . . . . . 131

5.8 Horizontal stiffness for the $w_{o}=0$ specimens. . . . . . . . . . . . . 135

5.9 Horizontal stiffness for the $w_{o}=1$ specimens. . . . . . . . . . . . . 136

5.10 Ultimate displacement of Plate A (first part). . . . . . . . . . . . 139

5.11 Ultimate displacements of Plates A and B (second part). . . . . . . 140

5.12 Fitted Distributions . . . . . . . . . . . . . . . . . . 141

5.13 Normality test for vertical displacement of PB . . . . . . . . . . . . 141

5.14 Fitted Distributions for PA . . . . . . . . . . . . . . . . 142

5.15 Values of friction coefficient used by different authors. . . . . . . . 157

5.16 Values of friction coefficients at different sliding points (plain con-

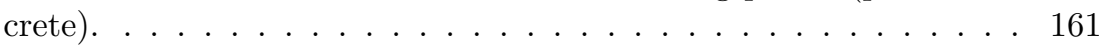

5.17 Values of friction coefficients at different sliding points (SFRC). . . 162

5.18 Basic friction coefficient for different steel fibers types and amounts. 162 


\section{Chapter 1}

\section{Introduction}

\subsection{Statement of problems}

The shear behavior of structural elements in reinforced concrete is still a topic of much interest in the international scientific community. Yet despite many papers having been published in recent decades, no consensus on concerning shear transfer mechanisms and the best way to model structural elements subjected to shear without transverse reinforcement has been reached. Thus, there is still a need to establish design and analysis methods that make realistic assessments of the strength, stiffness and ductility of structural elements subjected to shear loading. Cracks in concrete can transmit significant amounts of shear by means of aggregate interlock, which is known has been and pursued for some time (Walraven, 1981).

The international Shear Workshop held in Salò (Italy) (fib Bulletin 57, 2010) provided an opportunity to assess and analyze the shear behavior of reinforced concrete elements, and to also discuss the new shear approaches and verify how these meet or diverge one from another. In this workshop, the shear behavior of both reinforced concrete (RC) and fiber reinforced concrete (FRC) elements was discussed.

Nowadays, FRC is a widely recognized innovative material by the international codes, and interest in FRC structures is continuously growing (Walraven, 1999). In fact, the $2^{\text {nd }}$ FRC International Workshop (1 ${ }^{\text {st }}$ ACI-fib joint Workshop) held in Montreal, Canada (Proceeding ACI-fib Workshop FRC 2014), presented the opportunity to analyze and discuss the material properties, the structural applica- 
tions of FRC, and how both codes, ACI and fib, take into account the properties of FRC to the design expressions.

After cracking, the fibers that cross the crack start to work and restrain the crack width and the consequence is higher ultimate shear stress (Tan et. al, 1990). In this way, fibers also increase the ductility of concrete (ACI Committee 544, 2002). Fundamental knowledge of the shear failure and toughness of steel fiber reinforced concrete (SFRC) is essential for the introduction of ductility concepts and toughness parameters into relevant structural designs.

The publication of an annex to the EHE-08 Spanish code on FRC opens up numerous new possibilities to use this material for structural purposes. However, Model Code 2010 recognizes FRC as a composite material, defines the characteristics of materials and classifies FRC by means of residual flexural strength $\left(f_{R 1}\right.$ and $\left.f_{R 3}\right)$. Both codes include the contribution of fibers to shear strength.

The push-off test has been used to study shear transfer mechanisms in concrete under direct shear conditions (Hofbeck et al., 1969; Mattock, 2001). Given the difficulties in analyzing shear behavior in a localized section, several authors have performed this test by precracking specimens along the shear plane. Different reinforcements with various inclinations in relation to the shear plane have also been studied by means of the push-off test (Mattock, 1974). With this test method, Walraven analyzed the aggregate interlock response, and his studies are the basis of actual theories on shear behavior in concrete codes.

In any case, serious problems for performing and controlling this test remain, and doubts about its repeatability, results at high slip levels, or crack opening (and then at ultimate state) still need to be cleared. Some other variables also need to be analyzed, especially when special concrete is used.

The effectiveness of steel fibers in combination with traditional reinforcement in enhancing shear transfer behavior has been studied by means of the push-off test (Valle and Büyüköztürk, 1993; Lim et al., 2011). Some authors have proposed that this method can use the push-off test to assess the shear strength of SFRC for its incorporation into code-type structural design procedures (Barrragan et. al, 2006). Unfortunately, this influence is difficult to analyze with the current methodology, and it is necessary to generate a large enough data-base to draw conclusions about different variables and to quantify their influence.

\subsection{Research aims}

Nowadays, knowledge about the shear behavior of crack concrete reinforced with steel fibers, and how fibers modify the kinematics of the crack, is lacking. The influence of steel fibers on the shear friction theory also remains unclear. Most of the publications that involve the push-off test also present a low value of shear displacements (2 or $3 \mathrm{~mm}$ ). Thus, the influence of fibers beyond this point is still not clear. 
The main objective of this $\mathrm{PhD}$ thesis is to improve the methodology to test $\mathrm{z}$ type specimens. This involves both the precraking and puh-off phases. In the precracking phase, the vertical stability of the specimen and crack width are the principal parameters in mind. However in the push-off phase, crack control and normal stress to the shear plane are the main parameters to be controlled. In this way, it is possible to analyze the kinematics of the crack under planar, normal and shear stress conditions.

A standard methodology to analyze shear transfer mechanisms is lacking. Consequently, this thesis focuses on the design, calibration and experimental validation of an improvement, or "upgrade", of the so-called push-off test methodology. The final goal of this new push-off test is to set the basis of a new standard as a standard method to analyze the shear transfer mechanisms involved in a crack.

An experimental program has been designed to assess if different behaviors, according to the concrete properties, can be detected from a qualitative point of view. The aforementioned concrete terms refers to shear reinforcement (steel fibers or stirrups), maximum aggregate particle size or concrete strength, among others.

\subsubsection{Specific objectives}

This $\mathrm{PhD}$ thesis attempts to provide the guidelines to set a new methodology to carry out the push-off test, on precracked specimens under crack control conditions. The specific objectives pursued in this doctoral thesis are:

- Producing specimens with a perfectly defined pair of notches. Avoiding human errors due to the sawing process. These notches create a plane of weakness to precrack specimens.

- Developing a restraint frame with sufficient horizontal stiffness to control crack width throughout the test. The restraint frame must have as low a vertical stiffness as possible to allow free vertical movement of the two blocks of the push-off specimen.

- Reducing the frictional forces between the specimen and the restraint frame is a necessity.

- Designing a mechanical mechanism with in the restraint frame to set different initial crack width values, such as $0.5,1.0,2.0$. or even $3.0 \mathrm{~mm}$, with sufficient accuracy. This allows the analysis of shear behavior under different initial confinement.

- Improving the vertical stability of the precracking phase to avoid the rotation of the specimen around the knife of the precracking arrangement.

- Adopting different measurement techniques to know the relative displacement of the two halves of the cracked specimen. Thus these relative displacements can refer to the original (uncracked) specimen. 
- Guaranteeing the reliability of the present methodology, and the possibility of knowing the real normal and shear stresses transferred by crack interfaces.

- Designing an experimental program which verifies the new push-off test methodology. Based on these experimental results, the intention is to propose this new methodology as a standard method to analyze shear behavior.

- Analyzing the influence and contribution of steel fibers to shear strength and compare them with the influence of traditional rebars. Regarding the influence of steel fibers, another intention is to study how the type or amount of fibers affects crack behavior.

\subsection{Thesis arrangement}

The present $\mathrm{PhD}$ thesis is divided into six chapters:

Chapter 1 underlines the statement of the problem and the research aim.

Chapter 2 reports a literature review which focused on the different methodologies to test the aggregate interlock phenomenon discussed in this $\mathrm{PhD}$ thesis. An overview of shear behavior and the shear failure mode of structural elements made with both reinforced concrete and fiber reinforced concrete is also presented.

Chapter 3 presents the design procedure and experimental validation of the restraint frame. All the detected problems and the adopted solution are presented herein. A finite element (FE) model of the restraint frame has been built to observe the strain and global stiffness of the restraint frame. Finally, the experimental procedure of both precracking and push-off phases is presented as a guideline for future works.

Chapter 4 focuses on the experimental campaign and the concrete characterization results. The main variable of this research is aggregate interlock and its influence for greater shear slip values. The effect of different steel fibers and stirrups on aggregate interlock is also presented.

Chapter 5 This chapter is divided into three parts. First the experimental result of the complete push-off test is presented. Then an in depth study into the restraint frame is reported. The third part focuses on the analysis and discussion of the results of the parameters involved in the experimental program.

Chapter 6 summarizes the main conclusions drawn on this $\mathrm{PhD}$ thesis. 


\section{Chapter 2}

\section{State of the Art}

\section{$2.1 \quad$ Introduction}

In this chapter the state of the art is presented. In section 2.2 the fiber reinforced concrete, the material properties, and the used of steel fiber as shear reinforcement are introduced. Then in section 2.3, the main ideas on shear behavior and modes of failures are discussed. Section 2.4 is focused in the mechanisms involved in the transmission of shear forces across a crack.

Finally, in section 2.5 is dedicated to present the direct shear phenomenon. The principals theories developed to explain the direct shear, the experimental procedures used, and the experimental results of these procedures are presented and discussed.

Once all information have been analyzed, final conclusions have been obtained. Based on these conclusions, the present PhD thesis is carried out in order to design a new push-off test.

\section{$2.2 \quad$ Fiber Reinforced Concrete (FRC)}

Fiber reinforced concrete (FRC) is a composite material characterized by a cement matrix and discrete fibers (randomly distributed). The matrix is made of either concrete or mortar. Fibers can be made by steel, polymers, carbon, glass or natural material Bulletin 65 (2012). The amount of fibers added to the concrete depends 
on the type of fiber and target performance, but practical consideration limit the fiber dosage in structural elements to approximately $1.5 \%$ by volume. Traditional application of fiber reinforced concrete include slab on ground, tunnels liners and architectural elements, where fibers have been primarily used as replacement of minimum reinforcement for cracking control and, to a lesser degree, replacement of minimum shear and/or flexural reinforcement.

Applications of fiber reinforced concrete in building structures, on the other hand, have been rather limited. This has been primarily due to limited experimental research on the behavior of structural elements and consequently, the lack of design previsions in building codes Wright and MacGregor (2009). In fact, Model Code 2010 (hereafter MC2010) recognized FRC as structural material just in 2010 Bulletin 55 (2010), and American Concrete Institute in 2008 edition of ACI Code (ACI318-08, 2008). The Spanish Code, EHE-08, recognized FRC for structural purpose in 2008 by the inclusion of the $14^{\text {th }}$ Annex "Recommendation for the use of FRC" EHE-08 (2008).

\subsubsection{Material properties}

In FRC, the major role played by the fibers occurs when micro-cracks are formed in the concrete, in which the fibers bridge across the cracked matrix. The main advantage of adding fibers to concrete or mortar is that they generate a postcracking residual tensile strength in combination with a large tensile strain. As such, the material FRC is characterized by substantial ductility and toughness, related to the debonding and pull-out process of the fibers bridging the cracks. The properties of the composite depend on the characteristics of the constituting materials, as well as on their dosage. Other factors as geometry, type of fiber, aspect ratio $(l / d)$, volume fraction (amount of fibers in percentage by volume) and the mechanical properties of the matrix, significantly affect the FRC properties Bulletin 65 (2012).

Fibers can be used to improve the behavior at serviceability limit state (SLS) since they can reduce crack spacing and crack width, thereby improving durability. Fibers can be also used to improve the behavior at ultimate limit state (ULS) where fibers can partially or totally substitute conventional reinforcement Bulletin 65 (2012).

Depending on their composition, FRC, can show hardening or softening behavior under uniaxial tension, as shown in Fig. 2.1. Strain-softening FRC composite exhibits strain softening and crack localization immediately following first cracking. Strain-hardening FRC composite is characterized by a stress-strain response in tension that exhibits strain hardening behavior after first cracking accompanied by multiple cracking.

In tension, the ability of fibers to enhance concrete post-cracking behavior primarily depends on fiber strength, fiber stiffness, and bond with the surrounding concrete matrix. As opposed to reinforcing rebar, which are designed to be anchored in the concrete such that their yield strength can be developed; fiber are 


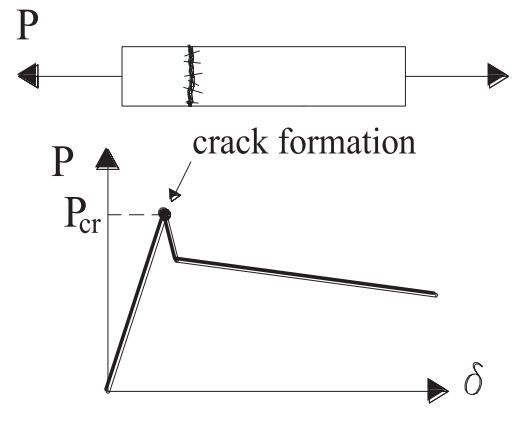

(a)

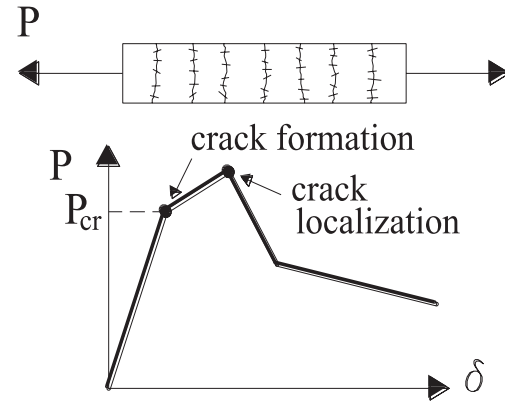

(b)

Fig. 2.1. Softening (a) and hardening (b) behavior in axial tension Bulletin 65 (2012).

in general designed to pull-out of the concrete matrix prior to achieving their strength. Thus, the behavior of the FRC is highly dependent on the ability of the fibers to maintain good bond with the concrete as they are pulled out Bulletin 65 (2012).

Ideally, the tension behavior of fiber reinforced concrete should be evaluated from direct tension tests. However, difficulties in conducting such a test have led to the use of a flexural test as the most common test method for evaluating the post-cracking behavior of the FRC Bulletin 65 (2012). In fact, MC2010 allows to carry out bending test aiming at determining the load-deflection relationship. Nominal values of the material properties can be determined by performing a 3point bending test on a notched beam according to (UNE-EN14651, 2005) (see Fig. 2.2). The diagram of the applied force (F) versus the deformation shall be produced (see Fig. 2.3). The deformation is generally expressed in terms of Crack Mouth Opening Displacement (CMOD). Parameters, $f_{R j}$, representing the residual flexural tensile strength, are evaluated from the F-CMOD relationship as follows:

$$
f_{R, j}=\frac{3 \cdot F_{j} \cdot l}{2 \cdot b \cdot h_{s p}^{2}}
$$

where: $f_{R, j}(\mathrm{MPa})$ is the residual flexural tensile strength corresponding to $C M O D$ $=C M O D_{j} ; F_{j}(\mathrm{~N})$ is the load corresponding to $C M O D=C M O D_{j} ; l(\mathrm{~mm})$ is the span length; $b(\mathrm{~mm})$ is the specimen width; $h_{s p}(\mathrm{~mm})$ is the distance between the notch tip and the top of the specimen (125 mm) Bulletin 65 (2012).

The results can be used for deriving the stress-crack width relation by inverse analysis as well. Moreover, other test can be accepted if correlation factors with the parameters of EN 14651 are proven Bulletin 65 (2012).

Instead, in the United States, specification for this test can be found in (ASTM, 2012). Four point flexural test on an unnotched specimen is suggested. The size of the flexural specimens depends on the fiber length and concrete aggregate size but typically, beams with $150 \mathrm{~mm}$ (6 in.) of cross section and $500 \mathrm{~mm}$ (20 in.) 


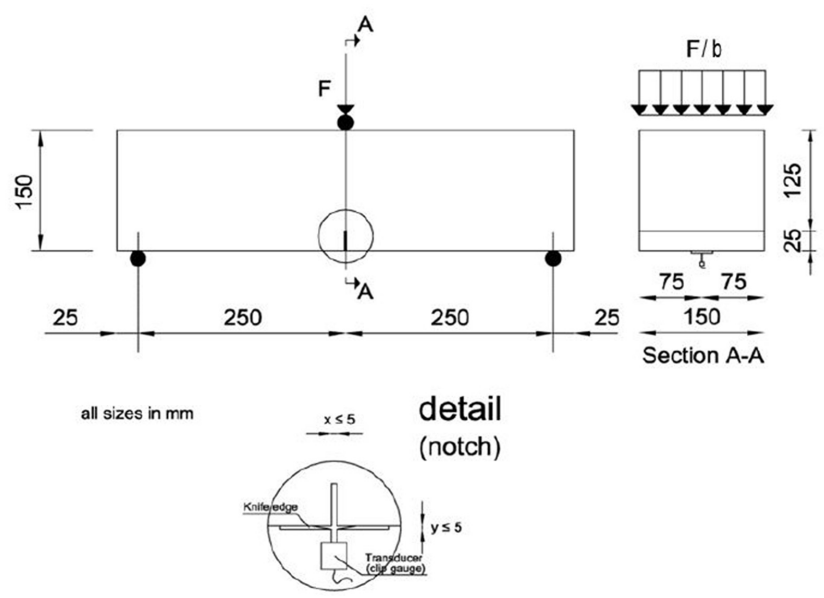

Fig. 2.2. Test set-up required by EN-14561 (dimension in mm) Bulletin 65 (2012).

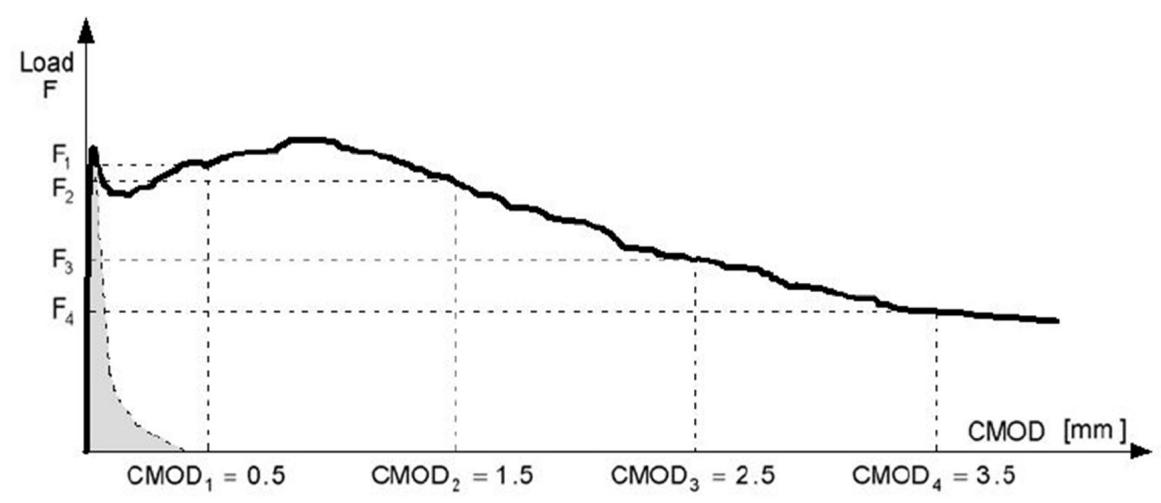

Fig. 2.3. Typical load F-CMOD curve for plain and FRC Bulletin 65 (2012).

length span are used. The test is run until a mid-span deflection equal to $1 / 150$ of the span length is reached (ASTM, 2012).

Based on its performance under flexure, FRC can be classified as either deflection softening or deflection hardening. Deflection softening implies a drop in the load at first cracking under a flexural test, while deflection hardening fiber reinforced concretes exhibits a flexural strength greater than their first cracking strength Wright and MacGregor (2009).

In regard to the behavior in compression of $\mathrm{FRC}$, in general the compressive relations valid for plain concrete apply to FRC as well Bulletin 65 (2012). In fact, the addition of fiber to concrete in low-to-moderate dosage $(\leq 1.5 \%$ by volume $)$ does not greatly affect compression strength and elastic modulus. Improvements in post-peak behavior, however, have been observed characterized by an increased compression strain capacity and toughness Wright and MacGregor (2009); Otter 
and Naaman (1988). Moreover, fibers can reduce the brittleness of concrete in compression, specially in high or ultra high strength concrete (see Fig. 2.4).

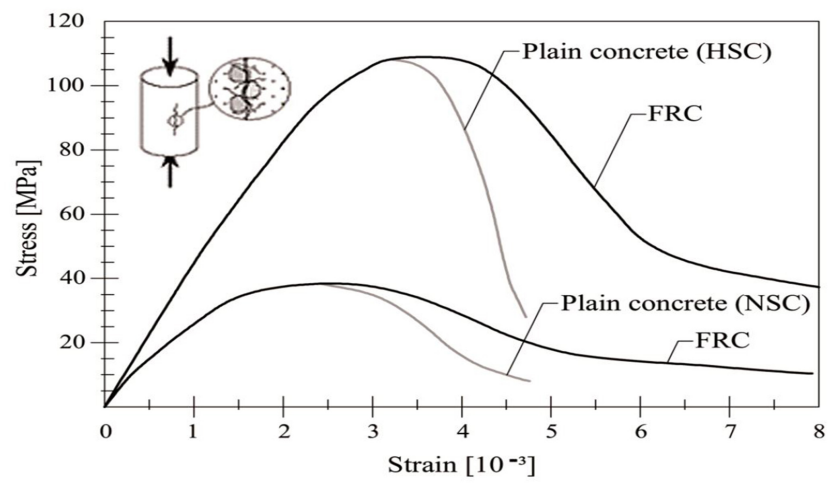

Fig. 2.4. Main differences between plain and fiber reinforced concrete having both normal and high strength under uniaxial compression Bulletin 65 (2012).

Fibers have also a negligible influence on the modulus of elasticity, Poisson's ratio, electrical conductivity and porosity, as it was found by Vondran (1991). Therefore, the behavior of concrete before cracking is not remarkably modified by fibers. In fact, fibers are together with the concrete matrix.

\subsubsection{Use of steel fibers as shear reinforcement}

The behavior and design of reinforced concrete (RC) members subjected to shear remains an area of much concern in spite of the vast number of experiments that have been carried out to assess the shear capacity of structural members. A consensus concerning mechanisms of shear transfer and the interpretation of shearcollapse mode for members without web reinforcement is still missing. It remains a pressing need to establish design and analysis methods that provide realistic assessments of the strength, stiffness and ductility of structural elements subjected to shear loading Vecchio (2000a) (Shear and Torsion, 1998).

However, recent attempts to provide a broadly acknowledged design procedures for shear for RC and FRC elements can be outlined in the final draft of MC2010 Bulletin 65 (2012); Bulletin 66 (2012), incorporating statements and models well recognized such as the Modified Compression Field Theory (hereafter MCFT) Vecchio and Collins (1986). In addition, the recent international shear workshop held in Salò(Italy) Bulletin 57 (2010) represented an opportunity to discuss the new approaches of MC2010 and verify how they meet or diverge from one another. Moreover, it gave a chance to foresee the implications that the new models may determine in the field and in structural design. In the workshop, both the shear behavior of RC and FRC elements were discussed. The opportunities and challenges of FRC were also discussed at the Eighth RILEM International Symposium (BE- 
FIB 2012) FIBRE REINFORCED CONCRETE: Challenges and Opportunities. 8th RILEM Internation Symposium (BEFIB 2012) (2012).

Several reports published over the past 25 years Parra-Montesinos (2006); Padmarajaiah and Ramaswamy (2001); Choi, Park, and Wight (2007); Dinh and Parra-Montesinos (2010); Cuenca and Serna (2010d); Calixto (2002); Vandewalle (2000); Juárez et al. (2007); Cuenca and Serna (2010a); Imam and Vandewalle (2000); Casanova and Rossi (1997); Swamy and Bahia (1985); Meda et al. (2005); Conforti (2013); Cuenca (2012); Dinh (2009) confirm the effectiveness of steel fibers reinforcement since they enhance the shear capacity of concrete and allow to partially or totally replace stirrups in $\mathrm{RC}$ structural members.

Test results have shown that the addition of steel fibers substantially improves the shear behavior of the beams. Due to the bridging effects provided by the fibers, less brittle shear failure were achieved. The effectiveness of fiber reinforcement to increase shear resistance, is dependent on several factors, including fiber properties (materials properties, aspect ratio, ans shape), fiber content, ans bond stress versus slip response of fibers Dinh and Parra-Montesinos (2010).

The MC2010 Bulletin 66 (2012) allows the use of fibers as shear reinforcement, for the first time in 2010, even though a minimum mechanical properties of FRC is required for structural use. In fact, fiber reinforcement can substitute (also partially) conventional reinforcement at (ULS), just if the following relationships are fulfilled:

$$
\begin{aligned}
f_{R 1 k} / f_{L k} & >0.4 \\
f_{R 3 k} / f_{R 1 k} & >0.5
\end{aligned}
$$

where: $f_{R 1 k}$ and $f_{R 3 k}(M P a)$ are the characteristic residual flexural tensile strength corresponding respectively to a CMOD equal to $0.5 \mathrm{~mm}$ and $2.5 \mathrm{~mm}$ UNEEN14651 (2005). Instead, $f_{L k}(M P a)$ is the characteristic limit of proportionality, as defined in (UNE-EN14651, 2005).

\subsection{Main ideas on shear behavior in cracked con- crete}

Consider a simply-supported, rectangular beam subjected to a concentrated load at mid-span (see Fig. 2.5). Any section of the beam is subjected to moment and shear that produce normal and shear stresses. Before the crack is formed, concrete could be idealized as an homogeneous material where the distribution of the principal tension stresses are plotted as curved lines (see Fig. 2.6). These stresses trajectories are steep near the bottom of the beam and flatter near the top. When the principal tensile stress is greater than the tensile concrete strength, the first crack is produced.

When longitudinal reinforcement is provided to the beam, the flexural strength increases significantly. The beam exhibits more flexural cracks due to the abil- 


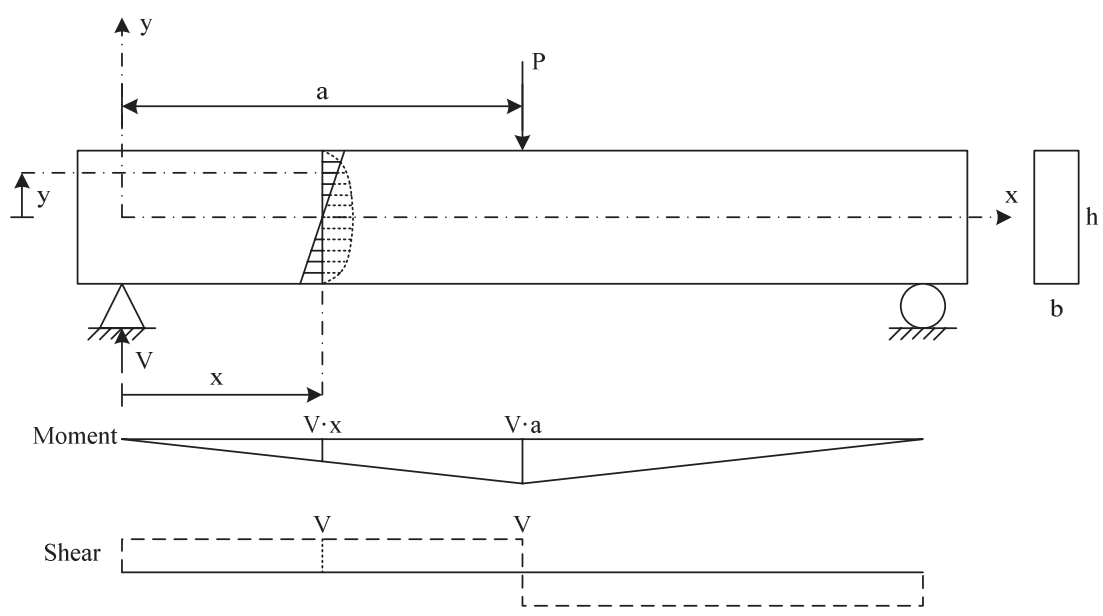

Fig. 2.5. Concrete beam subjected to a concentrated load.

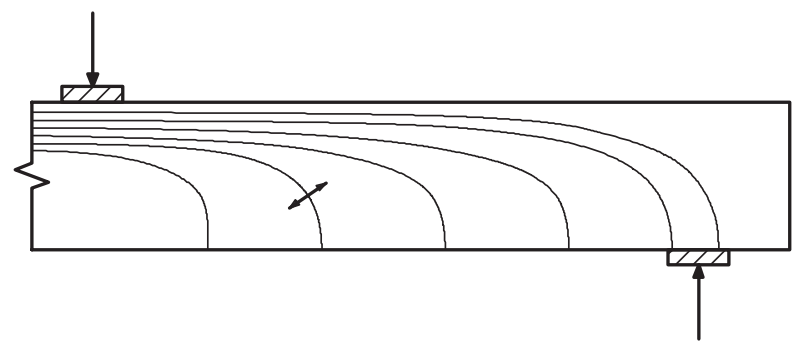

Fig. 2.6. Principal compression stress trajectories in an uncrack concrete beam Wright and MacGregor (2009).

ity of the longitudinal reinforcement to bridge the cracks and transfer the stress to the concrete, until the plain concrete starts cracking following the trajectory described in Fig. 2.6, and then shear failure is produced. A widly-accepted explanation for diagonal cracking is diagonal tension. This concept was first reported by (ASCE-ACI326, 1962). Diagonal tension, together with diagonal compression, occurs when shear is presented. When diagonal tension reaches the concrete tensile strength, diagonal cracks will form. The shear resisting components after formation of diagonal cracks is shown in Fig. 2.7. The external load is resisted by the following mechanisms, $V_{c y}$ the compression zone of the uncracked concrete, $V_{a y}$ the vertical component of the aggregate interlock and $V_{d}$ the dowel action of the longitudinal reinforcement. While the moment, is resisted by tensile force of the longitudinal reinforcement $\left(T=A_{s} \cdot f_{y s}\right)$, the compressive force $(C)$ of the compression block, and the lever arm $(z)$ which is the distance between both forces Wright and MacGregor (2009). 


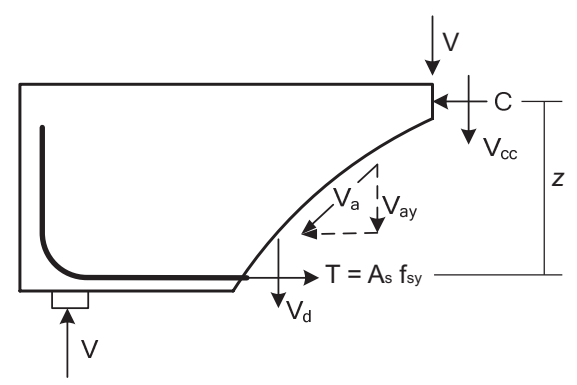

Fig. 2.7. Shear-resisting component after formation for diagonal crack Wright and MacGregor (2009).

\subsubsection{Failure modes}

In experimental studies, researches often describe different shear failure modes based on crack pattern. The beam failure modes are primary defined by (Committee426, 1973), as shown in Fig. 2.8. One of the main parameters that defines the failure mode of RC beams is the slenderness of the beam, that is its shear spanto-depth $(a / d)$ ratio. In order to avoid errors of interpretation, the description of the failures modes here presents has been literally taken from Nawy (2009). 

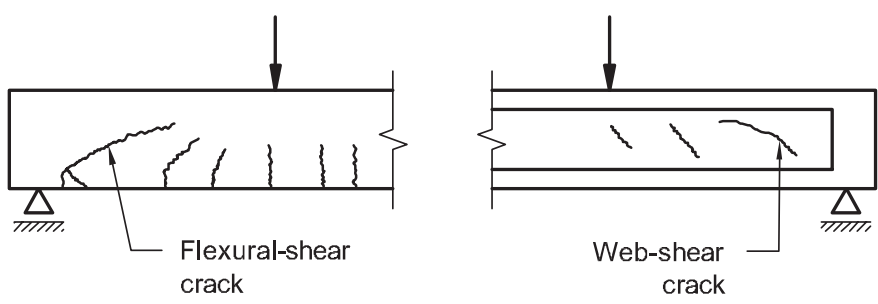

(a) Types of shear cracking.
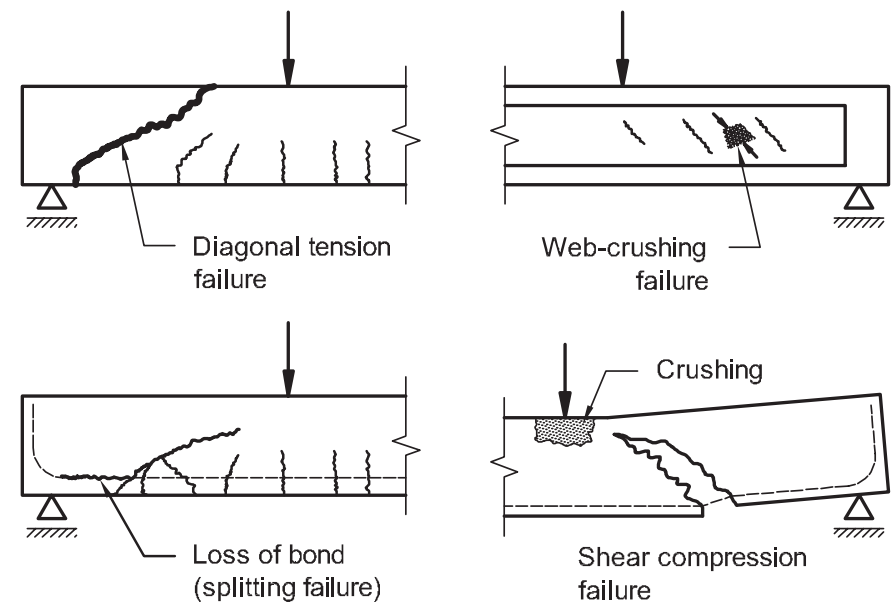

(b) Major type of shear failures.

Fig. 2.8. Shear cracking and shear failure Committee-426 (1973).

\section{- Flexural failure (F):}

If the shear span-to-depth increases, the beam becomes more slender, and the tendency of flexural behavior is greater. This kind of failure is characterized by the vertical cracks in the middle third of the beam span. All these cracks are perpendicular to the lines of principal stress. This behavior gives a clear warning of the imminent collapse of the beam. The $a / d$ ratio, for this behavior, exceeds a value of 5.5 in the case of concentrated load, and exceeds 16 for distributed loading Nawy (2009).

\section{- Diagonal tension failure (DT):}

This type of failure occurs if the strength of the beam in diagonal tension is lower than its strength in flexure. The $a / d$ ratio is of intermediate magnitude, varying between 2.5 and 5.5 for the case of concentrated load. Such beams can be considered of intermediate slenderness. Cracking starts with the development of a few fine vertical flexural cracks at midspan, followed by the destruction of the bond between the reinforcement and the surrounding concrete at the support. Notice that the flexural cracks do not propagate to the neutral axis in this essentially brittle failure mode, with relative small deflection at failure Nawy (2009). 


\section{- Shear compression failure (SC):}

Beams that are most subject to this failure mode have small $a / d$ ratio of magnitude 2.5 for concentrate loading and less than 5 for distributed loading. As in diagonal tension case, a few fine flexural cracks star to develop at midspan and stop propagating as destruction of the bond occurs between the reinforcement and the surrounding concrete at the support region. Thereafter, an inclined crack steeper than in diagonal tension suddenly develops and proceeds to propagate toward the neutral axis. The rate of its progress is reduced with the crushing of the concrete in the top compression fibers and a redistribution of stresses within the top region. Sudden failure takes place as the principal inclined cracks dynamically joins the crushed concrete zone. This type of failure can be considered relatively less brittle than diagonal tension failure due to the stress redistribution. Anyway, a brittle type of failure with limited warning should be avoided Nawy (2009).

\subsection{Shear transfer mechanisms across crack inter- faces}

The shear capacity of cracked concrete is still a subject of great concern, because the shear failure is extremely brittle and the mechanisms of failure are not well understood. In RC once the crack is formed, different shear mechanism are activated and the material behaves more anisotropic. Fig. 2.9 shows the relative contribution to inclined cracking shear of the resisting mechanisms; $V_{c y}$ is the contribution of the compression zone, $V_{a y}$ is the vertical component of shear transferred across the crack by aggregate interlock, $V_{d}$ is the dowel action of the longitudinal reinforcement and $V_{s}$ is the contribution of the shear reinforcement (Committee-426, 1973).

Aggregate interlock comes from the fact that the crack surface is not smooth, allowing the two protruding portions of the beams to bear against each other, and resist shear (sliding). Its influences decrease as the width of the crack increases. The ability of the compression zone to resist shear depends on the degree of penetration of the crack. Obviously there is an interaction of the three shear resisting components. if any of them fails, a redistribution of internal stresses occurs until all of them fail.

Due to the roughness of the crack faces, not only slip displacement $(\delta)$ but also a dilatancy of the faces normal to the crack plane are produced. This dilatancy is counteracted by the provided reinforcement as the bars are stressed and in this way apply a normal stress to the crack plane Walraven (1980). The induced stresses at the moment of failure, can be as high as the yielding stress of the steel. The resulting shear resistance is referred to as aggregate interlock or shear friction. 


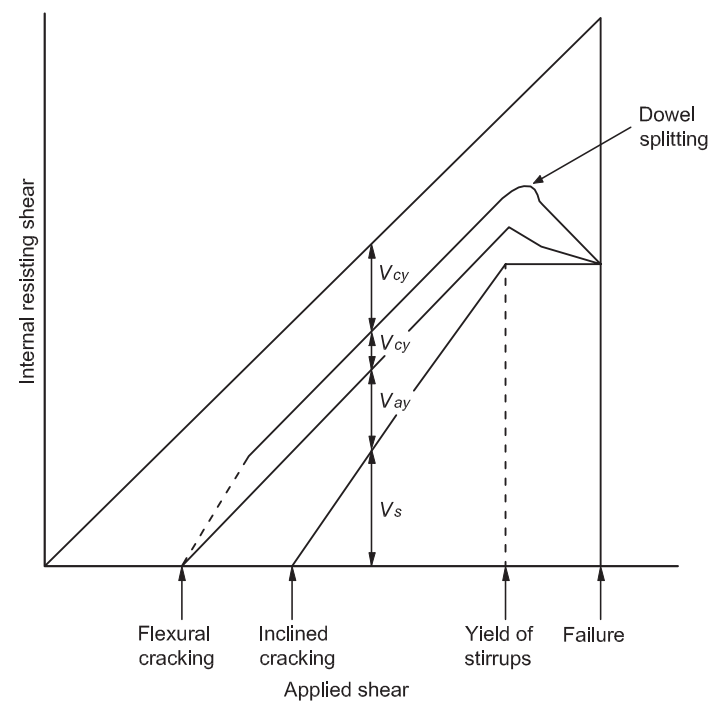

Fig. 2.9. Relative contribution from shear resisting components (Committee-426, 1973).

\subsubsection{Aggregate interlock}

The aggregate interlock mechanism is directly related to the way a crack is formed in concrete. In normal strength concrete, the strength of the cement paste is lower than the strength of the aggregate particles. As a consequence, the cracks are running through the cement paste and around the edge of the aggregate particles. For this reason, the crack plane has certain roughness and particles interlock with the opposite face of the crack is produced by shear displacement.

The roughness may be influenced by the grading curve of the aggregates and the strength difference between the matrix and the aggregates. Because of the roughness of the crack plane, a variation of the local crack width after a certain shear displacement is observed (see Fig. 2.10) Walraven (1978).

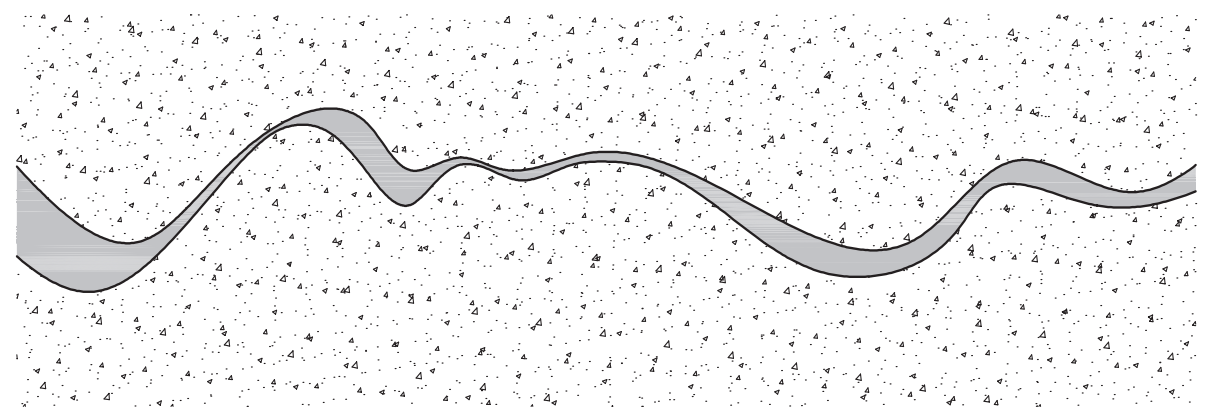

Fig. 2.10. Local variation of the crack width after a shear displacement Walraven (1978). 
In order to avoid confusion when talking about crack width, it is defined the crack width $(w)$ as the displacement that the crack faces have undergone in the normal direction in relation to each other. In this way, the definition for the crack width is independent of the shear displacement $(\delta$, hereafter slip). An idealized crack width indication of both, $w$ and $\delta$, is given if Fig. 2.11, according to Walraven (1978).

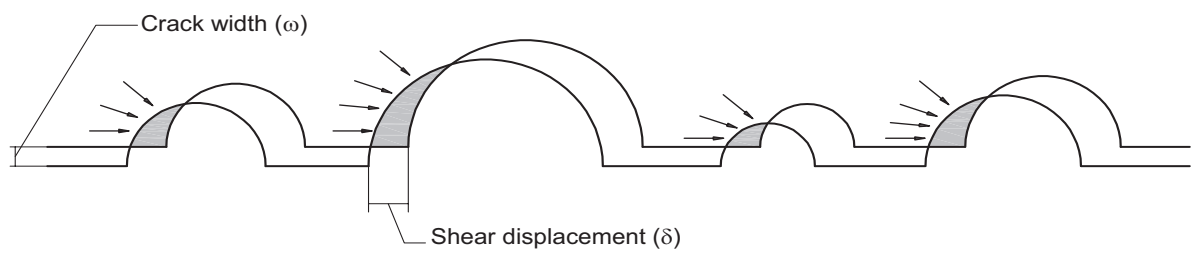

Fig. 2.11. Idealized roughness of the crack plane and definition of the crack displacements Walraven (1978).

The aggregate interlock is characterized by two fundamental modes of behavior, sliding at the contact area between particles and matrix at the opposite face, and plastic deformation of the matrix by high contact stress Walraven (1981). So the shear resistance stress is depending on the total contact area, and therefore is decreased when the contact area decreases (by the increases of the crack width).

\subsubsection{Dowel action}

Dowel action is defined as the capacity of reinforcing steel bars to transfer forces perpendicular to their axis (see Fig. 2.12) Walraven (1980). Due to the slip, the rebar is transferring shear forces from one side of the crack to the other.

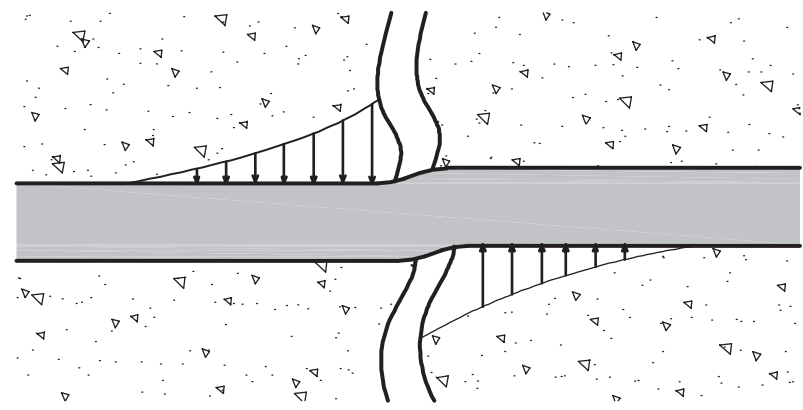

Fig. 2.12. The dowel action mechanism contributing to shear transfer along a crack Walraven (1980).

This mechanism is depending on the surrounding concrete of the bar, and also in the difference between the steel strength and concrete strength. If steel strength is greater than concrete strength (is the usually case) the concrete is crushed by 
the bar and large deformation can occur. In the opposite case, the plastic hinge is formed in the bar instead of the concrete, and a brittle behavior is developed.

Depending on the load level, the contribution of the different mechanism to the shear strength of concrete beam can be considered to be $35 \%$ to $50 \%$ for aggregate interlock mechanism, and $15 \%$ to $25 \%$ for the dowel action and contribution of the longitudinal reinforcement. The remaining $20 \%$ to $40 \%$ is delivered by the shear resistance of the compression zone Hassan, Hossain, and Lachemi (2008).

\subsubsection{Influencing factors}

Different influencing factors affect the shear transfer mechanism. The only mechanism in which the concrete properties like aggregate particle size compressive and tensile strength, play a significant role in shear transfer along a crack is the aggregate interlock Walraven (1980). The other mechanism, the dowel action, is more related to the steel properties.

\section{Concrete Strength}

The concrete strength has an important influence on the shear transfer mechanism, affecting both aggregate interlock and dowel action Cuenca (2012). In high strength concrete (HSC) the strength of the matrix is greater than the aggregate particles, as a consequence a smooth shear plane is produced, if is compared to the shear plane which is obtained from normal strength (NSC) Ahmad, Khaloo, and Poveda (1986); Elzanaty, Nilson, and Slate (1986); Mphonde and Frantz (1984). This is confirmed by the fact that the crack opening path ( $\delta$ vs. $w$ relation) is hardly influenced by the concrete strength as indicate Walraven and Reinhardt (1981).

Houde and Mirza (1974) conducted test on specimens with a cylinder compressive strength varying between 16.5 and $51 \mathrm{MPa}$. The elements were pre-cracked to obtain initial crack width of $0.05 \mathrm{~mm}$ to $0.50 \mathrm{~mm}$. The crack width was maintained during the experiments by applying an external normal force. The influence of the compressive strength on the shear stress vs. slip relationship was found to be proportional to the square root of $f_{c}$.

\section{Aggregate type and Size}

Paulay and Loeber (1974) conducted an experimental program in which was showed that influence of the maximum aggregate size or shape $\left(D_{\max }=9.5 \mathrm{~mm}\right.$ to $19 \mathrm{~mm}$, round and crush) seemed to be neglected compared to the influence of the initial crack width. This trend, was confirmed by Reinhardt and Walraven (1982). He showed for a concrete cube compressive strength of $32 \mathrm{MPa}$ and a maximum particle diameter of $32 \mathrm{~mm}$, that the contribution of the fraction between $0.6 D_{\max }$ and $1.0 D_{\max }$ on the ultimate shear strength was around $20 \%$ when $w=0.1 \mathrm{~mm}$. But the contribution of this fraction was $45 \%$ when $w=1 \mathrm{~mm}$. 
Walraven and Reinhardt (1981) showed that only for low mechanical reinforcement ratios a slight influence of the differences in concrete type (lightweight concrete, $D_{\max }$ of $32 \mathrm{~mm}$ instead of $16 \mathrm{~mm}$ ) can be detected. Mattock Mattock, Li, and Wang (1976) showed that the shear transfer strength of lightweight concrete is less than normal concrete if both types are compared. Also showed that the shear transfer strength is not affected by the type of lightweight aggregate. Years after, Sneed (2013) pointed out that the shear strength computed by the (ACI 318-11), using the coefficient of friction $\mu$ approach was conservative for all lightweight specimens test.

Xiao, Xie, and Yang (2012) investigated the influence of the recycled aggregate concrete (RAC) on the shear strength. They found that the RCA replacement ratio $R_{r}$ has significant effects on the ultimate shear load $P_{u}$ on specimens with similar concrete strength. Thus, $P_{u}$ is nearly the same as the normal aggregate concrete (NAC) for $R_{r}<30 \%$, but it reduce from $R_{r}=30 \%$ to $50 \%$, after which it stabilizes at about $0.85 P_{u}$ of NAC.

\section{Reinforcement ratio}

The reinforcement ratio $(\rho)$ is defined as the relation between the total steel crosssection $\left(A_{s}\right)$ of the longitudinal reinforcement and the concrete cross-section $\left(A_{c}\right)$. Walraven Walraven and Reinhardt (1981) investigated the influence of the amount of reinforcement for a constant concrete strength. Changing the reinforcement bar diameter $(6 \mathrm{~mm}$ to $16 \mathrm{~mm})$ for a fixed reinforcement ratio showed no significant influence; but an increase in the reinforcement ratio leads to an increase in the ultimate shear stress. The reinforcement ratio influenced the crack opening path, this is if more reinforcement was provided, the crack width was smaller. However, based on the experimental results, Walraven concluded that the dowel action in of minor importance in the shear behavior.

The influence of the reinforcement ratio in a beam, follows the trend previously explained. When the reinforcement ratio is small, flexural cracks extend into the beam and open more than would be with greater values of $\rho$. Experimental tests Mattock (1968); Rajagopalan and Ferguson (1968) have shown that the shear strength of reinforced concrete beams drops if the longitudinal reinforcement ratio is less than $1.2 \%$.

\subsection{Experimental tests on direct shear}

This section is focused on the direct shear. First a brief definition of this shear transfer mechanism is presented. Then, the main theories of direct shear are introduced. After, a complete and fully updated details of tests procedures are shown and discussed. This section ends with the presentation of the experimental results and mathematical expression obtained from different authors to obtained the ultimate shear stress. 


\subsubsection{Definition}

The aim of the direct shear test is analyzed the shear behavior of one or more cracks subjected to pure shear. Thus, the different shear transfer mechanisms can be studied. In order to produced a pure shear on the cracked section, different type of specimens and loading arrangement have been used by different authors.

As example of this kind of test, the push-off is used. In this test a z-shape specimen is used, as is shown in Fig. 2.13. This shapes is formed by two L-blocks, where the contact zone between this blocks is defined as shear plane. This shape of the specimen allows to apply a compression force $(\mathrm{P})$ to produce a direct shear on the shear plane. Also, the stress state of a material point on the shear plane is shown in Fig. 2.13.

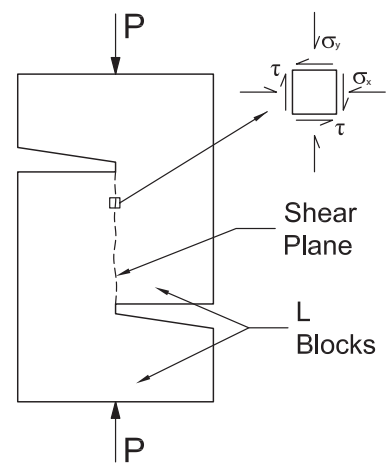

Fig. 2.13. General concept of the push-off test

\subsubsection{Theories on direct shear}

The analysis of the shear transfer mechanisms is studied by means of two theories. These two theories are, the "shear friction" and the "aggregate interlock". The shear friction theory is used to obtained the ultimate shear stress of a crack cross by stirrups. While, the aggregate interlock expressed normal and shear stresses as functions of crack width and slip displacements.

\section{Shear friction}

In 1966, Birkeland and Birkeland (1966) used the push-off test to introduce the shear friction approach, as it is known today. This theory was developed to deal with force transfer across joint in precast-concrete construction. The shear-friction theory hypothesis is illustrated in Fig. 2.14. Assuming sliding along the failure plane $m-m$, and simple Coulumb friction the shear force $(\mathrm{V})$, required to produce sliding is equal to $\mu P$, where $\mu$ is the coefficient of friction between the two element and $P$ is the clamping force perpendicular to the sliding plane. Due to the roughness of the crack $m-m$ the crack faces are forced to separate $(w)$ (see Fig 2.14b). 


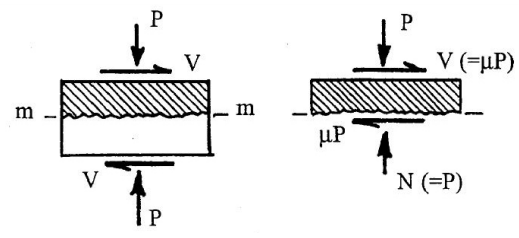

(a)

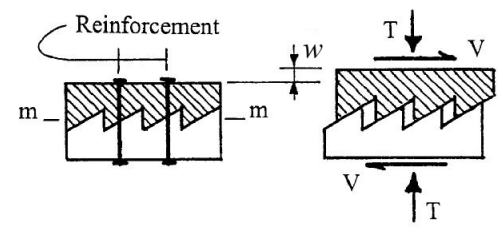

(b)

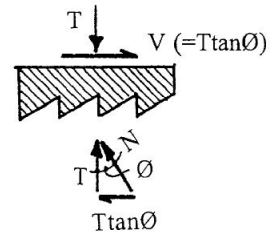

Fig. 2.14. Shear friction hypothesis Birkeland and Birkeland (1966).

If reinforcement is placed across the interface, this separation causes tension $(T)$ in the reinforcement. The tension force induced in the reinforcement is balanced by an equal compression force on the concrete acting across the crack. This compression force produce a frictional resistance to sliding between the faces of the crack, thus opposing the applied shear Mattock and Hawkins (1972). The roughness may be idealized as a series of frictionless fine sawtooth ramp having a slope of $\tan \theta$. Comparing Fig. 2.14a y $2.14 \mathrm{~b}$, it is seen that $T \tan \theta$ is equivalent to the frictional force $\mu P$. Thus:

$$
V_{n}=\mu \cdot A_{s} f_{s}
$$

The ultimate shear stress, is produced when the reinforcement reach its yielding stress. Dividing both term by the concrete area $\left(A_{c}\right)$, and replacing the steel stress for its yielding stress $\left(f_{s y}\right)$ is possible to express 2.4 as:

$$
v_{u}=\mu \cdot \rho f_{s y}
$$

This expression 2.5, present several advantages: (a) the shear-friction model, in which it is based, is clearly understandable, (b) the expression is simple and easy to use, and (c) it gives accurate results.

Birkeland and Birkeland (1966) suggested different values of $\mu$, according to the concrete-to-concrete interface. Thus $\mu=1.7$ for monolithic concrete, 1.4 for artificially roughened construction joints, and 0.8 to 1.0 for ordinary construction joints and for concrete to steel interfaces.

In order to prevent crushing of the concrete in the crack (caused by clamping force form the steel), before yielding of the steel; equation 2.5, is limited to the following conditions:

$$
\begin{gathered}
\rho \leq 1.5 \% \\
v_{u} \leq 5.5 \text { and } f_{c} \leq 27.6
\end{gathered}
$$




\section{Aggregate interlock}

This theory is based on the hypothesis that the bond between the matrix and the aggregated is the weakest link of the system. Also, is based in that the strength and stiffness of the aggregate particles are greater than the matrix. Therefore, cracking occurs through the matrix and around the aggregate particles, which are simplified as spheres.

Once the crack is formed, and slip displacement is produced, different contact areas between the aggregate particles and the matrix are produced. The projections of these contacts areas on the $\mathrm{x}$ and $\mathrm{y}$ direction are $a_{x}$ and $a_{y}$, respectively (see Fig. 2.15a). Due to plastic deformation of the matrix, high contact stresses are developed until the equilibrium is reached. These contact stresses are, a normal stress $\sigma_{p u}$ normal to the contact area and a stress $\tau_{p u}$ tangential to this area, as shown in Fig. 2.15b. Both stresses are interrelated by the condition that the contact areas are about to slide. The equilibrium condition is given by the coefficient of friction, and can be expressed as follows:

$$
\tau_{p u}=\mu \cdot \sigma_{p u}
$$

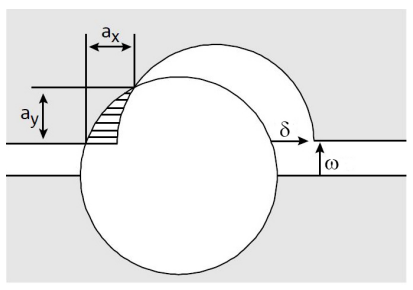

(a)

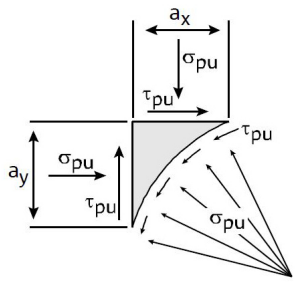

(b)

Fig. 2.15. Contact areas between aggregate and matrix (a) and stress condition (b) Walraven (1981).

The summation of $a_{x}$ and $a_{y}$, includes numerical integration and the use of the ratio of the volume of aggregates to the total concrete volume $p_{k}$, which takes a value of 0.75 for a concrete composition according to the Fuller grading curve. The summation of $a_{x}$ and $a_{y}$ can be written as

$$
\begin{aligned}
& A_{x}=\sum a_{x} \\
& A_{y}=\sum a_{y}
\end{aligned}
$$

Thus, the relationship between the both, normal and shear stresses, in the crack can be written as follows:

$$
\begin{array}{r}
\sigma=\sigma_{p u}\left(A_{x}-\mu A_{y}\right) \\
\tau=\sigma_{p u}\left(A_{y}+\mu A_{x}\right)
\end{array}
$$


In eq. 2.11, $A_{y}$ and $A_{x}$ depend on both displacements, crack width and slip. The experimental results reported in Walraven, Vos, and Reinhardt (1979) were used to validate the eq. 2.11. As it is reported in Walraven (1981).

\section{Superficial roughness}

Due to both theories used the friction coefficient $(\mu)$. It is decided make a brief explanation of this properties in the following paragraphs.

It is known that the type of surface texture or roughness at the interface influence the friction between concrete-to-concrete layers. Many researches have been carried out to investigate the friction coefficient. Tassios and Vintzeleou (1987), reported that for rough interface the maximum shear stress increases with the increasing of the external normal stress $\left(\sigma_{c}\right)$; but this increase is not proportional to the normal stress.

Fronteddu, Leger, and Tinawi (1998), observed that the coefficient of friction decreases with the increase in normal, and also that shear strength is dependent on the surface preparation. Based on experimental results, they defined the "basic friction coefficient", as express the following equation.

$$
\mu_{b}=\frac{\mu_{m e s}-\mu_{i}}{1+\mu_{m e s} \cdot \mu_{i}}
$$

where $\mu_{\text {mes }}$, is the measure friction coefficient defined as the ratio between the shear and normal forces $(V / N)$ to the shear plane; and $\mu_{i}$, is roughness friction coefficient defined as the ratio between crack width and shear slip $(w / \delta)$.

Fronteddu, demonstrated that the basic friction coefficient is indeed independent from the type of interface and thus may be considered as a fundamental material property. Mohamed et al. (2012) mentioned that the friction coefficient for the smooth surface was lower than the value in Eurocode 2, while for roughnned surface the experimental value of friction coefficient were higher than the value in Eurocode 2 Eurocode-2 (2004)

Issa et al. (2003) describe a modified slit-island method (photography technique) to measure the fractal geometries (i.e.roughness) of the surface, and found that fractal dimension increases with an increase in specimen and maximum aggregate size. For a complete review on roughness quantification methods for concrete surface see Santos and Júlio (2013)

\subsubsection{Test methodologies}

\section{Push-off test}

The push-off test is a non-standard, but widely recognized, test used to study the mechanisms of shear transfer. This test has the advantage of being relatively small, inexpensive, easy to perform, and not needing any highly specialized pieces 
of testing equipment. Along the years, the test has varied in size, instrumentation, reinforcement detail, and overall restraint conditions. But generally information is collected about the applied load, normal force, and the crack opening and slipping response to load.

Authors reported a too high stiffness before the crack appeared, if using an uncracked specimen, and then the crack is produced its shape was sometimes irregular starting by initial crack. As the shear cracks in beams usually are initiated by direct tension and look clearly defined, several authors proposed to test specimens precraced alon the shear plane prior to carry out the push-off test. All authors precracked the specimens by means of splitting test.

Table 2.1, summarize the different author, sort by year, that used push-off test to investigate shear behavior of cracked concrete. Is possible to see the total number of push-off tests, the quantity of initial precracked specimens, the initial crack width and the precracking method. Also, it can be seen the big scatter in the initial crack width (w0). This introduced the idea of the difficulties to fix this value.

Table 2.1. List of push-off tests.

\begin{tabular}{|c|c|c|c|c|}
\hline \multirow{2}{*}{ Author (year) } & \multirow{2}{*}{$\begin{array}{l}\text { Number of } \\
\text { specimens }\end{array}$} & \multicolumn{3}{|c|}{ Pre-cracked } \\
\hline & & quantity & $\mathrm{w} 0[\mathrm{~mm}]$ & Method \\
\hline Hofbeck (1969) & 38 & 23 & - & - \\
\hline Mattock (1972) & 28 & 10 & - & - \\
\hline Mattock (1974) & 23 & 15 & - & - \\
\hline Paulay (1974) & 44 & $44^{1}$ & $0,13-0,51$ & splitting \\
\hline Mattock (1976) & 64 & 30 & - & - \\
\hline Walraven (1979) & 83 & $32^{1}$ & $0,01-0,14$ & splitting \\
\hline Frénay (1991) & 46 & $12^{1}$ & $\approx 0,1$ & splitting \\
\hline Walraven (1994) & 15 & $9^{1}$ & $0,1-0,4$ & splitting \\
\hline Kahn (2002) & 50 & 19 & - & - \\
\hline Nagle (2007) & 18 & 18 & $0,03-0,86$ & splitting \\
\hline Mansur (2008) & 19 & 19 & $0,07-0,32$ & splitting \\
\hline Ince $(2007)$ & 54 & 0 & - & - \\
\hline Desnerk (2009) & 14 & 0 & - & - \\
\hline Jayaprakash (2009) & 6 & 6 & - & - \\
\hline Cuenca (2010) & 17 & 9 & + & - \\
\hline $\operatorname{Kim}(2010)$ & 48 & $48^{1}$ & $<0,5$ & splitting \\
\hline Sagaseta (2011) & 6 & 6 & $0,1-0,3$ & splitting \\
\hline Xiao (2012) & 32 & 32 & - & splitting \\
\hline Rahal (2012) & 4 & 0 & - & - \\
\hline
\end{tabular}

1 confined specimen

+ superficial treatment

Significant differences in the specimens (specially in geometry) can be found if a comparison among the authors are made. The geometry of the specimen is defined 
by its height $(\mathrm{H})$, height of the shear plane (Hs), width $(\mathrm{W})$, thickness $(\mathrm{B})$ and thickness of the shear plane (Bs), as is shown in Fig. 2.16. In Table 2.2, these properties used by each author are shown.

Table 2.2. Geometrical properties of different specimens.

\begin{tabular}{llllll}
\hline Author (year) & $\begin{array}{l}\mathrm{H} \\
{[\mathrm{mm}]}\end{array}$ & $\begin{array}{l}\text { Hs } \\
{[\mathrm{mm}]}\end{array}$ & $\begin{array}{l}\text { W } \\
{[\mathrm{mm}]}\end{array}$ & $\begin{array}{l}\text { B } \\
{[\mathrm{mm}]}\end{array}$ & $\begin{array}{l}\text { Bs } \\
{[\mathrm{mm}]}\end{array}$ \\
\hline Hofbeck (1969) & 546 & 254 & 254 & 127 & 127 \\
Mattock (1972) & 546 & 254 & 254 & 127 & 127 \\
Mattock (1974) & $610-715$ & $254-359$ & 356 & 178 & 178 \\
Paulay (1974) & 457 & 191 & 305 & 127 & 114 \\
Mattock (1976) & 559 & 254 & 305 & 127 & 127 \\
Walraven (1979) & 600 & 300 & 400 & 150 & 148 \\
Mansur (1990) & 600 & 300 & 300 & 150 & 150 \\
Frnay (1991) & 600 & 300 & 400 & 150 & 148 \\
Valle (1993) & 533 & 254 & 254 & 76 & 76 \\
Walraven (1994) & 600 & 300 & 400 & 150 & 148 \\
Khaloo (1997) & 520 & 220 & 300 & 125 & 125 \\
Kahn (2002) & 610 & 305 & 305 & 127 & 127 \\
Barragn (2007) & 260 & 60 & 150 & 150 & 150 \\
Nagle (2007) & $748-1149$ & $342-743$ & 508 & 165 & 165 \\
Kim (2007) & 660 & 305 & 400 & 125 & 126 \\
Ince (2007) & $350-750$ & $50-400$ & 200 & 160 & 160 \\
Mansur (2008) & 750 & 300 & 400 & 150 & 120 \\
Desnerk (2009) & $800-900$ & $300-200$ & 600 & 200 & 200 \\
Jayaprakash (2009) & 700 & 340 & 300 & 150 & 120 \\
Cuenca (2010) & 670 & 250 & 400 & 120 & 110 \\
Kim (2010) & 660 & 305 & 400 & 125 & 126 \\
Sagaseta (2011) & 700 & 350 & 300 & 165 & 135 \\
Xiao (2012) & 600 & 300 & 400 & 150 & 120 \\
Rahal (2012) & 540 & 250 & 250 & 125 & 125 \\
\hline
\end{tabular}
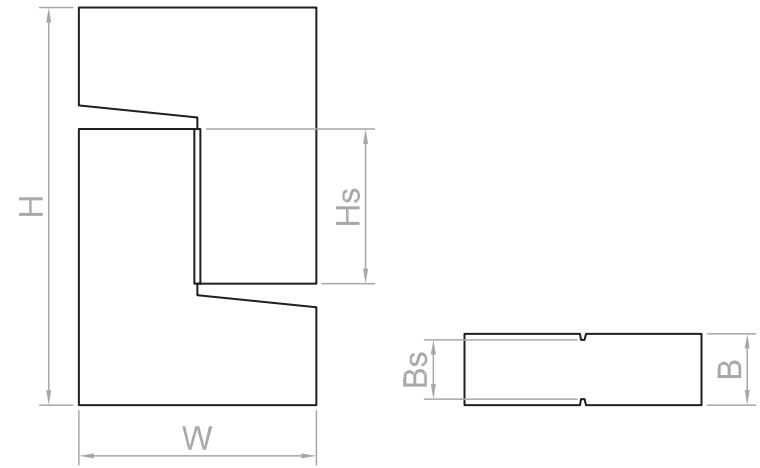

Fig. 2.16. Schematic representation of test specimen. 
To simulate the external effects in the shear cracked plane, some authors used an external system to produce a passive confinement in the specimen. This passive confinement is used to control the crack width evolution during the push-off test. Several systems or manners to control the crack width are reported in the literature. A common characteristic in the confined specimens was that all specimens were precracked along the shear plane prior to carry out the push-off test.

One of the first push-off test where the specimen was confined was reported by Paulay and Loeber (1974). In this investigation all specimens had bolts inserts, which were used to introduce a controlled tension force at right angle to the shear plane (see Fig. 2.17). This bolts did not pass through the shear plane but attached the two concrete blocks (of the specimen) to the stiff frame surrounding the specimen. During the test crack widths were adjusted, before each load increment, but only when the deviation from the specified value exceeded $5 \%$. The specified nominal crack widths used in the tests were $0.13,0.25$ and $0.51 \mathrm{~mm}$.

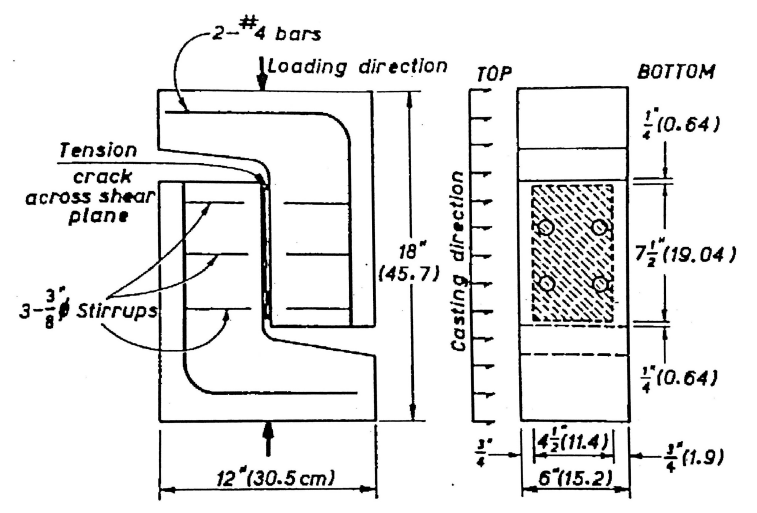

Fig. 2.17. Dimension and reinforcement of test specimens Paulay and Loeber (1974).

Based on the work of Paulay and Loeber, Walraven, Vos, and Reinhardt (1979), developed an steel frame to confine the specimen, as is shown if Fig. 2.18. The steel frame was conformed by two restraint plates which were fixed to the small side of the specimen by means of bolts and nuts. The plates were stiffened by transverse ribs, welded at the free side of the plates. Between these plates four external restraint bars were fastened. 


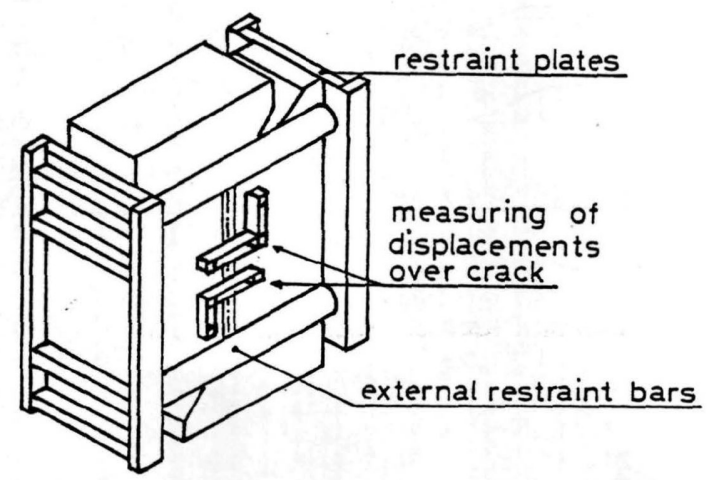

Fig. 2.18. Schematic representation of confined specimen Walraven, Vos, and Reinhardt (1979).

It is mentioned that the arrangement was designed that dowel action of the external bars would be negligible. But later is mentioned that the external bars were prestressed in order to compress a soft sand-cement paste layer between the restraint plate and the specimen, so a higher stiffness was obtained. In this way an average initial normal compressive stress on the crack plane of $1 \mathrm{MPa}$ was obtained. To adjust this initial compression, a pair of bolts in each extreme of the bars were used as shown in Fig. 2.19. In a subsequently study, Walraven (1980), it is reported that the restraint stiffness was not only a function of the diameter of the external bars, but depended also on the properties of the transverse plate and the thin layer of the sand-cement paste.

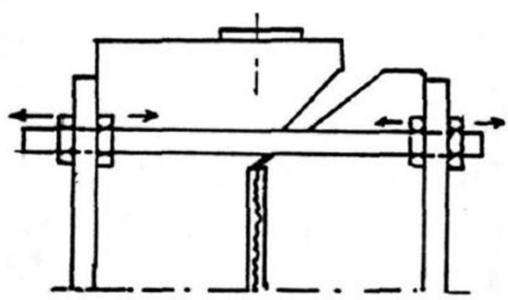

Fig. 2.19. Adjustment of the crack width by pairs of bolts Walraven (1980).

A similar restraint frame was used by Kim, Trejo, and Hueste (2007) (see Fig 2.20). In this case, the diameter of the external restraint bars was $31.8 \mathrm{~mm}$. But in the middle section the diameter reduces to $22.2 \mathrm{~mm}$. The aim of this design was avoided the dowel action of the restraint bars. The explanation for this was, "because the rod length $(400 \mathrm{~mm})$ is five times larger than the diameter $(22.2 \mathrm{~mm})$ the shear strains are negligible compare to the axial strains". Also, Kim, Trejo, and Hueste (2007) reported that an initial normal stress to the shear plane around $0.3 \mathrm{MPa}$ was applied. This value was obtained by adjusting the tightness of the nuts of the for steel roads. 


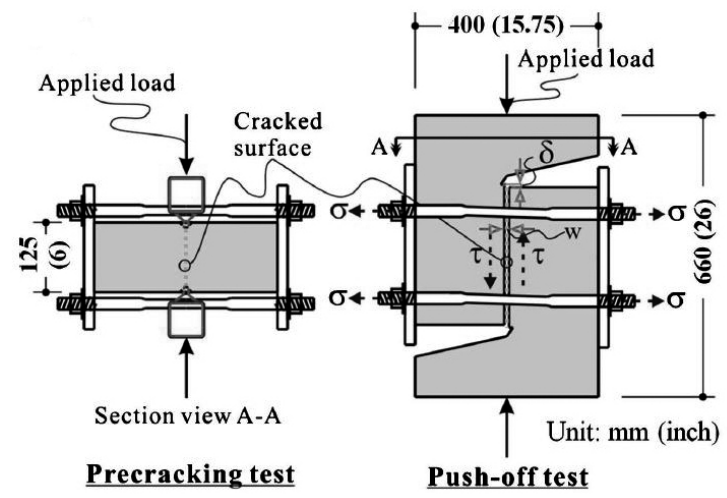

Fig. 2.20. Test specimen for evaluating aggregate interlock Kim et al. (2010).

\section{JSCE test}

In the context of material properties, there have been some attempts to use the push-off specimens (z-shape) to measure the shear strength and the shear toughness of both, reinforced concrete and fiber reinforced concrete. Although the push-off allows to measure all these properties under direct shear, the stress field in the specimens beyond cracking is highly complex, and stress conditions deviate significantly from being in pure shear Mirsayah and Banthia (2002).

The Japan Society of Civil Engineering (JSCE) proposed a standard method JSCE-SF6 (1990), which is an improvement over the push-off specimens. In this test the stress field remains substantially under pure shear. Also, a more reproducible shear response is obtained. In this test, a $150 \times 150 \times 500$ beam specimen is used, the load is applied by a loading block with two sharp loading knife edges $150 \mathrm{~mm}$ apart. The specimen is supported on another rigid block over a pair of knife edges that are separated $155 \mathrm{~mm}$. Thus, a narrow $0.25 \mathrm{~mm}$-wide region of the beam in between the loading and the supporting knife edges is subjected to a concentrated shear stress and this is where the shear failure is expected to occur.

However, Mirsayah detected that if the tests are conducted as per the JSCE-SF6 standard, the failure plane often deviated from the narrow region under concentrated shear, which is the prescribed plane for failure. These problem produced invalid results. To solve this problem, a pair of $15 \mathrm{~mm}$-deep all-around notch are made to the specimen forcing the shear failure occurred in the prescribed plane of fracture (see Fig. 2.21). 


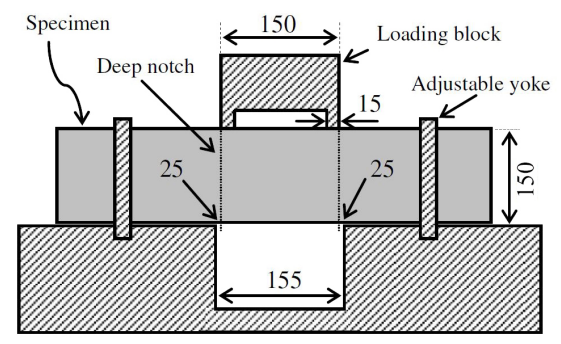

Fig. 2.21. Schematic representation of shear test Mirsayah and Banthia (2002).

Supporting the theory of Mirsayah, that FRC behave differently in shear than in flexure, the use of flexural properties to determine the shear response makes limited sense. Majdzadeh, Soleimani, and Banthia (2006) and Carmona and Cabrera (2009), use the JSCE-SF6 with some modifications to obtain the material properties of FRC in shear. Rao and Rao (2009), based on his experimental results reported that a pure shear failure is observed. Hence, the designed direct shear test (with modifications) could be used effectively to determine the fracture properties of FRC.

In spite of this test derive from the JSCE-SF6 standard, a series of modifications have been introduced for different reasons. As example, Table 2.3 shows the differences in specimen and notch sizes, of the studies citetd before.

Table 2.3. Specimen and notch differences

\begin{tabular}{lll}
\hline Author (year) & $\begin{array}{l}\text { Specimens } \\
{[\mathrm{mm}]}\end{array}$ & $\begin{array}{l}\text { notch depth } \\
{[\mathrm{mm}]}\end{array}$ \\
\hline Mirsayah $(2002)$ & $150 \times 150 \times 500$ & $2 \times 15$ \\
Majdzadeh $(2006)$ & $100 \times 100 \times 350$ & $2 \times 10$ \\
Appa Rao (2009) & $150 \times 150 \times 500$ & $2 \times 15$ \\
Carmona (2009) & $150 \times 150 \times 500$ & $2 \times 15$ \\
Boulekbache $(2012)$ & $100 \times 100 \times 350$ & $2 \times 10$ \\
Banthia (2013) & $100 \times 100 \times 350$ & $2 \times 10$ \\
\hline
\end{tabular}

\subsubsection{Experimental results and mathematical models}

Mast (1968) adopted the equation 2.5, but suggested an upper limit of $0.15 f_{c} \tan \theta$ for the ultimate shear stress. Also proposed different values for the coefficient of friction, $\mu=1.4$ for concrete-to-concrete rough interfaces, 1.0 for concrete-to-steel composite beams, and 0.7 for concrete-steel field-welded inserts or for concrete-toconcrete smooth interfaces.

Due to Mast (1968) pointed out the need to consider the case of a crack preexisting in the shear plane before shear acts. Hofbeck, Ibrahim, and Mattock (1969), conducted an extensive testing program in which precracked shear plane was one 
of their variables, between others. Also, Hofbeck, Ibrahim, and Mattock (1969) stated that preexisting cracks along the shear plane results in a decrease of the shear strength and in an increase of the relative slip between both concrete parts (see Fig. 2.22). Also reported that concrete strength has influences on the shear strength of the interface. For values of clamping force $\left(\rho f_{y}\right)$ below $4.14 \mathrm{MPa}$, the concrete strength does not affect the shear strength. Above this limit, the shear transfer is affected increasing when the concrete strength increases.

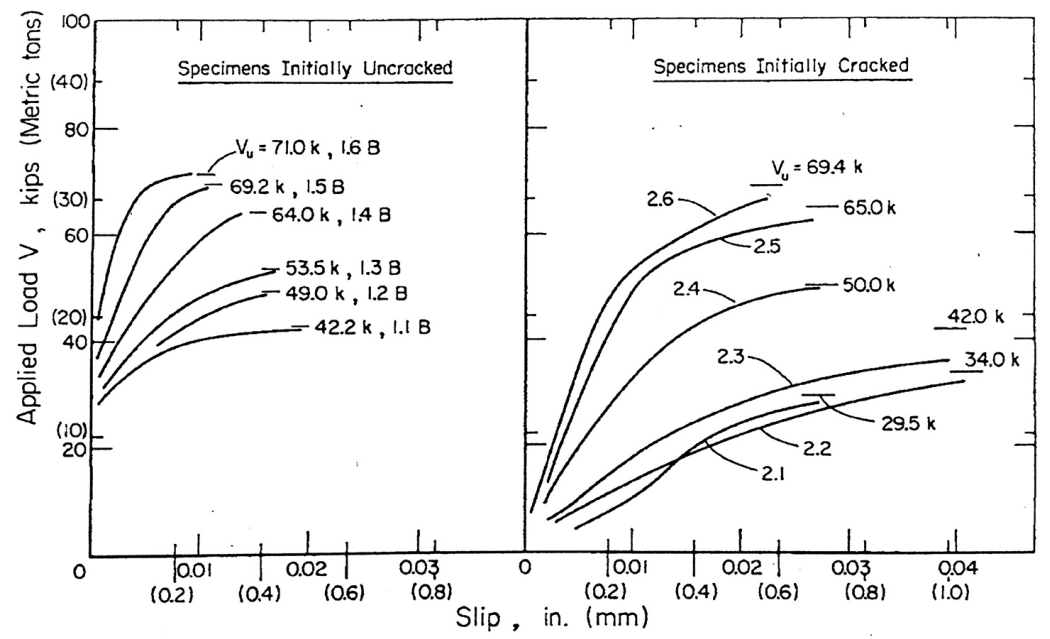

Fig. 2.22. Typically load-slip curves Hofbeck, Ibrahim, and Mattock (1969).

Mattock and Hawkins (1972), presented a design expression to predict the ultimate shear stress $\left(v_{u}\right)$. The lower bound of the experimental test was represented by:

$$
v_{u}=1.38+0.8\left(\rho f_{y s}+\sigma_{N}\right)(\mathrm{MPa})
$$

Where $\rho$ is the reinforcement ratio, $f_{y s}$ is the yield strength of the reinforcement, and $\sigma_{N}$ is the normal stress at the interface. The ultimate shear stress should not be greater than $0.3 f_{c}$ neither $10.34 \mathrm{MPa}$. The clamping stresses $\left(\rho f_{y s}+\sigma_{N}\right)$ have to be higher than $1.38 \mathrm{MPa}$. In equation 2.13, the first term is due to an apparent cohesion of the interface and tho dowel action of the reinforcement, the second term is due to clamping stresses. The coefficient of friction $(\mu)$ is equal to 0.8 .

Due to eq. 2.13 gives underestimated results, Mattock (1974), subsequently presented a modified expression calibrated with average values from new experimental results given by:

$$
v_{u}=2.76+0.8\left(\rho f_{y s}+\sigma_{N}\right)(\mathrm{MPa})
$$

Comparing eq. 2.13 and eq. 2.14, it can be seen that the cohesion term is increased from 1.38 to 2.76 . From a physical point of view, eq. 2.14 corresponds to a crack model according to Fig. 2.23, where the crack faces are characterized by a general roughness and a local roughness. The cohesion term reflects the shearing off of local asperities at the crack faces. 


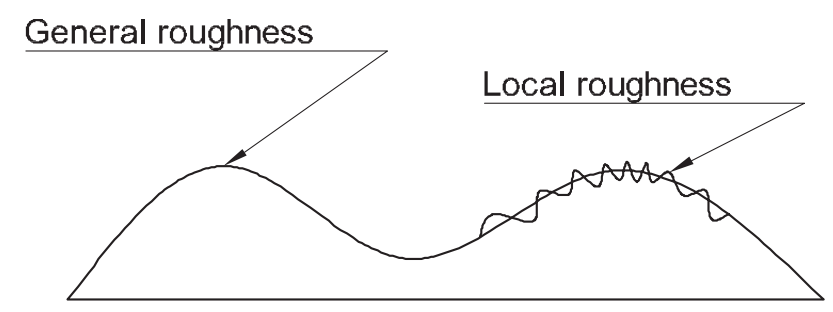

Fig. 2.23. General and local roughness Walraven, Frenay, and Pruijssers (1987).

Mattock (1974) also showed that the effects of reinforcement at an angle to the shear plane could be predicted based on the shear-friction theory. For that reason proposed the following expression:

$$
v_{u}=2.76 \sin ^{2} \theta+\rho f_{s}\left(0.8 \sin ^{2} \theta-0.5 \sin (2 \theta)\right)(\mathrm{MPa})
$$

Where $\theta$ is the angle between the reinforcement and the shear plane, $\rho$ is the reinforcement ratio. The ultimate shear stress is limited to the maximum of $0.3 f_{c}$. The coefficient of friction is equal to 0.8 . The term of $f_{s}$ was defined form experimental test, and is given by:

$$
\begin{gathered}
f_{s}=0 \text { for } 0 \leq \theta<51.3 \\
f_{s}=-1.6 f_{y s} \cos (\theta+38.7) \text { for } 51.3 \leq \theta<90 \\
f_{s}=f_{y s} \text { for } 90 \leq \theta<180
\end{gathered}
$$

Where $f_{y s}$ is the yield strength of the reinforcement.

Paulay and Loeber (1974), investigated the nature of the shear transfer across crack by aggregate interlock mechanism. Three variables were studied in this research, the influence of the crack width, the effect of aggregate size and shape, and the effect of load history. The maximum size of the aggregate particles $\left(D_{\max }\right)$ were used, $9.5 \mathrm{~mm}$ and $19 \mathrm{~mm}$; and two shapes of aggregate were used, crushed and round.

Based on the experimental results found that the major single factor affecting the shear transfer mechanism is the width of the crack across which shear stresses are to be transferred. After compared all specimens, no noticeable effect in the aggregate size or shape were found. For constant crack width the shear behavior could be satisfactorily represented by a bi-linear relationship as shown in Fig. 2.24.

The influence of the width of the crack was also confirmed by the statistical model of Walraven (1980). One example of the statistical model is shown in Fig. 2.25. In the figure can be seen that, when the width of the crack increases the amount of shear stress transmitted by the crack decrease. This model was experimentally validate, in the figure the experimental points are shown, also it can be seen the 


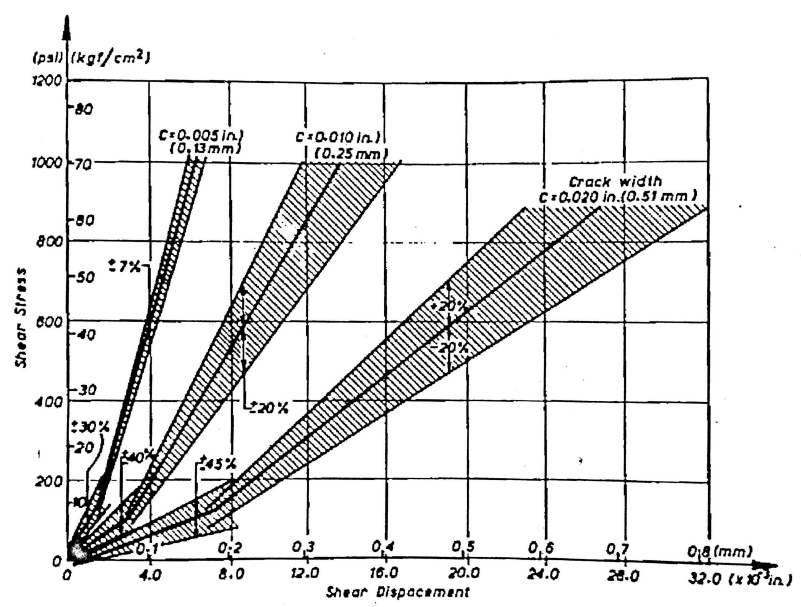

Fig. 2.24. The mean shear stress-shear displacement relationships for aggregate interlock action Paulay and Loeber (1974).

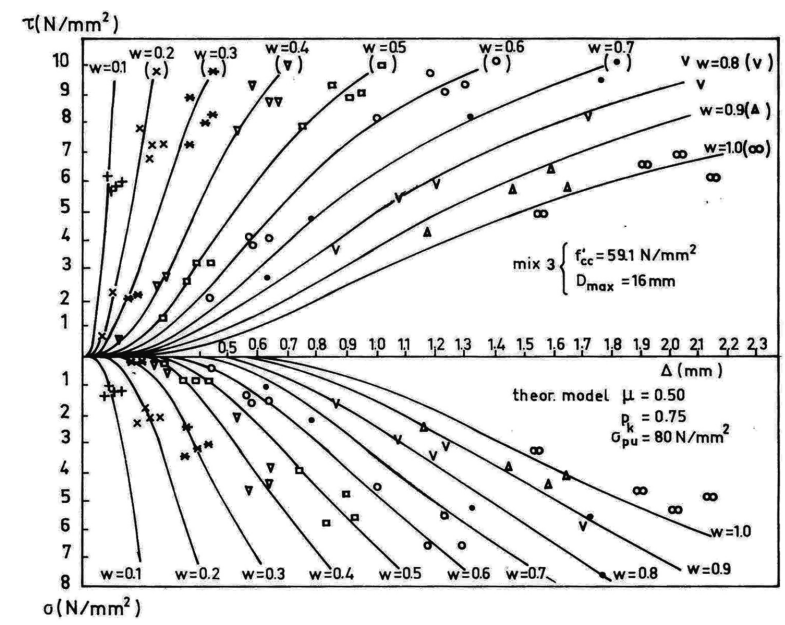

Fig. 2.25. Example of the statistical model of aggregate interlock Walraven (1980).

good fitting of the model. Walraven (1981) also confirmed with his model that, all aggregate particle sizes contributed to the shear transfer mechanism.

Mattock, Li, and Wang (1976), investigated shear friction in lightweight concrete and found the friction values to be lower than the corresponding to normal weight concrete with both, crack and uncrack specimens. For this reason, this study presented modifications of the eq. 2.14, depending on the type of aggregate to produce a better prediction. For all (aggregate and sand) lightweight concrete, the ultimate shear strength is obtained as it is expressed in eq. 2.19 (see Fig. $2.26 \mathrm{a}$ ), but the ultimate shear stress should not be greater than $0.2 f_{c}$ neither $5.52 \mathrm{MPa}$. While for sanded lightweight concrete, the ultimate shear strength is obtained according to eq. 2.20 (see Fig. 2.26b), and should not be greater than 
$0.2 f_{c}$ neither $6.90 \mathrm{MPa}$.

$$
\begin{aligned}
& v_{u}=1.38+0.8 \rho f_{y s}(\mathrm{MPa}) \\
& v_{u}=1.72+0.8 \rho f_{y s}(\mathrm{MPa})
\end{aligned}
$$

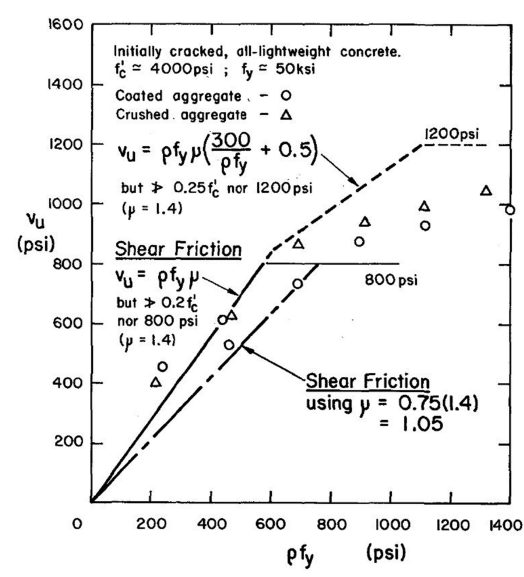

(a) All lightweight concrete

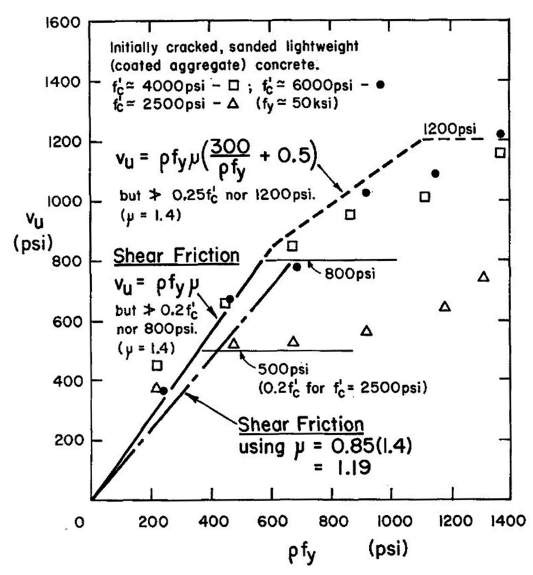

(b) Sanded light concrete

Fig. 2.26. Comparison of shear transfer strength of initially cracked concrete with strength predicted by design equations Mattock, Li, and Wang (1976).

The difference in shear transfer strength between lightweight concrete and normal weight concrete of the same compressive strength is probably due to differences in roughness of the crack faces in contact. In lightweight concrete the bond between the mortar and the aggregate is greater than the tensile strength of the the aggregate particles. Therefore, cracks propagate through the aggregate and a smoother 
crack face result Mattock, Li, and Wang (1976). While, in normal weight concrete, the bond strength between the mortar and the aggregates is smaller than the tensile strength of the aggregate particles. Cracks therefore propagate around the aggregate particles producing a rough surface Mattock, Li, and Wang (1976).

Walraven, Frenay, and Pruijssers (1987), in order to consider the concrete strength, develop a statistical study based on a large experimental campaign of 88 push-off. From this study a non-linear function to predict the shear strength of initially cracked interfaces was developed. One of the main objectives of this work was to extend the range of concrete strength, because Mattock's equation was developed for concrete strength varying between 20 to $30 \mathrm{MPa}$. Beyond this limit the predictions of Mattock's equation were valid but too conservatives.

The design expression, including the reinforcement ratio, the yield strength of the reinforcement, and the concrete compressive strength is:

$$
\begin{aligned}
& v_{u}=C_{1}\left(\rho f_{y s}\right)^{C_{2}}(\mathrm{MPa}) \\
& C_{1}=0.822 f_{c}^{0.406}(\mathrm{MPa}) \\
& C_{2}=0.159 f_{c}^{0.303}(\mathrm{MPa})
\end{aligned}
$$

Where $v_{u}$ is the ultimate shear strength, $\rho$ is the reinforcement ratio, $f_{y s}$ is the yield strength of the reinforcement, and $f_{c}$ is the concrete compressive strength.

Despite the excellent precision of eq. 2.21, the formulas (due to their complexity) are nor directly usable in design practice. To solve this deficiency, a design chart based on eq. 2.21 was developed as shown in Fig. 2.27. Using this chart, the required amount of shear reinforcement can be read directly Walraven, Frenay, and Pruijssers (1987). 


\section{Design Chart}

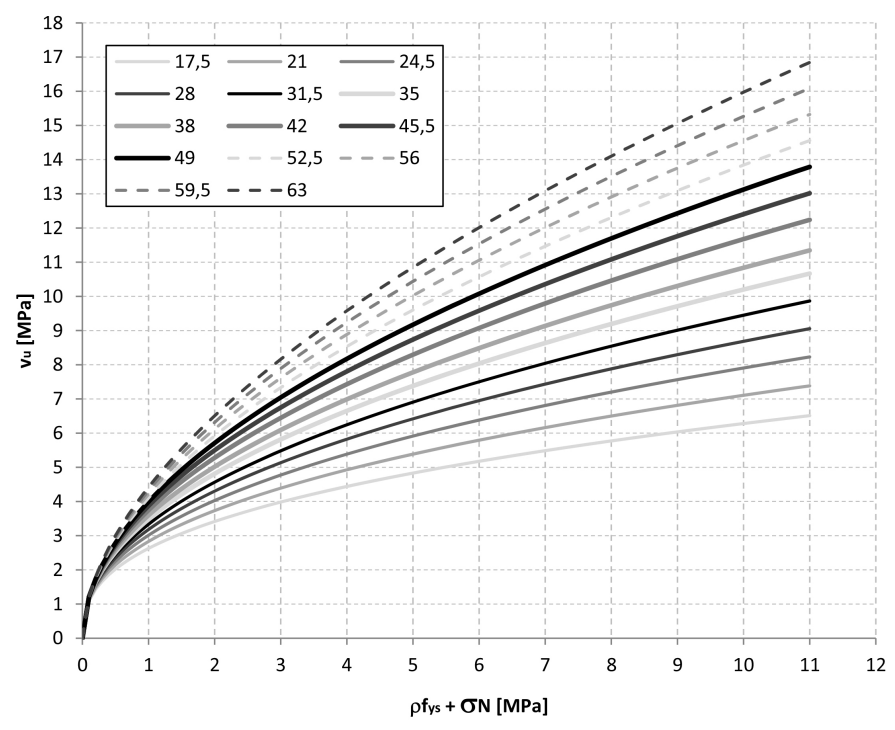

Fig. 2.27. Design chart for determining shear friction capacity by taking account the compressive strength of concrete Walraven, Frenay, and Pruijssers (1987).

Load history, such as previous sustained or repeated cyclic loading, was found to have little effect on the ultimate shear strength. It is believed that as ultimate load is approached, greater and virgin contact areas within the crack are mobilized. These virgin areas are not affected by the previous load history Walraven, Frenay, and Pruijssers (1987).

The influence of sustained shear load on cracked concrete is investigated by means of confined specimens Frénay, Reinhardt, and Walraven (1991a); Frénay, Reinhardt, and Walraven (1991b). These specimens are similar of those used by Walraven, and plain concrete specimens are confined by four internal steel bars of $\phi=$ $16 \mathrm{~mm}$. The bars passed through cylindrical holes of $\phi=22 \mathrm{~mm}$; thus, the dowel effect is negligible. Confined forces are introduced by adjusting the external rods, given an initial normal stress to the crack plane varying between 1 to $2 \mathrm{MPa}$.

\section{High strength concrete (HSC)}

When the strength of the matrix increase, fracture of aggregate will occur. This phenomenon is investigated by Walraven and Stroband (1994). They conducted tests on cube $(150 \mathrm{~mm})$ concrete strength of $100 \mathrm{MPa}$. They reported that reduction in shear capacity due to aggregate fracture is considerable. This reduction is taken in account in the aggregate interlock theory by the fracture coefficient $\mathrm{C}$, as following.

$$
\tau=C \cdot \sigma_{m}\left(A_{y}+\mu A_{x}\right)
$$




$$
\sigma=C \cdot \sigma_{m}\left(A_{x}-\mu A_{y}\right)
$$

where, $\sigma_{m}$ is the yielding stress of the matrix defined as $\left(\sigma_{m}=6.4 \cdot f_{c c}^{0.56}\right), \mu$ is the friction coefficient (equal to 0.4 ), and $f_{c c}$ is the cube concrete strength in $M P a$.

The use of the fracture factor is in some way artificial. Because of the shear resistance is support by virtue of macro-roughness of the crack faces. If crack of plain concrete is considered the fracture factor is 0.35 , but when crack intersected by reinforcement, the fracture factor varying between 0.55 to 0.75 .

Initially the shear strength increases very rapidly with increase in the yield strength of the shear friction reinforcement. However, the rate of increase gradually decreases to a constant value of 0.8 , and maintained until the shear plane becomes over-reinforced ( $V_{u}$ approximately $0.3 f_{c} A_{c}$ ). To prevent over-reinforcement, ACI Code places an upper limit of $0.2 f_{c} A_{c}$ neither $f_{c} \leq 28 \mathrm{MPa}$. Therefore is not possible to take advantage of any further increase in shear friction strength that may occur when high-strength concretes (HSC) are used.

To solve this situation, Mattock proposed the follow solution. When the normal stress $\left(\sigma_{N}\right)$, due to internal or external loads, acts across an irregular crack is equal or greater to $K_{1} / 1.45$, or when the ultimate shear strength is equal or greater to $1.55 K_{1}$, the ultimate shear strength is given by Mattock (2001):

$$
v_{u}=K_{1}+0.8\left(\rho f_{y s}+\sigma_{N}\right)(\mathrm{MPa})
$$

Where $K_{1}$ is a coefficient that depends of the concrete strength, $\rho$ is the reinforcement ratio, $f_{y s}$ is the yield strength of the reinforcement, and $\sigma_{N}$ is the normal stress at the interface due to external loads. The value of eq. 2.26 , should not be greater than $K_{2} f_{c}$ neither $K_{3}$.

When the normal stress $\left(\sigma_{N}\right)$, due to internal or external loads, is less than $K_{1} / 1.45$, or when the ultimate shear strength is less than $1.55 K_{1}$, the ultimate shear strength is given by:

$$
v_{u}=2.25\left(\rho f_{y s}+\sigma_{N}\right)(\mathrm{MPa})
$$

For normal weight and monolithic concrete, the values of the coefficient are:

$$
\begin{gathered}
K_{1}=0.1 f_{c} \leq 5.5 \mathrm{MPa} \\
K_{2}=0.3 \\
K_{3}=16.6 \mathrm{MPa}
\end{gathered}
$$

For normal weight and placed against hardened concrete with the substrate intentionally roughened, the values of the coefficient are:

$$
K_{1}=2.76 \mathrm{MPa}
$$




$$
\begin{gathered}
K_{2}=0.3 \\
K_{3}=16.6 \mathrm{MPa}
\end{gathered}
$$

An schematic representation of the equations 2.26 and 2.27 is shown in Fig. 2.28.

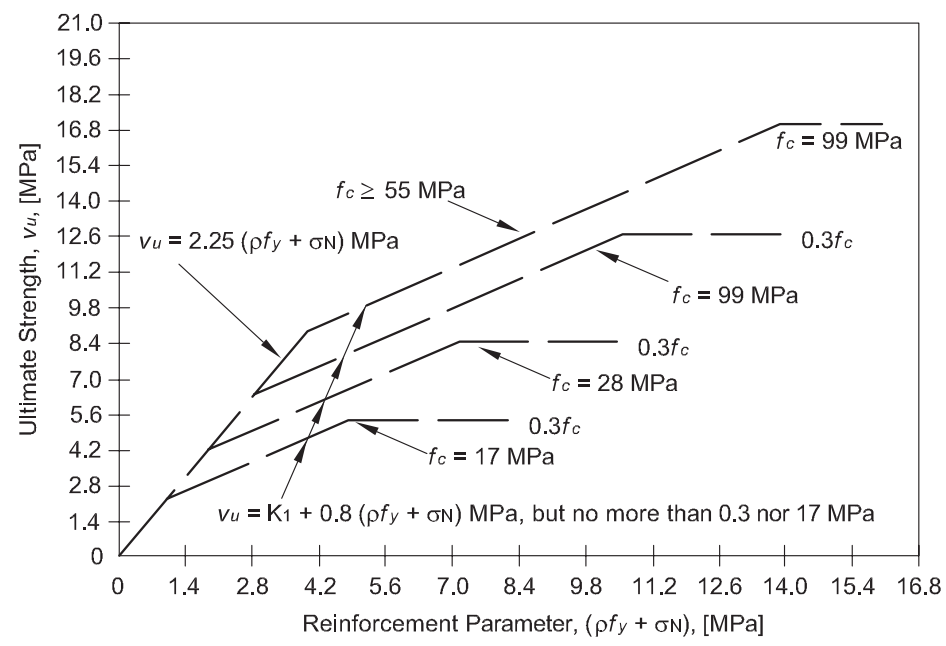

Fig. 2.28. Shear strength of cracked normal weight concrete Mattock (2001).

The tendency of the conservative prediction of the ACI 318-99 in the ultimate shear strength, was confirmed by Kahn and Mitchell (2002), which developed an experimental research on HSC. They found that the residual shear strength of coldjoint, uncracked, and cracked specimens were similar and that residual capacities were greater than predicted by the current model when $\mu$ of 1.0 was used. Also proposed that the upper limit of shear stress be only $0.2 f_{c}$ discarding the other limitation of 5.5 MPa. And suggested a design expression to be used with normal and high strength concrete:

$$
v_{u}=0.05 f_{c}+1.4 \rho f_{y s}
$$

Where $v_{u}$ is the ultimate shear stress, $f_{c}$ is the concrete compressive strength $\rho$ is the reinforcement ratio, $f_{y s}$ is the yield strength of the reinforcement. The adopted coefficient of friction $(\mu)$ is equal to 1.4, corresponding to a monolithic concrete connection.

The experimental behavior of the shear friction theory in high strength cracked concrete was extended by Nagle and Kuchma (2007). Based on their results, the ultimate shear stress calculated by the ACI 318-05 were conservative for all of the experiments in which shear failure was observed. The ultimate shear stress calculated by the AASHTO LRFD specifications was conservative in 11 of 16 experiments. Also they pointed out, that the ultimate shear resistance provided 
by the concrete is in excess of that calculated by the modified compression field theory (MCFT) for all cases when the crack width exceeding $1 \mathrm{~mm}$.

Mansur, Vinayagam, and Tan (2008), with the aim to extend the tests data on precracked z-shape specimens beyond concrete strength of $70 \mathrm{MPa}$ up to $120 \mathrm{MPa}$, developed and experimental work of 19 pre-cracked specimens. Also they reported a comparison between design codes, and those expressions suggested by Mattock and Hawkins (1972); Mattock, Li, and Wang (1976); Mattock (2001), Walraven, Frenay, and Pruijssers (1987), Mau and Hsu (1988), Loov and Patnaik (1994) was made.

From the test results, was concluded that the design expressions proposed by Walraven, Frenay, and Pruijssers (1987), and by Mau and Hsu (1988), give unsafe predictions of the ultimate shear stress. A new design expression was suggested, and calibrated with a set of 154 test results. Concrete compressive strength was between $18 \mathrm{MPa}$ and $100 \mathrm{MPa}$, while the normalized clamping forces $\left(\rho f_{y s} / f_{c}\right)$ were between 0.02 and 0.39 . The expression is given by:

$$
\frac{v_{u}}{f_{c}}=0.566 \sqrt{\frac{\rho f_{y s}}{f_{c}}} \leq 0.3
$$

After compared eq. 2.35 with the experimental data, Mansur et al. concluded that this expression could be unsafe for low values of the normalizes clamping forces. Therefore, a trilinear formulation is proposed. For normalized clamping forces lower o equal to 0.075 , the first part of the trilinear formulation is given by:

$$
\frac{v_{u}}{f_{c}}=2.5 \frac{\rho f_{y s}}{f_{c}} \text { for } \frac{\rho f_{y s}}{f_{c}} \leq 0.075
$$

For normalized clamping forces between 0.075 and 0.27 , the second part of the trilinear formulation is given by:

$$
\frac{v_{u}}{f_{c}}=\frac{0.56}{f_{c}^{0.358}}+0.55 \rho \frac{f_{y s}}{f_{c}} \text { for } 0.075<\frac{\rho f_{y s}}{f_{c}} \leq 0.27(\mathrm{MPa})
$$

For normalized clamping forces greater than 0.27 , the third part of the trilinear formulation is defined by:

$$
\frac{v_{u}}{f_{c}}=0.3
$$

The trilinear approximation of test data is shown in Fig. 2.29. The first part (or branch I) is defined by eq. 2.36, branch II is represented by eq. 2.37 , and branch III by eq. 2.38. Also from statistical analyses is found that the coefficient of friction between cracked concrete surfaces is independent of concrete strength and is equal to 0.55 , but the cohesion coefficient of cracked concrete may be expressed in terms of concrete strength.

A comparison between five models Walraven, Vos, and Reinhardt (1979), Mau and Hsu (1988), Loov and Patnaik (1994), Mattock (2001) and (ACI 318-05) and 


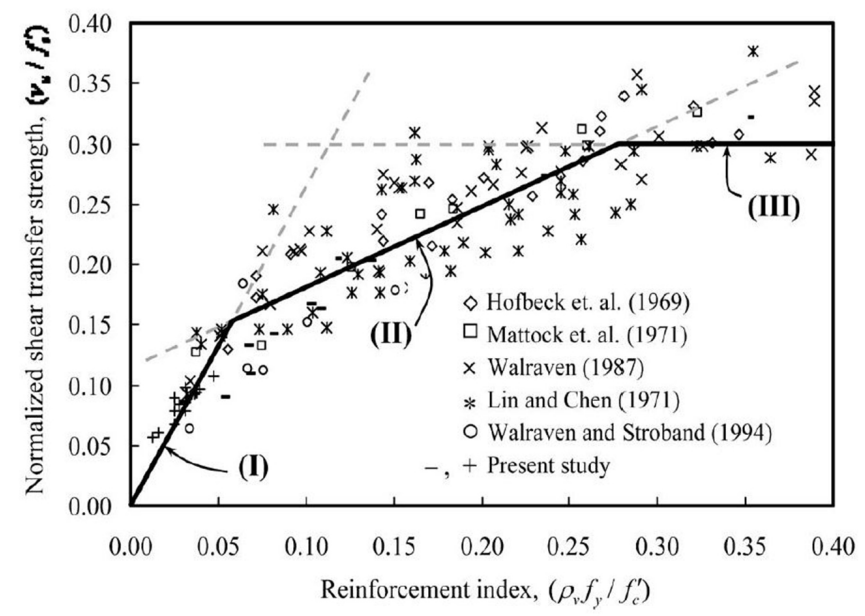

Fig. 2.29. Trilinear approximation of test data Mansur, Vinayagam, and Tan (2008).

the model called the simplified model for combined stress resultants (SMCS) was made by Rahal Rahal (2011). Based on the experimental results it was found that four of the five models were severely unconservative when used to calculate the shear strength of specimens with moderate (and practical) levels of reinforcement. Meanwhile, the ACI code results were adequate for these tests because of the markedly large margin of conservatism built-in in the ACI shear friction model.

The better accuracy of the SMCS was mainly due to its ability to account for the effect of the reinforcement in the direction parallel to the shear transfer plane.

\section{Fiber reinforced concrete (FRC)}

To analyze the contribution of steel fiber (SFRC) on shear transfer mechanisms, a comparison with reinforced concrete (RC) is done by Serna Serna (1984). Push-off specimens are used to produce a pure shear on the crack plane. The experimental results used to compare are reported by Walraven and Reinhardt (1981). The maximum shear stress that SFRC transmit is between those results of RC $\rho=$ $0.56 \%$ and $\rho=1.12 \%$.

Steel fibers enhance the shear strength, residual shear transfer strength and produce a overall ductility. While reduce both shear slip and crack width. Once the crack is formed, steel fibers are effective in bridging the crack, prevent excessive opening of the crack and contribute to post-peak load deformation Swamy, Jones, and Chiam (1987); Cuenca and Serna (2010b). These increases are reported in both uncracked an precracked specimens.

For uncracked specimens reinforced with fibers alone, failure occurred by the formation of several small cracks diagonal to the shear plane, which ultimately joined together and formed a crack band along the plane. A ductile failure mode is ob- 
tained for normal strength concrete when fibers are pull out of the matrix. But for high strength concrete, due to the improved bond between the fiber and the matrix, some of the fibers bridging the cracks yielded and eventually broke Valle and Buyukozturk (1993). The combination of steel fibers and stirrups proved to increase significantly the overall ductility when compared to reinforced concrete with stirrups alone.

For precracked specimens, less ultimate shear stress and increasing in shear slip at all stages of loading is observed compared with uncracked specimens. In addition, the shear slip decreased with rising the fiber volume and delayed the development of the existing crack along the shear plane Ahmed and Ansell (2010). When precracked lightweight concrete reinforced with steel fiber is subjected to shear loading, the same trend of normal and high strength is observed. Inclusion of fibers leads to an increase in shear transfer strength and the optimum fiber volume increases with the concrete strength Lim et al. (2011).

While concrete strength increases, the bond stress between matrix and fiber increases too, so the influence of fibers become greater. Higher fiber volume gives a greater number of fibers to sew the crack. Especially large fiber aspect ratio $(l / d)$,contributed to higher deformability on the composite material Khaloo and $\operatorname{Kim}$ (1997).

Two compact test specimens geometries are used to evaluate the shear strength and post-cracking toughness of FRC materials Barr (1987). Both specimens geometries showed that, experimental results are independent of the notches' separation. Shear strength are similar for both geometries and in good agreement with results obtained from other geometries.

Based on Barr's work, a simplified push-off specimen is reported by Barragan et al. (2006) to analyze shear failure of steel fiber reinforced concrete. The push-off specimen is cut from the $150 \times 150 \times 600 \mathrm{~mm}$ three-pointed bending test specimens. From experimental results demonstrate the energy dissipation capacity of steel fiber reinforced concrete in post-cracking behavior. The pull out resistance and dowel action of the fibers leads to considerable residual load-carrying capacity.

Table 2.4, shows a comparison between the total push-off tests made in reinforced concrete $(\mathrm{RC})$ and the fiber reinforced concrete (FRC). Also, the precracked specimens and the test done under crack control condition (confined) are presented. Almost $50 \%$ of RC push-off tests are precracked prior to do the main test, and around $30 \%$ are done with crack control condition. While, on FRC a less number of tests are reported, but the general trend is the same as RC, $50 \%$ for precracked and a very few percentage (only $3 \%$ ) for crack control condition.

Table 2.4. Comparison between RC and FRC push-off tests

\begin{tabular}{lll}
\hline & RC & FRC \\
\hline Tests & 657 & 177 \\
Pre-cracked & 380 & 58 \\
Confined & 193 & 6 \\
\hline
\end{tabular}




\section{Granular skeleton}

The concrete composition, and more specifically the amount of coarse aggregate, is significantly different for self-compacting concrete (SCC) than in conventional vibrated concrete (CVC). This differences could have an influences on the aggregate interlock and has been studied by means of push-off test Desnerck, De Schutter, and Taerwe (2009). It was found that the ultimate shear strength for SCC is around $15 \%$ to $20 \%$ higher than for CVC. So the aggregate interlock must be greater, probably because of the improved concrete matrix. While the vertical displacement corresponding to the ultimate shear strength is larger for SCC than for CVC.

The push-off setups was also used by Cuenca and Serna (2010c), to investigate the influence of the grain size and the reinforcement ratio. They cast specimens in two phases. The shear plane (or failure zone) was also plane and was prepared with different superficial treatment. These treatment consisted in flat shear plane, a shear plane created with a rough grid, or with a hardening retarder. It was found that for the same concrete type, the uncracked specimens were shown the highest peak loads. While, those specimens having flat treatment (smooth precracks) gave the lowest shear strengths.

On the other hand, when the precrack was rough and wide, the concrete type with coarse granular structure reached higher ultimate shear strength, but the residual strengths (after failure) were comparable. For concretes with a fine granular structure the shear strength as well as the residual strength were decreased.

Kim et al. (2010), using confined specimen as shows Fig. 2.20, defined the ratio of shear stress to normal stress $(\tau / \sigma)$, dividing eq. 2.24 into eq. 2.25. The plot of the ratio vs. crack width, provide an assessment of the aggregate interlock excluding the effect of $\sigma_{m}$ and $\mathrm{C}$. They reported that higher stress ratios represent higher aggregate interlock at a given crack width, and when the ratio converged at 1.0, indicate that there is no further aggregate interlock, as shows Fig. 2.30.

Kim et al. (2010) used these plots to compare the aggregate interlock between concretes made with river gravel and limestone gravel. Based on the experimental results, they concluded that concrete made with river gravel exhibit more aggregate interlock than concrete made with limestone gravel.

The particular case of the fracture of aggregates and its influences on the shear transfer strength was investigated by Sagaseta and Vollum (2011). In the present investigation the push-off setups was used. All specimens were pre-cracked before developing the push-off test. To investigate the fracture of the aggregate, crush limestone and marine gravel were used. It was reported that the crack passed through the limestone aggregate but around the gravel aggregate. Specimens made with crush limestone showed highest shear strength than the gravel's specimens. A possible explanation for this behavior could be due to interlocking at the macro-level. Limestone crush aggregate produced more irregular shape of the crack surfaces, allowed contact areas to develop despite the aggregate particles fracturing completely at the crack. 


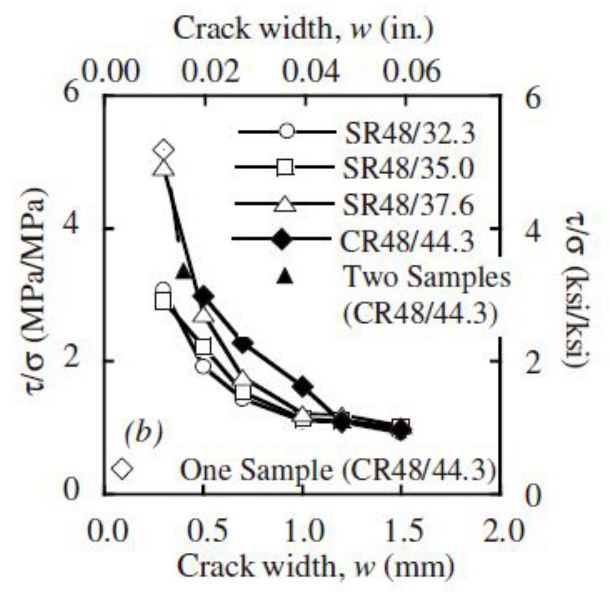

Fig. 2.30. Plot of mean shear-to-normal stress ratio versus crack width Kim et al. (2010).

This hypothesis is confirmed by Walraven, Belletti, and Esposito (2012), which developed an experimental investigation on shear capacity of lightweight, normal and high strength concrete beams. From the results they concluded that the reduced aggregate interlock action in cracks in lightweight and high strength concrete due to particle fracturing is largely compensated by others contact areas formed between the undulating and irregular crack faces.

Sagaseta and Vollum (2011) also found that, the relative crack displacement at maximum shear stress were greater in the gravel than in the limestone specimens. But the crack opening paths (which is the relationship between the increases of the slip vs. the increases of the crack width) were very similar in the gravel and limestone specimens.

\section{JSCE results}

In this section some experimental results obtained according to the JSCE method are presented. Mirsayah and Banthia (2002), used prismatic specimens of $150 \mathrm{x}$ $150 \times 500 \mathrm{~mm}$ in their investigation. In this case, a $15 \mathrm{~mm}$ deep notch was sawed all around the specimen in between the loading and supporting edges. In this case, the specimen was not rigidly fixed and how the rotation of the specimen was taken into account is not mentioned.

From the experimental results, Mirsayah and Banthia (2002) found that the addition of steel fibers significantly improves the shear strength as well as shear toughness. This improvement increase with the increment of fiber volume.

Recently, this test has been used by Boulekbache et al. (2012) to analyze the influence of paste yield stress (workability - OC:ordinary concrete,SSC: self-compacting concrete and HSC: high strength concrete), compressive strength (30, 60 and 80 
$\mathrm{MPa})$ on the behavior of FRC versus direct shear. Different aspect ratio of steel fibers $(65$ and 80$)$ and different volume fraction $(0.5 \%$ and $1.0 \%)$ were used.

In this study prismatic specimens of dimensions 100 x 100 x $350 \mathrm{~mm}$ were used. To ensure the failure plane, a $10 \mathrm{~mm}$ deep notch was sawed all around the specimen in between the loading and the supporting edges. The ends parts of the specimen were rigidly fixed in order to avoided the specimen rotation. In this study only vertical displacement (or slip) was measured by means of two LVDTs, while the crack width was not measured.

From the experimental results the following conclusions can be drawn. The increment of volume fraction from $0.5 \%$ to $1 \%$, shows slightly increment (around $20 \%$ ) in the shear strength for the same concrete compressive strength. The major increment in shear strength was obtained when the concrete compressive strength increases. Thus, an increment of $120 \%$ was observed when the concrete compressive strength varies from 30 to $80 \mathrm{MPa}$. The aspect ratio of steel fiber showed minor influences on shear behavior, only $5 \%$ of increase when aspect ratio changed from 65 to 80 .

On the other hand, Banthia et al. (2014) used this test to study the influence of the FRC hybridization in shear behavior. This term is used for referring to the combination of two or more different type of fibers. This combination has the potential to improve the mechanical properties of concrete.

Three types of fibers, two of steel (hooked-end and double deformed) and one of cellulose, were analyzed. In the study is mentioned that cellulose fibers absorb water during mixing, this water was after used in internal curing and pore refinement. The aggregate has a maximum particle size of $14 \mathrm{~mm}$, and was crush limestone.

Prismatic specimen of dimension $100 \times 100 \times 350 \mathrm{~mm}$ were used for the direct shear test. Prior to carry out the test, a pair of $15 \mathrm{~mm}$ deep notches all around the specimen were made. From the experimental results, Banthia et al. (2014) found, the hooked-end steel fibers were better compared to double deformed steel fibers. But when double deformed steel fibers were combined with cellulose fibers better behaviors were obtained if a compassion with hooked-end and cellulose fibers were made.

\subsubsection{Panels test}

The panel element shown in Fig. 2.31 represents a portion of a reinforced concrete structure subjected to constant normal and shear stresses. It is taken to be of uniform thickness and relatively small size ( $890 \times 890 \times 70 \mathrm{~mm})$. It contains an orthogonal grid of reinforcement with the longitudinal $(x)$ and transverse $(y)$ axes chosen to coincide with the reinforcement direction. The panel has twenty shear keys located around its perimeter, five on each side. through which loads are applied. Each key is connected to two hydraulic jacks that are perpendicular to each other and angled at $45^{\circ}$ to the panel, as shown in Fig. 2.31a. Adjustable 
links are connected to the shear keys and to the back frame of the machine to prevent out-of-plane movements (see Fig. 2.31b).

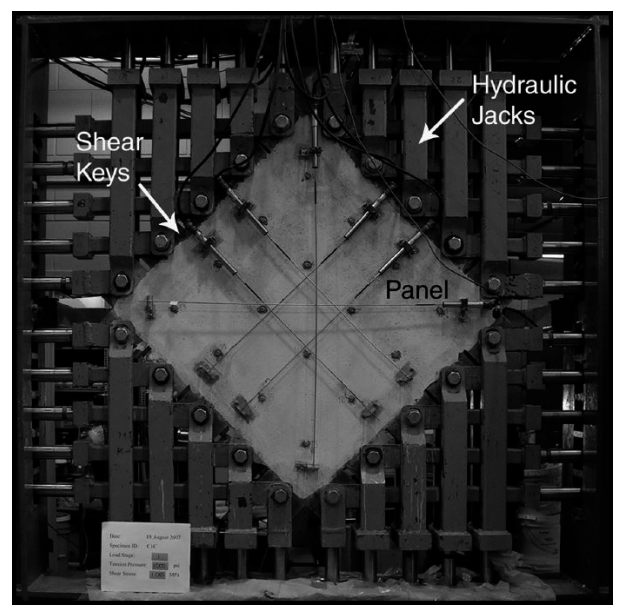

(a)

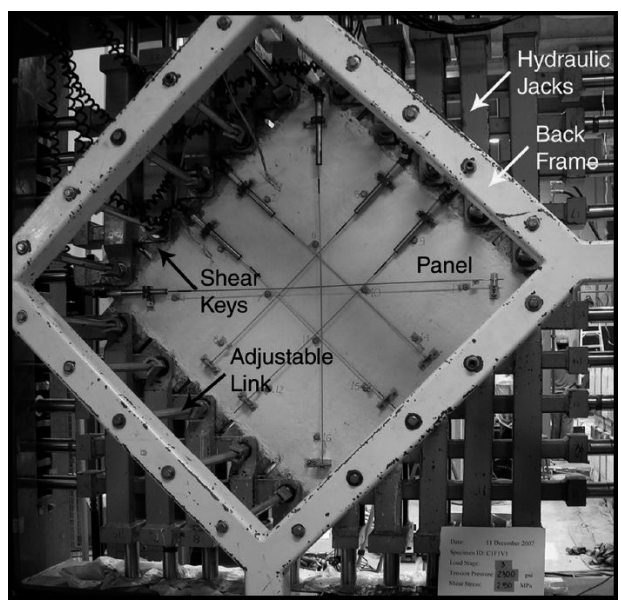

(b)

Fig. 2.31. Panel test machine: (a) front face and (b) back face Susetyo (2010).

The panel is loaded by means of 40 hydraulic jacks, each hydraulic jack has a capacity of $218 \mathrm{kN}$. The jacks on each opposing side of the panel apply the same force, thus resulting in a self-equilibrating system. Three of the jacks, two vertical and one horizontal, act as rigid links and are instrumented with load cells to determine the reaction forces.

Using this test methodology,Vecchio and Collins (1986) developed a shear material model known as, Modified Compression Field Theory (MCFT). The MCFT, has certain assumptions and used models from Mitchell and Collins (1974); Collins (1978)in previous works, to predict stress-strain interaction behavior. But based 
on Walraven's experimental work, Vecchio derived the expressions (eq. 2.39 and 2.40) which express the maximum shear strength of a single crack as a function of the crack width $(w)$ and maximum aggregate size $(D \max )$. The experimental work of Walraven and eq. 2.39, are represented on Fig. 2.32.

$$
\begin{gathered}
v_{c i}=0.18 v_{\text {cimax }}+1.64 \sigma-0.82 \frac{f_{c i}^{2}}{v_{\text {cimax }}} \\
v_{\text {cimax }}=\frac{\sqrt{f c}}{0.31+24 \frac{w}{a+16}}
\end{gathered}
$$

where $\left(v_{c i}\right)$ is the shear stress across the crack, limited by $\left(v_{c i m a x}\right)$ the maximum shear stress that a crack can resist for a crack width of $(w)$. The compressive stress on the crack surface is $\left(f_{c i}^{2}\right)$ and the concrete strength $\left(f_{c}\right)$.

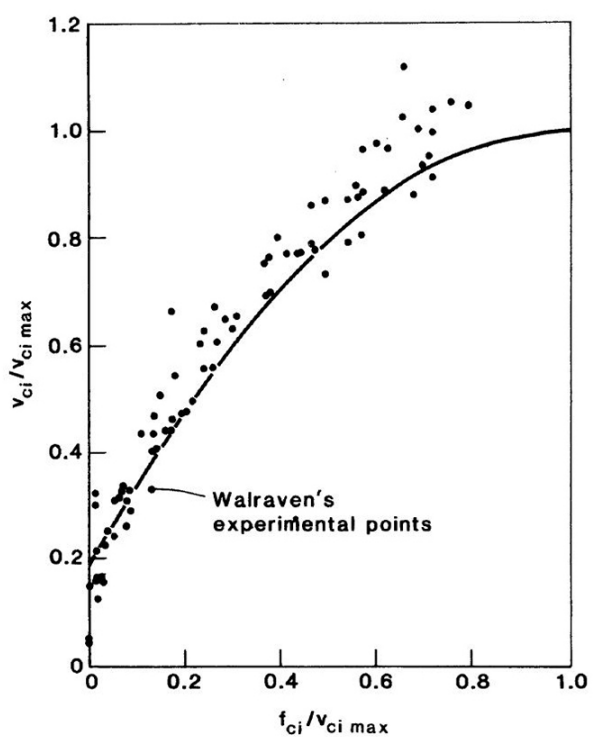

Fig. 2.32. Relationship between shear transmitted across crack and compressive stress on crack Vecchio and Collins (1986).

The two weakness of the MCFT, "the enforced alignment of principal stress and strain direction, and the handling of the crack shear stress", are somewhat solved in the Disturbed Stress Field Model (DSFM) Vecchio (2000b) by including a new approach to the reorientation of concrete stress and strain field, and improved treatment of shear stress on crack surfaces. This shear stress, depend now on the local shear slip, which equation (2.41) derived from Walravens' work, and is defined as follows:

$$
\delta_{s}^{a}=\frac{v_{c i}}{1.8 w^{-0.8}+(0.234 w-0.707-0.20) \cdot f c c}
$$

The instability that eq. 2.41 introduces into computational algorithm, is solved by a new formulation proposed in Vecchio and Lai (2004). Where combined the 
works of Okamura and Maekawa (1991), to define

$$
\begin{gathered}
\delta_{s}=\delta_{2} \sqrt{\frac{\Psi}{1-\Psi}} \\
\delta_{2}=\frac{0.5 v_{\text {cimax }}+f c c / 30}{1.8 w^{-0.8}+(0.234 w-0.707-0.20) \cdot f c c} \\
\Psi=\frac{v_{c i}}{v_{\text {cimax }}}
\end{gathered}
$$

\subsection{Conclusions}

Aggregate interlock resistance comes from micro-roughened contact between aggregate and the matrix resulting in either, (1) aggregate fracture or (2) matrix plastic deformation, and (3) wedging action between macro-roughened cracked surfaces resulting in crack dilatancy and frictional contact slip.

The knowledge and modeling related to shear forces in cracked concrete are still no fully understood because of the fact that shear loading leads to complicated physical mechanisms. To cover this field more direct shear test need to be done.

The push-off test is a non-standard, but widely recognized, test used in the testing of shear in concrete. While the JSCE method, beginning as standard method but for bad results, different author introduce modification in the notch depth. No standard specimen size is used in both, push-off and JSCE. Other disadvantage of the JSCE is that the crack width measurement in not clear. This does not happen in push-off test, but its disadvantage comes from the stress field on the specimen which reveals that this test is not a really direct shear test.

On the other hand, the problems of the size of the specimen, procedure and instrumentation, does not exist in Toronto method. If both methods, push-off and Toronto, are compared the following conclusion can be drawn. The push-off test has the advantage of being relatively small, inexpensive, easy to perform, and not needing any highly specialized pieces of testing equipment; studies using shear panels require the use of a dedicated and expensive test apparatus.

After having analyzed the push-off tests did on FRC, is possible to conclude that a few number of specimen have been tested so far when is compared with traditional reinforced concrete. Almost no precrecked specimens have been tested, and only a $30 \%$ used fibers as the only shear reinforcement.

For all of these reasons, in the present $\mathrm{PhD}$ thesis, the push-off method is chosen. To analyze the steel fiber contribution to the shear transfer mechanism under direct shear, a new restrain frame added to the traditional push-off test is designed. This frame helps to perform the precrack and the push-off test, under condition of crack control similar to real situations that may occur in beams. 


\section{Chapter 3}

\section{Design and development of test procedure}

\subsection{Introduction}

This section focuses on the design and development of the test procedure. The final test methodology is reached after two approaches. The information of this chapter is presented in four sections.

Section 3.2 presents the main ideas and concepts used to develop the methodology. The concept of the push-off test is provided in 3.2.1. Section 3.2.2 shows all the information on the specimen, such as dimensions, formworks, reinforcement and connectors links. Then section 3.2.3 introduces the restraint frame idea. This idea discusses the concepts of conditions for the restraint frame design, restraint frame assembly and the stiffness (horizontal and vertical) of the restraint frame. Section 3.2.4 presents details of a significant improvement in this methodology due to the inclusion of the ball bearing. Finally, section 3.2.5 defines the concept of the allowed initial crack width $\left(w_{o}\right)$.

Section 3.3 provides the first experimental approach to the final test methodology. This section presents an initial restraint frame design in 3.3.1 and the procedure used to set $w_{o}$ is explained in 3.3.2. Then, the precracking baseplate is defined in 3.3.3. In order to analyze experimental behavior, the first preliminary tests 
are shown in 3.3.4. The testing procedure and instrumentation used in these preliminary tests are presented in 3.3.5. Then the experimental results of the precracking phase are offered in 3.3.6, and the experimental results of the push-off phase are shown in 3.3.7. Based on these experimental results, some issues were detected. The list of these issues and the proposed solutions are presented in 3.3.8.

Section 3.4 presents the second approach to the final methodology. In this section, the modification results from the conclusion of the previous test are provided. The improvement of the testing frame to carry out both phases (precracking and push-off) is presented in 3.4.1. The new restraint frame design is schematically illustrated in 3.4.2. Next, a simple numerical model of the new restraint frame design is presented in 3.4.3, follow by a brief explanation of the testing procedure and instrumentation used in 3.4.4. A second campaign of preliminary tests was used to experimentally validate the methodology proposed herein, and is presented in 3.4.5. Based on the experimental results obtained, a series of final considerations was drawn. These considerations are offered in 3.4.6.

The last section presents the final test methodology in 3.5. This section offers a fully detailed explanation of the testing procedure. First the design of the stiffer testing frame used is shown in 3.5.1. The design of both the precracking and push-off sliding baseplate is provided in 3.5.2. The new restraint frame design is given in 3.5.3. This subsection provides details of dimensions and geometries, the assembly of the restraint frame, the criteria of prestressed the specimen, and the setting of $w_{o}$. Then two discrete measurement techniques are explained. First the photogrametry technique (optional) is presented in 3.5.4. The other technique is called DEMEC measurements, and is shown in 3.5.5. The new design used to place the strain gauges on the external restraint bars is presented in 3.5.5. Finally, the testing procedure used in both phases is offered. The precracking phase procedure is explained in 3.5.7, while the push-off phase procedure is defined in 3.5.8.

\subsection{Concepts and definitions of the test}

The first objective of this thesis was, to perform and improve a push-off test in order to analyze the direct shear behavior of cracked concrete, also verify its capability to detect the variables that influence these properties. More specifically, the aim of this work was to analyze the aggregate interlock as one of the shear transfer mechanisms. To do this, the push-off test was chosen as the experimental methodology for the study.

\subsubsection{Push-off concept}

As mentioned in 2.5.1, a z-shaped specimen is loaded in the push-off test, as shown in Fig. 3.1. This specimen is formed by two L-blocks, where the contact zone between these blocks is defined as the shear plane. 
Section 2.5.3 states that, if the push-off test is done on one block specimen (uncracked specimen) the disadvantage is that the stress field in the shear plane is not uniform and a crack shape is difficult to analyze. This problem can be solved if a previous crack in the shear plane is induced. For this reason, all the specimens in this research were precracked before carrying out the push-off phase; thus, this disadvantage has no affect. The shear plane is defined as the zone where the specimen is precracked and it represents the study area.

Once the precrack is done, relative displacements between the crack mouth are produced as a result of $\mathrm{P}$. The vertical displacement between the crack mouth is defined as slip $(\delta)$, and the horizontal displacement between the crack mouth is defined as crack width $(w)$. As a result of the loading applied, shear stress $(\tau)$ is also produced on the shear plane. If a confinement limits the crack opening by internal or external factors, then normal stress $(\sigma)$ acts on the shear plane (see Fig. 3.1).

In order to improve the testing procedure, and based on previous experiences a series of factors are proposed:

(a) A z-shape (hereafter specimen) was chosen.

(b) Two phases were needed in the push-off test. First, a precracking phase by splitting, and then a push-off phase.

(c) In the precracking and push-off phases, crack width is limited by confinement reactions.

(d) The specimen was modified to receive an external arrangement, which introduced the horizontal forces.

(e) This external confinement was applied to the specimen before carrying out the precracking phase. For this reason, its design must take this feature into account.

(f) The precracking procedure had to be improved to guarantee specimen stability when testing, as well as a good crack localization. Thus a pair of notches was necessary.

(g) The external arrangement had to transfer as a minimum shear stress as possible. For this reason, a ball bearing was placed between the specimen and the external arrangement.

(h) The push-off test had to allow to be developed with different levels of nominal crack width in order to analyze behaviors in different loading situations.

(i) The measurement devices had to control all the movements continuously throughout the complete test. This means that both phases had to be included. 


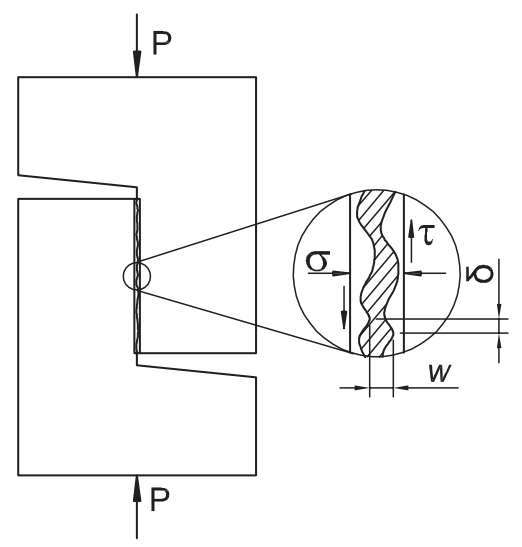

Fig. 3.1. Schematic representation of displacements and stresses on the crack plane.

\subsubsection{Specimen}

As mentioned in 3.2, some modifications had to be introduced into the specimen to carry out the push-off test. These modifications respond to the following aspects:

1. To modify the formworks to make a pair of notches while the specimen was cast. Thus the plane of weakness on the specimen was perfectly defined.

2. To introduce a series of connectors links into the specimen to fix the specimen and the external arrangement.

3. To heavily reinforce the specimen in order to avoid other failures that direct shear.

\section{Dimension and parts definitions}

A z-shape was used, which may be considered a composition of two L-blocks: one pointing upward and downward. The theoretical crack plane was defined as the contact area between these two L-blocks (see Fig. 3.1).

Specimen height was $670 \mathrm{~mm}$, width was $400 \mathrm{~mm}$ and thickness was $120 \mathrm{~mm}$, as shown in Fig. 3.2. Because of the notches, the shear plane was $260 \mathrm{~mm}$ high and $100 \mathrm{~mm}$ wide (see Fig. 3.2). 

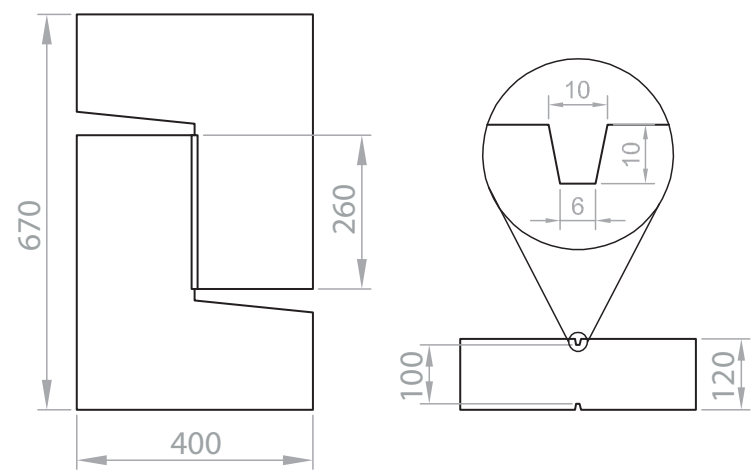

Fig. 3.2. Schematic representation of the test specimen (dimension in $\mathrm{mm}$ ).

In order to avoid any misunderstanding, the specimen half where the load was applied was defined as an "ACTIVE block". This name is because this specimen part was free to move vertically. The other half was defined as a "PASSIVE block", because this part came into contact with the testing frame base. The relative position of these parts is shown in Fig. 3.3.

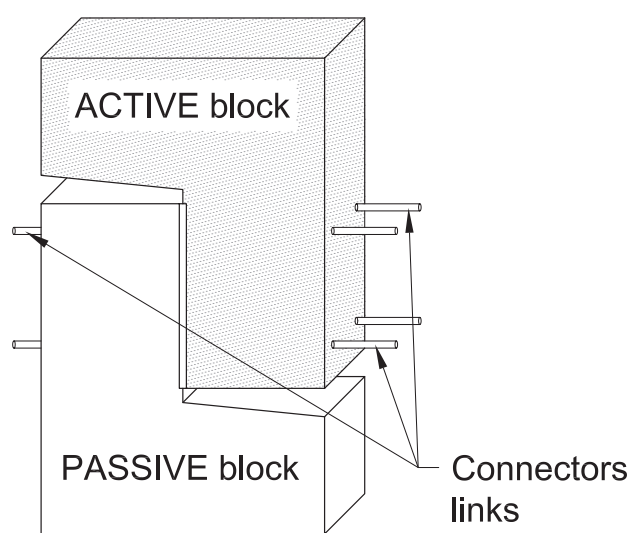

(a)

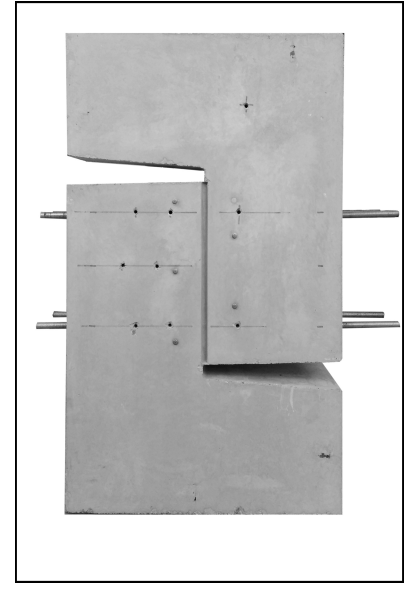

(b)

Fig. 3.3. Test specimen: (a) schematic representation, (b) photo of a specimen actually used.

Fig. 3.4 shows the different faces of the specimens. The names below were used to refer to the faces troughtout this research. The definitions are presented in the following list:

- Front Face: the face through which concrete was cast. This face was the only one which was not in contact with the formwork.

- Back Face: the major face which came into contact with the formwork base. 
- Upper Face: the face where the load was applied. This face must always be on the upside. It forms part of the ACTIVE block of the specimen.

- Bottom Face: the specimen base. This face came into contact with the testing frame. It forms part of the PASSIVE block of the specimen.

- Right Face: the face where the ball bearing was fixed. For this reason, the longer connector links were on this face. It forms part of the ACTIVE block of the specimen (see Fig. 3.4).

- Left Face: the opposite face of the right face. One part of the external arrangement was fixed on this face. It forms part of the PASSIVE block (see Fig. 3.4).

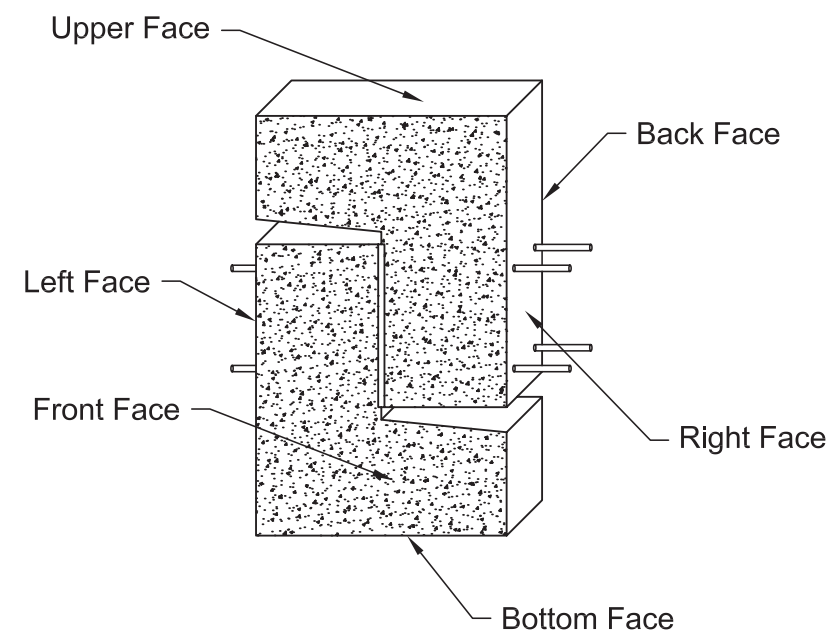

Fig. 3.4. Relative position of the specimen faces.

\section{Formworks}

Based on the studies mentioned in 2.5.3, we can see that a couple of notches were made using a hand procedure when concrete had hardened. In order to avoid this procedural error, a decision was made to introduce modifications into the formworks so that all the specimens had the same notches and in the same relative position.

The modifications made in the formworks responded to two groups. The first group corresponded to the modifications introduced in order to make the pair of notches while pouring concrete. For this aim, two rules were used, one (the lower rule) was fixed to the formwork base, as was shown in Fig. 3.5a. The other (the cross rule) was fixed to an external cross, as shows in Fig. 3.5b. The position of the external cross was guaranteed by means of a special arrangement (see Fig. $3.5 \mathrm{~b})$. 


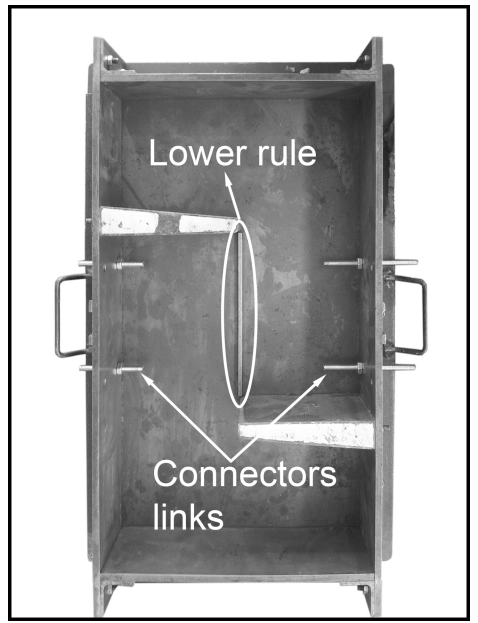

(a) Lower rule and connectors links

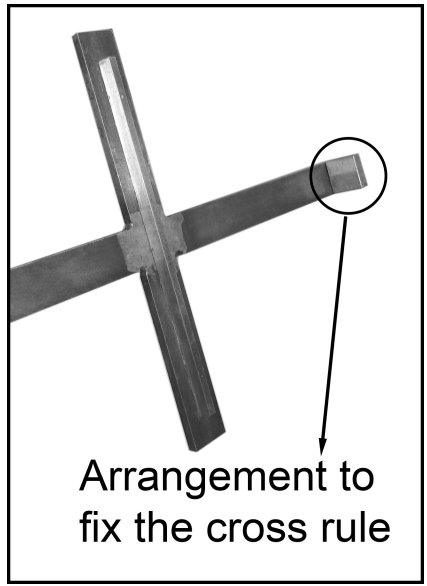

(b) Cross rule and arrangement to fix it

Fig. 3.5. Framework modifications.

The second group corresponded to a series of holes made on two walls of the formworks. These holes were used to pass the connector links through them. A watertight joint was obtained by means of a pair of nuts (see Fig. 3.5a).

These two groups of modifications ensured that all the specimens had the same perfectly defined notches. They also allowed the specimens to have rigidly fixed the connector links in order to receive the external arrangement which confined the specimen.

\section{Reinforcement}

The specimen was internally reinforced with cages of $12 \mathrm{~mm}$ in diameter and close stirrups of $8 \mathrm{~mm}$ to prevent a different failure outside the shear plane (like the failure cause by the bending moment at the top of the specimen). The final arrangement of the cages and connector links is shown in Fig. 3.6 and, to clarify, only half of the reinforcement cage is shown.

\section{Connector links}

In order to fix or connect the external arrangement to the specimen, a series of connector links was used. These connectors were made by means of eight threaded rods. These roads were embedded into the concrete of the specimen; therefore, the rods and the specimen were rigidly fixed.

Rods were $10 \mathrm{~mm}$ in diameter, while rod length depended on the block (ACTIVE or PASSIVE). Thus a length of $150 \mathrm{~mm}$ was used for the rods placed in the ACTIVE block, while a length of $100 \mathrm{~mm}$ for the rods placed in the PASSIVE block. The embed length also depended on these positions. Thus, an embed length 


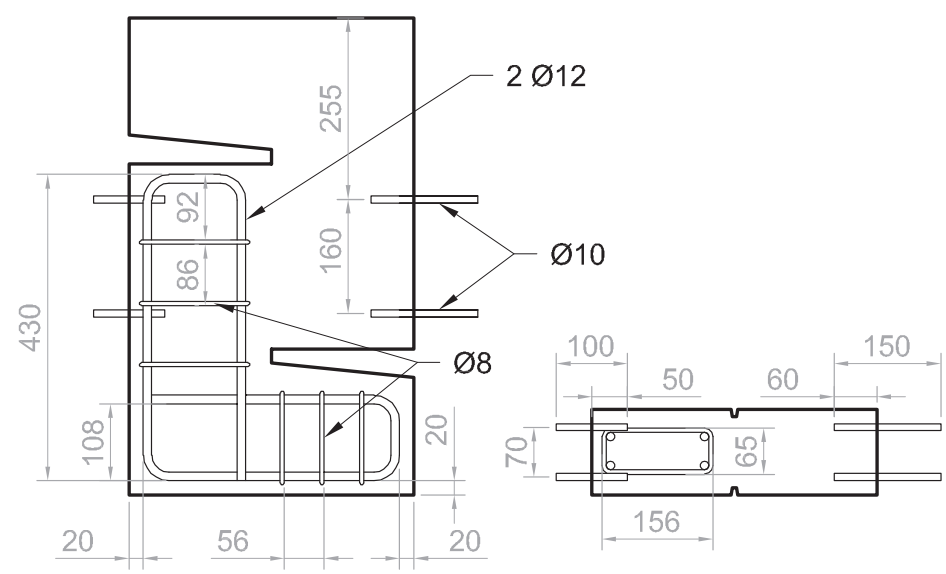

Fig. 3.6. Arrangement of the additional reinforcement cages and connectors links (dimensions in $\mathrm{mm})$.

of $60 \mathrm{~mm}$ was applied for the ACTIVE block, and an embed length of $50 \mathrm{~mm}$ was employed for the PASSIVE block (see Fig. 3.6). In this figure we can seen that the connector links are separated by $70 \mathrm{~mm}$, and the reinforcement cages are in the middle.

\subsubsection{Restraint frame}

The idea was to control the crack width evolution during the push-off test. Therefore, the horizontal and normal forces to the shear plane were needed to confine the specimen as shown in Fig. 3.7.

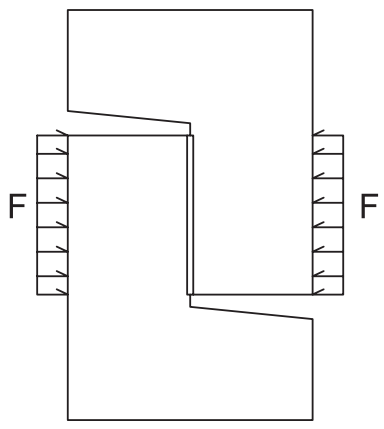

Fig. 3.7. Definition of the allowed initial crack width.

Based on this idea, an external arrangement (hereafter restraint frame) was designed to confine the specimen. The idea was to place two rectangular steel plates on the small specimen side (Left and Right faces). These plates were fastened by four external restraint bars. One of these plates was rigidly fixed to the PASSIVE 
block by means of the connector links and four nuts. The general arrangement of the restraint frame is shown in Fig. 3.8.

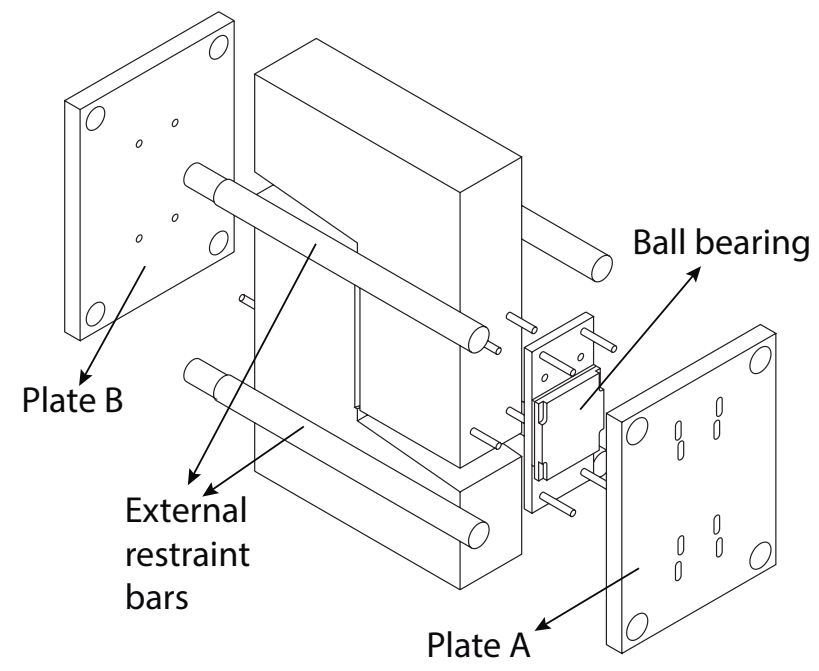

Fig. 3.8. Relative position of the parts of the restraint frame and specimen.

\section{Restraint frame design}

The restraint frame was composed by:

- Plate A: This plate was placed on the Right face on the ACTIVE block. In order to allow the slip displacement of the ACTIVE block, a series of slotted holes was introduced into this plate. It must be pointed out that this plate was not fixed to the specimen.

- Plate B: This plate was placed on the Left face of the PASSIVE block. The plate was rigidly fixed to the specimen by means of the connector links and nuts.

- Restraint bars: These bars were the links between both plates. The end of the bar used on Plate B had a reduced cross-section. This reduction, which worked as a stop for the bar, and only one nut was needed to fix the bar to the plate. The opposite end used a pair of nuts to fix the bar and Plate A. The pair of nuts produced a link that was higher stiff. This stiffer link was due to Plate A not being fixed to the specimen.

- Ball bearing: It was placed between the specimen and Plate A. It was fixed to the Right face on the ACTIVE block of the specimen by means of four bolts. This special mechanism was used to reduce frictional forces between the specimen and the restraint frame. It was the major contribution of the design. More details of this mechanism are discussed in 3.2.4.

The general arrangement of these parts is shown in Fig. 3.9. 


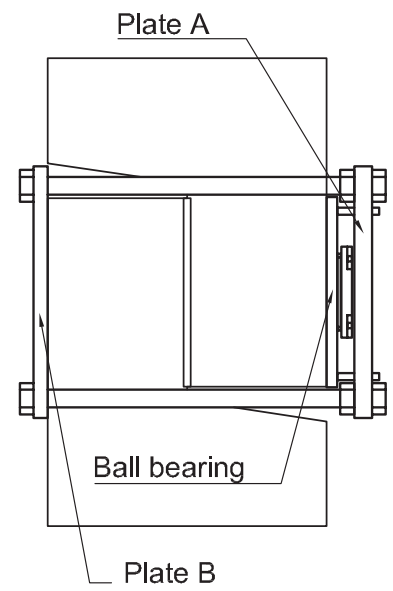

Fig. 3.9. Arrangement of restraint plates, bars and ball bearing on the specimen.

\section{Restraint frame assembly}

Before doing the frame assembly, the specimen should be set in a vertical position with the ACTIVE block on top. The following procedure was carried out:

1. On the Right face of the specimen, the ball bearing was fixed.

2. On the Left face of the specimen, the PASSIVE block and Plate B were fixed.

3. The four external restraint bars were passed through Plate B and were fixed to it.

4. Plate A was placed in a position to pass through the four external restraint bars and the connector links.

The above procedures is shown in Fig. 3.10

\section{Horizontal and vertical stiffness}

As mentioned in 3.2, the restraint frame had to simultaneously fulfill the conditions of the confined the specimen and did not transfer the shear loading. The first condition was met by means of horizontal stiffness $\left(k_{h}\right)$. Under ideal conditions, the horizontal stiffness must be infinity $\left(k_{h}=\infty\right)$. However under real and practical conditions, this stiffness must be as high as possible. The second condition was satisfied by means of vertical stiffness $\left(k_{v}\right)$. The ideal situation is that vertical stiffness was zero $\left(k_{v}=0\right)$. Therefore, under real conditions, vertical stiffness must be as low as possible. This was achieved by reducing the frictional forces between the restraint frame and the specimen. 


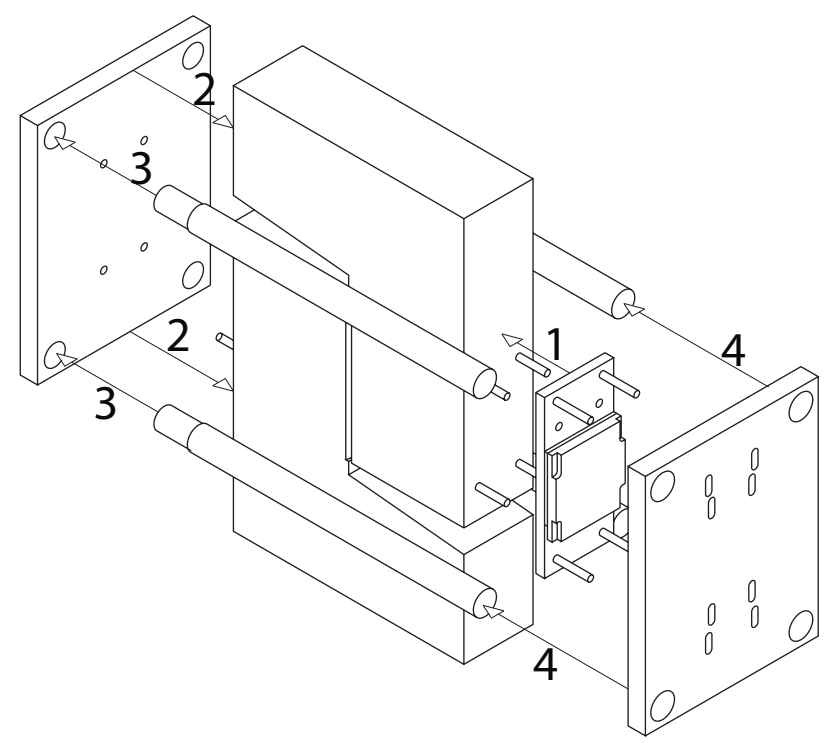

Fig. 3.10. Restraint frame assembly procedure.

\subsubsection{Ball bearing}

In order to reduce vertical stiffness $\left(k_{v}\right)$, it is necessary to reduce as much as possible the frictional forces between the specimen and the restraint frame. This aim was met by means of a ball bearing, which used a large numbers of small balls. The ball bearing is the key of this new methodology. It improved the pushoff test, if compared with previous authors who also confined the specimen with a steel frame.

The nearer to zero $k_{v}$ is, the fewer Plate A displacements produced. Therefore, there should be no dowel action on the external restraint bars, and the axial strain should become dominant. This means that the restraint frame does not transmit shear loading.

Four bolts were placed on the ball bearing base (see Fig. 3.11b). These bolts and the four connector links of the ACTIVE block passed through Plate A. The idea was to increase transverse stiffness and to avoid the relative rotation between both blocks (ACTIVE and PASSIVE).

Another very important feature of the ball bearing refers to the "allowed initial crack width $\left(w_{o}\right)$ ". The cover of the ball bearing is a reference point to this property. For more details of the allowed initial crack width, see 3.2.5.

\section{Ball bearing design}

The ball bearing was composed of two parts, steel body and steel cover. The body was a rectangular piece of $270 \mathrm{~mm}$ high, $120 \mathrm{~mm}$ wide and $15 \mathrm{~mm}$ thick. The 
body had four fixing holes used to fix the ball bearing on the Right face. It also had four bolts, and in the middle, a bowl was used to place the small balls (see Fig. 3.12). The cover was a rectangular piece of $130 \mathrm{~mm}$ high, $120 \mathrm{~mm}$ wide and $15 \mathrm{~mm}$ thick. The cover had four slotted holes, which allowed a displacement to run in parallel to the major body dimension. The cover and body were fixed by four screws.

Fig. 3.11 shows a schematic representation of the ball bearing. In the figure, we can seen the dimension, expressed in $\mathrm{mm}$, and the relative position of the fixing holes and the four bolts. Fig. 3.12 shows a picture of the ball bearing, where the bowl and small balls can be seen.

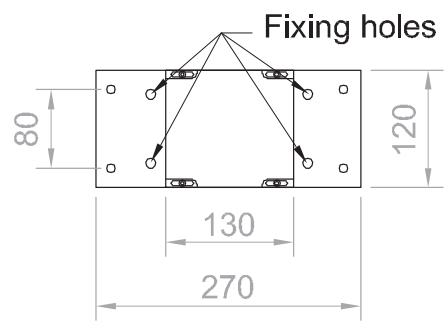

(a) Top view

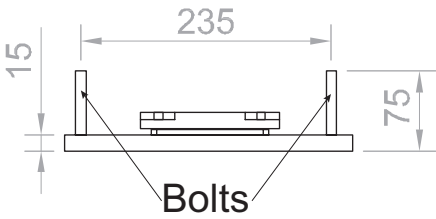

(b) Front view

Fig. 3.11. Dimension and details of the ball bearing (dimension in $\mathrm{mm}$ ).

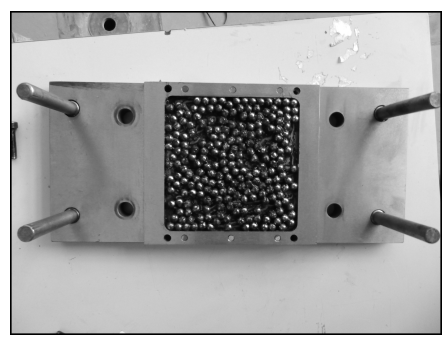

Fig. 3.12. Bowl of the ball bearing with small balls inside.

\subsubsection{Allowed initial crack width $\left(w_{o}\right)$}

As this property was frequently used to develop the present $\mathrm{PhD}$ thesis, it is necessary to clearly define the "allowed initial crack width" $\left(w_{o}\right)$. As mentioned before, one of the two aims of the ball bearing was precisely this property. Thus, the allowed initial crack width is defined as the distance between the cover of the ball bearing and the internal face of Plate A, as shown in Fig. 3.13. This distance is fixed by adjusting the couple of nuts of the external restraint bars. 


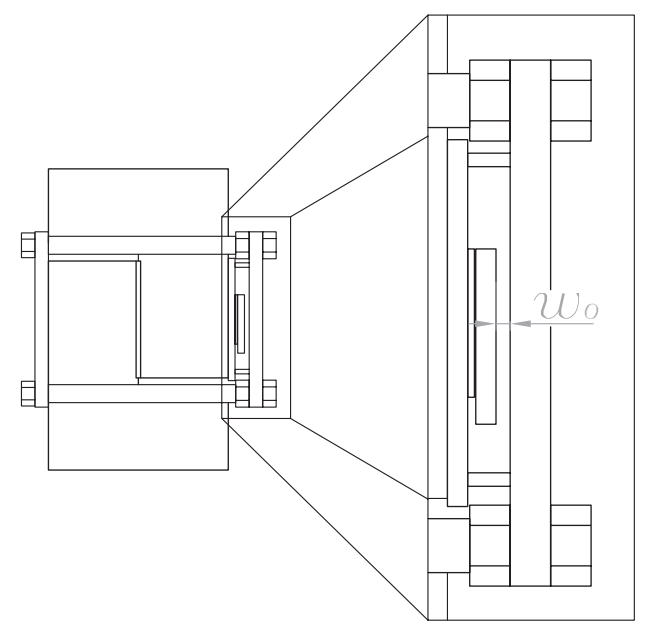

Fig. 3.13. Definition of the allowed initial crack width.

The aim of the allowed initial crack width was to study the kinematics of the crack under different confinement conditions. When $w_{o}=0$, the initial confined condition was defined. This name was due to certain normal stress that acts on the shear plane before beginning the push-off phase. While $w_{o} \neq 0$, the initial unconfined condition was defined due to this space between the ball bearing and Plate A. This condition allowed us to analyze the contribution of the shear reinforcement alone, until $w_{o}$ became zero and the restraint frame confined the specimen.

\subsection{Initial design and first approach}

This section presents the initial design of the restraint frame and a series of preliminary tests. A first restraint frame was built based on the ideas and concepts of the new methodology. Then a series of preliminary tests was used to experimentally validate the design of the restraint frame and the methodology proposed. Finally, the conclusions of these tests were used to improve both the restraint frame and the general methodology.

\subsubsection{First approach to the restraint frame}

The restraint frame concept presented in section 3.2.3, is geometrically defined here. The dimensions of the three parts of the restraint frame and the details used to build it are provided. The restraint frame was composed of the following parts:

- Plate A: $360 \mathrm{~mm}$ high, $270 \mathrm{~mm}$ wide, and $20 \mathrm{~mm}$ thick. There were 16 holes on the plate, four for the external restraint bars (a), four to set up the allowed initial crack width (b), and eight were slotted holes (c) (see Fig. 3.14a). The slotted holes allowed the slip displacement of the ACTIVE part. 
- Plate B: This plate had the same dimensions of Plate A (360 x 270 x 20 $\mathrm{mm})$. There were eight holes on the plate, four for the external restraint bars (a), and four to fix the plate and the specimen (d) (see Fig. 3.14b).

- External restraint bars Four steel rods with a solid cross-section, $25 \mathrm{~mm}$ in diameter and $530 \mathrm{~mm}$ long (see Fig. 3.14c) were used to link the plates. A pair of nuts was used to fix the bar and Plate A, while one nut was used to fix Plate B.

- Ball bearing: It was in accordance with the details presented in section 3.2.4.

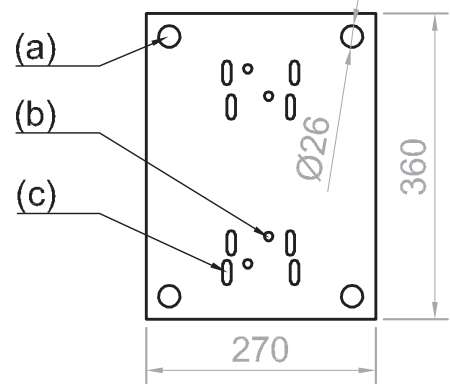

(a) Plate A

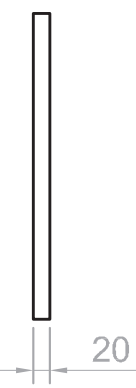

45

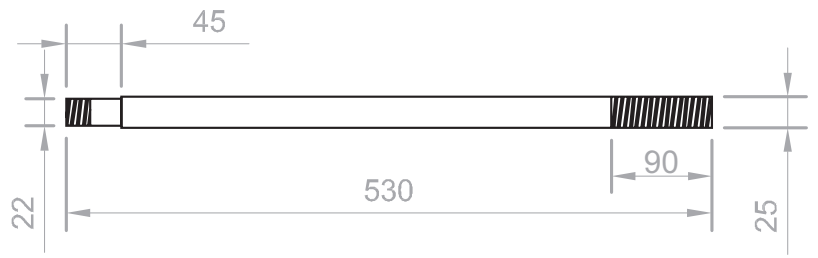

(c) External restraint bar

Fig. 3.14. Different parts of the restraint frame (dimensions in $\mathrm{mm}$ ).

\subsubsection{Procedure to set $w_{o}$}

Once the restraint frame was set on the specimen in accordance with the procedure defined in 3.2.3, the allowed initial crack width was fixed. To this end, Plate A was placed against the cover of the ball bearing and the four internal nuts were tightened until both nuts and Plate A came into contact with each other. After, Plate A was separated from the ball bearing by means of four special screws (see holes (b) of Fig. 3.14a). Finally, the eight nuts (four internal and four external) were strongly tightened and the screws were taken off. 


\subsubsection{Precraking baseplate}

Based on the experimental results reported by Cuenca and Serna (2010b) in the precracking phase, where serious difficulties were detected in this phase. These difficulties were due to the rotation of the specimen around the lower knife. Rotation was produced due to the supporting conditions of the specimen because it was supported only by the lower knife. This phenomenon made the precracking phase unstable, at it made the target crack width more difficult to achieve.

To solve this problem, a precracking baseplate was designed, which was a steel plate $670 \mathrm{~mm}$ high, $400 \mathrm{~mm}$ wide and $10 \mathrm{~mm}$ thick. On this plate, four springs and the lower knife were fixed, as shown in Fig. 3.15. Thus the specimen was then supported at five different points.

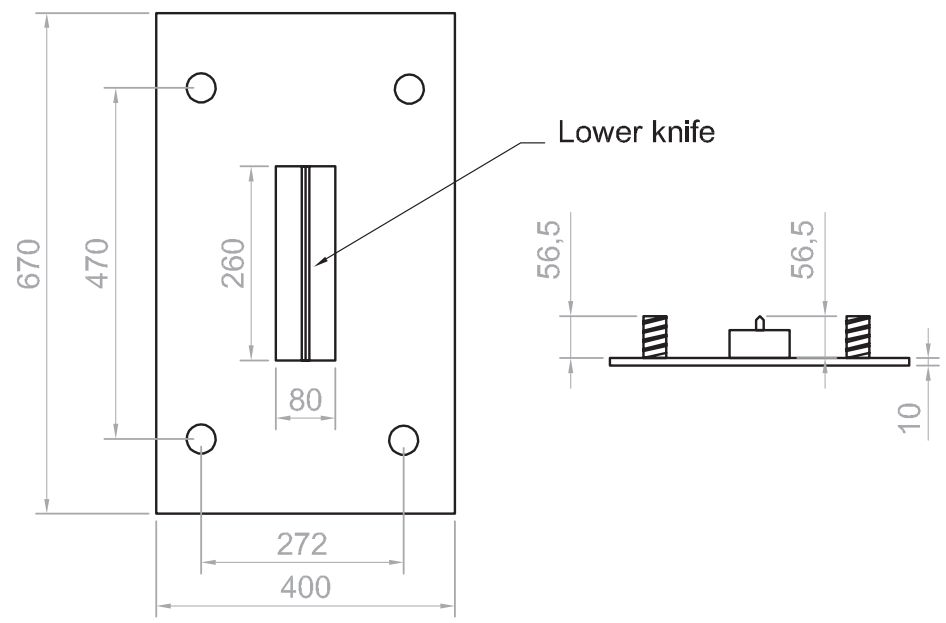

Fig. 3.15. Schematic arrangement of the precracking baseplate (dimensions in $\mathrm{mm}$ ).

\subsubsection{Preliminary tests}

An experimental program with seven specimens was designed to achieve these aims. All the specimens were made of self-compacting concrete $\left(f_{c}=40 \mathrm{MPa}\right)$. As mentioned before, the only variable of the present program was the reinforcement type:

- Amount of fibers: three different amounts of steel fibers were used for the same mix proportion. By keeping the fiber type constant (RC-65/35 BN), the following amounts were used: 30,50 and $80 \mathrm{~kg} / \mathrm{m}^{3}$.

- Type of fibers: two hooked-end steel fiber types were used. One was, low carbon, which is commonly used in industry. It was $35 \mathrm{~mm}$ long, with a nominal aspect ratio of 65 . This fiber is denominated by Bekaert ${ }^{\circledR}$ as Dramix RC-65/35 BN. The other one was, high carbon, and was $30 \mathrm{~mm}$ long 
with a nominal aspect ratio of 80 . This fiber is denominated by Bekaert ${ }^{\circledR}$ as Dramix RC-80/30 BP.

- Traditional reinforcement: two closed stirrups were used $8 \mathrm{~mm}$ in diameter. They perpendicularly crossed the shear plane.

Table 3.1 shows the specimens and reinforcement used. The identifying code for the specimens referred to three characteristic pieces of data. The symbols representing these data were separated by slashes (f.i. F/80/BN). The first character represented the reinforcement type, which could be $(\mathrm{F})$ for fiber reinforced concrete or $(\mathrm{S})$ for traditional reinforcement by stirrups. The second part referred to the amount of fiber express in $\mathrm{kg} / \mathrm{m}^{3}$ (or reinforcement ratio $\rho$ ). The final part indicated the fiber type used (or separation between stirrups). Some specimens had two identical samples, and a final character was added ( $\mathrm{a}$ or b) to these specimens.

Table 3.1. List of specimens

\begin{tabular}{lllll}
\hline Specimen & Reinforcement & $\begin{array}{l}\text { Fiber } \\
\text { Amount }\end{array}$ & Type & Stirrups \\
\hline F/30/BN-a & Fiber & 30 & $65 / 35-\mathrm{BN}$ & - \\
F/30/BN-b & Fiber & 30 & $65 / 35-\mathrm{BN}$ & - \\
F/50/BN-a & Fiber & 50 & $65 / 35-\mathrm{BN}$ & - \\
F/50/BN-b & Fiber & 50 & $65 / 35-\mathrm{BN}$ & - \\
F/80/BN & Fiber & 80 & $65 / 35-\mathrm{BN}$ & - \\
F/50/BP & Fiber & 50 & $80 / 30-\mathrm{BP}$ & - \\
E/0,2/14,5 & Stirrup & $\rho=0.2 \%$ & $\phi 8 @ 14.5 \mathrm{~cm}$ \\
\hline
\end{tabular}

To meet the flowability requirement and to avoid the risk of segregation, a Bolomey theoretical curve was used. The a parameter equalled 20, thus the fine content controlled the risk of segregation and a coarse aggregate equalled $12 \mathrm{~mm}$. River sand was round, which helped the concrete to flow. Table 3.2 shows the mix proportions, the water/cement and admixture/cement ratios, concrete strength (in $\mathrm{MPa}$ ) and slump flow (in $\mathrm{mm}$ ).

\subsubsection{Testing procedure and instrumentation}

This section focuses on the testing procedures and instrumentation used in the precraking and push-off phases.

\section{Precraking phase}

In this first approach, all the specimens were precracked using a flexible testing frame. A schematic representation of this testing frame is shown in Fig. 3.16a. The feature of this testing frame is obtaining stiffness in one direction (y direction). In 
Table 3.2. Mix proportion in $\mathrm{kg} / \mathrm{m}^{3}$

\begin{tabular}{ll}
\hline CEM II/B-V 42.5R & 350 \\
Water (total) & 210 \\
Gravel 7/12 & 509 \\
Gravel 4/7 & 313 \\
River sand & 917 \\
Filler & 90 \\
Viscocrete 5720 & 5.25 \\
w/c & 0.6 \\
\% HRWRA & 1.5 \\
\hline fcm (S.D.) & $51.1(0.8)$ \\
Slump flow 8' & 520 \\
\hline
\end{tabular}

the other direction (x direction) however, the testing frame displayed little stiffness and certain displacement could occur.

All the specimens were precracked prior to push-off phase. To this end, the specimen was placed horizontally over the knife. Since the precracking baseplate and the hydraulic jack were fixed, a long time was needed to correctly place the specimen. Having placed the specimen in its place, the upper knife was moved down until the specimen and the knife came into contact. In Fig. 3.16b, we can see the specimen situated between both the upper and lower knives, as well as the springs. Precracking was done by means of splitting. Load was step-wisely applied by a hydraulic jack of $500 \mathrm{kN}$ at a rate of $200 \mathrm{~N} / \mathrm{seg}$. The test finished when the specimen cracked.

The instrumentation for this test consists in six vertical LVDTs used to measure the vertical displacement (or rotation strength) point 1-6 (see Fig. 3.17a). This setting allowed us to obtain three points on each half, thus two planes are defined. Two horizontal LVDTs to measure crack width (w1 and w2) see Fig. 3.17b, and in some specimens two more vertical LVDTs were used to control the movement of Plate A (see Fig. 3.17b) - P1 and P2. Table 3.3 shows the specimens in which Plate A was instrumented, as well as the specimens on which the push-off phase was carried out.

Table 3.3. Specimens where Plate A was instrumented and the push-off phase was carried out.

\begin{tabular}{lll}
\hline Specimen & Plate & Push-off \\
\hline F/30/BN-a & yes & yes \\
F/30/BN-b & yes & no \\
F/50/BN-a & no & yes \\
F/50/BN-b & yes & yes \\
F/80/BN & no & no \\
F/50/BP & yes & yes \\
E/0,2/14,5 & yes & yes \\
\hline
\end{tabular}




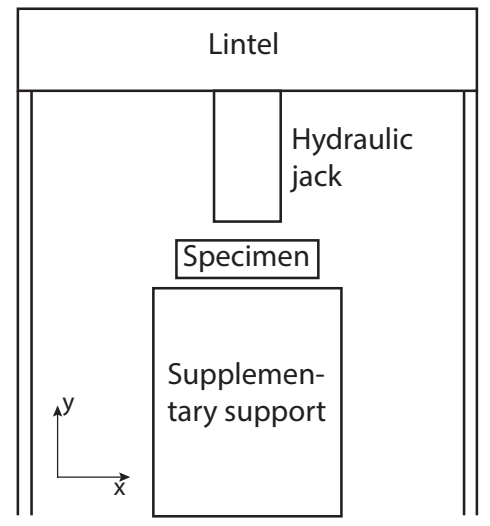

(a) Schematic representation of the flexible testing frame

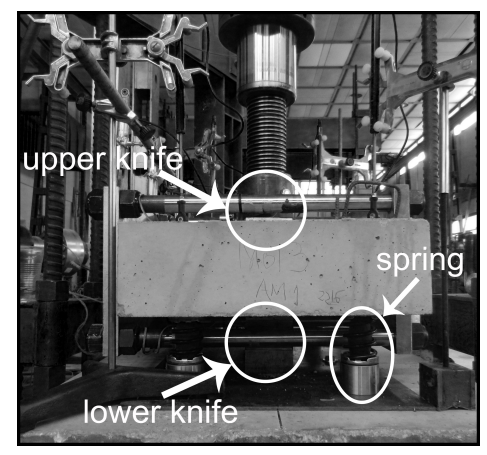

(b) Relative position of the precracking arrangement to the specimen

Fig. 3.16. General arrangement in the precracking phase.

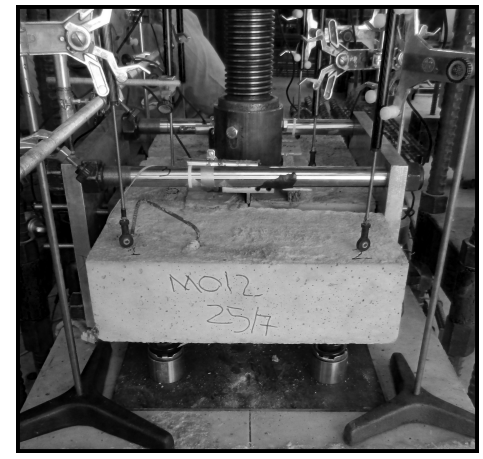

(a) Setup of vertical LVDT

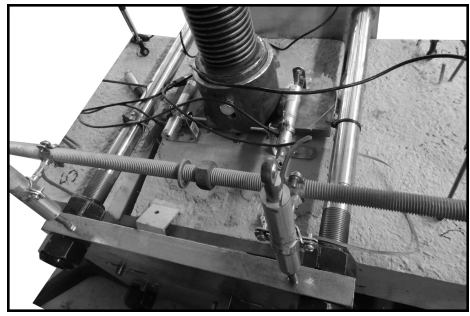

(b) Opcional vertical LVDT and position of w1 and w2

Fig. 3.17. Precracking test instrumentation.

It must be pointed out that it was necessary to move the upper knife downward in order to place both LVDTs, w1 and w2, on it. The aim of P1 and P2 was to 
know the movement of Plate A once the crack had formed. This is because the ACTIVE block and Plate A were not fixed and it was not possible to know the movement of Plate A by means of the movement of the ACTIVE block.

\section{Push-off phase}

Having performed precrackingne, the specimen was set in a vertical position in another testing frame to perform the push-off phase. This testing frame was completely stiff in all directions. To avoid any procedure failure, and to produce a pure shear on the shear plane, it was necessary to perfectly center the specimen under the hydraulic jack. The load was step-wisely applied by a hydraulic jack of $500 \mathrm{kN}$ at a rate of $50 \mathrm{~N} / \mathrm{seg}$. The test finished when slip displacement was greater than $10 \mathrm{~mm}$. Thus, it is guaranteed a sliding of $10 \mathrm{~mm}$

The following instrumentation was used in the push-off phase. Two vertical LVDTs (V1m, V2m and V1h, V2h) were used on each major face to measure slip displacement. The identifying code based on the following rule, the $\mathrm{V}$ character, meant that vertical displacement was recorded; the number gave the relative position in relation to Plate A, 1 for the nearest position. Finally, the letter representing the face of the specimen, "m" being the Back face (or mold face) and "h" the Front face, are shown in Fig. 3.18.

Crack width evolution was recorded by means of four horizontal LVDTs (w1m, w2m, w1h and w2h) placed normally to the shear plane. Two LVDTs were used on each face. The identifying code followed the same rule as the previous one used: that is, three characters. The first "w", indicated that a horizontal displacement was recorded, and the number gave the relative position to the loading point ("1" being the nearest one). "m" or "h" represented the face of the specimen (see Fig. $3.18)$.

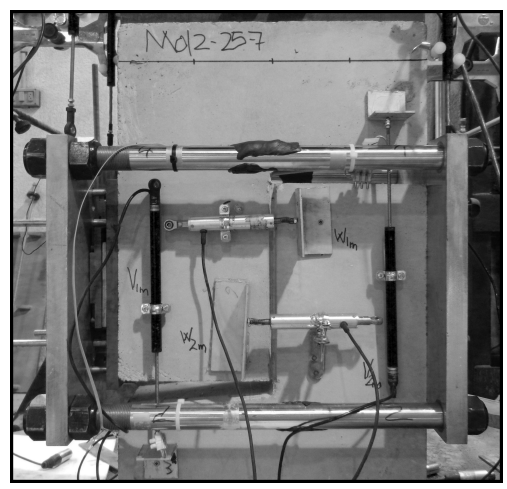

Fig. 3.18. Position of the measurement devices in the push-off experiments.

On both phases, the strain of the external restraint bar was measured by means of electrical strain gauges. One strain gauge was pasted on the middle section of the bar, which was in front of the shear plane. Once the strain and elasticity modulus 
were known, it was possible to calculate the stress on bars and, thus, the total confinement force applied to the specimen.

\subsubsection{Results of the precracking phase}

The experimental results focused on several factors: vertical stability, final crack width, and the movement of Plate A.

\section{Vertical stability}

The calibration of the stiffness of the springs was a long feedback process. Different situations were observed, when unequal low stiffness was used, and the specimen rotated about the lower knife prior to crack occurring (see Fig. 3.19a). Likewise, when equal very low stiffness was used $(\mathrm{k} \rightarrow 0)$, "a negative bending effect" was produced after cracking (see Fig. 3.19b). However, when equal high stiffness was used $(\mathrm{k} \rightarrow \infty)$, "a positive bending effect" at cracking was obtained (see Fig 3.19c).

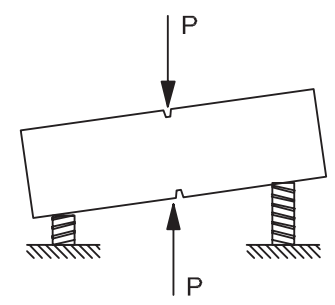

(a) Rotation about the lower knife

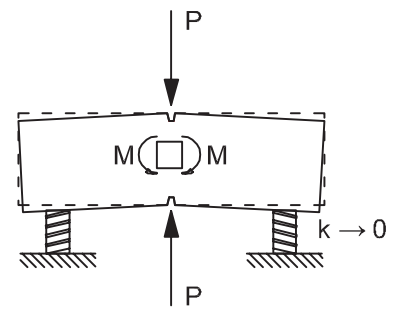

(b) Negative bending effect

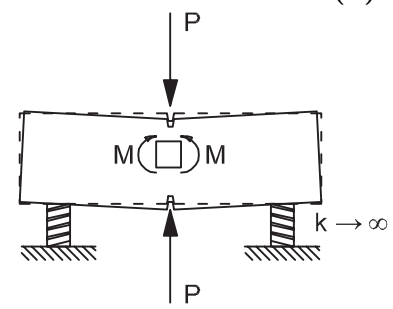

(c) Positive bending effect

Fig. 3.19. Schematic representation of vertical stability.

The three aforementioned behaviors, were evaluated by means of point $6-1$. The specimen rotating about the lower knife is shown in Fig. 3.20. Points 2, 4 and 6 obtained positive values, which means that the three LVDTs were compressed, while points 1, 3 and 5 had negative values. This situation is represented in Fig. 3.19a. 


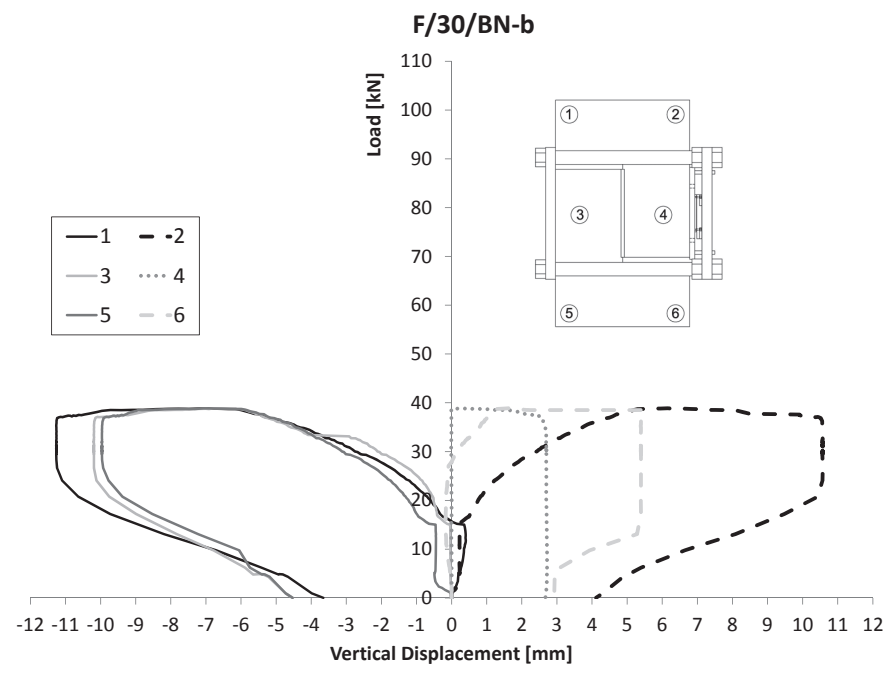

Fig. 3.20. First attempt of the precracking phase.

Fig. 3.20 illustrates, that when the load reached $38 \mathrm{kN}$, the crack was produced. As a result of cracking formation, the test became more unstable. This is shown by the increasing in displacement (in an absolute value) at the six points. Besides, the low stiffness of the springs, the upper knife was not fixed to the hydraulic jack in this stage.

When the stiffness of the four springs increased, behavior improved. In this case, the six LVDTs moved in the same direction (negative values). Yet the specimen still showed some rotation about the lower knife, as seen in Fig. 3.21. This rotation can be observed by the difference between the displacement of points 2,4 and 6 , and points 1, 3 and 5. Once again, when the precracking load was reached, this difference became bigger.

Finally, a decision was made to carry out the precracking phase in a testing frame with greater stiffness. The experimental result showed that no significant rotation of the specimen was observed, as shown in Fig. 3.22. Vertical displacement was almost the same for the six points, and after cracking, no major movements were observed because the test lost control. The behavior shown in Fig. 3.22, is the targeted behavior, so this testing procedure was adopted for the precraking phase. 


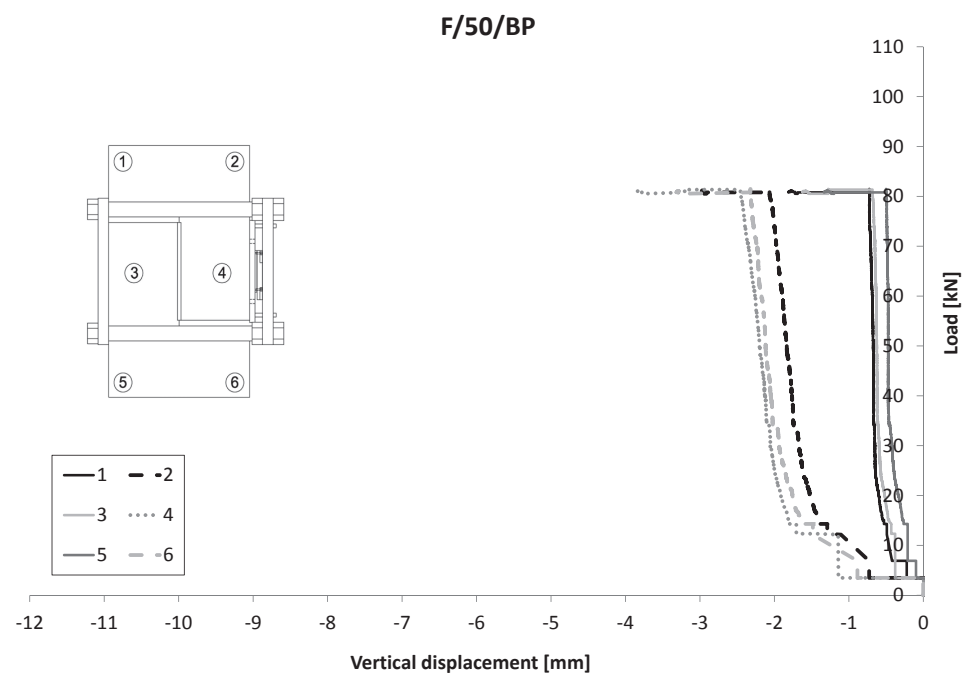

Fig. 3.21. Second attempt of the precracking phase.

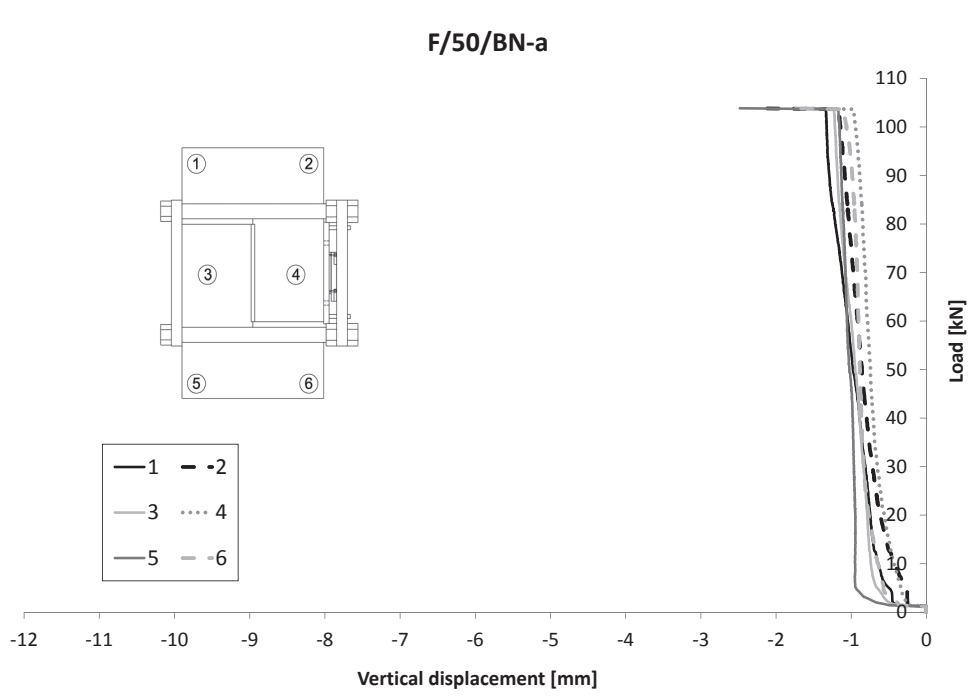

Fig. 3.22. Final step of the precracking experiments.

\section{Crack width}

Crack width stability was analyzed by means of the load vs. crack width relationship, as shown in Fig. 3.23. In these figures, no significant LVDT movement was observed until the precracking load was reached. Two fibers type of fibers were used to detect different behavior. Thus Fig. 3.23a represents a specimen with 30 $\mathrm{kg} / \mathrm{m}^{3}$, while Fig. $3.23 \mathrm{~b}$ presents a specimen with $50 \mathrm{~kg} / \mathrm{m}^{3}$. 
The obtained experimental results were not those expected as a narrower crack width was obtained with low fibers (see Fig. 3.23a). However, the reason for this behavior was found in the cracking load: the lower the cracking load, the narrower crack width becomes. Specimen F/50/BN-a (see Fig. 3.23b) represented the "negative bending effect", which was shown by the positive values of w1 and w2 after cracking took place. When crack width began to increase, both the LVDTs obtained negative values.

\section{F/30/BN-a}

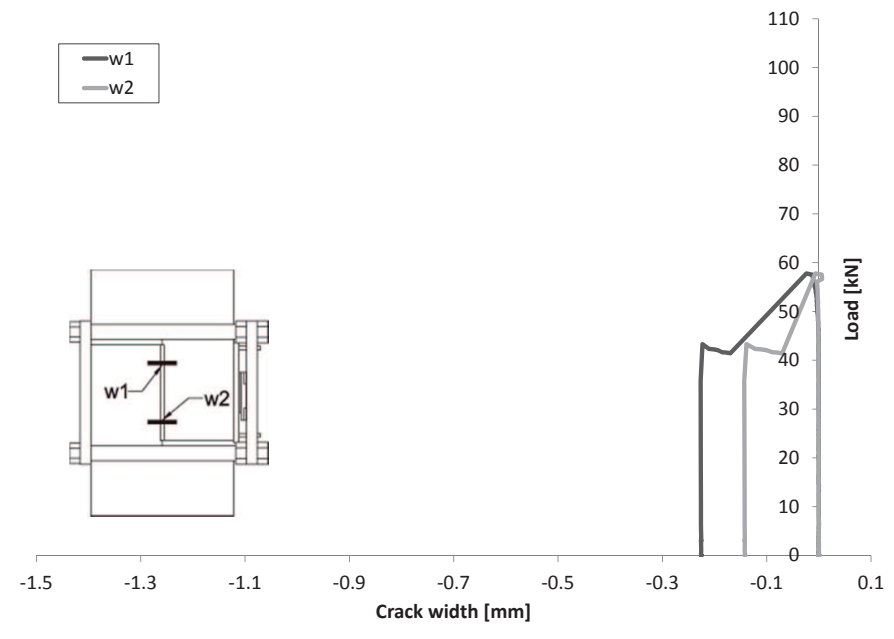

(a)

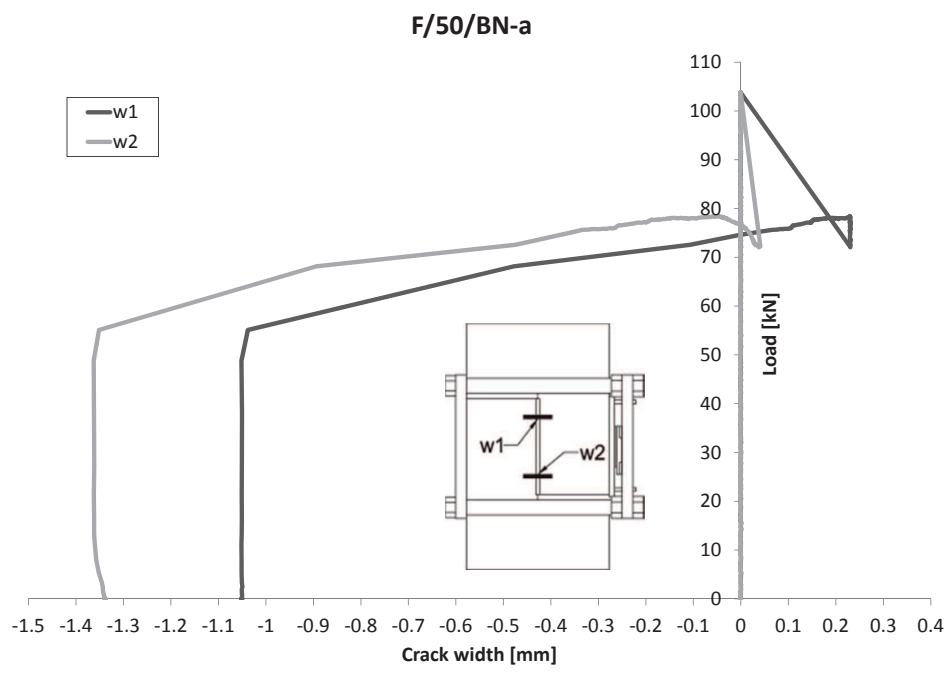

(b)

Fig. 3.23. Load vs. crack width relationship 
Based on these experimental results, it is shown that a new adjustment of springs stiffness must be made. The specimen shown in Fig. 3.23b was precracked in the testing frame which had greater stiffness. Thus it is concluded that the stiffness of the testing frame is more important than the stiffness of the springs for vertical stability, although the stiffness of the springs had more influences on the crack with stability.

\section{Movement of Plate A}

As mentioned in 3.3.5, Plate A was optionally instrumented. The idea was not only to know the movement of Plate A, but also the residual position. This is because the residual position may introduce stresses, and can modify the normal stress for the push-off phase at the beginning. As Plate A and the ACTIVE block were not fixed, the residual position of Plate A was more important in meaning. If the residual position of Plate A significantly differed with the final position of the ACTIVE block, initial the crack plane damage may have occurred. This initial crack plane damage is due to all the specimens being tested having an allowed initial crack width of $1 \mathrm{~mm}\left(w_{0}=1 \mathrm{~mm}\right)$.

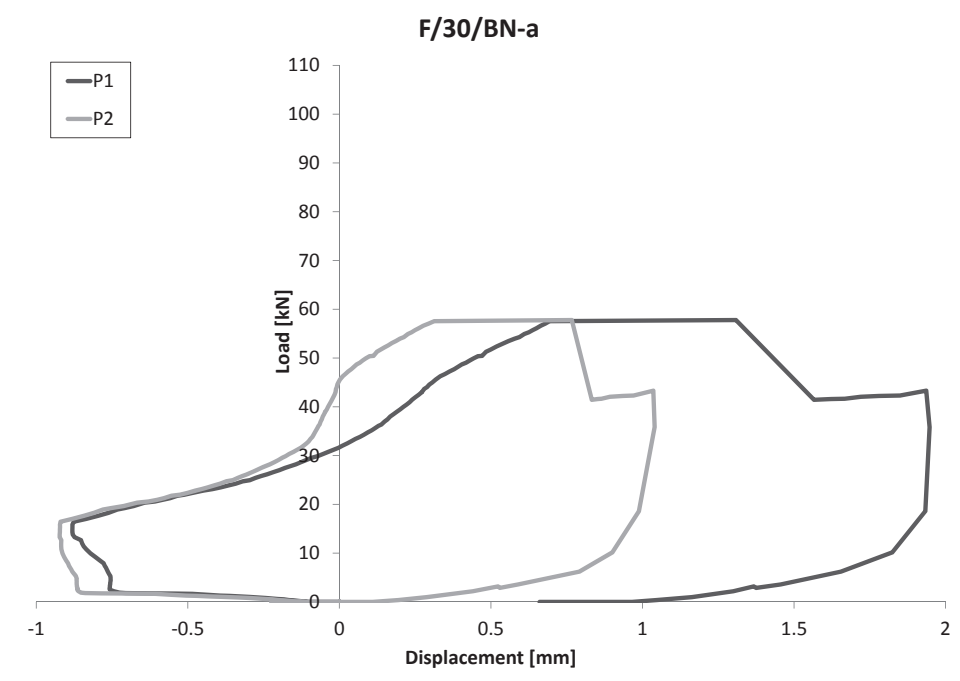

Fig. 3.24. Movement of Plate A in precracking phase.

Fig. 3.24 shows the movement of Plate $\mathrm{A}$ on the $\mathrm{F} / 30 / \mathrm{BN}-\mathrm{a}$ specimen. Plate A moved downwardly (negative LVDTs values). At around $20 \mathrm{kN}$, the movement changed to the opposite direction until the specimen cracks of around $60 \mathrm{kN}$. Then a sudden upward movement took place. When the specimen was unloaded, the residual position reported by Plate A was $0.3 \mathrm{~mm}$ (average value), which can be considered negligible. 


\section{Results of the precracking phase}

After presenting and discussing the stability of the precracking phase, the final results are presented herein. Table 3.4 summarizes the experimental results of all the specimens. This table reports the allowed initial crack width $\left(w_{o}\right)$; the final values of w1 and w2, and the average value (w.av). Precracking load (P.cr); the residual unitary mean confinement force (F.end) are presented. In F.end column, the negative values indicate that the external restraint bars confined the shear plane.

Table 3.4. Precracking test results

\begin{tabular}{|c|c|c|c|c|c|c|c|}
\hline \multirow{2}{*}{ Specimen } & \multirow{2}{*}{$\begin{array}{l}f_{c m} \\
{[\mathrm{MPa}]}\end{array}$} & \multirow{2}{*}{$\begin{array}{l}w_{o} \\
{[\mathrm{~mm}]}\end{array}$} & \multicolumn{3}{|c|}{ LVDT's [mm] } & \multirow{2}{*}{$\begin{array}{l}\text { P.pc } \\
{[\mathrm{kN}]}\end{array}$} & \multirow{2}{*}{$\begin{array}{l}\text { F.end } \\
{[\mathrm{kN}]}\end{array}$} \\
\hline & & & $\mathrm{w} 1$ & w2 & w.av & & \\
\hline $\mathrm{F} / 30 / \mathrm{BN}-\mathrm{a}$ & 50.5 & 1 & 0.23 & 0.14 & 0.18 & 57.78 & -2.44 \\
\hline $\mathrm{F} / 30 / \mathrm{BN}-\mathrm{b}$ & 50.5 & 1 & 0.17 & 0 & 0.08 & 38.87 & -1.66 \\
\hline $\mathrm{F} / 50 / \mathrm{BN}-\mathrm{a}$ & 50.1 & 1 & 1.05 & 1.34 & 1.19 & 103.9 & 1.70 \\
\hline $\mathrm{F} / 50 / \mathrm{BN}-\mathrm{b}$ & 50.1 & 1 & 0.13 & 0.65 & 0.39 & 93.65 & -0.26 \\
\hline $\mathrm{F} / 80 / \mathrm{BN}$ & 52.3 & 1 & 0.95 & 1.28 & 1.12 & 52.77 & 0.78 \\
\hline $\mathrm{F} / 50 / \mathrm{BP}$ & 51.3 & 1 & 0.63 & 0.6 & 0.61 & 79.93 & -0.43 \\
\hline $\mathrm{E} / 0,2 / 14,5$ & 51.4 & 1 & 0.17 & 0.24 & 0.2 & 73.75 & -17.91 \\
\hline
\end{tabular}

Table 3.4 indicates the serious difficulties to reach the target crack width. Those specimens with heavy shear reinforcement, such as traditional stirrups or BP fibers, show better control and smaller difference between w1 and w2. The results obtained from the confinement (F.end) also indicates significant scatter. In order to increase reliability, some modifications to the restraint frame are needed.

\subsubsection{Results of the push-off phase}

The performance and sensitivity of the restraint frame were analyzed in the pushoff test by means of two plot types:

- Shear stress vs. slip displacement, presented in section Slip.

- Shear stress vs. crack width, presented in section Crack width.

\section{Slip}

The results of the five specimens are presented. Fig. 3.25 shows the shear stress as a function of the slip displacement. We can see that the slope of the five specimens is almost the same at the beginning of the test. However, slope changed while the test continues, which means that the fibers started to fail. For F/30/BN-a, a stress drop to $\delta=3 \mathrm{~mm}$ was observed, and $\mathrm{F} / 50 / \mathrm{BN}-\mathrm{b}$, the stress drops was observed 
to $2 \mathrm{~mm}$ of slip. After these points, both specimens began to increases, which indicates that the specimen was not really confined by the restraint frame.

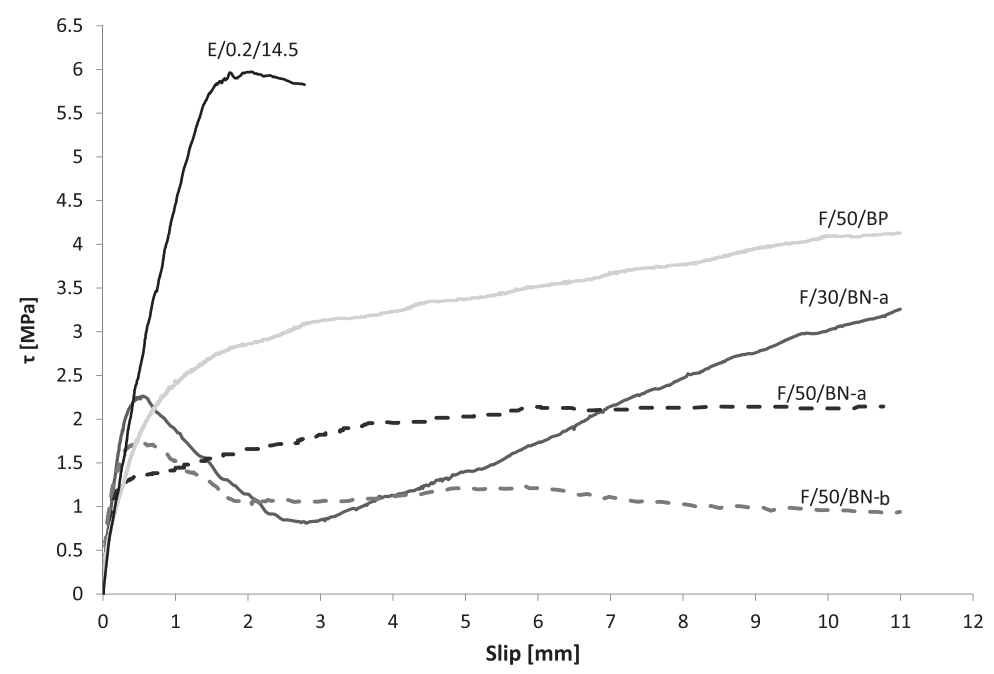

Fig. 3.25. Shear stress vs. slip relationship.

Once the restraint frame began working, an increment in shear stress for $\mathrm{F} / 30 / \mathrm{BN}$ a was observed. Yet the ultimate shear stress of $\mathrm{F} / 30 / \mathrm{BN}-\mathrm{a}$ was higher than the ultimate shear stress of $\mathrm{F} / 50 / \mathrm{BN}-\mathrm{a}$ and $\mathrm{F} / 50 / \mathrm{BN}-\mathrm{b}$. The explanation for this behavior is possibly the effect of the confinement. More logical behavior was observed for the $\mathrm{F} / 50 / \mathrm{BP}$ specimen, whose slope showed a progressive transition and its ultimate shear stress was greater than the other specimens made of FRC.

The effect of stirrups (specimen E/0.2/14.5) is clearly shown. Ultimate strength was reached for a value of $1.8 \mathrm{~mm}$ of slip, and the stress drop was observed. Unfortunately because of an operative issue, the test had to be finished for a slip value of around $3.0 \mathrm{~mm}$.

\section{Crack width}

The relationship between shear stress according to crack width was analyzed by means of Fig. 3.26, which provides the experimental results of the five specimens. In the figure, completely different behaviors to of those expected are seen. These differences are due to various issues, such as the poorer stiffness of the restrain frame. This is concluded from the crack width evolution note during the test. Certain difficulties in the correct placement of LVDTs to measure crack width were also detected. Deficiencies to set $w_{o}$ were also detected.

The global stiffness and wrong fixing of LVDTs are complementary issues, which are shown by the crack width increasing during the test. The combined effect of both issues justified the behavior of the five specimens shown in Fig. 3.26, 


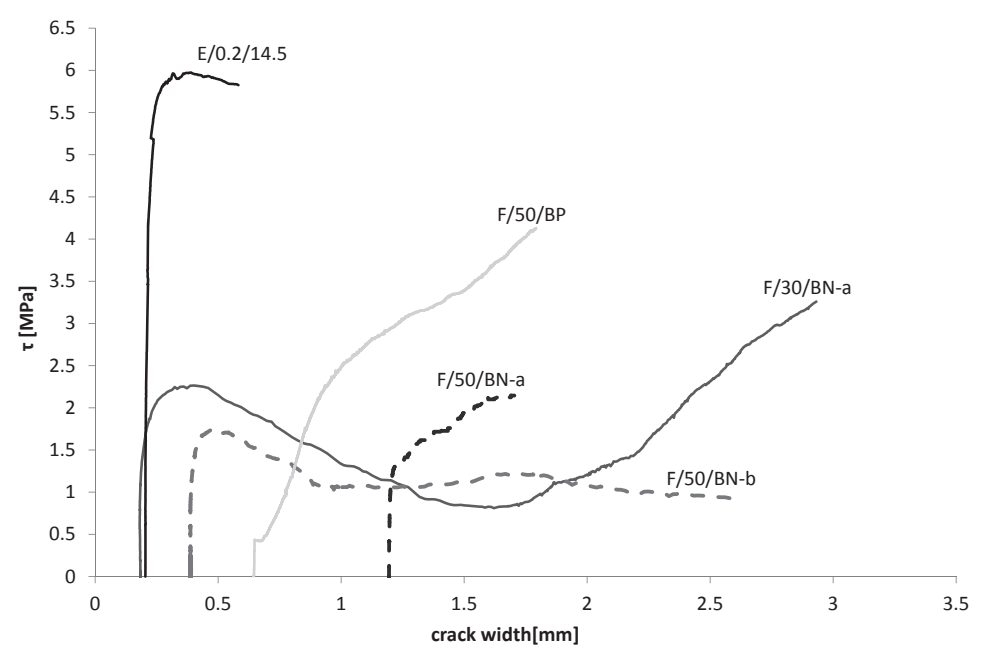

Fig. 3.26. Shear stress vs. crack width relationship.

especially for specimens $\mathrm{F} / 30 / \mathrm{BN}-\mathrm{a}$ and $\mathrm{F} / 50 / \mathrm{BN}-\mathrm{b}$. A reference value of $1 \mathrm{~mm}$ was also chosen for the allowed initial crack width for all the specimens. However, specimens $\mathrm{F} / 30 / \mathrm{BN}-\mathrm{a}$ and $\mathrm{F} / 50 / \mathrm{BN}-\mathrm{b}$ gave values of 3 -fold higher.

Table 3.5 summarizes the results of the five push-off specimens tested. In this table, the four values of crack width (w1h, w2h, w1m and w2m), the average value (w.av) and the standard deviation (S.D.) are shown for the ultimate state. Ultimate slip, ultimate shear stress $\left(\tau_{u}\right)$ and the unitary mean confinement force $(\mathrm{Fu})$ are also provided.

Unitary mean confinement force $(\mathrm{Fu})$ was obtained by applying eq. $3.1(\mathrm{kN})$. Here the values of the four bar strains $(\epsilon 1, \epsilon 2, \epsilon 3, \epsilon 4)$ were experimentally obtained. A theoretical value of $200000 \mathrm{MPa}$ was applied for the elasticity modulus of steel $\left(E_{s}\right)$. The cross-section of the restraint bars $\left(A_{b}\right)$ was obtained with the theoretical diameter $(\phi=25 \mathrm{~mm})$.

$$
F u=(\epsilon 1+\epsilon 2+\epsilon 3+\epsilon 4) \cdot E_{s} \cdot A_{b} \cdot \frac{1}{4 \cdot 1000}
$$

Table 3.5. Ultimate push-off test values.

\begin{tabular}{|c|c|c|c|c|c|c|c|c|c|}
\hline \multirow{2}{*}{ Probeta } & \multicolumn{6}{|c|}{ LVDTs $[\mathrm{mm}]$} & \multirow{2}{*}{$\begin{array}{l}\text { slip } \\
{[\mathrm{mm}]}\end{array}$} & \multirow{2}{*}{$\begin{array}{l}\tau_{u} \\
{[\mathrm{MPa}]}\end{array}$} & \multirow{2}{*}{$\begin{array}{l}\mathrm{Fu} \\
{[\mathrm{kN}]}\end{array}$} \\
\hline & w1h & $\mathrm{w} 2 \mathrm{~h}$ & $\mathrm{w} 1 \mathrm{~m}$ & $\mathrm{w} 2 \mathrm{~m}$ & w.av & S.D. & & & \\
\hline $\mathrm{A} / \mathrm{F} / 30 / \mathrm{BN}-\mathrm{a}$ & 3.65 & 4.05 & 2.27 & 2.14 & 3.46 & 0.96 & 10.00 & 3.01 & -26 \\
\hline $\mathrm{A} / \mathrm{F} / 50 / \mathrm{BN}-\mathrm{a}$ & 1.92 & 1.94 & 1.54 & 1.48 & 1.80 & 0.24 & 10.00 & 2.12 & -26.2 \\
\hline $\mathrm{A} / \mathrm{F} / 50 / \mathrm{BN}-\mathrm{b}$ & 3.22 & 2.55 & 1.76 & 2.15 & 3.61 & 0.62 & 10.00 & 0.96 & -7.35 \\
\hline $\mathrm{A} / \mathrm{F} / 50 / \mathrm{BP}-\mathrm{b}$ & 0.99 & 1.75 & 1.68 & 0.48 & 1.61 & 0.60 & 10.00 & 4.10 & -65.27 \\
\hline $\mathrm{A} / \mathrm{E} / 0.2 / 14.5$ & 0.44 & 0.65 & 0.15 & 0.27 & 1.49 & 0.22 & 2.78 & 5.82 & -65.29 \\
\hline
\end{tabular}




\subsubsection{Problems detected and their solutions}

Having analyzed the experimental results, several operative and procedures issues were detected. A list of these problems are described below:

1. Specimen rotation about the lower knife.

2. Serious difficulty to set the allowed initial crack width $\left(w_{o}\right)$.

3. Very time-consuming procedure to place the specimen in the correct position in both the precracking and push-off phases.

4. Lack of information about the relative movement between the ACTIVE and PASSIVE blocks of the specimens due to the handling between both phases.

5. Poor crack control during the push-off phase.

6. Poor reliability to measure the strains of the bars. Therefore, a high level of uncertainty of normal stress.

In order to solve the aforementioned problems, the following solutions were applied. It must be pointed out that the number presented in the list of problems corresponds to the number of the proposed solution:

1. Vertical stability and rotation of the specimen about the lower knife were, solved adjusting the stiffness of the springs. Fixing the upper knife with the hydraulic jack. Finally, the testing frame was changed for one with greater stiffness.

2. To set the allowed initial crack width $\left(w_{o}\right)$ reliably, three things were done. First, the thread of the rods was changed from $2 \mathrm{~mm}$ to $1 \mathrm{~mm}$ to increase the sensitivity. Thus, the nuts moved $1 \mathrm{~mm}$ along the edge of the bar when a turn was completed. Second, a special break was implemented on the external nuts to fix the nuts in at the specific position. Finally, Plate A and the ball bearing were outwardly fixed before the nuts were adjusted. This guaranteed that both the ball bearing and Plate A had the same inclination.

3. A sliding system for each phase was designed. This allowed to place the specimen as far as possible from the jack, and to push it to the final position.

4. In order to know the relative displacements between the ACTIVE and PASSIVE blocks, two discrete measurement techniques were applied. These displacements were produced by handling of the specimen needed to move the specimen from the precracking phase to the push-off phase. One technique consisted in photographing the specimen before each movement, and taking measurements using these photos. The other involved using the DEMEC target points, which gave measurements before each specimen movement.

5. A new restraint frame with greater global stiffness was needed to solve this issue. A decision was made to increase all the dimensions of the components of the restraint frame. This meant that the diameter of the rods and all plate dimensions had to be increase. 
6. In order to increase the reliability of normal stress, more strain gauges were pasted on the same cross-section. A decision was made to paste three strain gauges on each bar to obtain an average value of the strains.

\subsection{Second approach to the test methodology}

Based on the problems and solutions detected in the previous test (see section 3.3.8), a decision was made to design a new restraint frame. The main feature of this frame was the increase in global stiffness.

This section provides a brief explanation of the characteristics of the new frame. The same occurs with the test methodology and the instrumentation used. A complete and fully detailed explanation of the testing procedure is offered in section 3.5 .

A second series of preliminary tests were done to experimentally validate the behavior of the restraint frame. From the experimental results obtained, some issues were detected and solved. Based on these solutions, a final test procedures was designed.

\subsubsection{Testing frame}

A decision was made to carry out both the precracking and push-off phases, within the same testing frame. This presented two major advantages:

- First, the new testing frame gave stronger stiffness (in all directions) that the previous one. Given the greater stiffness, a better control during the test was obtained.

- Second, the specimen moved through over a shorter distance. This reduced handling in the specimen and, therefore, the possibility of relative displacement between both the ACTIVE and PASSIVE blocks occurred.

Fig. 3.27 shows the frontal view of the new testing frame, where we can see the precraking place on the left and the push-off place on the right. The sliding baseplate is also shown.

\subsubsection{Restraint frame (Frame 2.0)}

In order to increase the horizontal stiffness $\left(k_{h}\right)$ of the restraint frame, the axial stiffness $\left(E_{s} \cdot A_{b}\right)$ of the bars had to increase. Due to the increment in the elasticity modulus of steel $\left(E_{s}\right)$ being a material property, a decision was made to increase the cross-section of the bar $\left(A_{b}\right)$. Therefore, the increase in the diameter of the bars was proposed to change from $25 \mathrm{~mm}$ to $40 \mathrm{~mm}$. The size of both plates was also increased. 


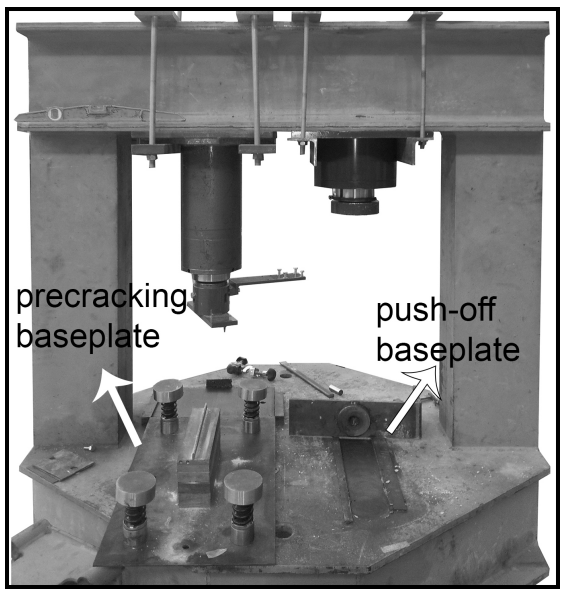

Fig. 3.27. Frontal view of the new testing frame.

Fig. 3.28 is a schematic representation of the new design, where we can see the difference between both restraint frames. Fig. 3.28a depicts the old restraint frame (Frame 1.0) and Fig. 3.28b illustrates the new design (Frame 2.0).

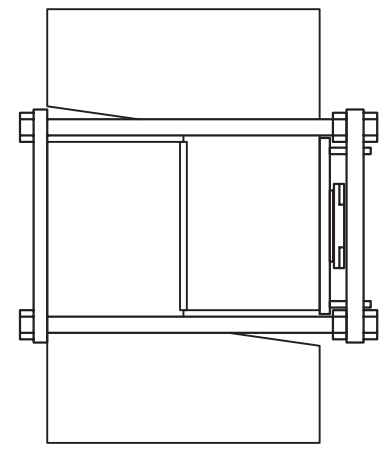

(a) Old design (Frame 1.0)

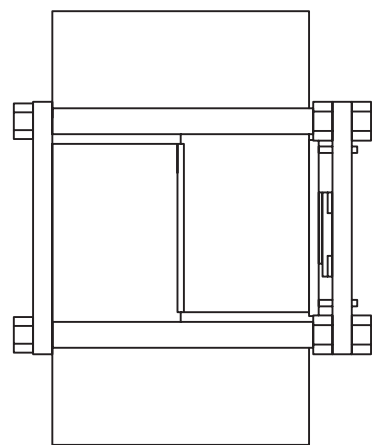

(b) New design (Frame 2.0)

Fig. 3.28. Comparison made between both the restraint frame designs.

\subsubsection{Numerical behavior of the restraint frame}

Once the design was obtained, a linear elastic analysis was performed to investigate the zone of maximum tensile strain on the bars and the general stiffness of the restraint frame. The restraint frame's finite element (FE) model is shown in Fig. 3.29 , where the cover of the ball bearing was marked because of the load applied on it.

The following hypotheses were applied to the analysis:

- The four bars were restrained with both Plates A and B. 


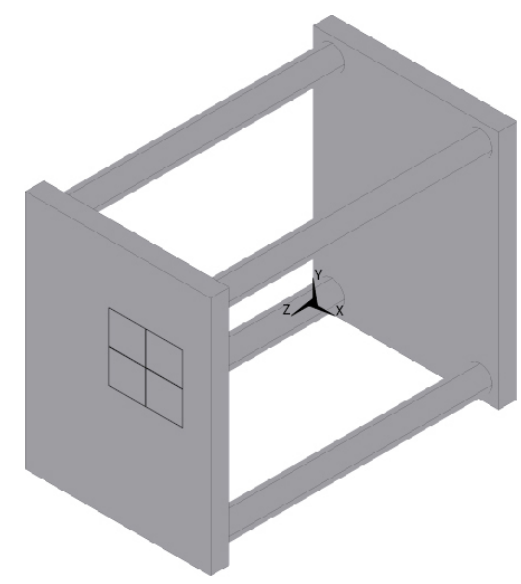

Fig. 3.29. Numerical model of the new restraint frame design.

- Plate B was restrained in all directions on a length equal to the width of the Left face of the specimen.

- Plate A and the cover of the ball bearing were fixed.

- A pressure of $1 \mathrm{MPa}$ (acting on the crack plane) was applied to the cover of the ball bearing.

From the FE analysis, the following results are reported. The external restraint bars gave the maximum tensile strain at their mid-length (see Fig. 3.30a), which means in front of the shear plane. It must be pointed out that tensile strain was the highest strain, but bending strain also appeared in that section because of the flexure of both plates (see Fig. 3.30b).

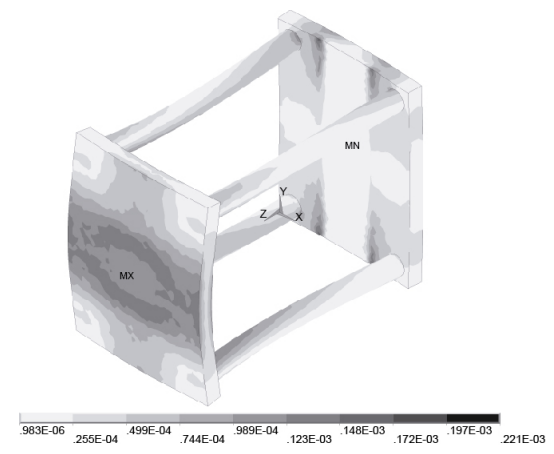

(a) Maximum strain of the restraint frame

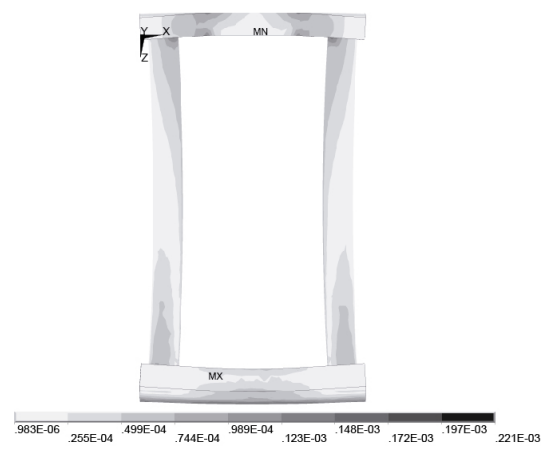

(b) Top view of the model

Fig. 3.30. Solution from the FE model.

To avoid the flexure of plates, it was necessary to increment their inertia. Increasing inertia implies increasing weight and also the geometrical dimensions of the 
restraint frame. If weight increases, more time will be need to set the restraint frame. Besides under real test conditions, the bars and plates do not restrain one another, so these flexure strains found in the FE analysis may be negligible.

\subsubsection{Testing procedures and instrumentation used}

\section{Setting of $w_{o}$}

Having get the restraint frame on the specimen, and according to the procedure presented in section 3.2.3, the allowed initial crack width was fixed. To set $w_{o}$, Plate A was placed against the ball bearing and the eight nuts (four external and four internal) were tightened by hand. In this position, some aligned fixed marks were made on the external nuts and Plate A. Then the external nuts were turned one complete turn until both mark were re-aligned. This turn produced a distance of $1 \mathrm{~mm}$ between the nuts and Plate A. In this new position, one nut was fixed by means of the special break to help avoid movements. This operation was repeated with the other three external nuts. Finally, Plate A was placed against the external nuts by the internal ones. Thus, the distances of $1 \mathrm{~mm}$ set between Plate A and the cover of the ball bearing were achieved.

\section{Precracking phase}

The specimen was placed in a horizontal position, and was placed under the hydraulic jack with the help of the sliding precraking baseplate. The specimen's vertical stability was recorded by means of six vertical LVDTs. Crack width was recorded by means of two LVDTs which were placed after the upper knife came into contact with the specimen. Then the twelve strain gauge were connected to the computer and the test began. More details of the procedure and instrumentation can be found in section 3.5.7.

\section{Push-off phase}

After precracked the specimen along the shear plane, the specimen was placed in a vertical position. Centering the specimen was guaranteed by the push-off sliding baseplate. In this position, the setting of $w_{o}$ was done. Afterward, four horizontal LVDTs were used to measure crack width, two on the Front face and two on the Back face. Slip displacement was recorded by means of two vertical LVDTd, one on each face. The vertical displacement of both Plates A and B was recorded by means of four LVDTs two on each plate. Complete details of the instrumentation and testing procedure are reported in section 3.5.8. 


\section{Photogrametry of crack width}

In order to know the increment of crack width due to specimen handling, the photogrametry technique was used, which is detailied in section 3.5.4.

\section{DEMEC calibration}

A second methodology, of known reliability, was used to make comparisons. In order to know the reliability of this technique, a series of 70 measurements was obtained. These 70 measurements are presented in Table 3.6. The seven sides of the three triangles (see Fig. 3.52) were measured 10 times to obtain the experimental length.

Table 3.6. Experimental length of the seven side of the triangles.

\begin{tabular}{llllllll}
\hline \multirow{2}{*}{ Measurements } & \multicolumn{7}{l}{ Relative distance $[\mathrm{mm}]$} \\
& $1-2$ & $2-3$ & $1-3$ & $3-4$ & $4-5$ & $2-4$ & $3-5$ \\
\hline M1 & 0.848 & 0.553 & 1.444 & 0.488 & 0.366 & 0.352 & 1.094 \\
M2 & 0.838 & 0.551 & 1.489 & 0.486 & 0.364 & 0.354 & 1.097 \\
M3 & 0.842 & 0.554 & 1.492 & 0.488 & 0.364 & 0.356 & 1.097 \\
M4 & 0.845 & 0.557 & 1.493 & 0.488 & 0.365 & 0.347 & 1.091 \\
M5 & 0.842 & 0.549 & 1.492 & 0.488 & 0.363 & 0.347 & 1.089 \\
M6 & 0.844 & 0.555 & 1.479 & 0.497 & 0.357 & 0.339 & 1.089 \\
M7 & 0.842 & 0.555 & 1.467 & 0.489 & 0.365 & 0.346 & 1.090 \\
M8 & 0.855 & 0.555 & 1.456 & 0.487 & 0.366 & 0.346 & 1.089 \\
M9 & 0.859 & 0.554 & 1.459 & 0.486 & 0.366 & 0.352 & 1.096 \\
M10 & 0.859 & 0.554 & 1.460 & 0.486 & 0.363 & 0.349 & 1.090 \\
\hline
\end{tabular}

Table 3.7 shows the average value (average), the standard deviation (S.D.) and the coefficient of variation (C.V.) for each side of the triangles deviated. The 5 $\%$ and $95 \%$ confidence intervals are also reported. If the difference between the average and each experimental value of each side was analyzed, it was found that the procedure error was less than $0.012 \mathrm{~mm}$, with a $95 \%$ confidence.

Table 3.7. Statistical parameters.

\begin{tabular}{llllllll}
\hline Parameter & $1-2$ & $2-3$ & $1-3$ & $3-4$ & $4-5$ & $2-4$ & $3-5$ \\
\hline average & 0.847 & 0.554 & 1.473 & 0.488 & 0.364 & 0.349 & 1.092 \\
S.D & 0.008 & 0.002 & 0.018 & 0.003 & 0.003 & 0.005 & 0.003 \\
C.V. [\%] & 0.897 & 0.409 & 1.228 & 0.662 & 0.738 & 1.410 & 0.314 \\
conf $(5 \%)$ & 0.840 & 0.550 & 1.449 & 0.486 & 0.360 & 0.342 & 1.089 \\
conf $(95 \%)$ & 0.859 & 0.556 & 1.493 & 0.493 & 0.366 & 0.355 & 1.097 \\
\hline
\end{tabular}




\subsubsection{Second preliminaries tests}

Having completed the design, FE modeling and restraint frame construction, its real behavior and the general working of the other parts were experimentally studied. This is the central topic of the present subsection.

\section{Experimental program}

A new experimental program, comprising seven specimens, was tested. All the specimens were made of SFRC with the same concrete strength. The only variable was the allowed initial crack width $\left(w_{o}\right)$, which was fixed at three levels (low, medium and high), as defined below:

- Low: target value of $0.5 \mathrm{~mm}$.

- Medium: target value of $1.0 \mathrm{~mm}$.

- High: target value of $3.0 \mathrm{~mm}$.

The identifying code was formed by three parts, separated by slashes (f.i. A5/0.5/3a). The first part shows the type and amount of fibers used in the mixture. Then the value of $w_{o}$, expressed in $\mathrm{mm}$ is shown. Finally the mix type design and repetition are shown. Table 3.8 shows all the specimens and the information summarized on the identifying code.

Table 3.8. Specimen name and characteristic

\begin{tabular}{lllllll}
\hline \multirow{2}{*}{ Id Specimen } & \multicolumn{2}{l}{ Reinforcement } & \multirow{2}{*}{$w_{o}$} & mix & \multirow{2}{*}{ Repeted } \\
\cline { 2 - 4 } & code & type & amount & & & \\
\hline $\mathrm{A} 5 / 0.5 / 3 \mathrm{a}$ & $\mathrm{A} 5$ & $65 / 35 \mathrm{BN}$ & 50 & 0.5 & 3 & $\mathrm{a}$ \\
$\mathrm{A} 5 / 0.5 / 3 \mathrm{~b}$ & $\mathrm{~A} 5$ & $65 / 35 \mathrm{BN}$ & 50 & 0.5 & 3 & $\mathrm{~b}$ \\
$\mathrm{~A} 5 / 1.0 / 3 \mathrm{a}$ & $\mathrm{A} 5$ & $65 / 35 \mathrm{BN}$ & 50 & 1.0 & 3 & $\mathrm{a}$ \\
$\mathrm{A} 5 / 1.0 / 3 \mathrm{~b}$ & $\mathrm{~A} 5$ & $65 / 35 \mathrm{BN}$ & 50 & 1.0 & 3 & $\mathrm{~b}$ \\
$\mathrm{~A} 5 / 1.0 / 3 \mathrm{c}$ & $\mathrm{A} 5$ & $65 / 35 \mathrm{BN}$ & 50 & 1.0 & 3 & $\mathrm{c}$ \\
$\mathrm{A} 5 / 1.5 / 3 \mathrm{a}$ & $\mathrm{A} 5$ & $65 / 35 \mathrm{BN}$ & 50 & 1.5 & 3 & $\mathrm{a}$ \\
$\mathrm{A} 5 / 3.0 / 3 \mathrm{a}$ & $\mathrm{A} 5$ & $65 / 35 \mathrm{BN}$ & 50 & 3.0 & 3 & $\mathrm{a}$ \\
$\mathrm{A} 5 / 3.0 / 3 \mathrm{~b}$ & $\mathrm{~A} 5$ & $65 / 35 \mathrm{BN}$ & 50 & 3.0 & 3 & $\mathrm{~b}$ \\
\hline
\end{tabular}

The mix proportions of mix type 3 , slump flow (in $\mathrm{mm}$ ) and $f_{c m}$ (in $\mathrm{MPa}$ ), in averages values, are shown in Table 3.9. Two fractions of crush limestone with a maximum aggregate size of $12 \mathrm{~mm}$ and river sand were used. The high-ranged water reducing admixture (HRWRA) were polycarboxylate ether-based, defined by Sika ${ }^{\circledR}$, as SikaViscocrete ${ }^{\circledR}$ 20HE. The slump flow value was taken 8 min after placing the admixture. From each batch of 100 lts, two push-off specimens and three $150 \times 300 \mathrm{~mm}$ cylinders were cast. 
Table 3.9. Mix proportion (in $\mathrm{kg} / \mathrm{m}^{3}$ ) and concrete properties.

\begin{tabular}{ll}
\hline CEM II/B-V 42,5R & 350 \\
Water (total) & 210 \\
Gravel 7/12 & 600 \\
Gravel 4/7 & 190 \\
River sand & 993 \\
Filler & 60 \\
Fibres & 50 \\
Viscocrete 20HE & 4,36 \\
Total [kg/m3] & 2457,36 \\
w/c & 0,60 \\
\% HRWRA & 1,25 \\
\hline$f_{c m}$ (S.D.) & $53,3(2,5)$ \\
Slump flow 8 & 530 \\
\hline
\end{tabular}

\section{Results of the precracking phase}

It must be taken into account that, the allowed initial crack width was fixed before the precracking test. So the worst condition $\left(w_{o}=1.0\right.$ and $\left.w_{o}=3.0\right)$ was analyzed. From Fig. 3.31, where specimen A5/1.0/3a is shown, two conclusions are drawn. First, no significant specimen rotation about the lower knife was observed, and a low scatter among the 6 points was obtained. Second, an uncontrolled zone was observed when the specimen cracked as the test no longer controlled when the crack was formed. The test result was not affected by this zone.

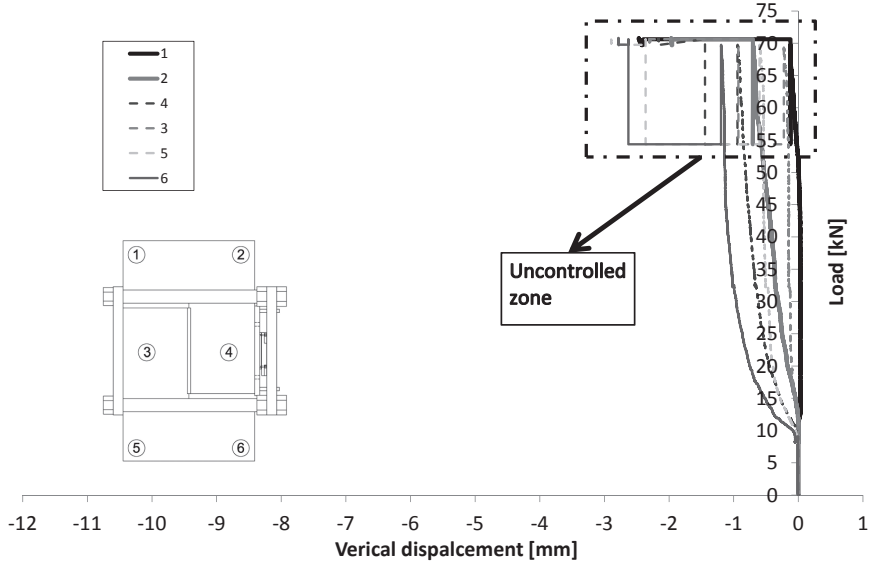

Fig. 3.31. Vertical stability of specimen A5/1.0/3a. 
If the behavior of a specimen with a higher allowed initial crack width (f.i. A5/3.0/3b) was analyzed (Fig. 3.32), the following conclusion can be drawn. No specimen rotation about the lower knife was observed, and a low scatter among the 6 points was obtained. For these specimens however, the uncontrolled zone was bigger when compared to the other specimens. This was due to the allowed initial crack width being too big $\left(w_{o}=3 \mathrm{~mm}\right)$, and also because both steel knives were driven into the specimens immediately after specimen cracks.

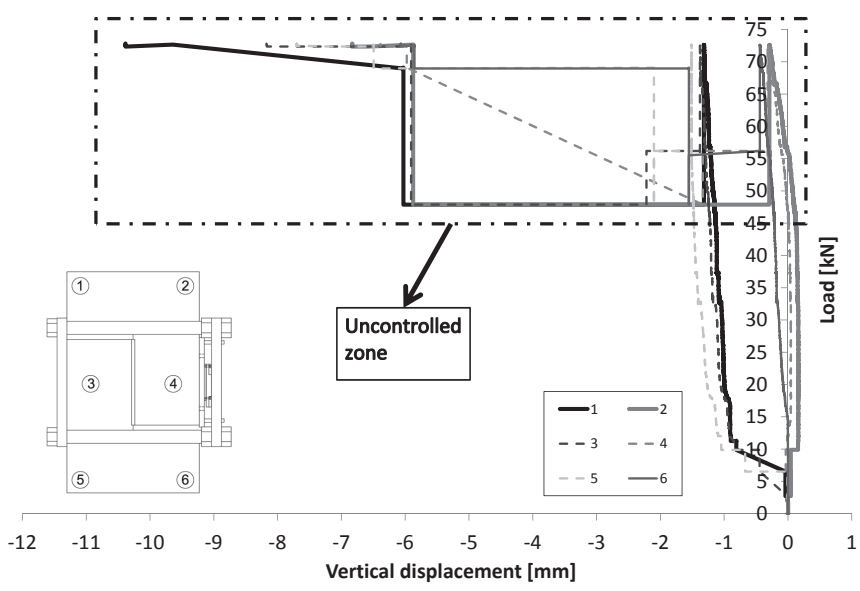

Fig. 3.32. Vertical stability of specimen A5/3.0/3b.

Table 3.10 summarizes the experimental results of the precracking test. First, the specimen name, concrete strength (in $\mathrm{MPa}$ ) and the allowed initial crack width (in $\mathrm{mm}$ ) are shown. Then the values of both LVDTs, w1 and w2, along with the average value (w.av), are reported. Finally, the precracking load (P.cr) and the averaged residual unitary force (F.end) of each bar are provided.

Table 3.10. Results of the precracking test.

\begin{tabular}{|c|c|c|c|c|c|c|c|}
\hline \multirow{2}{*}{ Specimen } & \multirow{2}{*}{$\begin{array}{l}f_{c m} \\
{[\mathrm{MPa}]}\end{array}$} & \multirow{2}{*}{$\begin{array}{l}w_{o} \\
{[\mathrm{~mm}]}\end{array}$} & \multicolumn{3}{|c|}{ LVDT $[\mathrm{mm}]$} & \multirow{2}{*}{$\begin{array}{l}\text { P.cr } \\
{[\mathrm{kN}]}\end{array}$} & \multirow{2}{*}{$\begin{array}{l}\text { F.end } \\
{[\mathrm{kN}]}\end{array}$} \\
\hline & & & $\mathrm{w} 1$ & w2 & & & \\
\hline & & & & & & & -2.79 \\
\hline & & & & 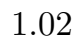 & & & \\
\hline & 53.6 & & 0.78 & & & & -2.55 \\
\hline & 53.6 & & 2.25 & 1.51 & & & -3.83 \\
\hline $\mathrm{c}$ & 54.2 & & 1.39 & 1.07 & & 72.93 & -4.96 \\
\hline & 51.6 & & 3.50 & 3.30 & 3.40 & 68.65 & -8.94 \\
\hline $\mathrm{A} 5 / 3.0 / 3 \mathrm{~b}$ & 51.6 & 3.00 & 3.45 & 3.21 & 3.33 & 72.61 & -7.08 \\
\hline
\end{tabular}

If we compared values of $w_{o}$ and w.av, we can conclude that the procedure of fixing $w_{o}$ remains unclear. In other words, doing the fixing procedure of $w_{o}$ before 
cracking the specimen obtains a great scatter of results. So the average residual unitary force (F.end) was used as an indirect measurement to avoid doubts. The following idea was applied: if the procedure for fixing $w_{o}$ was reliable, a higher value of the difference between w.av and $w_{o}\left(\mathrm{w} . \mathrm{av}-w_{o}\right)$ gave a higher value of the F.end as a result. This is shown in Fig. 3.33, where a linear relationship is observed. Two specimens (A5/0.5/3b and A5/1.0/3b) were outside it. One possible explanation is that a bad fixing procedure of $w_{o}$ on these two specimens was carried out.

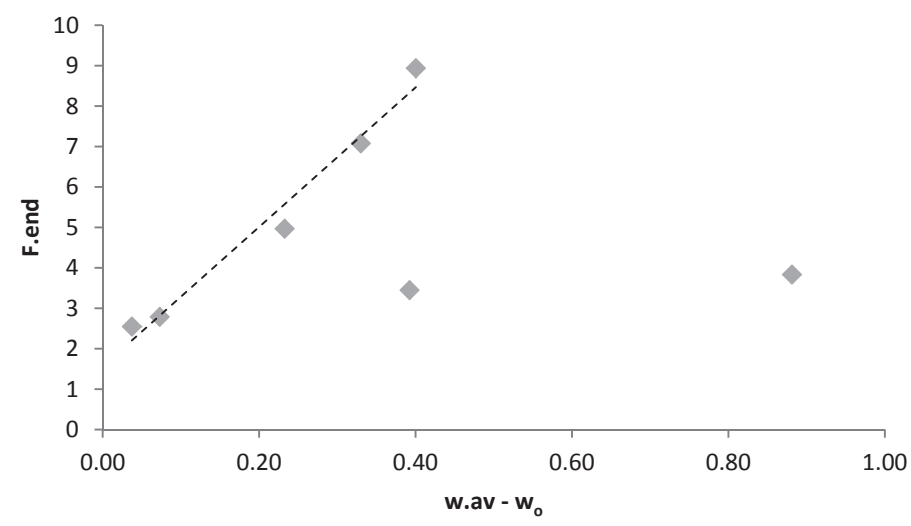

Fig. 3.33. Restraint force vs crack width differences relationship.

\section{Results of the push-off phase}

The general behavior of this new design was experimentally validated by means of the present experimental campaign. Depending on the allowed initial crack width, different behaviors were expected. Shear behavior was analyzed by means of four plot types: (a) shear stress vs. slip relationship; (b) shear stress vs. crack width relationship; (c) crack opening path relationship; (d) normal stress vs. crack width relationship.

In order to clearly show these behaviors, only one specimen of each class (A5/0.5/3a; A5/1.0/3a and A5/3.0/3b) was used as examples. Fig. 3.34 shows shear stress vs. slip relationship for those three specimens. Different behaviors were observed according to $w_{o}$ : the lower $w_{o}$, the greater the shear stress transmitted by crack interfaces for the same slip value. Thus a $100 \%$ increment (from 0.5 to $1.0 \mathrm{~mm}$ ) represented a reduction of $22 \%$ (from 3.74 to $2.92 \mathrm{MPa}$ ), while a $600 \%$ increment (from 0.5 to $3.0 \mathrm{~mm}$ ) led to a reduction of $82 \%$ (from 3.74 tom $0.68 \mathrm{MPa}$ ). 


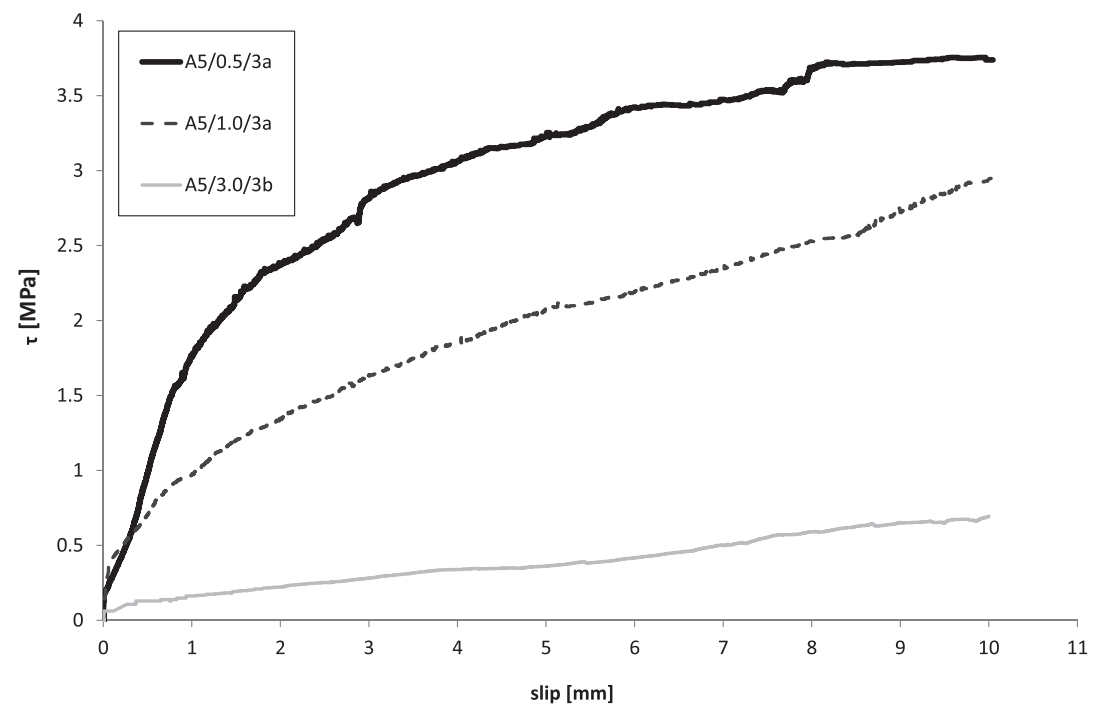

Fig. 3.34. Shear stress vs. slip relationship.

Fig. 3.35 shows the shear stress vs. crack width relationship for these three specimens (A5/0.5/3a; A5/1.0/3a and A5/3.0/3b). The closing crack width at the beginning of the test, reported for specimens A5/0.5/3a and A5/3.0/3b, must be taken into account. This behavior can be explained by the normal stress that acts on the shear plane before the push-off starts (see the F.end column in Table 3.10). Thus the initial normal stress was $0.45 \mathrm{MPa}$ for $\mathrm{A} 5 / 0.5 / 3 \mathrm{a}$ and $1.10 \mathrm{MPa}$ for $\mathrm{A} 5 / 3.0 / 3 \mathrm{~b}$ if non stresses were induced by the handling process. When sliding began, a new contacted zone between the crack interfaces was produced, which allowed reduction (or relaxation) of the tensile stress on the bars which, in turn, leads to a closing crack width. 


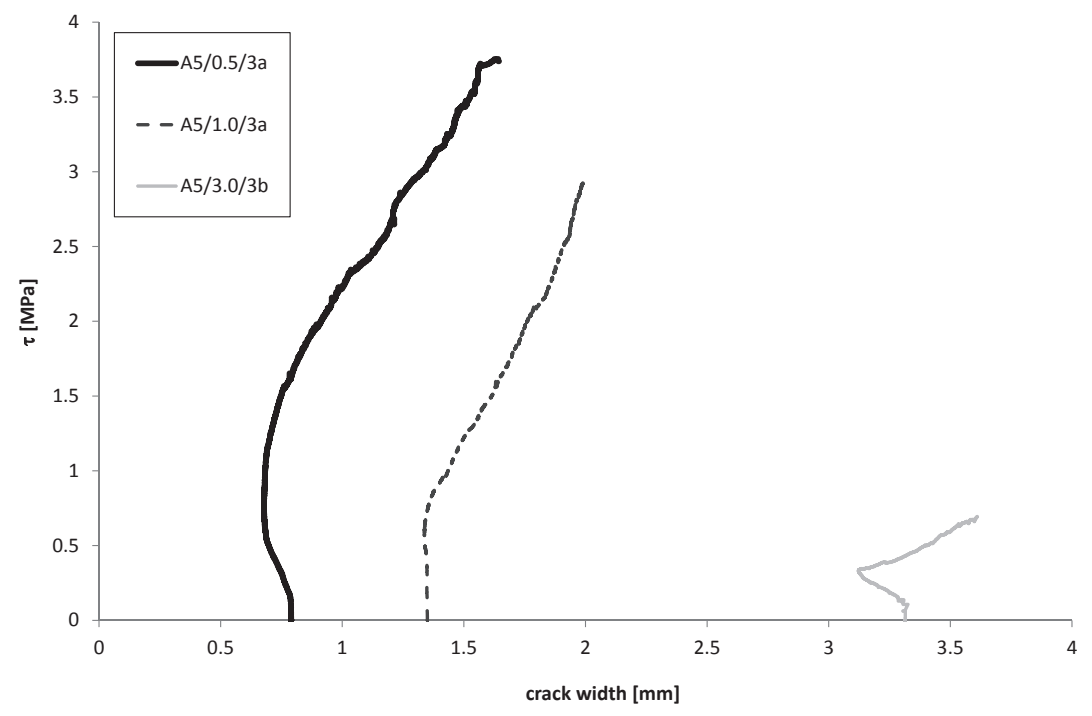

Fig. 3.35. Shear stress vs. crack width relationship.

Fig. 3.36 shows the crack opening path which gave the slip vs. crack width relationship. In this figure, we can see the slip length where the crack width closing occurred. Thus for A5/0.5/3a, crack width closing happened until $0.7 \mathrm{~mm}$ of slip, while, this phenomenon occurred for A5/3.0/3b until $3.0 \mathrm{~mm}$ of slip. We can alse see that the shape of the three curves (after those points) was similar to an exponential function $\left(y=a \cdot e^{b x}\right)$. This means that the crack opening path depends on restraint frame stiffness. 


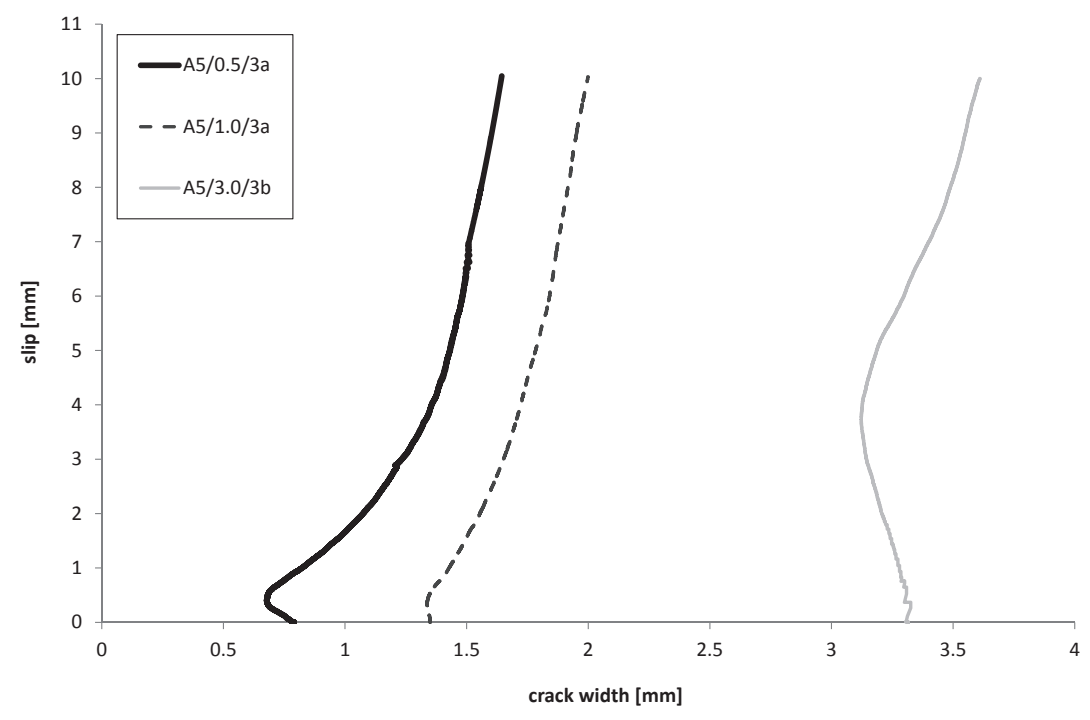

Fig. 3.36. Crack opening path relationship.

Finally, the relationship between normal stress and crack width is shown in Fig. 3.37. As normal stress is dependent on both crack width and restraint frame stiffness, a linear relationship was expected. Nonetheless a non linear relationship was obtained from the experimental results, according to the results reported by Walraven, Vos, and Reinhardt (1979). One possible explanation for this behavior in this case is that the specimen and the restraint frame did not fully come into contact. Thus normal stress depends on crack width, but this dependence was not linear until full contact was achieved (see point A in Fig. 3.37), after which linear dependence was observed. 


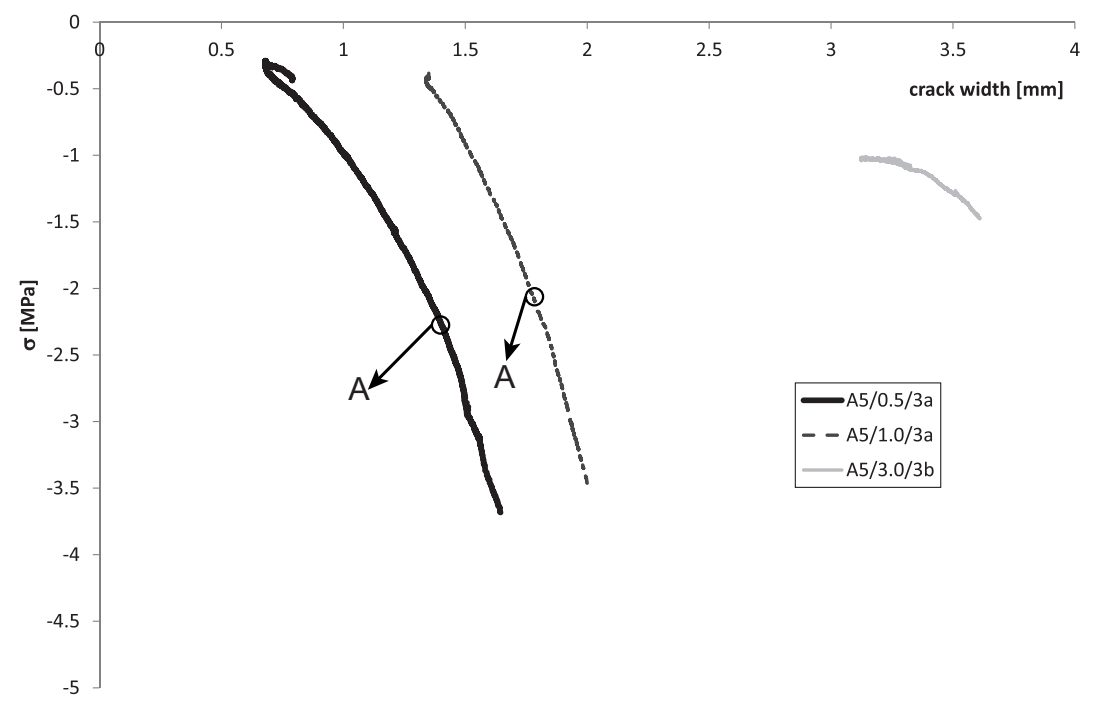

Fig. 3.37. Normal stress vs. crack width relationship.

Table 3.11 presents the ultimate push-off test value. The information is arranged as follows. The value of the four horizontal LVDTs (w1, w2, w3 and w4); the averaged value $(w)$ and the standard deviation (S.D.) are shown. The ultimate average value (slip) of both the vertical LVDTs (Vc and Vm), the ultimate shear stress $\left(\tau_{u}\right)$ and the normal stress $\left(\sigma_{u}\right)$ are also provided. If the values of $\tau_{u}$ and $\sigma_{u}$ are taken into account, we can observe that both are similar. This means that the shear stress is balanced by frictional forces.

Table 3.11. The push-off test results.

\begin{tabular}{|c|c|c|c|c|c|c|c|c|c|}
\hline \multirow{2}{*}{ Specimen } & \multicolumn{6}{|c|}{ LVDTs $[\mathrm{mm}]$} & \multirow{2}{*}{$\begin{array}{l}\text { slip } \\
{[\mathrm{mm}]}\end{array}$} & \multirow{2}{*}{$\begin{array}{l}\tau_{u} \\
{[\mathrm{MPa}]}\end{array}$} & \multirow{2}{*}{$\begin{array}{l}\sigma_{u} \\
{[\mathrm{MPa}]}\end{array}$} \\
\hline & w1 & w2 & w3 & $\mathrm{w} 4$ & $w$ & S.D. & & & \\
\hline $\mathrm{A} 5 / 0.5 / 3 \mathrm{a}$ & 1.68 & 1.76 & 1.52 & 0.81 & 1.45 & 0.43 & 10.05 & 3.74 & -3.29 \\
\hline $\mathrm{A} 5 / 0.5 / 3 \mathrm{~b}$ & 1.97 & 1.74 & 1.72 & 1.34 & 1.69 & 0.26 & 10.02 & 3.86 & -3.25 \\
\hline $\mathrm{A} 5 / 1.0 / 3 \mathrm{a}$ & 1.72 & 2.05 & 1.77 & 2.44 & 2.00 & 0.33 & 10.03 & 2.95 & -3.06 \\
\hline $\mathrm{A} 5 / 1.0 / 3 \mathrm{~b}$ & 2.61 & 2.94 & 2.54 & 2.87 & 2.74 & 0.19 & 10.00 & 2.10 & -2.49 \\
\hline $\mathrm{A} 5 / 1.0 / 3 \mathrm{c}$ & 2.64 & 2.82 & 2.63 & 2.44 & 2.63 & 0.15 & 10.01 & 3.16 & -3.81 \\
\hline $\mathrm{A} 5 / 3.0 / 3 \mathrm{a}$ & 3.57 & 4.52 & 4.22 & 4.35 & 4.16 & 0.42 & 10.02 & 1.76 & -2.24 \\
\hline $\mathrm{A} 5 / 3.0 / 3 \mathrm{~b}$ & 3.61 & 3.63 & 3.60 & 3.60 & 3.61 & 0.02 & 10.03 & 0.69 & -0.39 \\
\hline
\end{tabular}

\section{Results of Photogrammetry and DEMEC}

Here the results of both measurement techniques are presented. The experimental data are acquired following the procedures described in 3.5.4 and 3.5.5. The anal- 
ysis is presented in parallel for both techniques, but it is separated for each test. The major face of the specimen, which came into contact with the formwork, is Back face; while the opposite face is the Front face.

The experimental values for the precracking test are offered in Table 3.12. First the average value of the LVDTs (w.av), expressed in mm, is shown. The photogrammetry values are provided for both faces, first the Front face (front column), the Back face (back column), and then the average value (ph.av). The same idea applies for the DEMEC values, first the Front face (front column) and then the Back face (back column), and finally the average value (de.av).

Table 3.12. Values of the measurements obtained from the photogrammetry and DEMEC techniques.

\begin{tabular}{llllllll}
\hline \multirow{2}{*}{ Specimen } & \multirow{2}{*}{ w.av } & \multicolumn{3}{c}{ PHOTO $[\mathrm{mm}]$} & \multicolumn{3}{c}{ DEMEC $[\mathrm{mm}]$} \\
\cline { 3 - 8 } & & front & back & ph.av & front & back & de.av \\
\hline A5/0.5/3a & 0.57 & 0.81 & 0.78 & 0.79 & 0.83 & 0.78 & 0.81 \\
A5/0.5/3b & 0.89 & 0.82 & 0.88 & 0.85 & 0.79 & 0.81 & 0.80 \\
A5/1.0/3a & 0.96 & 1.21 & 1.49 & 1.35 & 1.40 & 1.60 & 1.50 \\
A5/1.0/3b & 1.88 & 2.08 & 1.71 & 1.89 & 1.97 & 1.79 & 1.88 \\
A5/1.0/3c & 1.23 & 1.43 & 1.65 & 1.54 & 1.47 & 1.52 & 1.49 \\
A5/3.0/3a & 3.40 & 3.14 & 3.43 & 3.29 & 3.73 & 3.97 & 3.85 \\
A5/3.0/3b & 3.33 & 3.31 & 3.70 & 3.51 & 2.99 & 4.08 & 3.54 \\
\hline
\end{tabular}

If we compared the three average values (w.pc, ph.av and de.av) for specimens $\mathrm{A} 5 / 0.5 / 3 \mathrm{~b}$ and $\mathrm{A} 5 / 1.0 / 3 \mathrm{~b}$, we conclude that a wrong procedure was applied for fixing $w_{o}$. This reveals that the real value of $w_{o}$ for both cases was higher than the expected value. We can also see that the general trend was that higher values were obtained by photogrammetry and DEMEC than those values obtained with the LVDTs. The reason for this is may be the handling process between both phases as the photogrammetry and DEMEC data were acquired once the specimen was placed in a vertical position. Another general trend found was that the highest crack width values were obtained for the Back face, as reported for both techniques. This confirms the hypothesis of no full contact between the specimen and the restraint frame at the beginning of the push-off test.

As the photogrammetry technique proved time-consumed to acquire and process the data, a comparison with the DEMEC technique was made. To do this, the average photogrammetry value (ph.av) vs. the average DEMEC value (de.av) were plotted (see Fig. 3.38). A linear relationship with $R^{2}=0.98$ was found, which indicates a good correlation between both techniques. More tests must be done to obtained enough reliability. 


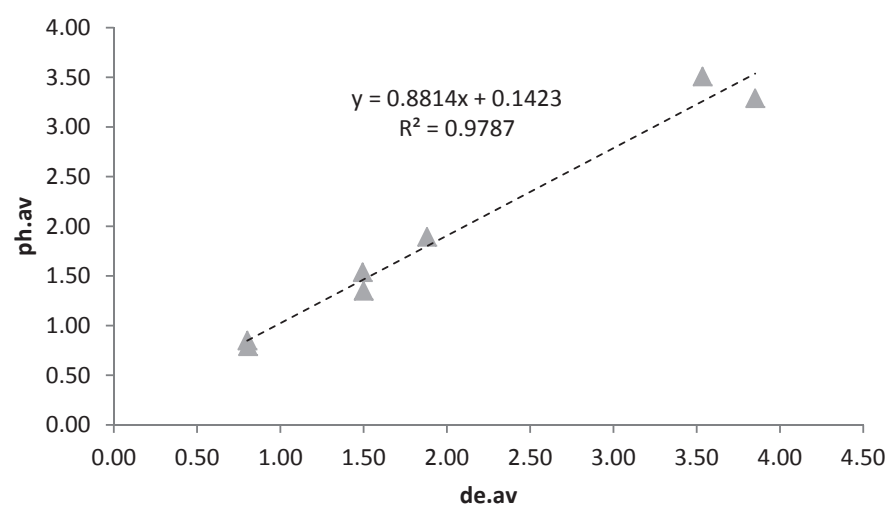

Fig. 3.38. Comparison between the photogrammetry and DEMEC measurements.

\subsubsection{Final considerations}

After analyzing the experimental results, the following conclusions were drawn:

- This new frame design offers greater stiffness, which provides a better control condition to do the push-off test. The implementation of three gauges on each bar also provides more information to measure the normal stress that acts on the crack plane.

- A wrong procedure for fixing $w_{o}$ was detected on two specimens. This issue was confirmed by several techniques like photogrammetry and DEMEC and also indirectly by tensile strain on the external restraint bars.

- A non uniform contact between the specimen and the restraint frame came about at the beginning of the push-off test. This was confirmed by the differences in the precrack width between both specimen faces (Front and Back). These differences can be attributed to the handling process to move the specimen between both the precracking and push-off phases. One proposed solution is to pre-stresses the specimen, precrack it, put in a vertical position and finally set $w_{o}$.

- Two discrete techniques were applied to measure the crack width evolution between both phases. Both techniques gave satisfactory results, but needed much more time to acquire and process the experimental data. So a comparison was made between the average values, which showed a good correlation. More tests must be done to obtained enough reliability. 


\subsection{Final test methodology}

This section focuses on the final design and methodology procedures proposed in the present $\mathrm{PhD}$ thesis. This new design includes modifications to the testing frame, the sliding baseplate for both phases and the restraint frame.For other authors to reproduce this methodology, the dimensions of testing frame, the sliding base plate and restraint frame are provided.

The procedure of the discrete measurements techniques (photogrametry and DEMEC) is presented and then the instrumentation of the external restraint bars by means of strain gauges is shown. Finally, the instrumentation and testing procedure of both phases (precracking and push-off) are introduced.

\subsubsection{Testing frame}

According to 3.3.8, this "new design" begins with the testing frame. Both phases are done within the same testing frame. For this purpose, the precracking (PC) and push-off (PO) hydraulic jacks are fixed to the lintel, as shown in Fig. 3.39. Base on the testing frame, both sliding bases are fixed as shown in Fig. 3.40a. For these sliding bases, the precracking baseplate and the push-off base are positioned (see Fig. 3.40b).

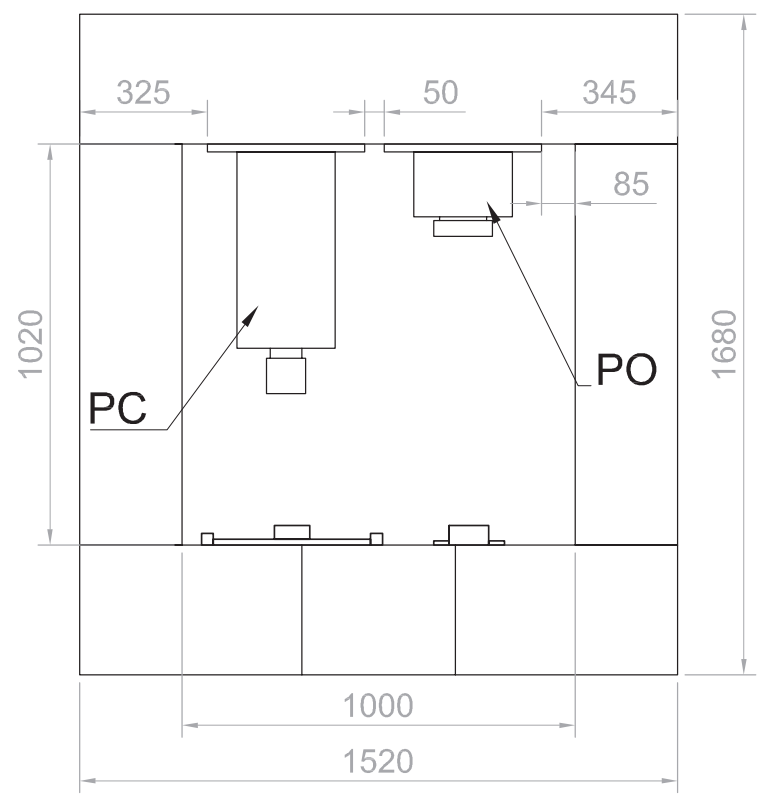

Fig. 3.39. Testing frame modification (dimensions in $\mathrm{mm}$ ). 


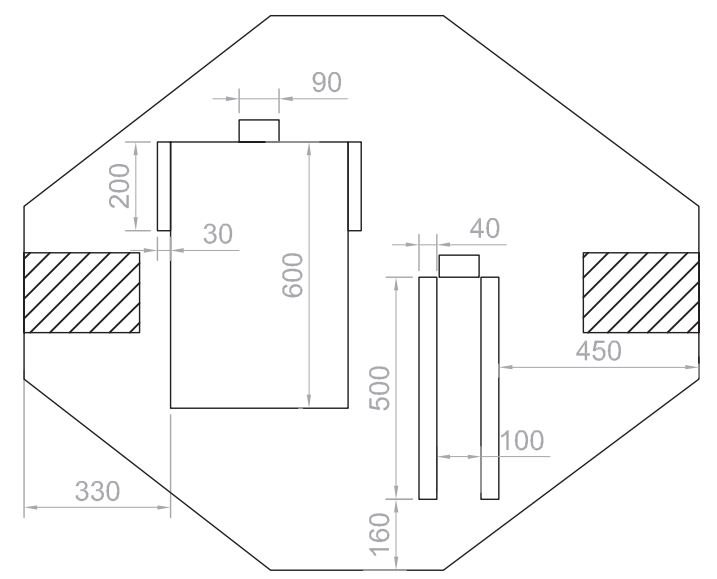

(a) Relative position and dimensions of sliding guides (in $\mathrm{mm}$ )

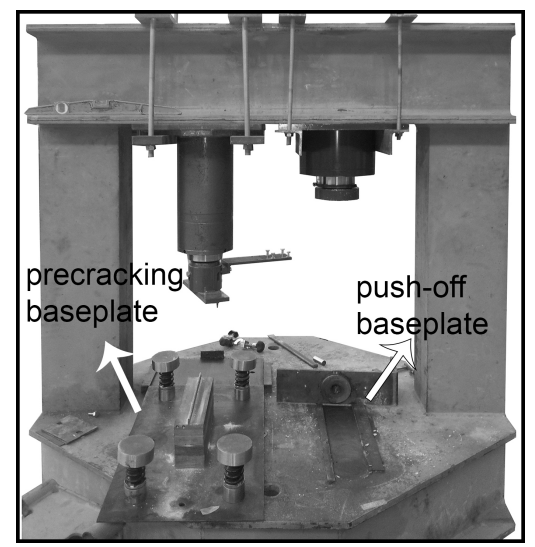

(b) Photo of the new testing frame

Fig. 3.40. New testing frame.

\subsubsection{Sliding baseplates}

\section{Precracking baseplate}

As mentioned in 3.3.8, a sliding precracking baseplate is built based on the precracking baseplate (see section 3.3.3). This sliding baseplate allows to place the specimen as far as possible from the hydraulic jack. This extra space helps place the specimen on the lower knife.

Then, the specimen with the sliding baseplate are pushed to the final position. This final position is clearly defined, and with the helps of the sliding guides and stops (see Fig. 3.40a), the same position is always occupies in all the tests. In order to reduce the force needed to move the group (specimen and sliding baseplate), 
the bottom of the sliding baseplate is painted with grease. A thin film of grease reduces the fiction between the baseplate and the testing frame base.

Fig. 3.41 shows the final sliding baseplate design. In this figure, all the dimensions are expressed in mm. It must be pointed out that the stiffness of the springs needs to be re-adjusted because the increase in the weight of the new restraint frame must be taken into account.
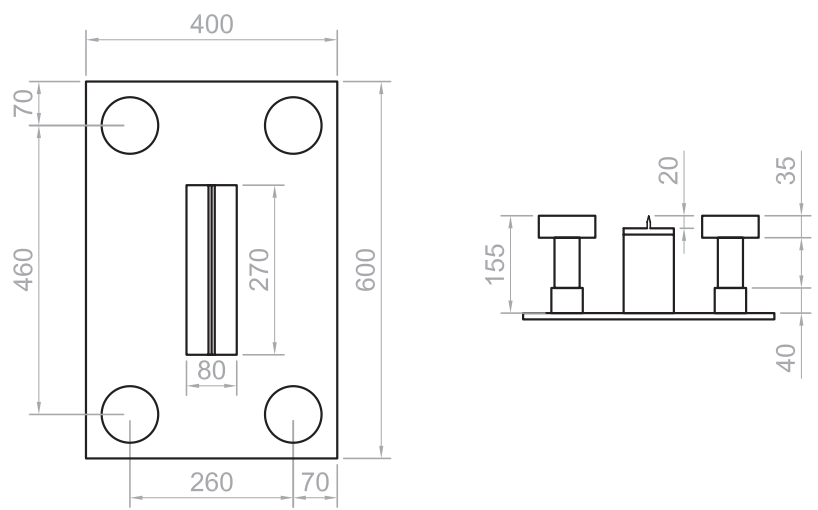

Fig. 3.41. Precracking sliding baseplate (dimensions in $\mathrm{mm}$ ).

\section{Push-off baseplate}

For the push-off phase, a sliding baseplate was designed. The sliding baseplate allowed to place the specimen as far away the hydraulic jack as possible. The aim of this sliding baseplate is to guarantee centering the specimen in relation to the hydraulic jack. A pair of guides and a final stop (see Fig. 3.40a) guarantee this position. With this sliding baseplate, the specimen is placed in a very short time.

The sliding baseplate is fixed to the Bottom face of the specimen, as shown in Fig. 3.42. This procedure is done when the specimen is placed in a horizontal position before carrying out the precracking phase.

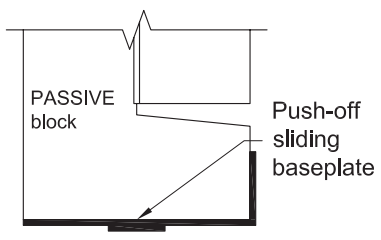

Fig. 3.42. Positioning the push-off sliding baseplate.

Fig 3.43 shows the final design of this sliding basplate. It is formed by an Lshape steel body up on which a washer is welded (see Fig. 3.43). The diameter of washer is $100 \mathrm{~mm}$ and it is $10 \mathrm{~mm}$ thick. The washer is arranged in the same way through which compression loading $(\mathrm{P})$ is applied. This condition guarantees that the supporting conditions are the same. 

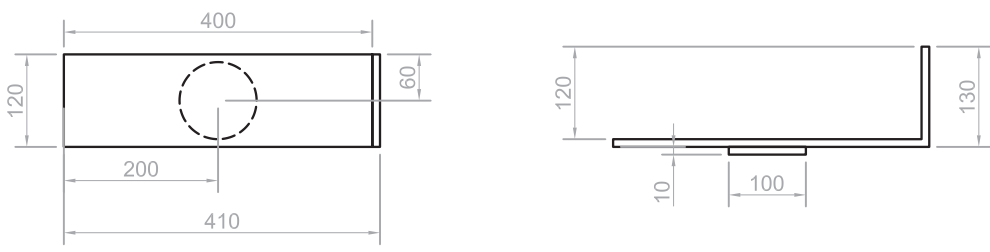

Fig. 3.43. Push-off sliding baseplate (dimensions in $\mathrm{mm}$ ).

\subsubsection{New restraint frame}

This section introduces the new restraint frame and the following structure is used. First the dimensions of all the restraint frame parts are provided. After giving a detailed explanation of the restraint frame assembly, followed by the criteria used to pre-stressed the shear plane, finally the methodology used for setting $w_{o}$ is shows.

\section{Dimensions and geometries}

Since the aim was improved the global stiffness of the restraint frame, bigger component parts were used. Thus both plates and the four external restraint bars were built after increasing their geometrical dimensions. The ball bearing was left out of this increasing process.

Plate A was $300 \mathrm{~mm}$ wide, $390 \mathrm{~mm}$ high and $30 \mathrm{~mm}$ thick. Plate A had fourteen holes, andthe four biggest holes (a) were used to fix the external restraint bars; then eight slotted holes, $20 \mathrm{~mm}$ long (b), are used to cross the connectors link of the specimen and the ball bearing. Two last holes (c) were used to fix the cover of the ball bearing to Plate A. A schematic view of Plate A is shown in Fig. 3.44a.

Plate B had the same dimensions as Plate A and eight holes: four for the external restraint bars (a), and the four to fix it (d) with the PASSIVE block of the specimen (see Fig. 3.44b). The diameter of the external restraint bars was $40 \mathrm{~mm}$, it was $576 \mathrm{~mm}$ long, and the end of Plate A had a $1 \mathrm{~mm}$ thread (see Fig. 3.44c). 


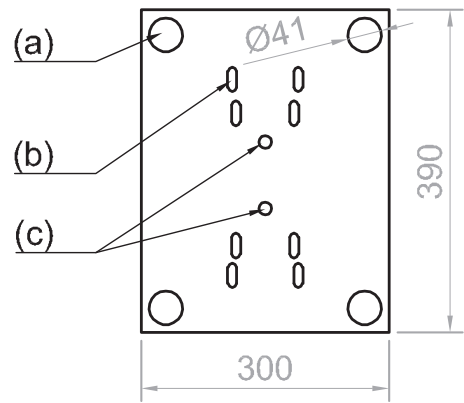

(a) Plate A

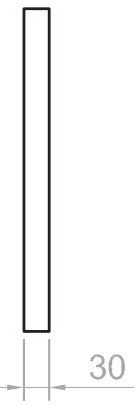

30

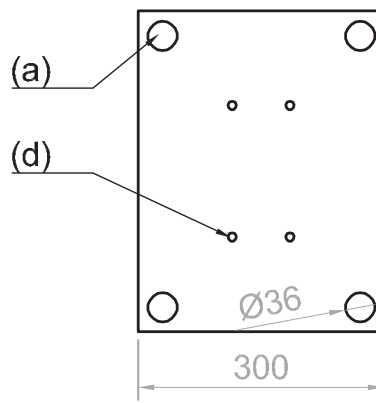

(b) Plate B

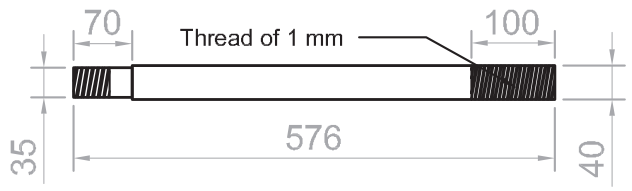

(c) External restraint bar

Fig. 3.44. New design of the restraint frame parts (dimensions in $\mathrm{mm}$ ).

To improve the reliability when setting $w_{o}$, the thread of the external restraint bars was changed. Moreover, a special break was implemented on the four external nuts. This new tread allowed the nut to move $1 \mathrm{~mm}$ in the direction of the edge of the bar when a turn was completed. Thus the sensitivity of this mechanism increased. The special break applied to the external nuts helped fix the nut in a specific position. Fig. 3.45 shows one external nut where the special beak is seen.

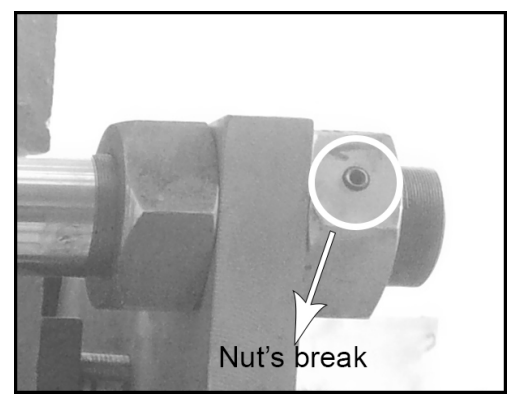

Fig. 3.45. Picture of the special break on the external nut.

\section{Restraint frame assembly}

Before the frame assembly is done, the specimen should set in a vertical position with the ACTIVE block on top. Then the following procedure is carried out:

1. On the Right face of the specimen, the ball bearing is fixed.

2. On the Left face of the specimen, the PASSIVE block and Plate B are fixed. 
3. The four external restraint bars are passed through Plate B and are fixed to it. It must be pointed out that one strain gauge must be "looking" at the specimen (see Fig. 3.47). In the figure the name and position of the bars are shown.

4. Plate $\mathrm{A}$ is placed in a position to pass through the four external restraint bars and the connector links.

The aforementioned procedure is shown in Fig. 3.46

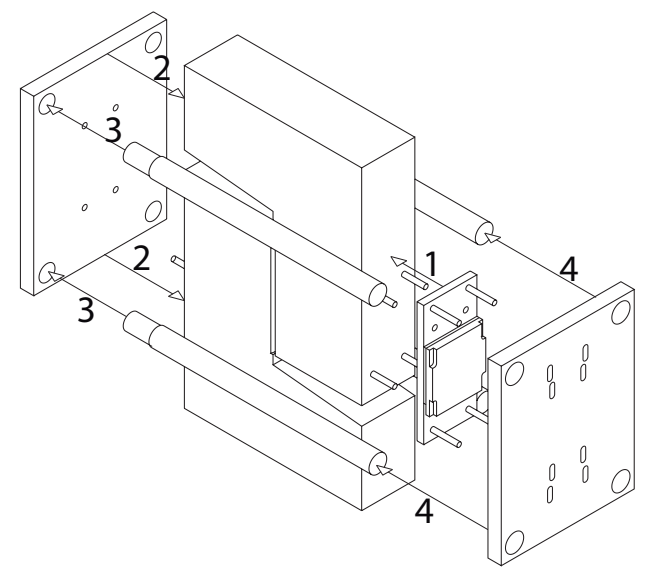

Fig. 3.46. The final restraint frame assembly procedure.

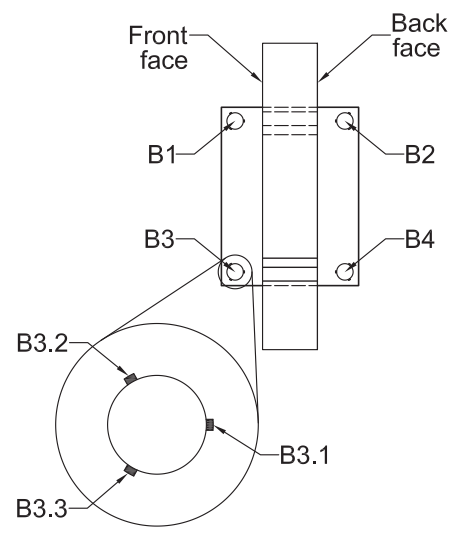

Fig. 3.47. Position of the restraint bars and strain gauges..

\section{Prestressed criteria}

After placing the restraint frame on the specimen, and Plate A comes into contact with the cover of the ball bearing, the prestressed specimen is made according to the following procedure: 
1. The eight nuts of the restraint bars on the end of Plate A are tightened. Thus the restraint bars fixes and avoids them turning around the edge.

2. The four nuts of the restraint bars on the end of Plate B are strongly tightened.

3. The eight nuts of the restraint bars on the end of Plate A are loosened. A certain distance (pair of millimeters) is left between the nuts and Plate A.

4. The three strain gauges are connected and begin to take reading.

5. The four external nuts are tightened to form a 1-4 and 2-3 cross (see Fig. 3.48). This process finishes when the average strain of each bar equals 0.015 mirostrains $\left(\epsilon_{b}=0.015 \mu \epsilon\right)$.

6. Disconnect the twelve strain gauges.

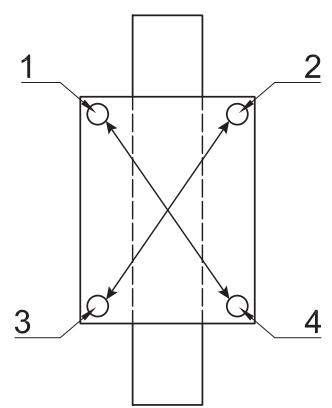

Fig. 3.48. Schematic representation of the tightened nuts.

\section{Setting of $w_{o}$}

This procedure is applied to specimens which allowed an initial crack width other than zero $\left(w_{o} \neq 0\right)$. After precracking was done, the specimen had to be placed in a position to carry out the push-off phase. Then a fixed mark was made on the external nuts and Plate A.

Based on these marks, the distance for the allowed initial crack with the turns of the nuts was obtained. For instance, $1 \mathrm{~mm}$ was applied for $w_{o}$. Therefore a completed turn was required to reach this value. When the fixed marks on Plate A and the nut were aligned, the special break of the nut was used. This break avoided the nut from moving, and it was possible to do the aforementioned procedure with other nuts. The condition of the fixed marks aligned on Plate A and one nut is shown in Fig. 3.49. 


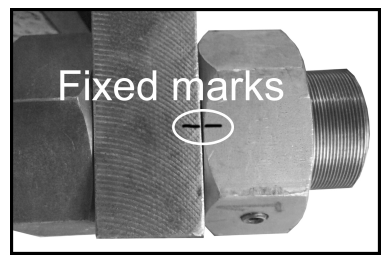

Fig. 3.49. Fixed marks on Plate A and external nut.

\subsubsection{Crack width photogrametry (optional)}

A photography series on five target points along each notch was taken. In each photo, the bottom of the notch was taken (see Fig. 3.50) and its distance was measured. All the photos were taken by an electronic microscope with a field of view of $10 \mathrm{~mm} \times 10 \mathrm{~mm}$.

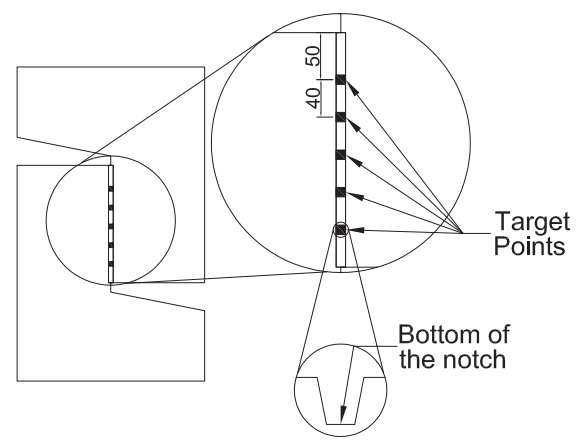

Fig. 3.50. Photography target points (dimensions in $\mathrm{mm}$ ).

The procedure consisted in taking from each point one photo before each test, which means before and after precracking, and also after push-off. The crack width in each stage was obtained by subtracting the previous value from the value of the bottom width. As the reliability of this technique was unknown, the bottom width was measured at three parts on each photo. An example procedure is shown in Fig. 3.51.

\subsubsection{DEMEC measurements}

Relative crack width and slip were derived at various points on both faces along the crack plane. This is done by means of increasing the length of three triangles.

Five DEMEC metallic discs were pasted on the vertex of the triangles as shown in Fig. 3.52. Three equilateral triangles were imaginarily defined on the specimen surface. Knowing the side lengths of each triangle, it is possible to calculate the interior angles $(\alpha, \beta$ and $\gamma)$ by applying the cosine theorem. Then the coordinates of each DEMEC disc can be assessed. Crack width (x-value) and slip (y-value) 


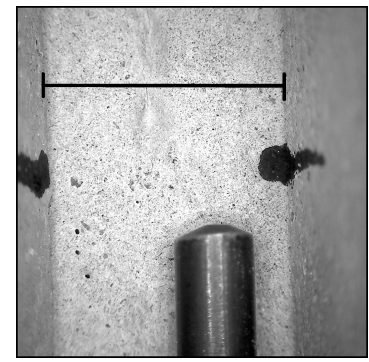

(a) Before precracking phase

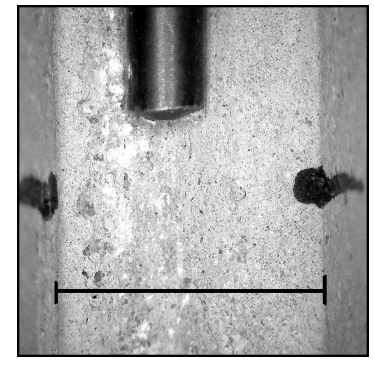

(b) After precracking phase

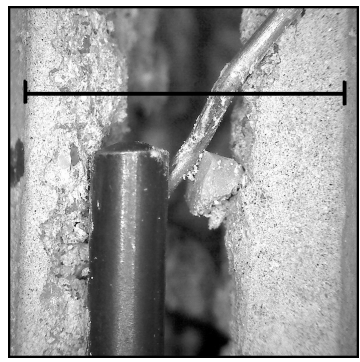

(c) Before push-off phase

Fig. 3.51. Photogrammetry sequence.

were obtained by subtracting the value of the previous stage from the point's position (f.i. 2) in one stage (see Fig. 3.53). As an additional control, sides 1-3, 2-4 and 3-5 were non-deformable, so the values among the three stages should be similar.

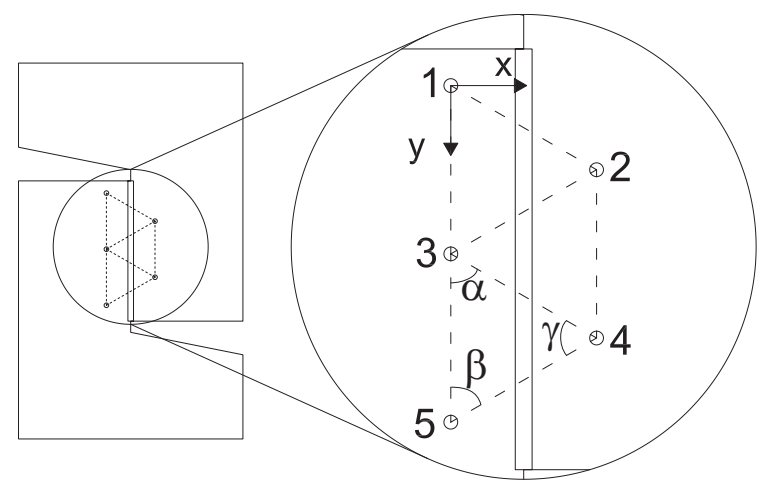

Fig. 3.52. DEMEC points on the specimen.

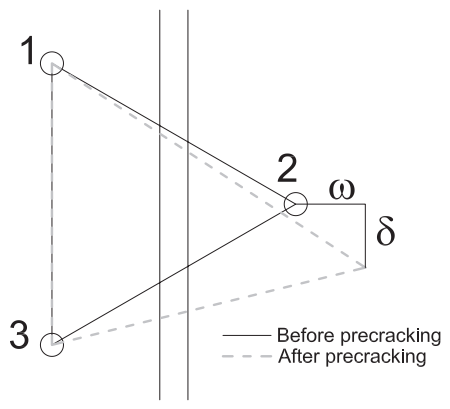

Fig. 3.53. Crack width and slip definition. 


\subsubsection{Strain gauges on the external restraint bars}

Due to the difficulties reported in the previous restraint frame, and after predicting the strains by the FE model, a decision was made to paste three strain gauges on the external restraint bars. As in the previous bars, these strain gauges were pasted on the middle section in front of the notch. Strain gauges were separated $120^{\circ}$ from each other (see Fig. 3.54).

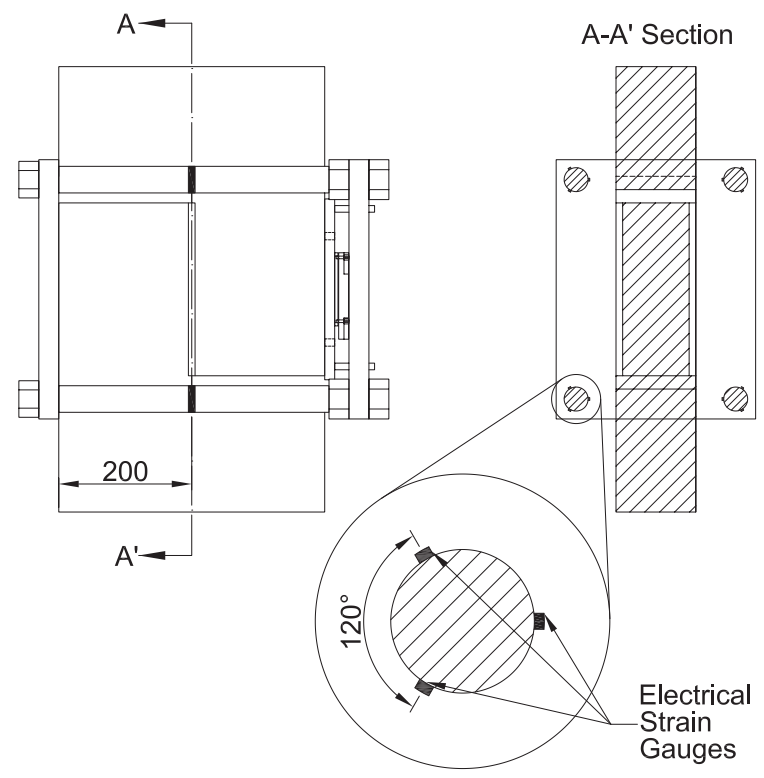

Fig. 3.54. Strain gauge instrumentation.

Fig. 3.54 shows that one of the three strain gauges was in front of the specimen surface. Due to the downward movements of Plate A, a flexural moment occurred on the bars. Therefore, the strain gauges setting was chosen based on the neutral axis position. Since the strain gauge position in front of the specimen and the neutral axis was on the same plane, the reading of this strain gauge were mainly due to tensile stress. In any case, the average value of the three strain gauges was used as the experimental strain value of the bar. The tensile force $\left(F_{b}\right)$ acting on each bar was deviated according to eq. 3.2. The strain value used in eq. 3.2 was the average value of the three strain gauges deviated according to eq. 3.3. Finally, the experimental value of the normal stress acting on the shear plane was obtained by eq. 3.4.

$$
F_{b, i}=E_{s} \cdot \epsilon_{i}
$$

where $E_{s}$ is the elasticity modulus of the steel, $\epsilon$ is the average strain value of the bar, and $i$ is the number of the bar (1,2, 3 and 4$)$.

$$
\epsilon_{i}=\frac{\epsilon_{i .1}+\epsilon_{i .2}+\epsilon_{i .3}}{3}
$$




$$
\sigma=\frac{\sum_{i=1}^{4} F_{b, i}}{h_{s p} \cdot b_{s p}}
$$

where $h_{s p}$ is the shear plane height (in $\mathrm{mm}$ ) and $b_{s p}$ is the shear plane width (in $\mathrm{mm})$.

\subsubsection{Precracking procedure and instrumentation}

All the specimens were intentionally cracked along the shear plane before carrying out the push-off phase. To this end the specimen was placed horizontally on the precracking sliding baseplate, and pushed to its final position. Then the upper steel knife along the notches was provided. After load was applied step-wisely by a hydraulic jack, of $500 \mathrm{kN}$ at a rate of $200 \mathrm{~N} / \mathrm{seg}$. The test finished when the specimen cracked.

The instrumentation for this phase was carried out using six LVDTs to measure vertical displacements (points 1 to 6 ) and two LVDTs to measure crack width (w1 and w2), as shown in (Fig. 3.55). This configuration allowed three target points on each specimen half to be obtained, and defines the displacements of the plane of the specimen surface.

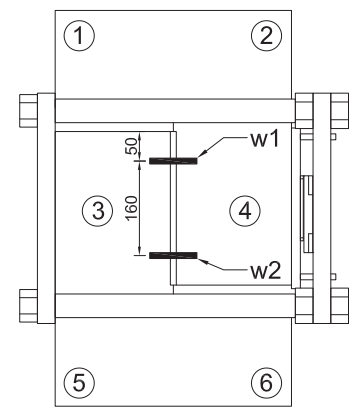

(a) Schematic disposition of the LVDT

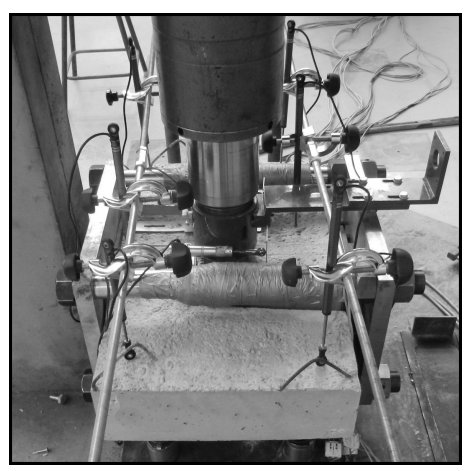

(b) Disposition of the LVDT during real test

Fig. 3.55. Precracking phase setup.

\subsubsection{Push-off procedure and instrumentation}

Having precracked the specimen along the shear plane, it was vertically placed. The specimen was correctly centered under the hydraulic jack by means of the sliding baseplate. in this phase, load was applied with another servo-hydraulic jack, of $500 \mathrm{kN}$, at a constant piston displacement rate of $0.015 \mathrm{~mm} / \mathrm{s}$. Load is measured by a HBM ${ }^{\circledR}$ load cell of $500 \mathrm{kN}$. The test finished when the average slip was greater than $10 \mathrm{~mm}$. 
In the push-off phase, both crack width and slip along the shear plane were measured. To measure crack width, two horizontal LVDTs were used, and one in a vertical position for measuring slip (Fig. 3.56). This arrangement was repeated on both specimen faces. Therefore four horizontal LVDTs (w1, w2, w3 and w4) and two vertical LVDTs (Vc and Vm) were used. Four LVDTs were also placed on both plates to record the vertical displacements of the restraint frame.

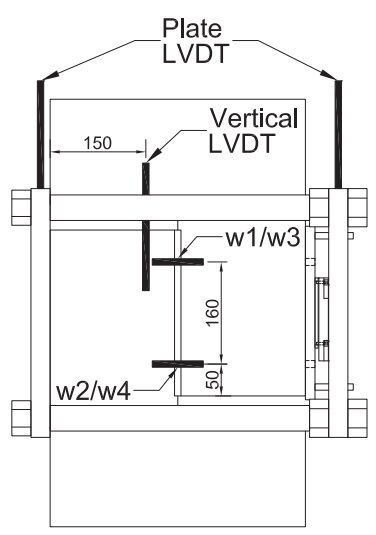

(a) Disposition of the LVDT on the specimen

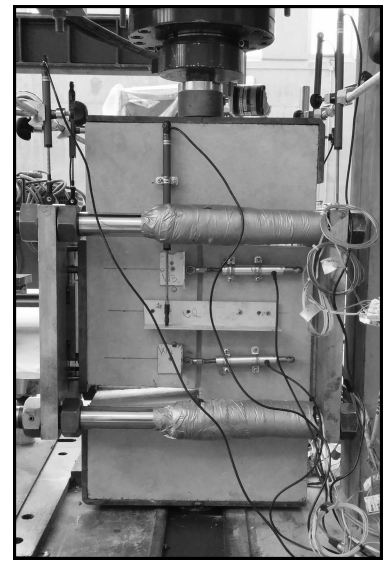

(b) Disposition of the LVDT during real phase.

Fig. 3.56. Push-off phase instrumentation

\subsubsection{Experimental results obtained}

The final test methodology presented in section 3.5, helped us to obtain experimental results with a high level of confidence. This is shown in Fig. 3.57, where the experimental results of $\mathrm{C} 7-0-2$ are presented by way of example. The average behavior is shown using the "Material id code" as the name according to Table 4.4. This average behavior is shown by a thicker black line for all the figures.

This figure depicts four subfigures. The shear stress vs. slip relationship is shown in the left upper corner (see Fig. 3.57a). The shear stress vs. crack width relationship is presented in the right upper corner (see Fig. 3.57b), and the crack opening path is shown in the left lower corner (see Fig. 3.57c). Finally, the normal stress vs. crack width relationship is presented in the right lower corner (see Fig. 3.57d). 


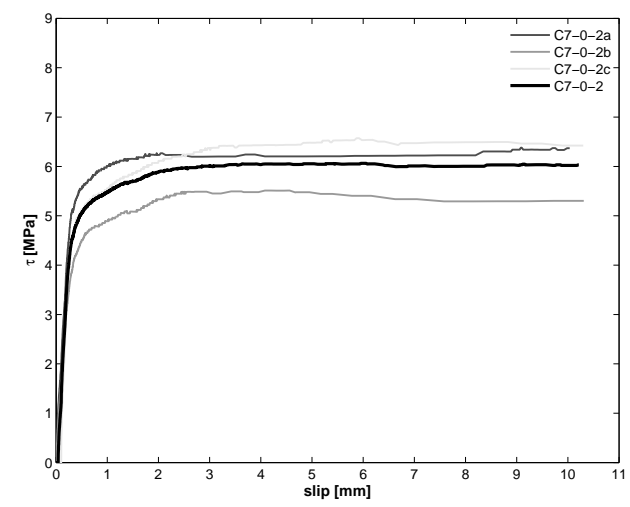

(a) Shear stress vs. slip relationship

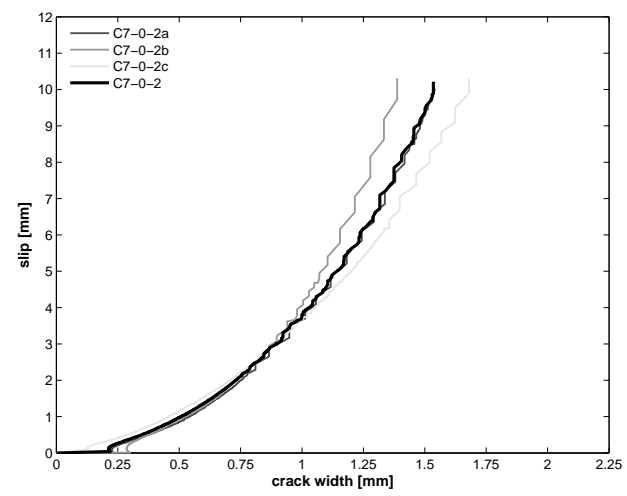

(c) Crack opening path relationship

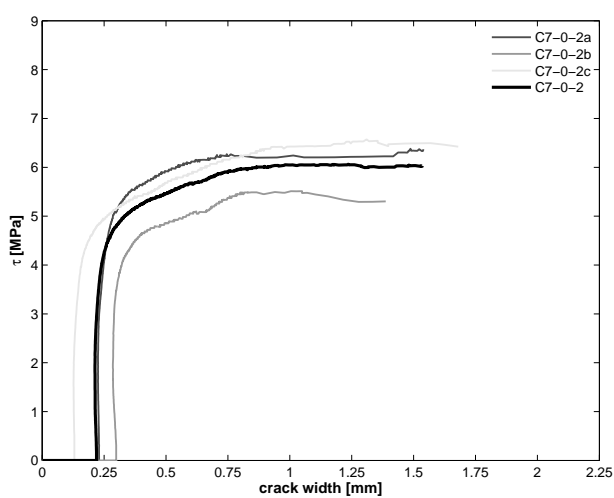

(b) Shear stress vs. crack width relationship

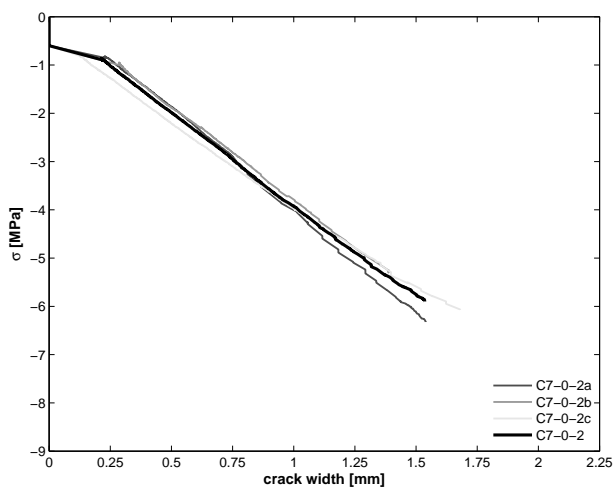

(d) Normal stress vs crack width relationship

Fig. 3.57. Examples of curves of the experimental results obtained with the final test methodology $(\mathrm{C} 7-0-2)$. 


\section{Chapter 4}

\section{Experimental program}

\subsection{Introduction}

In this chapter the experimental program carried out in this doctoral thesis is presented. The experimental program focused more on how to validate the final methodology presented in section 3.5, and how to detect different influences as a result of concrete properties (maximum aggregate size, type of fiber, transverse reinforcement ratio, among others). Thus the experimental program was designed to achieve the following specific goals:

- To analyze the viability of the testing procedure presented in section 3.5.

- To verify the sensitivity of the methodology to the parameters that have an influence on the shear transfer mechanisms.

- To confirm test repeatability.

- To detect, from a qualitative point of view, the parameters that can affect the shear transfer mechanisms.

It must be pointed out that the following goals go beyond the aims of the present experimental program: 
- To do an in-depth analysis n order to quantify the different effects on the shear transfer mechanisms.

- To relate the residual flexural strength with the effect of shear transfer mechanisms.

- To analyze the expressions proposed in the different codes.

\subsection{Experimental outline}

\subsubsection{Study parameters}

When assessing the shear transfer mechanism of fiber reinforced concrete (FRC), the following parameters were chosen: concrete strength, maximum aggregate size, fiber amount, fiber length, fiber aspect ratio, and fiber tensile strength. Table 4.1, lists their significance in relation to the effectiveness of fiber reinforcement and the values being investigated in this research.

Table 4.1. The significance of the study parameters and their research range.

\begin{tabular}{|c|c|c|}
\hline Parameter & Significance & Value \\
\hline $\begin{array}{l}\text { Concrete } \\
\text { strength, } f_{c}\end{array}$ & $\begin{array}{l}\text { Influences tensile strength of concrete matrix and bond } \\
\text { characteristics between fiber and concrete }\end{array}$ & $\begin{array}{l}40 \mathrm{MPa} \\
50 \mathrm{MPa} \\
60 \mathrm{MPa}\end{array}$ \\
\hline $\begin{array}{l}\text { Maximum } \\
\text { aggregate size, } \\
\text { ag }\end{array}$ & $\begin{array}{l}\text { Influences shear behavior. Increase in maximum size } \\
\text { leads to increased shear strength, but reduces the } \\
\text { uniform fiber distribution }\end{array}$ & $\begin{array}{l}12 \mathrm{~mm} \\
20 \mathrm{~mm}\end{array}$ \\
\hline $\begin{array}{l}\text { Fiber } \\
\text { content, } V_{f}\end{array}$ & $\begin{array}{l}\text { Indicates the additional amount of fiber. Increase in } \\
\text { fiber content leads to enhanced fiber reinforcing } \\
\text { effectiveness, but also to reduced concrete workability. }\end{array}$ & $\begin{array}{l}40 \mathrm{~kg} / \mathrm{m}^{3} \\
50 \mathrm{~kg} / \mathrm{m}^{3} \\
70 \mathrm{~kg} / \mathrm{m}^{3}\end{array}$ \\
\hline $\begin{array}{l}\text { Fiber aspect } \\
\text { ratio, } l_{f} / d_{f}\end{array}$ & $\begin{array}{l}\text { Indicates fiber stiffness. A higher fiber aspect ratio leads } \\
\text { to better fiber reinforcing effectiveness, but also to } \\
\text { reduced concrete workability. }\end{array}$ & $\begin{array}{l}65 \\
80\end{array}$ \\
\hline $\begin{array}{l}\text { Fiber } \\
\text { length, } l_{f}\end{array}$ & $\begin{array}{l}\text { Increase in fiber length leads to enhanced fiber efficiency } \\
\text { in bridging cracks, but also to reduced concrete } \\
\text { workability. }\end{array}$ & $\begin{array}{l}30 \mathrm{~mm} \\
35 \mathrm{~mm} \\
50 \mathrm{~mm}\end{array}$ \\
\hline $\begin{array}{l}\text { Fiber tensile } \\
\text { strength, } f_{u f}\end{array}$ & $\begin{array}{l}\text { Influences the fiber failure mode and bond } \\
\text { characteristics between fiber and concrete. }\end{array}$ & $\begin{array}{l}1100 \mathrm{MPa} \\
2300 \mathrm{MPa}\end{array}$ \\
\hline
\end{tabular}

The idea is to cover a wide range of possibilities in the SFRC field that are commonly used for structural design. It must be pointed out that, ultra high perfor- 
mance fiber reinforced concrete (UHPFRC) was not included in this experimental program.

The typical concrete strength used in industry was used in this research: 40, 50 and $60 \mathrm{MPa}$. Concrete exhibits a more brittle behavior when concrete compressive strength increases. Concrete compressive strength also influences concrete tensile strength. Increased concrete compressive strength generally results in higher concrete matrix tensile strength.

It was found that an increase in maximum aggregate size generally increased ultimate shear stress. I FRC, maximum aggregate size was limited by fiber length, and adopted a minimum reference value of $0.5 \times l_{f}$ (see Annex 14 of EHE-08 (2008)). This was to achieve uniform fiber distribution and to reduce the fiber tendency to ball or clump together, thus forming an aggregates trap. Therefore, two maximum aggregate sizes of $12 \mathrm{~mm}$ and $20 \mathrm{~mm}$ were chosen in this research.

Fiber content was chosen within the range of practical applications in real structures. A fiber volume fraction under $0.25 \%$ was found to not significantly improve brittle concrete matrix behavior, whereas a fiber volume fraction over $2 \%$ was deemed to reduce workability significantly. Special mixing processes and placing methods were necessary according to ACI-ASCE-ACI544 (2008). Therefore, a decision was made to use in this research fiber contents of $0.5 \%\left(40 \mathrm{~kg} / \mathrm{m}^{3}\right), 0.65 \%$ $\left(50 \mathrm{~kg} / \mathrm{m}^{3}\right)$ and $0.9 \%\left(70 \mathrm{~kg} / \mathrm{m}^{3}\right)$.

For the purpose of investigating the influence of fiber length, fiber aspect ratio, and fiber tensile strength, three Dramix ${ }^{\circledR}$ hooked-end steel fibers were used: RC$80 / 30 \mathrm{BP}, \mathrm{RC}-80 / 50 \mathrm{BN}$, and $\mathrm{RC} 65 / 35 \mathrm{BN}$. The properties of these fibers are given in section 4.3.3.

In order to make a comparison, traditional transverse reinforcement by stirrups (RC) was used.

\subsubsection{Experimental program}

The experimental program reported in this chapter was designed to study the influence of the parameters considered in 4.2.1. In addition to these parameters, the influence of allowed initial crack width $\left(w_{o}\right)$ was also investigated. The analysis of the interaction of these parameters is summarized in Table 4.2.

In the present study, concrete mix 2 was the referenced concrete. Indeed, 44 pushoff specimens were made using this mix. In order to analyze particular and local effects, some specimens were made with different concrete mixes. Therefore, 30 push-off specimens were allocated for SFRC, 12 push-off specimen were allocated for RC, while 14 push-off specimens were used as control specimens with no reinforcement $(\mathrm{PC})$. In all, 56 push-off specimens were tested in the present research.

Table 4.2 is a crosstab where reinforcement type is shown at the top. The identification code used to classify reinforcement consisted in two characters. By way of example, PC was used to refer to plain concrete. The code for steel fiber reinforced 
Table 4.2. Experimental program.

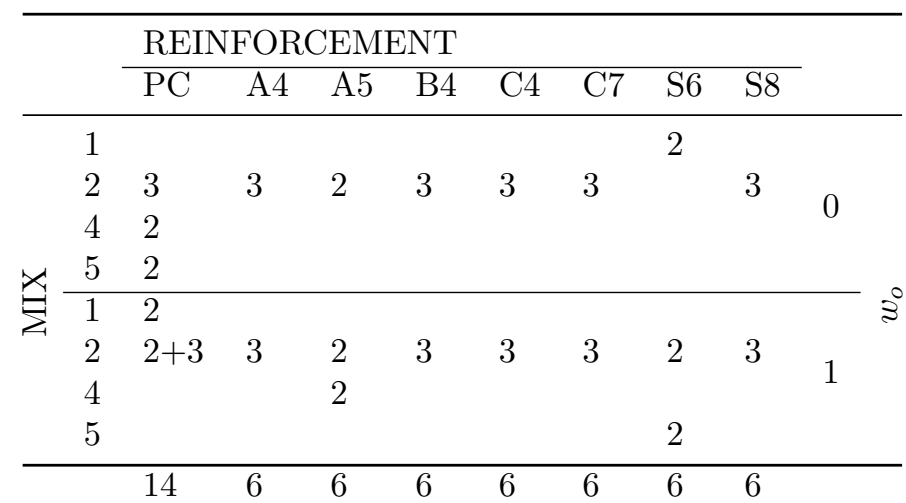

concrete (SFRC) is summarized in Table 4.3. For traditional reinforcement concrete, the following characters were used: "S" to identify the specimens reinforced with steel stirrups, and " 6 " or " 8 " to refer to the nominal diameter (in mm). On the left, the mix type identified with numbers from 1 to 5 is shown. Complete details of these type of mixes, the mix design and the procedure used are described in 4.3.1 and 4.3.2. On the right of the crosstab, we find the two allowed initial crack width values.

In this table, the quantity of specimen is read, f. i., three specimens reinforced with steel fiber RC-80/30 BP and $70 \mathrm{~kg} / \mathrm{m}^{3}$ (C7); made with concrete type 2 and under initially confined condition $\left(w_{o}=0\right)$. At the bottom of the crosstab, we can see the total specimens made with each reinforcement type. Thus, 14 specimens were done for plain concrete and there were six samples for the other specimens.

In Table 4.2, MIX 3 is not reported because that mix was used to validate the general behavior of the restraint frame experimentally (see 3.4.5).

Table 4.3. Identification code used for SFRC.

\begin{tabular}{lll}
\hline Code & Fiber & Amount \\
\hline A4 & RC-65/35 BN & 40 \\
A5 & RC-65/35 BN & 50 \\
B4 & RC-80/50 BN & 40 \\
C4 & RC-80/30 BP & 40 \\
C7 & RC-80/30 BP & 70 \\
\hline
\end{tabular}

\subsubsection{Test series}

In order to clarify further analyses, a complete list and the description of the test specimen are presented in Table 4.4. The identification, or "id code", for the specimens refers to three characteristic piece of data. The symbols representing 
these data are separated by dashes (f.i. F-W-N). The meaning of these symbols is provided below:

- F: represents reinforcing type; PC, A4, A5, B4, C4, C7, S6, and S8, according to the explanation provided in 4.2.2.

- W: represents allowed initial crack width; 0 or $1 \mathrm{~mm}$.

- $\mathrm{N}$ : represents concrete type, identified by the mix number; 1,2 , 4, and 5 .

PC was used to refer to plain concrete; A, B or C were applied to refer to fiber reinforced concrete (for more details see Table 4.3), while $\mathrm{S}$ refers to traditional reinforced concrete. $\mathrm{N}$ is composed of two subparts, the number refers to the mix type; the nominal strength and maximum aggregate size are found in Table 4.5, and the letter represents the repeatability (column Rep.).

Since the same specimens have two samples and the others have three samples, we used the mean behavior of these samples. For this reason, the "Material id code" name was chosen to refer to the average behavior. This is shown in the column (Material Id Code) in the table. It must be pointed out that for traditional reinforced concrete, the column amount refers to the reinforcement ratio $(\rho)$. 
Table 4.4. Test specimen details.

\begin{tabular}{|c|c|c|c|c|c|c|c|}
\hline \multirow{2}{*}{$\begin{array}{l}\text { Material } \\
\text { Id Code }\end{array}$} & \multicolumn{3}{|c|}{ Reinfocement } & \multirow{2}{*}{$\begin{array}{l}w_{o} \\
{[\mathrm{~mm}]}\end{array}$} & \multirow{2}{*}{ MIX } & \multirow{2}{*}{ Rep. } & \multirow{2}{*}{$\begin{array}{l}\text { Specimen } \\
\text { Id Code }\end{array}$} \\
\hline & code & type & amount & & & & \\
\hline \multirow{4}{*}{ A4-0-2 } & \multirow{4}{*}{$\mathrm{A} 4$} & \multirow{4}{*}{$65 / 35 \mathrm{BN}$} & \multirow{4}{*}{40} & \multirow{4}{*}{0} & \multirow{4}{*}{2} & $\mathrm{a}$ & A4-0-2a \\
\hline & & & & & & $\mathrm{b}$ & $\mathrm{A} 4-0-2 \mathrm{~b}$ \\
\hline & & & & & & c & $\mathrm{A} 4-0-2 \mathrm{c}$ \\
\hline & & & & & & $\mathrm{a}$ & $\mathrm{A} 4-1-2 \mathrm{a}$ \\
\hline \multirow[t]{2}{*}{ A4-1-2 } & \multirow[t]{2}{*}{$\mathrm{A} 4$} & \multirow[t]{2}{*}{$65 / 35 \mathrm{BN}$} & \multirow[t]{2}{*}{40} & 1 & 2 & $\mathrm{~b}$ & $\mathrm{~A} 4-1-2 \mathrm{~b}$ \\
\hline & & & & & & c & A4-1-2c \\
\hline $\mathrm{A} 5-0-2$ & $A 5$ & $65 / 35 \mathrm{BN}$ & 50 & 0 & 2 & $\mathrm{a}$ & A5-0-2a \\
\hline$A D-0-2$ & & & & & & $\mathrm{~b}$ & A5-0-2b \\
\hline A $5-1-2$ & A5 & $65 / 35 \mathrm{BN}$ & 50 & 1 & 2 & $\mathrm{a}$ & A5-1-2a \\
\hline & AJ & 0.J/SDNN & 30 & 1 & & $\mathrm{~b}$ & A5-1-2b \\
\hline A.5-1-4 & A5 & $65 / 35 \mathrm{BN}$ & 50 & 1 & 4 & $\mathrm{a}$ & A5-1-4a \\
\hline АЬ- $1-4$ & A5 & 65/35BN & 50 & 1 & 4 & $\mathrm{~b}$ & A5-1-4b \\
\hline & & & & & & $\mathrm{a}$ & B4-0-2a \\
\hline B4-0-2 & B4 & $80 / 50 \mathrm{BN}$ & 40 & 0 & 2 & $\mathrm{~b}$ & B4-0-2b \\
\hline & & & & & & c & B4-0-2c \\
\hline & & & & & & $\mathrm{a}$ & B4-1-2a \\
\hline B4-1-2 & B4 & $80 / 50 \mathrm{BN}$ & 40 & 1 & 2 & $\mathrm{~b}$ & B $4-1-2 b$ \\
\hline & & & & & & c & B4-1-2c \\
\hline & & & & & & $\mathrm{a}$ & C4-0-2a \\
\hline C4-0-2 & $\mathrm{C} 4$ & $80 / 30 B P$ & 40 & 0 & 2 & $\mathrm{~b}$ & C4-0-2b \\
\hline & & & & & & c & C4-0-2c \\
\hline & & & & & & $\mathrm{a}$ & C4-1-2a \\
\hline C4-1-2 & $\mathrm{C} 4$ & $80 / 30 \mathrm{BP}$ & 40 & 1 & 2 & $\mathrm{~b}$ & $\mathrm{C} 4-1-2 \mathrm{~b}$ \\
\hline & & & & & & c & $\mathrm{C} 4-1-2 \mathrm{c}$ \\
\hline & & & & & & $\mathrm{a}$ & C7-0-2a \\
\hline C7-0-2 & $\mathrm{C} 7$ & $80 / 30 B P$ & 70 & 0 & 2 & $\mathrm{~b}$ & $\mathrm{C} 7-0-2 \mathrm{~b}$ \\
\hline & & & & & & c & $\mathrm{C} 7-0-2 \mathrm{c}$ \\
\hline & & & & & & $\mathrm{a}$ & C7-1-2a \\
\hline C7-1-2 & $\mathrm{C} 7$ & $80 / 30 \mathrm{BP}$ & 70 & 1 & 2 & $\mathrm{~b}$ & $\mathrm{C} 7-1-2 \mathrm{~b}$ \\
\hline & & & & & & c & $\mathrm{C} 7-1-2 \mathrm{c}$ \\
\hline & & & & & & $\mathrm{a}$ & PC-0-2a \\
\hline PC-0-2 & $\mathrm{PC}$ & - & - & 0 & 2 & $\mathrm{~b}$ & PC-0-2b \\
\hline & & & & & & c & PC-0-2c \\
\hline $\mathrm{PC}-\mathrm{O}-4$ & $\mathrm{PC}$ & 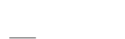 & - & 0 & 4 & $\mathrm{a}$ & PC-0-4a \\
\hline $\mathrm{PC}-\mathrm{U}-4$ & $\mathrm{PC}$ & - & - & 0 & 4 & $\mathrm{~b}$ & PC-0-4b \\
\hline PC-0-5 & $\mathrm{PC}$ & - & - & 0 & 5 & $\mathrm{a}$ & PC-0-5a \\
\hline & PU & - & - & 0 & 5 & $\mathrm{~b}$ & PC-0-5b \\
\hline PC-1-1 & $\mathrm{PC}$ & - & - & 1 & 1 & $\mathrm{a}$ & PC-1-1a \\
\hline & & & & & & $\mathrm{b}$ & PC-1-1b \\
\hline & & & & & & $\mathrm{a}$ & PC-1-2a \\
\hline & & & & & & $\mathrm{b}$ & PC-1-2b \\
\hline PC-1-2 & $\mathrm{PC}$ & - & - & 1 & 2 & c & PC-1-2c \\
\hline & & & & & & d & PC-1-2d \\
\hline & & & & & & e & PC-1-2e \\
\hline$S 6-0-1$ & $\mathrm{~S} 6$ & $4 \phi 6$ & 0.44 & 0 & 1 & $\mathrm{a}$ & S6-0-1a \\
\hline & & & & 0 & 1 & $\mathrm{~b}$ & S6-0-1b \\
\hline S6-1-2 & S6 & $4 \phi 6$ & 0.44 & 1 & 2 & a & S6-1-2a \\
\hline & & & & & & $\mathrm{b}$ & S6-1-2b \\
\hline S6-1-5 & S6 & $4 \phi 6$ & 0.44 & 1 & 5 & $\mathrm{a}$ & S6-1-5a \\
\hline & & & & & & $\mathrm{b}$ & S6-1-5b \\
\hline & & & & & & a & S8-0-2a \\
\hline S8-0-2 & S8 & $4 \phi 8$ & 0.79 & 0 & 2 & $\mathrm{~b}$ & $\mathrm{~S} 8-0-2 \mathrm{~b}$ \\
\hline & & & & & & c & $\mathrm{S} 8-0-2 \mathrm{c}$ \\
\hline & & & & & & $\mathrm{a}$ & S8-1-2a \\
\hline S8-1-2 & $\mathrm{S} 8$ & $4 \phi 8$ & 0.79 & 1 & 2 & $\mathrm{~b}$ & S8-1-2b \\
\hline & & & & & & c & S8-1-2c \\
\hline
\end{tabular}




\subsection{Material properties}

\subsubsection{Mix design}

Five types of concrete mixes were used throughout the research program. The main differences between these series were the water/cement $(\mathrm{w} / \mathrm{c})$ ratio, and the maximum aggregate size $\left(a_{g}\right)$. Two different High Range Water Reduction Admixtures (HRWRA) were used. Both HRWRA were provided by Sika ${ }^{\circledR}$. The mixes proportions used in the present research are shown in Table 4.5.

Table 4.5. The dry composition of concrete used in the research $\left(\mathrm{kg} / \mathrm{m}^{3}\right)$.

\begin{tabular}{|c|c|c|c|c|}
\hline \multirow{2}{*}{ Materials } & \multicolumn{4}{|l|}{ Mix } \\
\hline & 1 & 2 & 4 & 5 \\
\hline CEM II/B-V 42,5R & 300 & 300 & 350 & 350 \\
\hline Water (total) & 210 & 210 & 192.5 & 192.5 \\
\hline Gravel 12/20 & 321 & - & 334 & - \\
\hline Gravel 7/12 & 288 & 512 & 262 & 516 \\
\hline Gravel 4/7 & 249 & 322 & 283 & 332 \\
\hline River sand & 858 & 917 & 885 & 916 \\
\hline Filler & 170 & 140 & 120 & 110 \\
\hline Viscocrete 5720 & 4.50 & 4.00 & - & - \\
\hline Viscocrete $20 \mathrm{HE}$ & - & - & 4.55 & 4.55 \\
\hline Total $\left[\mathrm{kg} / \mathrm{m}^{3}\right]$ & 2400 & 2404 & 2431 & 2421 \\
\hline $\mathrm{w} / \mathrm{c}$ & 0.70 & 0.70 & 0.55 & 0.55 \\
\hline$\%$ HRWRA & 1.50 & 1.33 & 1.30 & 1.30 \\
\hline$f_{c}[\mathrm{MPa}]$ & 40 & 40 & 60 & 60 \\
\hline$a_{g}[\mathrm{~mm}]$ & 20 & 12 & 20 & 12 \\
\hline
\end{tabular}

Self-compacting concrete was used in the present research. This type of concrete is characterized by its ability to flow, and also for its high fines content which avoids the risk of segregation. Besides, this high fines content fills the voids between the aggregate particle and the fibers, also helping to achieve a uniform fiber distribution. With this, higher workability is achieved and no concrete adjustment has to be made.

The cementitious material used in this experimental program is obtained from Lafarge S.A.

\subsubsection{Concrete mix procedure}

Due to the limited capacity of the concrete mixer used, the concrete mixture for each test set was conducted in two batches. For the first batch, two push-off specimens and three concrete cylinders were cast. And for the second batch one 
push-off specimen and seven concrete cylinders were cast. The mixing of concrete followed a six-step procedure:

1. The aggregates and the half of the required water were mixed for fourteen minutes. Thus, all pores of the aggregates are filled by water.

2. The fine materials (filler and cement) were added and mixed for one minute.

3. The rest of the required water and the HRWRA were added to the mix. It must be pointed out that the mixer never stopped until the end of the process.

4. For those concretes where steel fibers were used, the fibers are sprinkled slowly added after four minutes of the HRWRA.

5. All materials were mixed for four more minutes, and then the mixer was stopped.

6. The mixer was then cleaned up and prepared for the next concrete batch mix.

The workability of concrete was assessed using the slump-flow test (see Fig. 4.1) according to UNE-EN UNE-EN12350-8 (2011), which was done after eight minutes of the HRWRA addition. Finally, the casting of the formworks began.

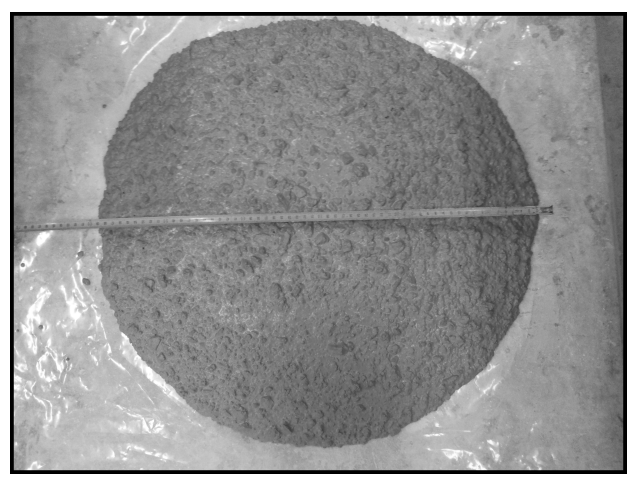

Fig. 4.1. Slump-flow test of PC-1-2a.

The same procedure was followed in both batches, first the slump-flow test was done, after the two (or one) specimen were cast, and finally the cylinder specimens were cast. After the concrete was placed, the surface of the concrete was finished using trowels. However, it was difficult to obtain a smooth surface, particularly for push-off specimens. The cylinders and push-off test specimens were demolded the next day, and cylinders specimens were placed in a couring chamber, in which the relative humidity is kept constant, until the test day. The push-off test specimens were placed at laboratory condition. 


\subsubsection{Steel fiber}

Three types of Dramix ${ }^{\circledR}$ hooked-end steel fibers were used in this research program: RC-80/50 BN, RC-80/30 BP, and RC-65/35 BN. These fibers were presented in Fig. 4.2. The differences in the properties of these steel fibers were in fiber length, fiber diameter, and fiber tensile strength. The material properties of steel fibers were listed in Table 4.6, which were obtained directly from Bekaert S. A.

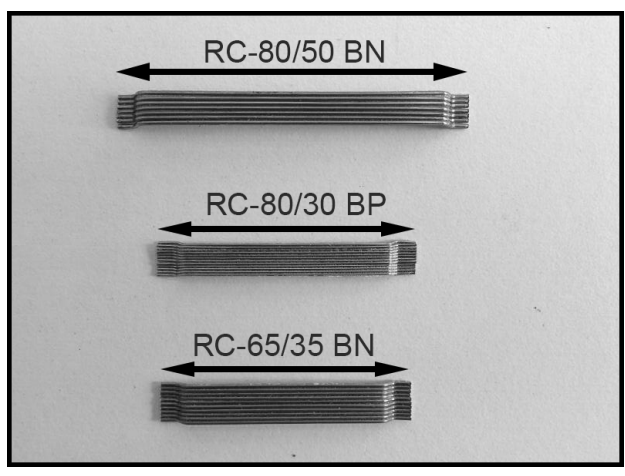

Fig. 4.2. Dramix $^{\circledR}$ hooked-end steel fibers.

Table 4.6. Mechanical properties of steel fibres.

\begin{tabular}{lllll}
\hline Designation & $\begin{array}{l}l_{f} \\
{[\mathrm{~mm}]}\end{array}$ & $\begin{array}{l}d_{f} \\
{[\mathrm{~mm}]}\end{array}$ & $\begin{array}{l}\text { Aspect ratio } \\
l_{f} / d_{f}\end{array}$ & $\begin{array}{l}f_{u f} \\
{[M P a}\end{array}$ \\
\hline $\mathrm{RC}-80 / 50 \mathrm{BN}$ & 50 & 0.62 & 81 & 1050 \\
$\mathrm{RC}-80 / 30 \mathrm{BP}$ & 30 & 0.38 & 79 & 2300 \\
$\mathrm{RC}-65 / 35 \mathrm{BN}$ & 35 & 0.55 & 64 & 1100 \\
\hline
\end{tabular}

\subsubsection{Reinforcing steel}

Two diameters of transverse reinforcement were used: $\phi 8 \mathrm{~mm}$ and $\phi 6 \mathrm{~mm}$. To characterize the reinforcing steel direct tensile test were carried out. The results are presented in Table 4.7. Due to the cold-forming of the deformed wires, no defined yield plateau is observed during the tests. The yield strength and the yield strain were determined by measuring the proportional limit of the material. 
Table 4.7. Mechanical properties of the reinforcement.

\begin{tabular}{llllllll}
\hline \multirow{2}{*}{ Wire } & $\begin{array}{l}d_{s} \\
{[\mathrm{~mm}]}\end{array}$ & $A_{s}$ & $E_{s}$ & $f_{y s}$ & $\epsilon_{y s}$ & $f_{u s}$ & $\epsilon_{u s}$ \\
& {$\left[\mathrm{~mm}^{2}\right]$} & {$[G p a]$} & {$[M P a]$} & {$\left[\mathrm{x} 10^{-3}\right]$} & {$[M P a]$} & {$[\%]$} \\
\hline 6 & 6.01 & 28.37 & 200.00 & 608.08 & 3.3 & 730.15 & 8.9 \\
8 & 8.03 & 50.60 & 187.77 & 532.03 & 3.4 & 641.79 & 7.3 \\
\hline
\end{tabular}

\subsection{Concrete characterization}

\subsubsection{Concrete compressive strength}

The purpose of the concrete compression cylinder test was to assess the compressive strength of the concrete. The test was conducted according to EN-UNE UNE-EN12390-3 (2009). All the cylinder test specimens were covered on their top by sulfur cap. This was to guarantee a uniform surface where load was applied. Fig. 4.3, shows a concrete cylinder test specimen between the plates of the testing machine. The test was conducted until the complete failure of the specimen, and the concrete compressive strength was obtained.

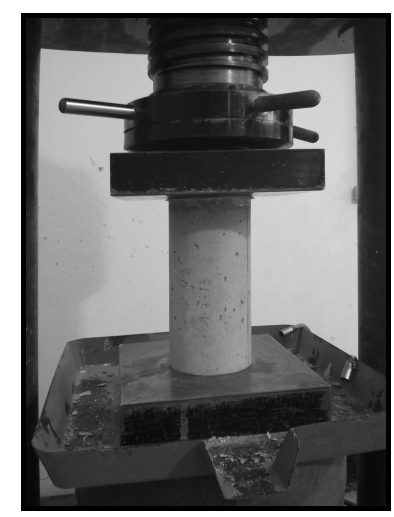

Fig. 4.3. Cylinder compresion test.

Table 4.8 shows the value of each cylinder test specimen and the average value $\left(f_{c m}\right)$. We can see that concrete compressive strength was not clearly increased by the addition of steel fibers (type or amount). For the same w/c ratio, the increase of the maximum aggregate size leads to lower concrete compressive strength.

A brittle failure was observed for the plain concrete when the compression test finishes. This was observed due to the rupture of the cylinder, as shows Fig. 4.4a. When steel fibers were used, more ductile failure was reported. Also, fibers sewed the cracks, so the pieces of the cylinder remains together as shown in Fig. 4.4b. 


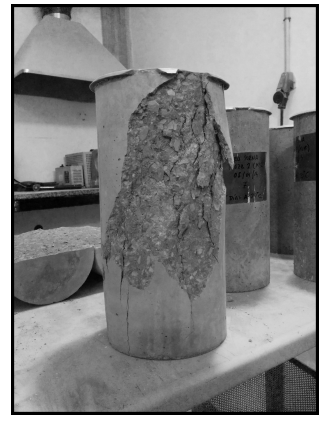

(a) Plain concrete

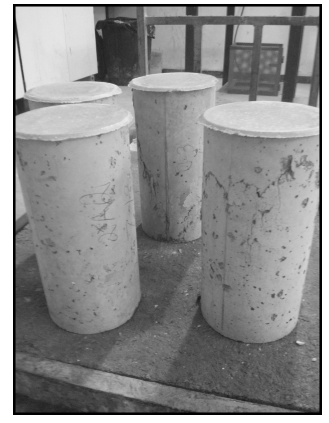

(b) SFRC, RC-65/35 BN

Fig. 4.4. Crack pattern of the cylinder compression test specimens.

\subsubsection{Concrete tensile strength}

Concrete splitting tests were carried out to evaluate concrete tensile strength. The test was curried out according to EN-UNE UNE-EN12390-6 (2010). Fig. 4.5 shows the specimen in the testing machine.

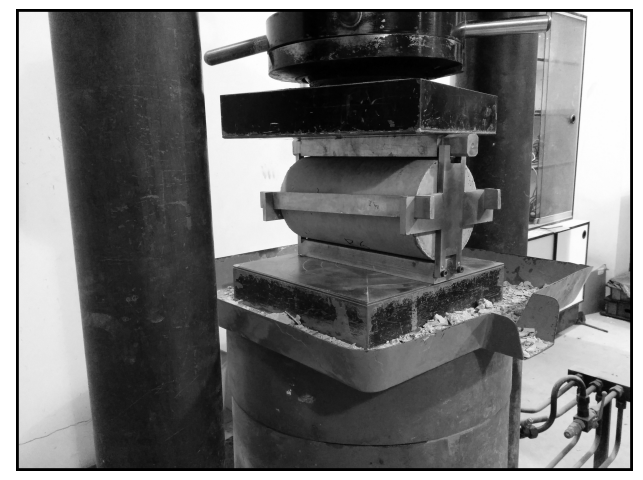

Fig. 4.5. Cylinder splitting test.

The results of cylinder splitting tests are summarized in Table 4.9. The values of the splitting tensile strength $\left(f_{c t}\right)$ were calculated using the equation outlined in EN-UNE UNE-EN12390-6 (2010) as follows:

$$
f_{c t}=\frac{2 \cdot P}{\pi \cdot L \cdot d}
$$

where $(P)$ is the maximum applied load (in $\mathrm{N}) ;(L)$ is the length of the cylinder (in $\mathrm{mm}$ ); and $(d)$ is the diameter of the cylinder (in $\mathrm{mm}$ ).

The results summarized in Table 4.9, indicate that the effect of fiber addition remains unclear on the splitting tensile strength of the concrete. The increased in fiber amount did not enhance the splitting strength. The increased of concrete compressive strength clearly enhanced the splitting tensile strength. The same 
Table 4.8. Concrete compression strength results.

\begin{tabular}{|c|c|c|c|c|c|}
\hline \multirow{2}{*}{ Material } & \multirow{2}{*}{ Mix } & \multicolumn{3}{|c|}{ Cylinder test specimen } & \multirow{2}{*}{$\begin{array}{l}f_{c m} \\
{[\mathrm{MPa}]}\end{array}$} \\
\hline & & 1 & 2 & 3 & \\
\hline \multirow{2}{*}{ A4- $0-2$} & \multirow{2}{*}{2} & 52.70 & 50.50 & 50.70 & \multirow{2}{*}{50.83} \\
\hline & & 49.90 & 50.20 & 51.00 & \\
\hline \multirow{2}{*}{ A4-1-2 } & \multirow{2}{*}{2} & 49.80 & 49.00 & 48.40 & \multirow{2}{*}{49.17} \\
\hline & & 48.80 & 49.20 & 49.80 & \\
\hline A5-0-2 & 2 & 47.10 & 48.30 & 49.90 & 48.43 \\
\hline A5-1-2 & 2 & 53.00 & 48.30 & 50.50 & 50.60 \\
\hline A5-1-4 & 4 & 56.31 & 55.81 & 56.71 & 56.28 \\
\hline \multirow{2}{*}{ B4-0-2 } & \multirow[t]{2}{*}{2} & 43.70 & 44.60 & 43.60 & \multirow{2}{*}{44.33} \\
\hline & & 43.70 & 47.10 & 43.30 & \\
\hline \multirow{2}{*}{ B4-1-2 } & \multirow{2}{*}{2} & 46.60 & 47.10 & 47.40 & \multirow{2}{*}{47.60} \\
\hline & & 48.00 & 49.40 & 47.10 & \\
\hline \multirow{2}{*}{ C4-0-2 } & \multirow[t]{2}{*}{2} & 51.56 & 50.37 & 51.65 & \multirow{2}{*}{52.39} \\
\hline & & 52.61 & 53.72 & 54.40 & \\
\hline \multirow{2}{*}{ C4-1-2 } & \multirow{2}{*}{2} & 50.70 & 51.60 & 51.00 & \multirow{2}{*}{51.15} \\
\hline & & 52.40 & 50.20 & 51.00 & \\
\hline \multirow[t]{2}{*}{ C7-0-2 } & \multirow[t]{2}{*}{2} & 51.56 & 51.90 & 49.51 & \multirow[t]{2}{*}{52.83} \\
\hline & & 54.92 & 55.12 & 53.99 & \\
\hline \multirow{2}{*}{ C7-1-2 } & \multirow{2}{*}{2} & 51.00 & 52.10 & 52.70 & \multirow{2}{*}{51.98} \\
\hline & & 51.00 & 52.70 & 52.40 & \\
\hline PC-0-2 & 2 & 48.79 & 48.32 & 47.66 & 48.80 \\
\hline & & 48.50 & 49.90 & 49.60 & \\
\hline PC-0-4 & 4 & 55.50 & 54.60 & 57.40 & 55.83 \\
\hline PC-0-5 & 5 & 62.70 & 57.40 & 63.20 & 61.10 \\
\hline PC-1-1 & 1 & 36.80 & 49.00 & 36.00 & 40.60 \\
\hline & 2 & 47.90 & 51.13 & 49.11 & 48.54 \\
\hline PC-1-2 & & 46.40 & 51.02 & 45.69 & \\
\hline & 2 & 46.00 & 48.50 & 46.60 & 47.03 \\
\hline S6-0-1 & 1 & 43.00 & 51.00 & 45.50 & 46.50 \\
\hline S6-1-2 & 2 & 53.80 & 51.00 & 54.40 & 53.07 \\
\hline S6-1-5 & 5 & 73.20 & 69.90 & 72.10 & 71.73 \\
\hline S8-0-2 & 2 & 52.70 & 49.40 & 48.80 & 51.17 \\
\hline & & 50.70 & 52.40 & 53.00 & \\
\hline S8-1-2 & 2 & 51.00 & 50.50 & 51.60 & 50.75 \\
\hline & & 51.00 & 50.50 & 49.90 & \\
\hline
\end{tabular}


trend was observed with maximum aggregate size. When maximum aggregate size decreases, for the same w/c ratio, an increase of splitting tensile strength is observed.

It must be pointed out that, fracture of aggregates in non-fiber reinforced concrete was observed, as shown in Fig. 4.6. The addition of fibers altered the failure mode of the cylinders tested. However, brittle splitting of the cylinders was observed in non-fiber reinforced concrete, the only indication that the fiber reinforced concrete cylinders have failed is the drop in the loading applied.

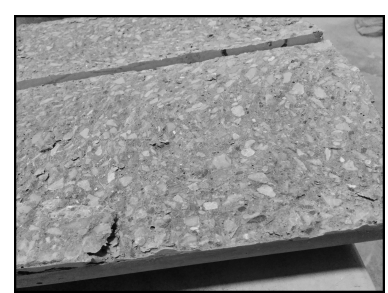

Fig. 4.6. Cylinder surface profile. 
Table 4.9. Results of the concrete tensile strength.

\begin{tabular}{|c|c|c|c|c|c|c|}
\hline \multirow{2}{*}{ Specimen } & \multirow{2}{*}{ Mix } & \multicolumn{4}{|c|}{ cylinder test specimen } & \multirow{2}{*}{$\begin{array}{l}f_{c t} \\
{[\mathrm{MPa}]}\end{array}$} \\
\hline & & 1 & 2 & 3 & 4 & \\
\hline $\mathrm{A} 4-0-2$ & 2 & 4.64 & 3.95 & 4.23 & 4.52 & 4.34 \\
\hline $\mathrm{A} 4-1-2$ & 2 & 4.85 & 4.23 & 3.86 & 4.08 & 4.26 \\
\hline A5-0-2 & 2 & 3.75 & 3.81 & 3.90 & 3.76 & 3.80 \\
\hline A5-1-2 & 2 & 4.06 & 3.81 & 3.93 & 3.49 & 3.82 \\
\hline A5-1-4 & 4 & 4.23 & 4.20 & 4.25 & 4.58 & 4.31 \\
\hline B4-0-2 & 2 & 4.16 & 3.95 & 4.23 & 4.16 & 4.13 \\
\hline B4-1-2 & 2 & 4.23 & 3.40 & 3.81 & 4.40 & 3.96 \\
\hline C4-0-2 & 2 & 4.30 & 4.64 & 4.23 & 3.74 & 4.23 \\
\hline C4-1-2 & 2 & 3.74 & 4.30 & 3.74 & 3.88 & 3.92 \\
\hline $\mathrm{C} 7-0-2$ & 2 & 4.44 & 4.44 & 4.51 & 2.77 & 4.04 \\
\hline $\mathrm{C} 7-1-2$ & 2 & 4.23 & 3.81 & 3.54 & 4.58 & 4.04 \\
\hline PC-0-2 & 2 & 4.16 & 3.74 & 3.60 & 3.47 & 3.74 \\
\hline PC-0-4 & 4 & 3.86 & 4.14 & 4.28 & 4.18 & 4.11 \\
\hline PC-0-5 & 5 & 4.54 & 4.28 & 4.56 & 4.85 & 4.56 \\
\hline PC-1-1 & 1 & 3.18 & 3.85 & 3.14 & 2.77 & 3.23 \\
\hline \multirow{2}{*}{ PC-1-2 } & 2 & 4.16 & 4.78 & 4.30 & 4.58 & 4.46 \\
\hline & 2 & 3.69 & 3.82 & 3.72 & 3.65 & 3.72 \\
\hline S6-0-1 & 1 & 3.53 & 3.96 & 3.67 & 3.74 & 3.72 \\
\hline S6-1-2 & 2 & 4.10 & 3.96 & 4.13 & 4.24 & 4.11 \\
\hline S6-1-5 & 5 & 5.03 & 4.88 & 4.98 & 4.83 & 4.93 \\
\hline S8-0-2 & 2 & 3.71 & 4.14 & 3.92 & 3.81 & 3.90 \\
\hline S8-1-2 & 2 & 3.88 & 4.02 & 3.81 & 4.02 & 3.93 \\
\hline
\end{tabular}




\section{Chapter 5}

\section{Results, analysis and discussions}

\subsection{Introduction}

This chapter focuses on the presentation, analysis and discussion of the experimental results. For this reason, this chapter is arranged into three sections.

In the first section, section 5.2, the experimental results of both the precracking and push-off phases are shown. This section begins by showing the precracking results in 5.2.1. Then a comparison between the photogrammetry and DEMEC measurements is reported in 5.2.2. This section ends by presenting the results of the push-off phase in 5.2.3.

The second section 5.3 studies the restraint frame. An in-depth study on the vertical stiffness of the restraint frame is offered in 5.3.1. In this subsection, a simple model is developed to correct shear stress depending on the relative vertical displacement $(\Delta)$ of restraint plates A and B. An analysis of the horizontal stiffness of the restraint frame is presented in 5.3.2. A comparison of previous test methodologies in which the ball bearing was not applied is reported in 5.3.3. Finally, a statistical study about the vertical displacement of both restraint plates is found in 5.3.4. 
The last section, 5.4, focuses on the analysis and discussion of the different parameters presented in the experimental program. The influence of the allowed initial crack width is presented in 5.4.1. After this, the different behavior depending on the type of fibers and how these modify the shear transfer mechanism is reported in 5.4.2. Then a comparison between two different fiber amounts (40 vs. 50 and 40 vs. $70 \mathrm{~kg} / \mathrm{m}^{3}$ ) is shown in 5.4.3. The influence of the transverse reinforcement $(\rho)$ ratio is analyzed in 5.4.4. The modifications in the shear transfer mechanisms introduced by the concrete compressive strength and the maximum aggregate size is presented in 5.4.5. A comparison between steel fiber reinforced concrete (SFRC) and traditional reinforcement with stirrups $(\mathrm{RC})$ is shown in 5.4.6. Finally, and given the fact that the friction coefficient is an important parameter, an analysis of this property is reported in 5.4.7.

\subsection{Presentation of the experimental results}

The experimental results of both the precracking and push-off phases, are reported in this section. The presentation follows the experimental procedure. This means that the precracking results are first shown, followed by the discrete measurements results (mainly DEMEC measurements), and finally the push-off phase results.

A comparison between the DEMEC measurements and photogrammetry (20 specimens only) is also reported. This comparison was made to increase the reliability of the linear relationship reported in 3.4.5.

\subsubsection{Results of the precracking phase}

Table 5.1 summarizes the experimental results of the precracking phase. In this table, the ultimate values of crack width (w1 and w2) and the average value (w.pc) are reported. The average crack width obtained from the DEMEC measurements (w.de) is also presented. Finally, the average residual unitary confinement force (F.end) is also given because in the specimens with $w_{o}=0$, this force multiplied by the number of restraint bars represents the start point for the evolution of the normal stress $(\sigma)$.

In Table 5.1 we can see a large difference between w1 and w2 in some specimens. One possible explanation for this behavior is how the LVDTs are fixed to the specimen, as Fig. 5.1 shows. Due to the long distance from the surface to the LVDTs $(50 \mathrm{~mm})$, any minor rotation of the specimen leads to significant modifications in the LVDTs readings. 
Table 5.1. Results of the precracking phase.

\begin{tabular}{|c|c|c|c|c|c|}
\hline \multirow{2}{*}{ Specimen } & \multicolumn{3}{|c|}{ LVDT $[\mathrm{mm}]$} & \multirow{2}{*}{$\begin{array}{l}\text { w.de } \\
{[\mathrm{mm}]}\end{array}$} & \multirow{2}{*}{$\begin{array}{l}\text { F.end } \\
{[\mathrm{kN}]}\end{array}$} \\
\hline & w1 & w2 & w.pc & & \\
\hline A4-0-2a & 0.38 & 0.21 & 0.29 & 0.41 & -6.40 \\
\hline $\mathrm{A} 4-0-2 \mathrm{~b}$ & 0.42 & 0.00 & 0.21 & 0.33 & -4.22 \\
\hline $\mathrm{A} 4-0-2 \mathrm{c}$ & 0.16 & 0.12 & 0.14 & 0.24 & -4.62 \\
\hline $\mathrm{A} 4-1-2 \mathrm{a}$ & 0.16 & 0.11 & 0.13 & 0.30 & -4.86 \\
\hline $\mathrm{A} 4-1-2 \mathrm{~b}$ & 0.37 & 0.17 & 0.27 & 0.40 & -5.52 \\
\hline $\mathrm{A} 4-1-2 \mathrm{c}$ & 0.13 & 0.07 & 0.10 & 0.27 & -3.40 \\
\hline A5-0-2a & 0.13 & 0.24 & 0.19 & 0.38 & -2.68 \\
\hline A $5-0-2 b$ & 0.06 & 0.37 & 0.21 & 0.51 & -3.30 \\
\hline A5-1-2a* & 0.10 & 0.11 & 0.11 & 0.49 & -7.48 \\
\hline A5-1-2b & 0.08 & 0.00 & 0.04 & 0.46 & -5.08 \\
\hline A5-1-4a & 0.31 & 0.34 & 0.32 & 0.29 & -2.97 \\
\hline A5-1-4b & 0.42 & 0.11 & 0.26 & 0.72 & -11.82 \\
\hline B4-0-2a & 0.35 & 0.01 & 0.18 & 0.34 & -3.77 \\
\hline B4-0-2b & 0.35 & 0.26 & 0.30 & 0.24 & -4.58 \\
\hline B4 $-0-2 c$ & 0.01 & 0.08 & 0.04 & 0.27 & -3.33 \\
\hline B4-1-2a & 0.17 & 0.01 & 0.09 & 0.27 & -4.25 \\
\hline B4-1-2b & 0.30 & 0.23 & 0.27 & 0.35 & -5.16 \\
\hline B4-1-2c & 0.02 & 0.07 & 0.05 & 0.17 & -1.84 \\
\hline C4- $0-2 \mathrm{a}$ & 0.38 & 0.33 & 0.36 & 0.27 & -5.46 \\
\hline $\mathrm{C} 4-0-2 \mathrm{~b}$ & 0.47 & 0.24 & 0.35 & 0.33 & -4.50 \\
\hline C4-0-2c & 0.06 & 0.13 & 0.09 & 0.18 & -2.91 \\
\hline C4-1-2a & 0.01 & 0.01 & 0.01 & 0.27 & -4.66 \\
\hline $\mathrm{C} 4-1-2 \mathrm{~b}$ & 0.23 & 0.11 & 0.17 & 0.28 & -4.59 \\
\hline C4-1-2c & 0.10 & 0.00 & 0.05 & 0.25 & -3.24 \\
\hline C7-0-2a & 0.16 & 0.07 & 0.12 & 0.23 & -3.60 \\
\hline $\mathrm{C} 7-0-2 \mathrm{~b}$ & 0.23 & 0.02 & 0.12 & 0.30 & -5.38 \\
\hline C7-0-2c & 0.02 & 0.01 & 0.01 & 0.13 & -2.76 \\
\hline C7-1-2a & 0.17 & 0.12 & 0.14 & 0.26 & -3.17 \\
\hline $\mathrm{C} 7-1-2 \mathrm{~b}$ & 0.13 & 0.32 & 0.23 & 0.27 & -2.88 \\
\hline $\mathrm{C} 7-1-2 \mathrm{c}$ & 0.11 & 0.06 & 0.08 & 0.17 & -1.78 \\
\hline PC-0-2a & 0.51 & 0.51 & 0.51 & 0.44 & -6.21 \\
\hline PC-0-2b & 0.45 & & 0.49 & 0.50 & -7.84 \\
\hline PC-0-2c & 0.52 & 0.38 & 0.45 & 0.60 & -7.62 \\
\hline PC-0-4a & 0.29 & 0.29 & 0.29 & 0.39 & -4.30 \\
\hline PC-0-4b & 0.35 & 0.55 & 0.45 & 0.24 & -2.15 \\
\hline PC-0-5a & 0.59 & 0.39 & 0.49 & 0.59 & -8.89 \\
\hline PC-0-5b & 0.69 & 0.33 & 0.51 & 0.34 & -4.35 \\
\hline PC-1-1a & 0.27 & 0.11 & 0.19 & 0.77 & -5.79 \\
\hline PC-1-1b & 0.30 & 0.42 & 0.36 & 0.75 & -8.74 \\
\hline PC-1-2a & 0.49 & 0.25 & 0.37 & 0.75 & -9.08 \\
\hline PC-1-2b & 0.09 & 0.15 & 0.12 & 0.48 & -7.04 \\
\hline PC-1-2c & 0.08 & 0.11 & 0.10 & 0.48 & -2.42 \\
\hline PC-1-2d & 0.93 & 0.05 & 0.49 & 1.09 & -8.73 \\
\hline PC-1-2e & 0.84 & 0.62 & 0.73 & 0.90 & -7.29 \\
\hline S6-0-1a & 0.18 & 0.02 & 0.10 & 0.13 & -3.60 \\
\hline S6-0-1b & 0.02 & 0.09 & 0.05 & 0.35 & -1.54 \\
\hline S6-1-2a & 0.09 & 0.04 & 0.06 & 0.14 & -1.04 \\
\hline S6-1-2b & 0.12 & 0.17 & 0.14 & 0.13 & -1.22 \\
\hline S6-1-5a & 0.16 & 0.00 & 0.08 & 0.14 & -0.57 \\
\hline S6-1-5b & 0.20 & 0.11 & 0.16 & 0.12 & -1.33 \\
\hline S8-0-2a & 0.00 & 0.03 & 0.01 & 0.18 & -0.42 \\
\hline S8-0-2b & 0.07 & 0.00 & 0.04 & 0.18 & -1.93 \\
\hline S8-0-2c & 0.08 & 0.00 & 0.04 & 0.15 & -1.58 \\
\hline S8-1-2a & 0.10 & 0.03 & 0.06 & 0.08 & -0.91 \\
\hline S8-1-2b & 0.05 & 0.00 & 0.03 & 0.09 & -1.25 \\
\hline S8-1-2c & 0.03 & 0.00 & 0.02 & 0.24 & -0.63 \\
\hline
\end{tabular}

\footnotetext{
${ }^{*}$ Precracking test continued even after crack
} was done. 


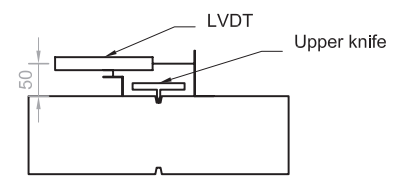

Fig. 5.1. Schematic position of the LVDTs during the precracking test.

Due to the confinement forces depending on crack width, a decision was made to plot the average residual unitary confinement force (F.end) vs. crack width, as shown in Fig. 5.2. This figure clearly shows the problems detected in the crack width measurements by the LVDT, which are reported in Table 5.1.

If the average crack width (w.pc) and the average residual unitary confinement force (F.end) are compared, a poor linear relationship is found, as shown in Fig. 5.2a. The goodness of linear adjusting is represented by the coefficient of determination $\left(R^{2}\right)$, whose value is 0.38 . A better fit is obtained when the crack width values from the DEMEC measurement are used (see Fig. 5.2b). This is confirmed by $R^{2}$, with a value of 0.67 .

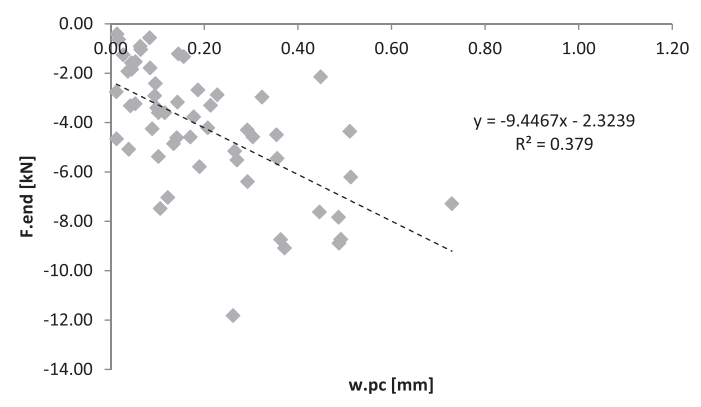

(a) LVDT measurements

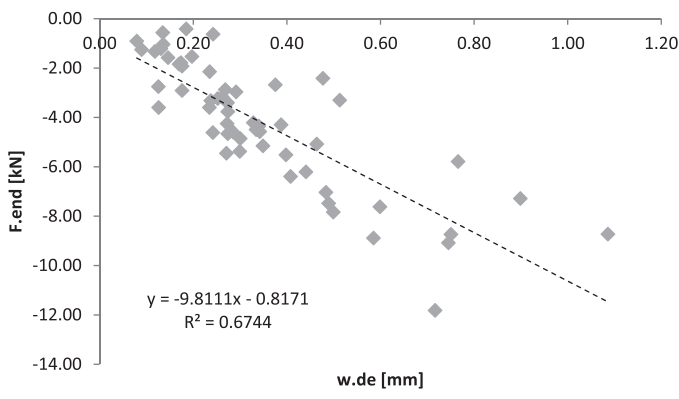

(b) DEMEC measurements

Fig. 5.2. Linear fit of F.end according to the LVDT or DEMEC measurements.

Based on these experimental results, a decision was made to use the DEMEC measurements values, such as initial crack width, prior to carrying out the pushoff phase. 


\subsubsection{Comparison between photogrammetry and DEMEC measurements}

In order to increase the reliability of photogrammetry, a new comparison between DEMEC and photogrammetry measurements was made. All the measurements were taken once the specimen was placed in a vertical position prior to carry out the push-off. For this analysis, 20 specimens were used, which are shown in Table 5.2 .

Table 5.2. List of the specimens used to make the comparison.

\begin{tabular}{ccccc}
\hline \multicolumn{5}{c}{ Specimen Id Code } \\
A5-0-2a & A5-1-4a & PC-0-5a & PC-1-2d & S6-1-2a \\
A5-0-2b & A5-1-4b & PC-0-5b & PC-1-2e & S6-1-2b \\
A5-1-2a & PC-0-4a & PC-1-1a & S6-0-1a & S6-1-5a \\
A5-1-2b & PC-0-4b & PC-1-1b & S6-0-1b & S6-1-5b \\
\hline
\end{tabular}

The present research presents the value of both faces (front and back). Photogrammetry gives the same information as the DEMEC measurements, but an important visual analysis is provided from the picture. The photo provides qualitative information like crack mouth or how fibers sweep the crack (see Fig. 5.3). Unfortunately, photogrammetry is a time-consuming technique that requires too much time to obtain and process data.

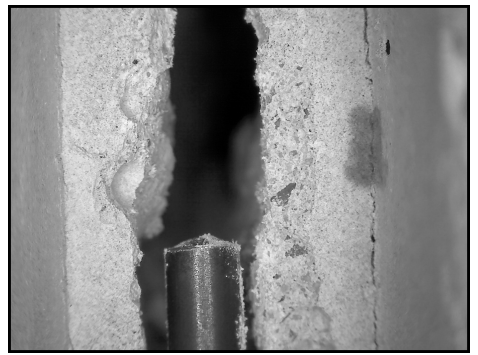

(a) Crack mouth formed

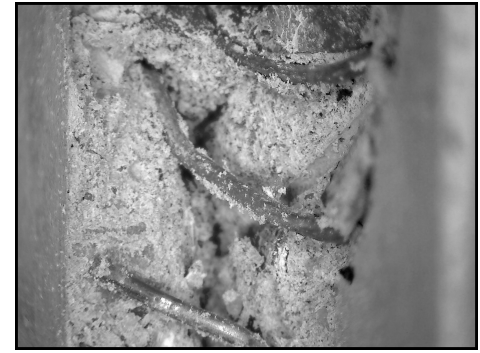

(b) Steel fibers sweeping the crack

Fig. 5.3. Qualitative information of the picture.

Table 5.3 shows the crack width values obtained with both techniques. The information is presented by the faces of the specimens (front or back), and the average value for each technique is also provided. It must be pointed out that due to the irregular superficial condition of PC-0-4b, wrong measurements were taken. For this reason, this specimen was removed from the table. 
Table 5.3. Photogrammetry and DEMEC measurements of crack width.

\begin{tabular}{lllllll}
\hline \multirow{2}{*}{ Specimen } & \multicolumn{3}{l}{ Photogrammetry $[\mathrm{mm}]$} & \multicolumn{3}{c}{ DEMEC [mm] } \\
\cline { 2 - 7 } & Front & Back & w.ph & Front & Back & w.de \\
\hline A5-0-2a & 0.09 & 0.61 & 0.35 & 0.02 & 0.73 & 0.38 \\
A5-0-2b & 0.32 & 0.61 & 0.46 & 0.36 & 0.67 & 0.51 \\
A5-1-2a & 0.29 & 0.59 & 0.44 & 0.32 & 0.66 & 0.49 \\
A5-1-2b & 0.26 & 0.45 & 0.36 & 0.31 & 0.61 & 0.46 \\
A5-1-4a & 0.32 & 0.21 & 0.27 & 0.41 & 0.17 & 0.29 \\
A5-1-4b & 0.65 & 0.79 & 0.72 & 0.71 & 0.72 & 0.72 \\
PC-0-4a & 0.39 & 0.31 & 0.35 & 0.46 & 0.32 & 0.39 \\
PC-0-4b & - & - & - & - & - & - \\
PC-0-5a & 0.77 & 0.57 & 0.67 & 0.39 & 0.78 & 0.58 \\
PC-0-5b & 0.44 & 0.24 & 0.34 & 0.41 & 0.27 & 0.34 \\
PC-1-1a & 0.68 & 0.79 & 0.73 & 0.57 & 0.96 & 0.77 \\
PC-1-1b & 0.53 & 0.79 & 0.66 & 0.74 & 0.76 & 0.75 \\
PC-1-2d & 0.82 & 1.29 & 1.06 & 0.93 & 1.24 & 1.09 \\
PC-1-2e & 0.84 & 0.87 & 0.86 & 0.89 & 0.91 & 0.90 \\
S6-0-1a & 0.17 & 0.08 & 0.12 & 0.16 & 0.10 & 0.13 \\
S6-0-1b & 0.18 & 0.18 & 0.18 & 0.49 & 0.20 & 0.35 \\
S6-1-2a & 0.08 & 0.24 & 0.16 & 0.07 & 0.20 & 0.14 \\
S6-1-2b & 0.17 & 0.14 & 0.16 & 0.13 & 0.13 & 0.13 \\
S6-1-5a & 0.13 & 0.06 & 0.09 & 0.18 & 0.09 & 0.13 \\
S6-1-5b & 0.12 & 0.10 & 0.11 & 0.14 & 0.09 & 0.12 \\
\hline
\end{tabular}

Fig. 5.4 shows the comparison made between both techniques and for each specimen face. Thus, a linear relationship between them was found. A better fit was obtained for the back face, as represented by the coefficient of determination $\left(R^{2}\right)$, which came close to 0.95 , while this value for the front face came close to 0.75 . The reason for this difference is the concrete surface. The back face came into contact with the mold and was completely smooth. This allowed to paste all the DEMEC metallic discs on the same plane and without inclination. The same occurred with the microscope base; if the surface was smoother, better photos were taken. 


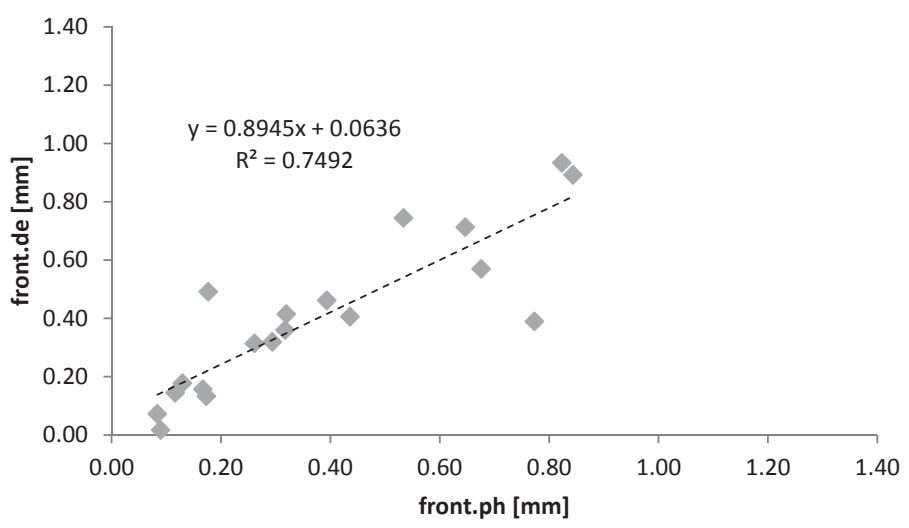

(a)

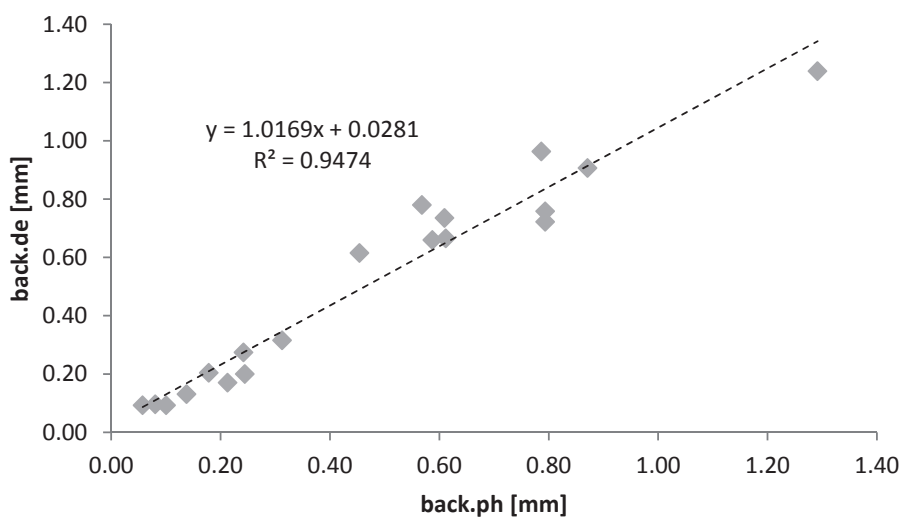

(b)

Fig. 5.4. Linear correlation between the photogrammetry and DEMEC measurements.

To conclude this linear correlation, a decision was made to not apply the photogrammetry technique in the second part of the experimental campaign. In general, the values obtained from the back face were slightly higher than the values obtained from the front face. This suggests that a positive bending effect was produced when the specimen cracked. Besides the LVDT were $50 \mathrm{~mm}$ apart from the specimen surface, which increased this phenomenon.

\subsubsection{Results of the push-off phase}

The experimental results of the push-off phase are presented in Table 5.4. Crack width $(w)$ and slip (slip) under the failure conditions are reported. Ultimate shear stress $\left(\tau_{u}\right)$ and normal stress $\left(\sigma_{u}\right)$ are included. 
The specimen had initial crack width (from the precraking phase and handling process) and slip (from the handling process only). Values, which are shown in the tables in columns w.de (for crack width) and $\delta$ (for sliding). The residual unitary confinement force (F.end) from the precracking phase is also shown. All these values are given inside the group defined as "Initial values". It must be pointed out that for the specimens with allowed initial crack width $\left(w_{o}=1\right)$, the residual unitary confinement force equalled zero $(\mathrm{F}$.end $=0)$. This was because when $w_{o}=1$ was fixed, the four nuts had to be loosened and thus, reduced the stress of the bars.

Based on the aforementioned results, the crack width (w.de) and sliding $(\delta)$ values were obtained from the DEMEC measurements. 
Table 5.4. Results of the push-off phase.

\begin{tabular}{|c|c|c|c|c|c|c|c|}
\hline \multirow[b]{2}{*}{ Specimen } & \multicolumn{3}{|c|}{ Initial values } & \multirow[b]{2}{*}{$\begin{array}{l}w \\
{[\mathrm{~mm}]}\end{array}$} & \multirow[b]{2}{*}{$\begin{array}{l}\text { slip } \\
{[\mathrm{mm}]}\end{array}$} & \multirow[b]{2}{*}{$\begin{array}{l}\tau_{u} \\
{[\mathrm{MPa}]}\end{array}$} & \multirow[b]{2}{*}{$\begin{array}{l}\sigma_{u} \\
{[\mathrm{MPa}]}\end{array}$} \\
\hline & $\begin{array}{l}\text { w.de } \\
{[\mathrm{mm}]}\end{array}$ & $\begin{array}{l}\delta \\
{[\mathrm{mm}]}\end{array}$ & $\begin{array}{l}\text { F.end } \\
{[\mathrm{kN}]}\end{array}$ & & & & \\
\hline A4-0-2a & 0.41 & 0.01 & -6.40 & 1.40 & 10.11 & 4.79 & -5.27 \\
\hline $\mathrm{A} 4-0-2 \mathrm{~b}$ & 0.33 & 0.01 & -4.22 & 1.41 & & 4.79 & -5.11 \\
\hline A4-0-2c & 0.24 & 0.00 & -4.62 & 1.43 & 10.04 & 6.78 & -6.36 \\
\hline $\mathrm{A} 4-1-2 \mathrm{a}$ & 0.30 & 0.01 & 0.00 & 2.08 & 10.01 & 3.69 & -4.37 \\
\hline $\mathrm{A} 4-1-2 \mathrm{~b}$ & 0.40 & 0.05 & 0.00 & 2.09 & & 3.57 & -4.32 \\
\hline $\mathrm{A} 4-1-2 \mathrm{c}$ & 0.27 & 0.05 & 0.00 & 2.03 & 10.04 & 4.29 & -4.48 \\
\hline A $5-0-2 a$ & 0.38 & 0.07 & -2.68 & 1.80 & 10.03 & 5.71 & -6.50 \\
\hline A $5-0-2 b$ & 0.51 & -0.08 & -3.30 & 1.58 & 10.02 & 4.83 & -5.03 \\
\hline A $5-1-2 a$ & 0.49 & 0.07 & 0.00 & 1.67 & & 2.64 & -2.80 \\
\hline$A 5-1-2 b$ & 0.46 & 0.08 & 0.00 & 1.95 & 10.01 & 2.96 & -2.83 \\
\hline A5-1-4a & 0.29 & 0.01 & 0.00 & 2.12 & 10.01 & 3.75 & -3.72 \\
\hline A $5-1-4 b$ & 0.72 & 0.01 & 0.00 & 1.92 & 10.11 & 3.72 & -3.90 \\
\hline B4-0-2a & 0.27 & 0.04 & -3.77 & 1.03 & 5.77 & 5.25 & -4.45 \\
\hline B4-0-2b & 0.34 & 0.05 & -4.58 & 1.31 & 10.02 & 4.83 & -4.86 \\
\hline B4-0-2c & 0.24 & 0.04 & -3.33 & 1.35 & 02 & 4.94 & -5.20 \\
\hline B4-1-2a & 0.27 & 0.04 & 0.00 & & & 3.80 & -3.73 \\
\hline B4-1-2b & 0 & 0. & 0.00 & 1.90 & 1 & 3.74 & -3.64 \\
\hline B4-1-2c & 17 & 0.0 & 0.00 & 1.77 & 10.04 & 3.79 & -3.40 \\
\hline $\mathrm{C} 4-0-2 \mathrm{a}$ & 0.27 & 0 . & -2.25 & 1 & & 6.05 & -5.63 \\
\hline $\mathrm{C} 4-0-2 \mathrm{~b}$ & 0.33 & 0.05 & -2.25 & 9 & & 4.94 & -4.96 \\
\hline $\mathrm{C} 4-0-2 \mathrm{c}$ & 0.18 & 0.04 & -1.46 & 1.38 & 05 & 5.63 & -5.38 \\
\hline C4-1-2a & 0.27 & 0.0 & 0.00 & 1.83 & 01 & 3.80 & -3.58 \\
\hline $\mathrm{C} 4-1-2 \mathrm{~b}$ & 0.28 & 0.0 & 0.00 & 1.87 & & 4.75 & -4.12 \\
\hline $\mathrm{C} 4-1-2 \mathrm{c}$ & 0.25 & & 0.00 & 1 & 2 & 4.79 & -4.48 \\
\hline C7-0-2a & 0.23 & & -3.60 & 1. & 94 & 6.73 & -6.32 \\
\hline $\mathrm{C} 7-0-2 \mathrm{~b}$ & 0.30 & 0 & -5.38 & 9 & 31 & 5.55 & -5.30 \\
\hline $\mathrm{C} 7-0-2 \mathrm{c}$ & 0.13 & 0 . & -2.76 & 8 & 30 & 6.48 & -6.07 \\
\hline C7-1-2a & 0.26 & 0.05 & 0.00 & 183 & 9.27 & 3.33 & -3.78 \\
\hline $\mathrm{C} 7-1-2 \mathrm{~b}$ & 0.27 & 0.0 & 0.00 & 1.71 & 10.08 & 3.34 & -3.14 \\
\hline $\mathrm{C} 7-1-2 \mathrm{c}$ & 0.17 & 0.02 & 0.00 & & 31 & 2.82 & -3.13 \\
\hline PC-0-4a & & -0 . & -4.30 & & & 8. & -6.36 \\
\hline PC-0-4b & 24 & -0.06 & -2.15 & 1 & 1 & 6.65 & -5.41 \\
\hline PC-0-5a & 0 & 0.21 & -8.89 & 4 & 01 & 5.29 & -6.06 \\
\hline PC-0-5b & 0.34 & 0.08 & -4.35 & 1 & 94 & 6.78 & -6.50 \\
\hline PC-0-2a & 0.44 & 0.06 & -6.21 & 1.74 & 10.01 & 5.32 & -6.25 \\
\hline PC- $0-2 b$ & 0.50 & 0.04 & -7.84 & 1.58 & 10.03 & 5.51 & -6.03 \\
\hline PC-0-2c & 0.60 & 0.02 & -7.62 & & & 7.01 & -6.22 \\
\hline PC-1-1a & 0.77 & 0.1 & 0.00 & & & 4. & -4.13 \\
\hline PC-1-1b & 0.75 & 0.1 & 0.00 & 1.70 & 10.01 & 3.33 & -3.67 \\
\hline PC-1-2a & 0.75 & 0.1 & 0.00 & 2.06 & 94 & 3.56 & -4.10 \\
\hline PC-1-2b & 0.48 & 0.04 & 0.00 & 1.71 & .04 & 3.01 & -3.41 \\
\hline PC-1-2c & 0.48 & 0.07 & 0.00 & 2.11 & 10.01 & 4.06 & -4.34 \\
\hline PC-1-2d & 1.09 & 0.34 & 0.00 & 1.95 & 10.03 & 2.46 & -2.85 \\
\hline PC-1-2e & 0.90 & 0.25 & 0.00 & 2.19 & 10.02 & 2.92 & -3.04 \\
\hline S6-0-1a & & 0.02 & -3.60 & 1.29 & 12.77 & 5.82 & -4.87 \\
\hline S6-0-1b & 0.20 & 0.01 & -1.54 & 1.65 & 10.09 & 7.22 & -4.83 \\
\hline S6-1-2a & 0.14 & 0.04 & 0.00 & 1.70 & 10.05 & 5.48 & -2.19 \\
\hline S6-1-2b & 0.13 & 0.00 & 0.00 & 1.86 & 10.02 & 4.52 & -1.33 \\
\hline S6-1-5a & 0.14 & 0.02 & 0.00 & 1.78 & 10.23 & 4.18 & -4.24 \\
\hline S6-1-5b & 0.12 & 0.01 & 0.00 & 2.04 & 11.66 & 3.99 & -4.74 \\
\hline S8-0-2a & 0.18 & 0.02 & -0.42 & 1.14 & 10.03 & 8.40 & -4.33 \\
\hline $\mathrm{S} 8-0-2 \mathrm{~b}$ & 0.18 & 0.01 & -1.93 & 2.40 & 10.83 & 7.00 & -4.34 \\
\hline S8-0-2c & 0.15 & 0.01 & -1.58 & 1.47 & 10.01 & 8.93 & -4.89 \\
\hline S8-1-2a & 0.08 & 0.01 & 0.00 & 2.01 & 10.15 & 6.05 & -1.83 \\
\hline $\mathrm{S} 8-1-2 \mathrm{~b}$ & 0.09 & 0.01 & 0.00 & 1.63 & 10.03 & 6.20 & -1.48 \\
\hline S8-1-2c & 0.24 & 0.01 & 0.00 & 1.77 & 10.89 & 5.59 & -1.75 \\
\hline
\end{tabular}


Based on the values in Table 5.4, it can be seen that the ultimate crack width (in average terms) was around $1.60 \mathrm{~mm}$. Slight differences are observed according to the allowed initial crack width $\left(w_{o}\right)$. For instance, for the $\mathrm{C} 7$ specimens $(\mathrm{RC}-80 / 30$ $\mathrm{BP}$ and amount of $\left.70 \mathrm{~kg} / \mathrm{m}^{3}\right)$, an ultimate crack width of $1.54 \mathrm{~mm}$ for $w_{o}=0$ and $1.74 \mathrm{~mm}$ for $w_{o}=1$ is reported. The same trend was seen, if the traditional reinforced specimens were compared. Thus, the lower average crack width was obtained for long fibers (RC-80/50 BN), while the lower scatter was given by $\mathrm{C} 7$ specimens. The plain concrete specimens reported the highest crack width values of around $1.82 \mathrm{~mm}$. The average ultimate crack width, classified by the reinforcing type, are presented in Table 5.5.

Table 5.5. Average ultimate crack width (in $\mathrm{mm}$ ).

\begin{tabular}{lll}
\hline Type & $w_{o}=0$ & $w_{o}=1$ \\
\hline $\mathrm{A} 4$ & 1.42 & 2.07 \\
$\mathrm{~A} 5$ & 1.69 & 1.91 \\
$\mathrm{~B} 4$ & 1.23 & 1.86 \\
$\mathrm{C} 4$ & 1.35 & 1.88 \\
$\mathrm{C} 7$ & 1.54 & 1.74 \\
$\mathrm{PC}$ & 1.72 & 1.97 \\
$\mathrm{~S} 6$ & 1.47 & 1.84 \\
$\mathrm{~S} 8$ & 1.67 & 1.80 \\
\hline
\end{tabular}

\subsection{Study of the restraint frame behavior}

The restraint frame designed to control the crack width in the push-off test should provide the following two effects under ideal conditions:

(a) Zero stiffness in the vertical direction $\left(k_{v}=0\right)$

(b) Infinite stiffness in the horizontal direction $\left(k_{h}=\infty\right)$

In the present push-off tests, these two aspects were not completely fulfilled. Thus it is essential to study the extent to which aspected (a) and (b) were accomplished.

\subsubsection{Real shear stress transmitted by the crack}

As mentioned before, vertical stiffness under ideal conditions should come close to zero and result in very small relative displacements between Plates A and B (see Fig.5.5). If these relative displacements cannot be neglected, a fraction of the total shear force applied to the specimen in the push-off test will be transmitted through the restraint frame rather than through the crack. Thus in this test it is totally necessary to control the real shearing stress transmitted in the crack, which is why it was necessary to record the vertical displacements of Plates A and B. 


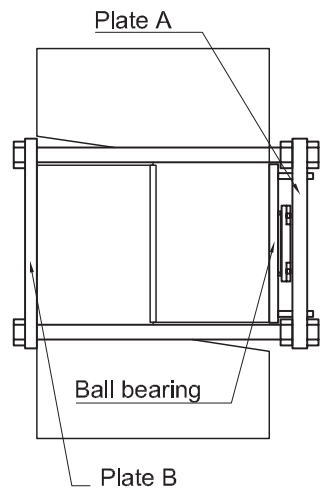

Fig. 5.5. Relative position of Plates A, B and the ball bearing respect to the specimen.

Since the vertical displacements of both Plates A and B are known, it was possible to evaluate the shear force transmitted through the restraint frame applying the following idea. Each external restraint bar can be modeled as a beam with length "L", with both extremes (A and B) totally restrained, and with relative vertical displacement, as shown in Fig. 5.6a. Due to the presence of the ball bearing, extreme $\mathrm{A}$ of the beam has the restraint setting shown in Fig. 5.6b. This figure also illustrate the shear loading $\left(V_{b}\right)$ that should act on the restraint bar. This situation can be assumed as a bi-restraint beam, which has a double length (2L) and a double loading $\left(2 V_{b}\right)$, applied as shown in Fig 5.6c.

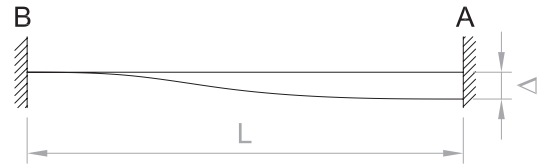

(a) Deformed shape due to vertical displacement

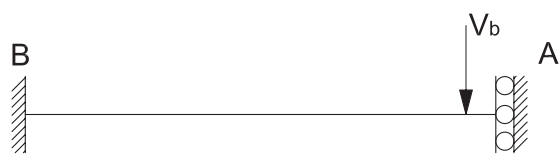

(b) External restraint bar idealization

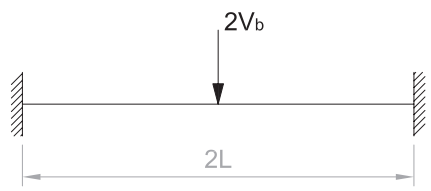

(c) Calculation scheme

Fig. 5.6. Simplified model to calculate the shear force transmitted by the restraint frame.

From the linear elastic beam analysis, it is known that the maximum vertical displacement, as shown in Fig. 5.6c, was located in the middle of the beam (under the loading point). The following equation can be applied ENSIDESA (1982) to obtain the maximum displacement:

$$
y_{\max }=\frac{P \cdot L^{3}}{192 \cdot E \cdot I}
$$


where: $(P)$ is the external loading applied; $(L)$ is the length of the beam; $(E)$ is the elastic modulus; and $(I)$ is the inertia moment of the cross-section.

By expressing eq. 5.1 according to the simplified model presented in Fig. 5.6c, the following expression is obtained:

$$
\Delta=\frac{2 V_{b} \cdot(2 L)^{3}}{192 \cdot E \cdot I}=\frac{V_{b} \cdot L^{3}}{12 \cdot E \cdot I}
$$

Given the fact that the vertical displacements in Plates A and B were measured during the push-off test, it was possible to calculate relative displacement $(\Delta)$. Finally by using eq. 5.2, it was possible to estimate the fraction of the shear load transmitted through the frame $\left(V_{f}\right)$ as follows:

$$
V_{f}=\frac{12 \cdot E \cdot I \cdot \Delta}{L^{3}}
$$

The parameters used in eq. 5.3, were applied according to:

- $\Delta$ was the relative displacement and was experimentally measured, which was defined as the difference between the vertical displacements of Plate A and Plate $\mathrm{B}(\Delta=P A-P B)$.

- $E$ was the steel elastic modulus and was assumed to be $E_{s}=200000 M P a$.

- I was the moment of inertia of the restraint bars; and for a circular crosssection $(r=20 \mathrm{~mm})$ by assuming the same behavior for the four bars, it was defined as follows:

$$
I=4 \cdot \frac{\pi \cdot r^{4}}{4}
$$

External loading $(P)$, which was applied by the hydraulic jack, was obtained as the sum of the shear force transmitted by the crack $\left(V_{c}\right)$ and the shear force transmitted by the restraint frame $\left(V_{f}\right)$. Thus, the shear force transmitted by the crack $V_{c}$ was mathematically obtained as:

$$
V_{c}=P-V_{f}
$$

By substituting eq. 5.3 by eq. 5.5, and dividing by the total shear plane crosssection area, the real shear stress transmitted by the crack was calculated as follows:

$$
\tau_{c}=\frac{P}{b_{s p} \cdot h_{s p}}-\frac{12 \cdot E \cdot I}{b_{s p} \cdot h_{s p} \cdot L^{3}} \cdot \Delta
$$

where: $b_{s p}=100 \mathrm{~mm}$ is the depth/height of the shear plane; $h_{s p}=260 \mathrm{~mm}$ is the width of the shear plane, and $L=436 \mathrm{~mm}$ is the nominal length of the bar.

The coefficients that multiplied $\Delta$ in eq. 5.6 were defined as the vertical stiffness $\left(k_{v}\right)$ of the restraint frame. As mentioned before, vertical stiffness should be zero under ideal conditions. However under real conditions, a different behavior 
was observed. It must be pointed out that these relative displacements were not negligible.

Total shear stress $\left(\tau_{\text {tot }}\right)$ was defined as external loading $(P)$ divided into the shear plane $\left(b_{s p} \cdot h_{s p}\right)$. The shear stress transmitted by the crack $\left(\tau_{c}\right)$ according to eq. 5.6 , and the shear stress transmitted by the restraint frame $\left(\tau_{f}\right)$ according to the second term of eq. 5.6, both depended on the relative vertical displacements. Later chapter 5 will analyze the importance of this effect on the vertical behavior of the push-off tests when using the corresponding experimental results.

A decision was made to present the analysis by dividing the specimens into two groups (first part and second part) because of different issues occurring in the LVDT of Plate B for some specimens. Accordingly, the recorded values of Plate B were discarded. Therefore in the first part, the specimens whose Plate B values were discarded are shown.

The ultimate values of $\tau_{t o t}, \tau_{c}$ and $\tau_{f}$ are summarized in Table 5.6 for the first part and in Table 5.7 for the second part. These tables also offer the effectiveness ratio $(I E F)$. This ratio was defined according to eq. 5.7, and represents the percentage of the shear stress transmitted by the restraint frame from total shear stress. In other words, this ratio expresses the efficiency of the ball bearing to avoid the specimen and the restraint frame moving downward together.

$$
\operatorname{IEF}(\%)=\frac{\tau_{f}}{\tau_{\text {tot }}} \cdot 100
$$

It must be pointed out that eq. 5.7 was not been applied for specimen B4-0-2a. This was because specimen B4-0-2a was used as a counterexample. More details of this counterexample are provided in subsection 5.3.3.

Table 5.6 offers the average $I E F$, which was around $10 \%$, and its coefficient of variation (C.V.) was around $3 \%$. Table 5.7 reports a lower average $I E F$ value, but a larger bigger coefficient of variation. One possible explanation for this is that in the first part, some problems in the experimental procedure appeared, and reliable Plate $\mathrm{B}$ vertical displacement values were obtained for a few specimens. Due to this problem, the relative displacement $(\Delta)$ used to obtain $\tau_{f}$, equalled the vertical displacement of Plate A.

In the second part, the relative displacement was obtained as the difference between the displacements of Plate A and Plate B. The displacement of Plate B firstly showed that the restraint frame moved downward. Moreover, ball bearing efficiency was quite good. Unfortunately, when the influence of Plate B was taken into account, a bigger scatter was obtained, which is why a $69 \%$ C.V. was obtained for the second part. 
Table 5.6. Ultimate values of shear stresses (first part).

\begin{tabular}{lllll}
\hline Specimen & $\begin{array}{l}\tau_{\text {tot }} \\
{[\mathrm{MPa}]}\end{array}$ & $\begin{array}{l}\tau_{c} \\
{[\mathrm{MPa}]}\end{array}$ & $\begin{array}{l}\tau_{f} \\
{[\mathrm{MPa}]}\end{array}$ & $\begin{array}{l}\text { IEF } \\
{[\%]}\end{array}$ \\
\hline A5-0-2a & 5.71 & 5.07 & 0.64 & 11.15 \\
A5-0-2b & 4.83 & 3.81 & 1.02 & 21.06 \\
A5-1-2a & 2.64 & 2.57 & 0.07 & 2.62 \\
A5-1-2b & 2.96 & 2.76 & 0.20 & 6.66 \\
A5-1-4a & 3.75 & 3.30 & 0.45 & 11.90 \\
A5-1-4b & 3.72 & 3.51 & 0.21 & 5.62 \\
PC-0-4a & 8.10 & 7.42 & 0.68 & 8.38 \\
PC-0-4b & 6.65 & 6.13 & 0.52 & 7.85 \\
PC-0-5a & 5.29 & 4.42 & 0.87 & 16.39 \\
PC-0-5b & 6.78 & 6.28 & 0.50 & 7.36 \\
PC-1-1a & 4.18 & 3.97 & 0.21 & 5.01 \\
PC-1-1b & 3.33 & 3.05 & 0.28 & 8.41 \\
PC-1-2d & 2.46 & 2.20 & 0.27 & 10.83 \\
PC-1-2e & 2.92 & 2.68 & 0.24 & 8.38 \\
S6-0-1a & 5.82 & 4.81 & 1.01 & 17.28 \\
S6-0-1b & 7.22 & 6.35 & 0.87 & 12.06 \\
S6-1-2a & 5.48 & 4.34 & 1.14 & 20.80 \\
S6-1-2b & 4.52 & 3.91 & 0.62 & 13.63 \\
S6-1-5a & 4.18 & 3.83 & 0.35 & 8.47 \\
S6-1-5b & 3.99 & 3.73 & 0.26 & 6.49 \\
\hline & & & mean & 10.52 \\
& & & C.V. & 3.05
\end{tabular}

In spite of this, the effectiveness ratio in both parts showed the same trend. Higher average $I E F$ values were obtained for reinforced concrete as compared with the average $I E F$ value for plain concrete. In the first part, the $I E F$ values were around $13 \%$ and $9 \%$, for reinforced and plain concrete, respectively. In second part, the reported $I E F$ values came close to $12 \%$ and $9 \%$, for reinforced and plain concrete, respectively.

The reason for this behavior was that when a direct shear was applied to the specimen, stirrups were yielded by shear stress instead of normal stress. When this happened a hinge appeared in the stirrup, which led to a rapid increase in slip displacement. This movement in the specimen gave rise to Plate A moving downward following the specimen.

An example of such behavior was shown in Fig. 5.7. This figure presents two specimens of the second part (PC-1-2a and S8-1-2a). In both specimens $w_{o}=1$ $\mathrm{mm}$ was chosen as a clear example of this behavior. 
Table 5.7. Ultimate values of shear stresses (second part).

\begin{tabular}{lllll}
\hline Specimen & $\tau_{\text {tot }}$ & $\tau_{c}$ & $\tau_{f}$ & $I E F$ \\
& {$[\mathrm{MPa}]$} & {$[\mathrm{MPa}]$} & {$[\mathrm{MPa}]$} & {$[\%]$} \\
\hline A4-0-2a & 4.79 & 4.18 & 0.61 & 12.80 \\
A4-0-2b & 4.79 & 4.30 & 0.49 & 10.26 \\
A4-0-2c & 6.78 & 6.44 & 0.34 & 4.98 \\
A4-1-2a & 3.69 & 3.65 & 0.04 & 1.13 \\
A4-1-2b & 3.57 & 2.93 & 0.64 & 17.97 \\
A4-1-2c & 4.29 & 4.17 & 0.12 & 2.81 \\
B4-0-2a & 5.25 & Not measured & \\
B4-0-2b & 4.83 & 4.05 & 0.78 & 16.10 \\
B4-0-2c & 4.94 & 4.44 & 0.50 & 10.21 \\
B4-1-2a & 3.80 & 3.46 & 0.34 & 8.93 \\
B4-1-2b & 3.74 & 3.61 & 0.13 & 3.59 \\
B4-1-2c & 3.79 & 3.66 & 0.13 & 3.54 \\
C4-0-2a & 6.05 & 5.98 & 0.07 & 1.13 \\
C4-0-2b & 4.94 & 4.24 & 0.70 & 14.13 \\
C4-0-2c & 5.63 & 5.45 & 0.19 & 3.31 \\
C4-1-2a & 3.80 & 3.42 & 0.38 & 10.04 \\
C4-1-2b & 4.75 & 4.45 & 0.31 & 6.47 \\
C4-1-2c & 4.79 & 4.63 & 0.16 & 3.26 \\
C7-0-2a & 6.73 & 6.37 & 0.36 & 5.36 \\
C7-0-2b & 5.55 & 5.30 & 0.25 & 4.49 \\
C7-0-2c & 6.48 & 6.42 & 0.05 & 0.84 \\
C7-1-2a & 3.33 & 3.00 & 0.33 & 9.97 \\
C7-1-2b & 3.34 & 3.32 & 0.01 & 0.42 \\
C7-1-2c & 2.82 & 2.53 & 0.28 & 10.00 \\
PC-0-2a & 5.32 & 4.87 & 0.46 & 8.58 \\
PC-0-2b & 5.51 & 4.47 & 1.04 & 18.91 \\
PC-0-2c & 7.01 & 6.07 & 0.94 & 13.44 \\
PC-1-2a & 3.56 & 3.42 & 0.13 & 3.74 \\
PC-1-2b & 3.01 & 2.94 & 0.07 & 2.39 \\
PC-1-2c & 4.06 & 3.82 & 0.24 & 5.86 \\
S8-0-2a & 8.40 & 7.13 & 1.27 & 15.17 \\
S8-0-2b & 7.00 & 6.40 & 0.60 & 8.51 \\
S8-0-2c & 8.93 & 8.32 & 0.61 & 6.79 \\
S8-1-2a & 6.05 & 4.68 & 1.36 & 22.57 \\
S8-1-2b & 6.20 & 5.83 & 0.37 & 6.01 \\
S8-1-2c & 5.59 & 4.97 & 0.62 & 11.09 \\
\hline & & & mean & 8.14 \\
& & & C.V. & 69.10
\end{tabular}

From Fig. 5.7, we can also seen that the stirrups yielded after a slip of $0.5 \mathrm{~mm}$ was reached (point A). Straight lines were produced by linking the singular experimental points. These straight lines confirmed the rapid slip increment. If the 


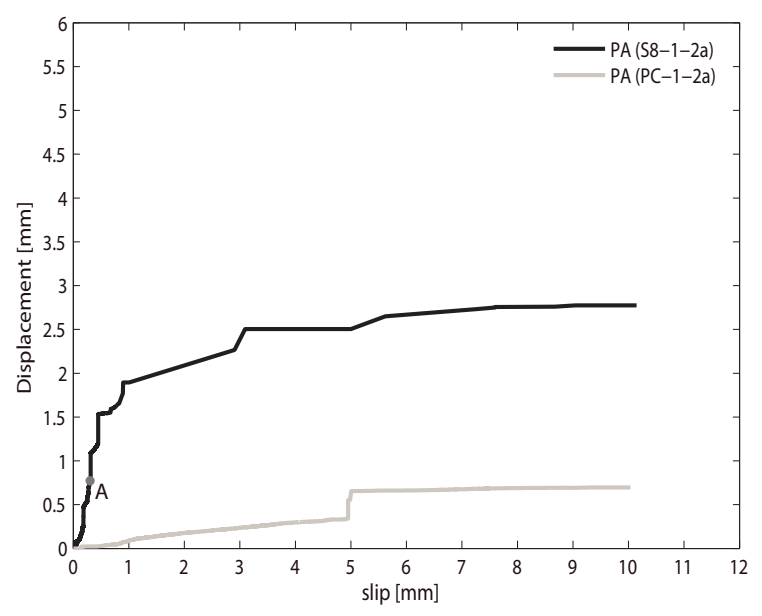

Fig. 5.7. Vertical displacement of Plate A during the push-off test.

Shear stress vs. slip relationship for specimen S8-1-2a is observed (see Annex A), shear stress drops after a slip value of $0.5 \mathrm{~mm}$. This confirms the idea of the stirrups yielded for a value closer to $0.5 \mathrm{~mm}$. Similar behavior has been reported by Loov and Patnaik (1994), where stirrups yielded for slip values around $0.5 \mathrm{~mm}$. A plain concrete specimen showed a gradual increase in vertical displacement, and singular points were found around $5 \mathrm{~mm}$ of slip. After this point, the position of Plate A remained constant, while slip still continued to increase until failure.

Fig. 5.8 shows the relationship between shear stresses $\tau_{t o t}, \tau_{c}$ and $\tau_{f}$. In this figure, a specimen of the second part (C4-0-2b) was used to represent the evolution of the three shear stresses as a function of the slip displacement. The total shear stress is represented in black, frame shear stress as a gray dashed line, and crack shear stress is depicted in gray. This figure also clearly shows that despite the small $\tau_{f}$ values, total shear stress must be corrected to obtain not only the real shear stress, but also the real curve of the shear stress vs. slip displacement. 


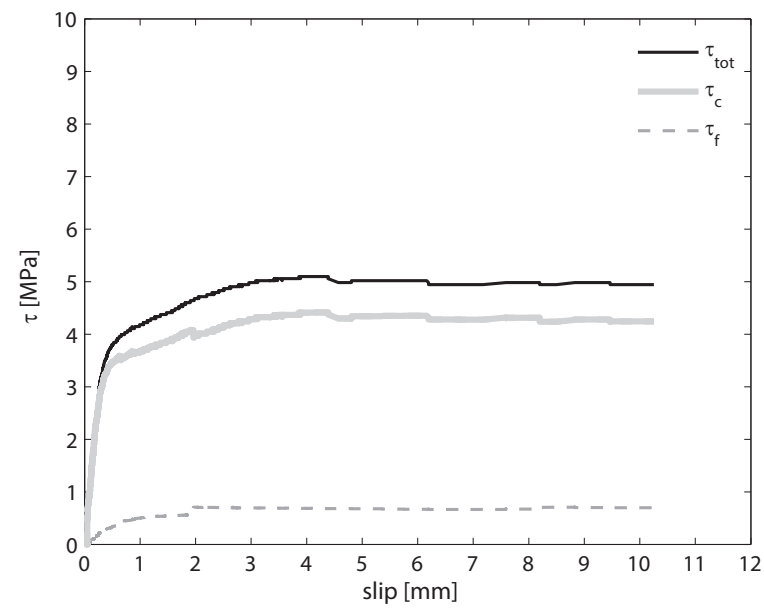

Fig. 5.8. Real shear stress transmitted by the crack (C4-0-2b specimen).

\subsubsection{Study of horizontal stiffness of the restraint frame}

The treatment and analysis of horizontal stiffness $\left(k_{h}\right)$ of the restraint frame is presented in this section. As mentioned in chapter 3 , under ideal conditions $k_{h}$ should be infinite $\left(k_{h}=\infty\right)$. Unfortunately, this is impossible to achieve under real test conditions.

It is a fact that confinement force depends on crack width evolution. Horizontal stiffness is assessed by means of normal stress as a function of the crack width, as shown in Fig. 5.9. This feature is defined as the slope of the straight curve. For this reason $k_{h}$ has the same units of $k_{v}, \mathrm{MPa} / \mathrm{mm}$ (see Fig. $5.9 \mathrm{~b}$ ). If horizontal stiffness was infinite, a parallel line to the " $y$ " axis would be observed as shown in Fig. 5.9a.

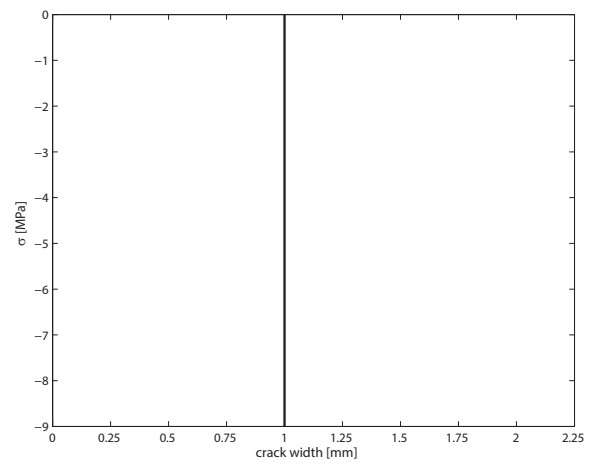

(a) Ideal condition

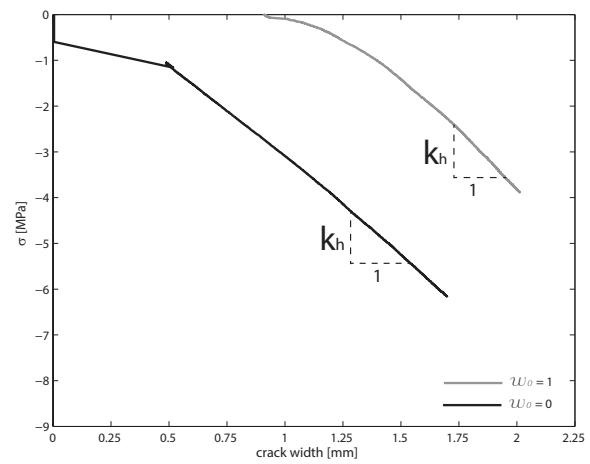

(b) Real condition

Fig. 5.9. Representation of horizontal stiffness. 
In Fig. 5.9b different behaviors depending on the allowed initial crack width $\left(w_{o}\right)$ are observed. Thus, for initially confined specimens $\left(w_{o}=0\right)$, three straight lines are reported. For initially unconfined specimens $\left(w_{o}=1\right)$, a curve part is first observed, and then a straight line is shown. This behavior has also been reported by Walraven, Vos, and Reinhardt (1979). The reason for this non linear behavior is because the specimen and Plate A do not fully come into contact in the first loading steps.

In the specimens with $w_{o}=0$, the three linear behavior is due to two particular points. First, the prestressed (or initial confinement) of 0.6 MPa prior to precracking the specimen. Second, the extra confinement force (or residual confinement force) from the precracking test. In the specimens tested with $w_{o}=1 \mathrm{~mm}$, Plate $\mathrm{A}$ and the ball bearing are separated from each other. When crack width starts to increase, Plate A and the ball bearing come into contact. However as a result of the natural roughness of the crack interface, this contact is not fully achieved.

As a result of these two behaviors, the experimental values of $k_{h}$ must be obtained from the experimental results by means of linear fitting according to eq. 5.8 for all the specimens with $w_{o}=0$. For the specimens with $w_{o}=1$, the first zone of the experimental curve can be fitted by a cubic function and then a linear line, as shown in Fig. 5.10. Three crack width points are defined, $w_{a}, w_{b}$ and $w_{\text {test }}$ to set the confinement curve in a simplified way. The point where confinement (or normal stress) begins corresponds to $w_{a}$. The point where the straight line starts is $w_{b}$. Finally, $w_{\text {test }}$ represents the crack width which the linear behavior originates (see Fig 5.10). Thus, the fitting expression for the specimens with $w_{o}=1$ is given in eq. 5.9 .

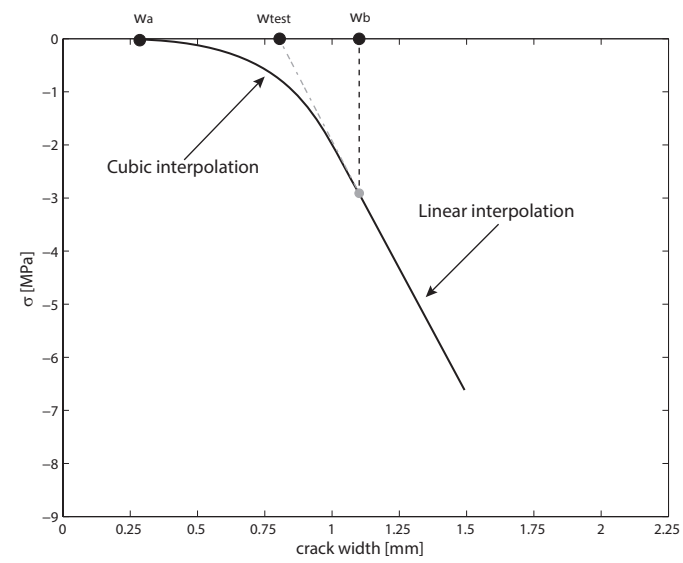

Fig. 5.10. Fitting curves for normal stress in the specimens with $w_{o}=1$.

$$
\sigma_{0}=k_{h} \cdot\left(w-w_{\text {test }}\right)
$$




$$
\begin{aligned}
\sigma_{1} & =0 \text { for } w \leq w_{a} \\
\sigma_{1} & =-k_{h} \cdot\left(\frac{w-w_{a}}{w_{b}-w_{a}}\right)^{2} \cdot\left[\left(w_{a}+w_{b}-2 w_{\text {test }}\right) \cdot\left(\frac{w-w_{a}}{w_{b}-w_{a}}\right)\right. \\
& +\left(-w_{a}-2 w_{b}+3 w_{\text {test }}\right) \text { for } w_{a}<w \leq w_{b} \\
\sigma_{1} & =k_{h} \cdot\left(w-w_{\text {test }}\right) \text { for } w \geq w_{b}
\end{aligned}
$$

A decision was made to analyze $k_{h}$ based on $w_{o}$. For this reason, Table 5.8 summarizes the experimental values of $k_{h}$ for each specimen with $w_{o}=0$. In Table 5.9, the values of $k_{h}$ for each specimen with $w_{o}=1$ are shown. In both tables, horizontal stiffness was obtained by using eq. 5.8 and eq. 5.9. For this

\begin{tabular}{|c|c|c|c|c|}
\hline Specimen & $R^{2}$ & $\begin{array}{l}k_{h} \\
{[\mathrm{MPa} / \mathrm{mm}]}\end{array}$ & Material & $\begin{array}{l}k_{h} \\
{[\mathrm{MPa} / \mathrm{mm}]}\end{array}$ \\
\hline $\mathrm{A} 4-0-2 \mathrm{a}$ & 0.9995 & -4.24 & \multirow{3}{*}{ A4-0-2 } & \multirow{3}{*}{-4.21} \\
\hline $\mathrm{A} 4-0-2 \mathrm{~b}$ & 0.9998 & -3.87 & & \\
\hline $\mathrm{A} 4-0-2 \mathrm{c}$ & 0.9997 & -4.51 & & \\
\hline A5-0-2a & 0.9963 & -3.68 & \multirow{2}{*}{ A5-0-2 } & \multirow{3}{*}{-3.60} \\
\hline $\mathrm{A} 5-0-2 \mathrm{~b}$ & 0.9957 & -3.52 & & \\
\hline B4-0-2a & 0.9968 & -4.28 & \multirow{3}{*}{ B4-0-2 } & \\
\hline B4-0-2b & 0.9974 & -4.05 & & \multirow[t]{3}{*}{-4.07} \\
\hline B4-0-2c & 0.9993 & -3.88 & & \\
\hline C4-0-2a & 0.9979 & -4.51 & \multirow{3}{*}{ C4-0-2 } & \\
\hline $\mathrm{C} 4-0-2 \mathrm{~b}$ & 0.9989 & -3.75 & & \multirow[t]{3}{*}{-3.98} \\
\hline C4-0-2c & 0.9973 & -3.69 & & \\
\hline $\mathrm{C} 7-0-2 \mathrm{a}$ & 0.9985 & -4.10 & \multirow{3}{*}{ C7-0-2 } & \\
\hline $\mathrm{C} 7-0-2 \mathrm{~b}$ & 0.9980 & -3.98 & & \multirow[t]{3}{*}{-3.88} \\
\hline $\mathrm{C} 7-0-2 \mathrm{c}$ & 0.9965 & -3.55 & & \\
\hline PC-0-2a & 0.9996 & -3.91 & \multirow{3}{*}{ PC-0-2 } & \\
\hline PC-0-2b & 0.9975 & -4.42 & & \multirow{2}{*}{-4.21} \\
\hline PC-0-2c & 0.9993 & -4.29 & & \\
\hline PC-0-4a & 0.9998 & -3.04 & \multirow{2}{*}{ PC-0-4 } & \multirow{2}{*}{-3.31} \\
\hline PC-0-4b & 0.9985 & -3.58 & & \\
\hline PC-0-5a & 0.9982 & -5.29 & \multirow{2}{*}{ PC-0-5 } & \multirow{2}{*}{-4.70} \\
\hline PC-0-5b & 0.9996 & -4.11 & & \\
\hline S6-0-1a & 0.9961 & -3.47 & \multirow{3}{*}{ S6-0-1 } & \multirow{3}{*}{-3.47} \\
\hline S6-0-1b & - & - & & \\
\hline S8-0-2a & - & - & & \\
\hline S8-0-2b & - & - & \multirow[t]{2}{*}{ S8-0-2 } & \multirow[t]{2}{*}{ - } \\
\hline S8-0-2c & - & - & & \\
\hline & mean & -3.99 & & \\
\hline & C.V & 11.89 & & \\
\hline
\end{tabular}
reason, the values of $k_{h}$ shown in the tables are obtained when the coefficient of determination $\left(R^{2}\right)$ is greater than 0.995 .

Table 5.8. Horizontal stiffness for the $w_{o}=0$ specimens. 
Table 5.9. Horizontal stiffness for the $w_{o}=1$ specimens.

\begin{tabular}{|c|c|c|c|c|c|c|c|}
\hline Specimen & $\begin{array}{l}w_{a} \\
{[\mathrm{~mm}]}\end{array}$ & $\begin{array}{l}w_{b} \\
{[\mathrm{~mm}]}\end{array}$ & $\begin{array}{l}w_{\text {test }} \\
{[\mathrm{mm}]}\end{array}$ & $R^{2}$ & $\begin{array}{l}k_{h} \\
{[\mathrm{MPa} / \mathrm{mm}]}\end{array}$ & Material & $\begin{array}{l}k_{h} \\
{[\mathrm{MPa} / \mathrm{mm}]}\end{array}$ \\
\hline $\mathrm{A} 4-1-2 \mathrm{a}$ & 0.07 & 1.29 & 0.88 & 0.9997 & -3.64 & \multirow{3}{*}{ A4-1-2 } & \multirow{3}{*}{-3.93} \\
\hline $\mathrm{A} 4-1-2 \mathrm{~b}$ & 0.07 & 1.40 & 0.99 & 0.9992 & -3.90 & & \\
\hline $\mathrm{A} 4-1-2 \mathrm{c}$ & 0.25 & 1.36 & 0.99 & 0.9985 & -4.26 & & \\
\hline A5-1-2a & 0.56 & 1.38 & 1.11 & 0.9956 & -5.02 & \multirow{2}{*}{ A5-1-2 } & \multirow{2}{*}{-4.79} \\
\hline A5-1-2b & 0.25 & 1.87 & 1.33 & 0.9966 & -4.55 & & \\
\hline A $5-1-4 a$ & 0.00 & 2.00 & 1.35 & 0.9950 & -4.83 & \multirow{2}{*}{ A5-1-4 } & \multirow{3}{*}{-4.58} \\
\hline A5-1-4b & 0.61 & 1.23 & 1.02 & 0.9991 & -4.33 & & \\
\hline B4-1-2a & 0.61 & 1.37 & 1.00 & 0.9992 & -4.13 & \multirow{3}{*}{ B4-1-2 } & \\
\hline B4-1-2b & 0.28 & 1.33 & 0.95 & 0.9992 & -3.83 & & \multirow{3}{*}{-4.43} \\
\hline B4-1-2c & 0.00 & 1.76 & 1.13 & 0.9950 & -5.34 & & \\
\hline $\mathrm{C} 4-1-2 \mathrm{a}$ & 0.51 & 1.32 & 0.91 & 0.9950 & -3.85 & \multirow{3}{*}{ C4-1-2 } & \\
\hline $\mathrm{C} 4-1-2 \mathrm{~b}$ & 0.57 & 1.26 & 0.92 & 0.9950 & -4.29 & & \multirow[t]{3}{*}{-4.16} \\
\hline $\mathrm{C} 4-1-2 \mathrm{c}$ & 0.45 & 1.23 & 0.92 & 0.9993 & -4.32 & & \\
\hline $\mathrm{C} 7-1-2 \mathrm{a}$ & 0.42 & 1.63 & 1.06 & 0.9950 & -4.98 & \multirow{3}{*}{ C7-1-2 } & \\
\hline $\mathrm{C} 7-1-2 \mathrm{~b}$ & 0.50 & 1.80 & 1.17 & 0.9979 & -5.81 & & \multirow[t]{2}{*}{-5.39} \\
\hline $\mathrm{C} 7-1-2 \mathrm{c}$ & - & - & - & - & - & & \\
\hline PC-1-1a & 0.74 & 1.53 & 1.09 & 0.9986 & -4.37 & \multirow{2}{*}{ PC-1-1 } & \multirow{2}{*}{-5.13} \\
\hline PC-1-1b & 0.64 & 1.46 & 1.07 & 0.9924 & -5.90 & & \\
\hline PC-1-2a & 0.61 & 1.53 & 1.11 & 0.9992 & -4.28 & \multirow{5}{*}{ PC-1-2 } & \multirow{5}{*}{-4.21} \\
\hline PC-1-2b & 0.51 & 1.44 & 0.99 & 0.9969 & -4.70 & & \\
\hline PC-1-2c & 0.49 & 1.49 & 0.98 & 0.9991 & -3.84 & & \\
\hline PC-1-2d & 0.39 & 1.65 & 1.35 & 0.9971 & -4.71 & & \\
\hline PC-1-2e & 0.73 & 1.54 & 1.30 & 0.9978 & -3.50 & & \\
\hline S6-1-2a & - & - & - & - & - & \multirow{2}{*}{ S6-1-2 } & \multirow{2}{*}{ - } \\
\hline S6-1-2b & - & - & - & - & - & & \\
\hline S6-1-5a & - & - & - & - & - & \multirow{3}{*}{ S6-1-5 } & \multirow{3}{*}{ - } \\
\hline S6-1-5b & - & - & - & - & - & & \\
\hline S8-1-2a & - & - & - & - & - & & \\
\hline S8-1-2b & - & - & - & - & - & \multirow[t]{2}{*}{ S8-0-2 } & \multirow[t]{2}{*}{-} \\
\hline S8-1-2c & - & - & - & - & - & & \\
\hline & & mean & 1.07 & & -4.47 & & \\
\hline & & C.V. & 13.65 & & 14.50 & & \\
\hline
\end{tabular}

Some specimen results are not included in Tables 5.8 and 5.9 because their fitting curves obtained values of $R^{2}$ below 0.995 . Table 5.8 presents the average value of $k_{h}$ of around $4.0 \mathrm{MPa} / \mathrm{mm}$. The average value of $k_{h}$ for $w_{o}=1$ come close to 4.5 $\mathrm{MPa} / \mathrm{mm}$ (see Table 5.9). Bigger differences are reported for the C.V. of around to $12 \%$ and $15 \%$ for $w_{o}=0$ and $w_{o}=1$, respectively. In any case, a low scatter between these two groups was obtained. It can be stated that this restraint frame has an average horizontal stiffness of $4.25 \mathrm{MPa} / \mathrm{mm}$, which is quite independent of the initial confinement conditions. It is important to outline that these $k_{h}$ values represent the horizontal stiffness of the whole restraint system (external restraint bars + Plates A and B).

In Table 5.9 we can also see that the average value of $w_{\text {test }}$ came close to $1.0 \mathrm{~mm}$. This result experimentally confirms that the chosen procedure for fixing $w_{o}(1 \mathrm{~mm}$ 
in this case) offers a good level of accuracy. The C.V. value also comes close to $14 \%$ to offer enough confidence to accept the experimental procedure presented in this thesis.

\subsubsection{Verification of the ball bearing}

In order to experimentally validate eq. 5.6, Plate $\mathrm{A}$ in specimen B4-0-2a was placed upside down. This wrong position is schematically shown in Fig. 5.11. In this position, the bars of the ball bearing come into contact with Plate A (see Fig. $5.11 \mathrm{~b})$. When this happens the ball bearing locks, and it is possible to simulate the experimental tests as other researchers have done as Walraven, Vos, and Reinhardt (1979); Paulay and Loeber (1974); Kim et al. (2010).

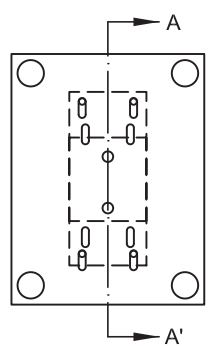

(a) Correct position

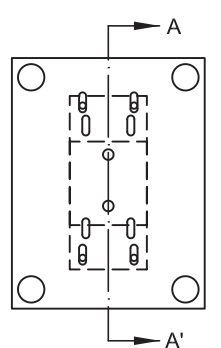

(b) Wrong position

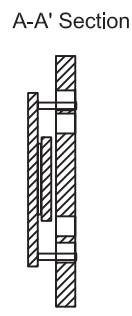

Fig. 5.11. Upside down position of Plate A.

Thus the specimen pushed down Plate A as a result of slip movement. In this test, it was impossible to reach $10 \mathrm{~mm}$ of slip given the possibility of damaging the restraint frame by increasing with slip. The test finished when slip was around 6 mm. First, the vertical displacement of Plates A and B as a function of the slip is given in Fig. 5.12. In this figure, we can seen that Plate A vertical displacement reached $5.5 \mathrm{~mm}$, while specimen slip was around $6 \mathrm{~mm}$, which confirms that the specimen pushed down Plate A. Plate B only underwent a displacement of 0.5 $\mathrm{mm}$.

The evolution of the three shear stresses $\left(\tau_{t o t}, \tau_{c}\right.$ and $\left.\tau_{f}\right)$ as a function of slip is shown in Fig 5.13 for this particular specimen. With this figure, the reliability of eq. 5.6, and the importance of the ball bearing are confirmed. Thus if $\tau_{\text {tot }}$ (black line) is observed, a typical shape of shear stress vs. slip displacement can be seen. Yet if $\tau_{f}$ (dash gray color) is observed, the shear stress transmitted through the restraint frame increases with shear slip. This stress $\left(\tau_{f}\right)$ is the reason for total shear stress $\left(\tau_{t o t}\right)$ having the typical shape. While $\tau_{f}$ increases, the shear transferred through the crack $\left(\tau_{c}\right)$ (gray light color) decreases. At the end of the test, $\tau_{f}$ has a value higher than $\tau_{c}$. Therefore, if $\tau_{\text {tot }}$ is taken as a correct value instead of correcting it and finding $\tau_{c}$, a significant overestimation of the real shear stress can be made. 


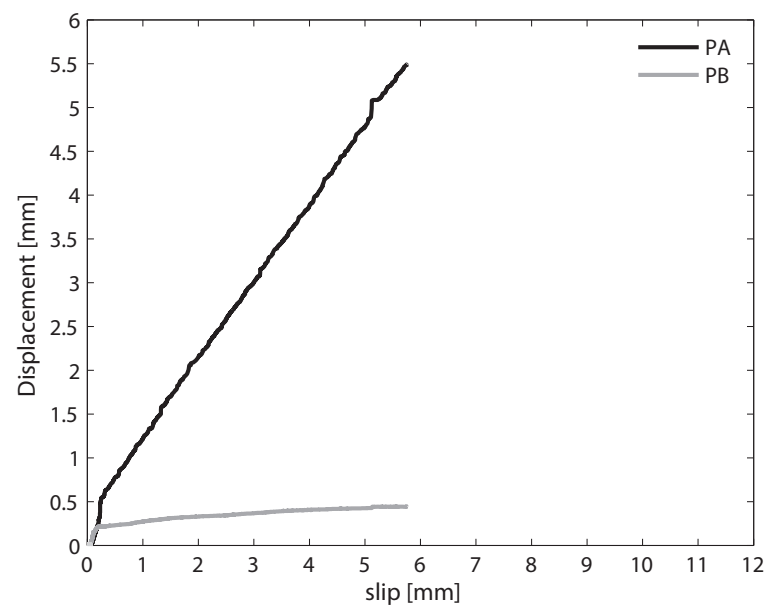

Fig. 5.12. Vertical displacement of Plates A and B (B4-0-2a specimen).

From this figure, we can also see that for a slip value of $2.0 \mathrm{~mm}, \tau_{\text {tot }}$ is around 4.15 $\mathrm{MPa}$ and $\tau_{c}$ is $3.15 \mathrm{MPa}$. This means that with $2.0 \mathrm{mmm}$ of slip, the real shear stress transmitted by the crack is around $25 \%$ lower than the assumed shear stress measured. At the failure (slip around $6 \mathrm{~mm}$ ), the shear stress values are $5.25 \mathrm{MPa}$ for $\tau_{\text {tot }}$ and $2.39 \mathrm{MPa}$ for $\tau_{c}$. Thus, the contribution of the restraint frame to the transmission of shear stress is more than $50 \%$, which does not seem admissible at all.

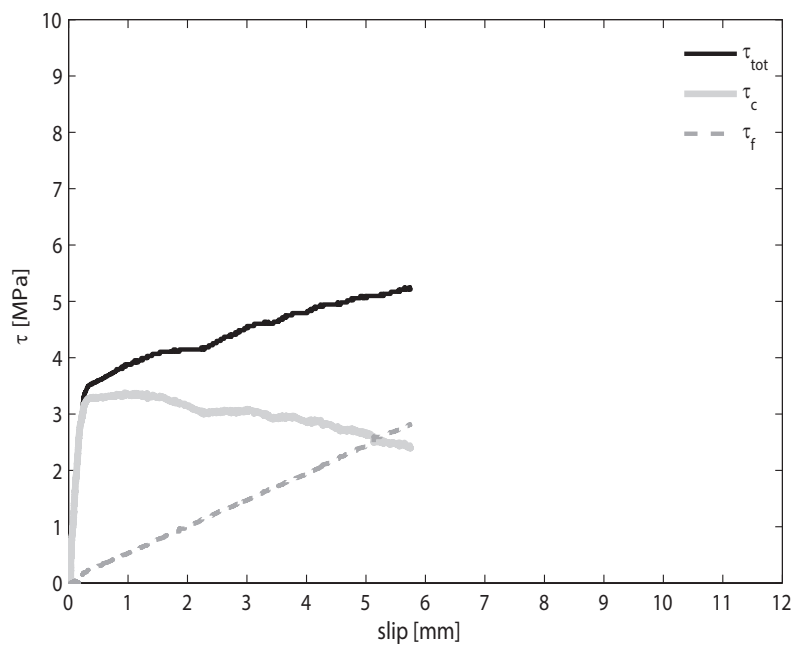

Fig. 5.13. Shear stresses vs. slip relationship 
This behavior is the best proof that the ball bearing mechanism works well and is of vital importance for the shear behavior of the crack, even if low slip values are analyzed $($ slip $<2.0 \mathrm{~mm})$. For this reason, the shear behavior reported by previous authors Walraven, Vos, and Reinhardt (1979); Paulay and Loeber (1974); Kim et al. (2010) who confined specimens and where no ball bearing was used, might have overestimated shear stress.

\subsubsection{Statistical study of plate displacements}

In this subsection, a statistical analysis of the vertical displacements of both Plates $\mathrm{A}$ and $\mathrm{B}$ is presented. The aim of this study was to show the ultimate vertical displacements and how these can be fitted to a probabilistic distribution.

It must be pointed out that both Plates A and B move downwards. Thus, this direction was taken as positive values. In Table 5.10 (first part) and Table 5.11 (second part), the ultimate vertical displacements of the plates are shown. In Table 5.10 , the movements of Plate B are not reported because some problems appears in the procedure and reliable values were obtained in few specimens. However, these problems were solved for the second part of the experimental tests.

Table 5.10. Ultimate displacement of Plate A (first part).

\begin{tabular}{ll}
\hline & PA \\
Specimen & {$[\mathrm{mm}]$} \\
\hline A5-0-2a & 1.13 \\
A5-0-2b & 1.81 \\
A5-1-2a & 0.12 \\
A5-1-2b & 0.35 \\
A5-1-4a & 0.80 \\
A5-1-4b & 0.38 \\
PC-0-4a & 1.22 \\
PC-0-4b & 0.94 \\
PC-0-5a & 1.55 \\
PC-0-5b & 0.89 \\
PC-1-1a & 0.38 \\
PC-1-1b & 0.51 \\
PC-1-2d & 0.48 \\
PC-1-2e & 0.44 \\
S6-0-1a & 1.78 \\
S6-0-1b & 1.58 \\
S6-1-2a & 2.03 \\
S6-1-2b & 1.10 \\
S6-1-5a & 0.96 \\
S6-1-5b & 0.28 \\
\hline
\end{tabular}


Table 5.11. Ultimate displacements of Plates A and B (second part).

\begin{tabular}{|c|c|c|}
\hline Specimen & $\begin{array}{l}\mathrm{PA} \\
{[\mathrm{mm}]}\end{array}$ & $\begin{array}{l}\mathrm{PB} \\
{[\mathrm{mm}]}\end{array}$ \\
\hline $\mathrm{A} 4-0-2 \mathrm{a}$ & 1.55 & 0.44 \\
\hline $\mathrm{A} 4-0-2 \mathrm{~b}$ & 0.17 & 1.05 \\
\hline $\mathrm{A} 4-0-2 \mathrm{c}$ & 1.34 & 0.74 \\
\hline A4-1-2a & 0.40 & 0.62 \\
\hline $\mathrm{A} 4-1-2 \mathrm{~b}$ & 0.12 & 1.27 \\
\hline $\mathrm{A} 4-1-2 \mathrm{c}$ & 0.52 & 0.74 \\
\hline B4-0-2a & 5.49 & 0.44 \\
\hline B4-0-2b & 1.98 & 0.58 \\
\hline B4-0-2c & 1.49 & 0.59 \\
\hline B4-1-2a & 0.97 & 0.37 \\
\hline B4-1-2b & 1.05 & 0.82 \\
\hline B4-1-2c & 0.33 & 0.57 \\
\hline C4-0-2a & 0.79 & 0.66 \\
\hline C4-0-2b & 1.63 & 0.37 \\
\hline $\mathrm{C} 4-0-2 \mathrm{c}$ & 0.85 & 0.52 \\
\hline C4-1-2a & 1.17 & 0.48 \\
\hline $\mathrm{C} 4-1-2 \mathrm{~b}$ & 1.40 & 0.84 \\
\hline C4-1-2c & 0.47 & 0.74 \\
\hline C7-0-2a & 1.14 & 0.49 \\
\hline $\mathrm{C} 7-0-2 \mathrm{~b}$ & 1.03 & 0.55 \\
\hline $\mathrm{C} 7-0-2 \mathrm{c}$ & 1.03 & 0.92 \\
\hline C7-1-2a & 1.33 & 0.74 \\
\hline $\mathrm{C} 7-1-2 \mathrm{~b}$ & 0.27 & 0.24 \\
\hline $\mathrm{C} 7-1-2 \mathrm{c}$ & 0.32 & 0.85 \\
\hline PC-0-2a & 1.30 & 0.48 \\
\hline PC-0-2b & 2.64 & 0.76 \\
\hline PC-0-2c & 2.24 & 0.56 \\
\hline PC-1-2a & 0.70 & 0.46 \\
\hline PC-1-2b & 0.23 & 0.34 \\
\hline PC-1-2c & 0.26 & 0.68 \\
\hline S8-0-2a & 3.00 & 0.68 \\
\hline $\mathrm{S} 8-0-2 \mathrm{~b}$ & 2.03 & 0.83 \\
\hline $\mathrm{S} 8-0-2 \mathrm{c}$ & 1.81 & 0.72 \\
\hline S8-1-2a & 2.78 & 0.33 \\
\hline $\mathrm{S} 8-1-2 \mathrm{~b}$ & 1.06 & 0.40 \\
\hline $\mathrm{S} 8-1-2 \mathrm{c}$ & 1.81 & 0.65 \\
\hline
\end{tabular}

\section{Statistical study of Plate B (PB)}

Due to the problems reported in the first part of the experimental tests, a decision was made to use the second part to make an statistical analysis of the vertical 
displacements at the ultimate state of both plates. First a histogram and a normal fitting distribution of Plate B are presented in Fig. 5.14. From the 36 values, ranging from 0.24 to $1.26 \mathrm{~mm}$, fitting was possible with a good normal fitting curve. The estimated parameters of the fitted distribution are shown in Table 5.12 .

Table 5.12. Fitted Distributions

\begin{tabular}{ll}
\hline Normal & \\
\hline mean & 0.626 \\
S.D. & 0.215 \\
\hline
\end{tabular}

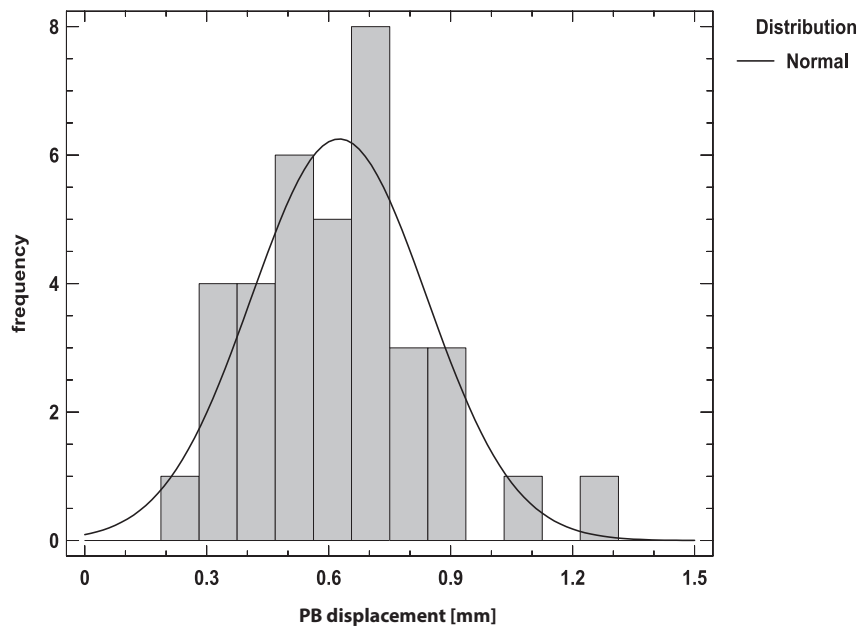

Fig. 5.14. Histogram for $\mathrm{PB}$ displacement.

In order to determine if the experimental data were well-modeled by normal distribution, a normality test was applied. In other words, this test allows to know the goodness-of-fit of the data to a normal model. If the fit is poor, then the data cannot be well-modeled by a normal distribution. By consider the values shown in Table 5.13, and since the smallest P-value in the Shapiro-Wilk test performed was over 0.05 , it is concluded that the vertical displacement of Plate B (PB) can be fitted to normal distribution with $95 \%$ confidence.

Table 5.13. Normality test for vertical displacement of PB

\begin{tabular}{lll}
\hline Test & Statistic & P-Value \\
\hline Shapiro-Wilk & 0.967 & 0.441 \\
\hline
\end{tabular}




\section{Statistical study of Plate A (PA)}

Vertical displacement was measured in 56 specimens. However, the specimen B40-2a was excluded from this analysis due to the wrong setting of Plate A. The data of 55 samples were used in the statistical analysis. The values of these 55 samples ranged from 0.116 to $2.995 \mathrm{~mm}$ of vertical displacement.

The analysis shows that a poor normal fit to a normal distribution was adjusted.From the same statistical analysis, a better fit was adjusted by Weibull distribution. In Table 5.14, the parameters of both normal and Weibull distribution are shown.

Table 5.14. Fitted Distributions for PA

\begin{tabular}{llll}
\hline \multicolumn{2}{c}{ Normal } & \multicolumn{2}{c}{ Weibull } \\
\hline mean & 1.089 & Shape & 1.570 \\
S.D. & 0.707 & Scale & 1.213 \\
\hline
\end{tabular}

Fig. 5.15 shows the histogram of the vertical displacement of PA and the two fitted distribution: Normal and Weibull. In the figure we can seen that the vertical displacement of Plate A at failure was better fitted by Weibull distribution.

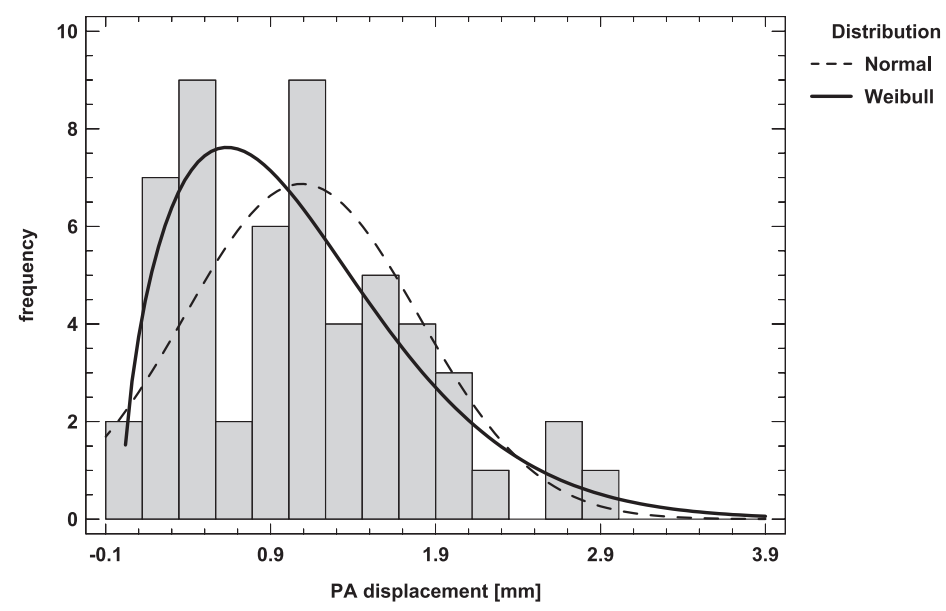

Fig. 5.15. Histogram for PA displacement.

By means of these statistical studies, the ultimate values of the vertical displacements of both plates, A and B, were obtained. Based on these ultimate values, relative vertical displacement $(\Delta)$ was obtained. Knowing $\Delta$, it was possible to correct ultimate shear stress eq. 5.6. 


\subsection{Analysis and discussion of the experimental program results}

This section focuses on the analysis and discussion of the influence on shear behavior of the different parameters considered in the experimental program. In the following sections, the influence of each parameter is studied to gain special insight into detecting different mechanical behaviors.

\subsubsection{Influence of $w_{o}$}

The aim pursued when testing specimens with two levels of allowed initial crack width was to simulate two different shear failure modes. The first shear failure mode is due to diagonal tension $\left(w_{o}=1\right)$. This failure mode is explained in section 2.3.1. The second shear failure mode is known as sliding plane, and in this case the allowed initial crack width was equal to zero $\left(w_{o}=0\right)$. This failure mode has been widely studied and, in recent years, several tests have been reported by different authors, such as Haskett et al. (2010); Hatano et al. (2011); Haskett et al. (2011); Lucas, Oehlers, and Ali (2011); Lucas et al. (2012); Zhang, Oehlers, and Visintin (2014); Zhang et al. (2014). The influence of this parameter was analyzed by means the curves of response previously presented in section 5.2.3. Plain concrete was used as an example to study these two different modes of failure, and Fig. $5.16 \mathrm{~b}$ shows the four plots. Since several identical repetitions were carried out (2 or 3 ), this section only provided the average values for simplicity sake.

It is observed in Fig. 5.16a that when $w_{o}=0$ (black line), a shear stress of 3 MPa was transmitted by the crack interface at a slip value of $1 \mathrm{~mm}$. While when $w_{o}=1$ (grey line), the crack only transmitted a shear stress of $0.6 \mathrm{MPa}$ for the same slip value of $1 \mathrm{~mm}$. This is a huge difference (around 500\%), even though this difference reduced with increasing slip displacements. Thus for a slip value of $6 \mathrm{~mm}$, shear stresses rose to around $5 \mathrm{MPa}$ for $w_{o}=0$ and to $2 \mathrm{MPa}$ for $w_{o}=1$. Therefore with a slip value of $6 \mathrm{~mm}$, a shear stress of $w_{o}=0$ is around $250 \%$ higher than the shear stress for $w_{o}=1$. At failure ( $\left.\operatorname{slip}=10 \mathrm{~mm}\right)$, the difference between them was only of $200 \%$.

With plain concrete, resistance shear mechanisms are the aggregate interlock and the combined effect of confinement with the macro-roughness (CMR) of the shear plane. For specimens with $w_{o}=0$, the influence of both mechanisms was strong. Moreover under these conditions, when the aggregate interlock began to fail, CMR was the mechanism which allowed the increment. Yet when $w_{o}=1$ was analyzed, the influence of the aggregate interlock was minor. Moreover, CMR needs a certain crack width value to be effectively activated. In other words, these two resisting mechanisms activate at different times as a result of $w_{0}$.

In Fig. 5.16b, the influence of crack width on shear behavior is shown. For the initially confined conditions, $\left(w_{o}=0\right)$ is observed, a huge shear stress developed and crack width increased as a result of macro-roughness. The amount of shear stress developed for both failure modes is seen in this figure. In Fig. 5.16b, we 


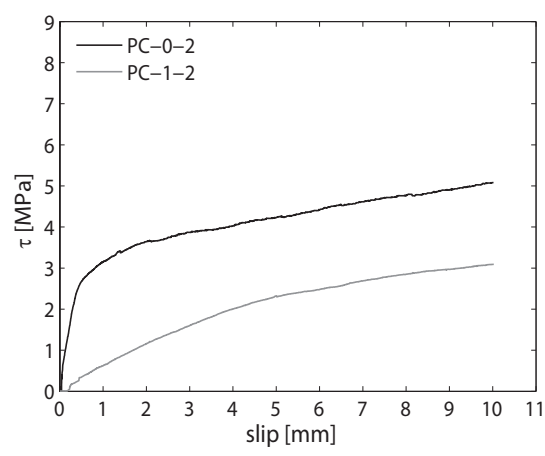

(a) Shear stress vs slip relationship

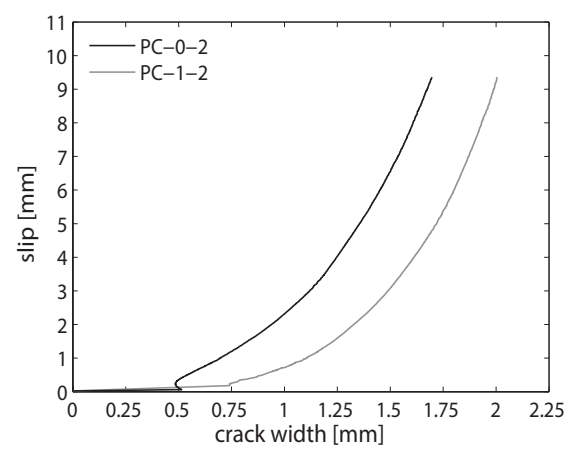

(c) Crack opening path relationship

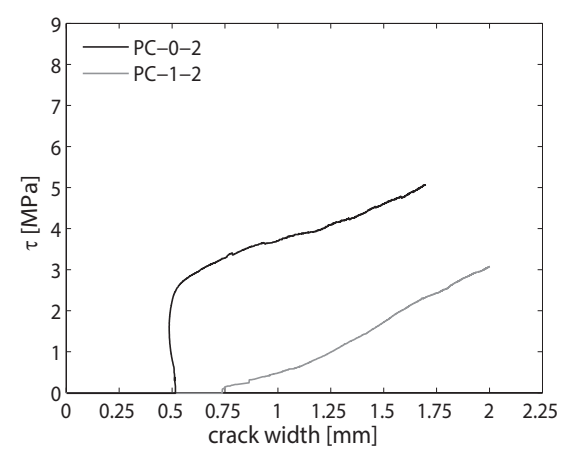

(b) Shear stress vs crack width relationship

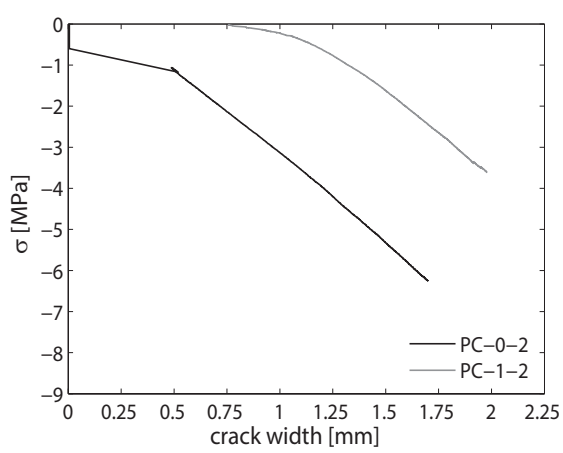

(d) Normal stress vs crack width relationship

Fig. 5.16. Influence of the allowed initial crack width on shear behavior (plain concrete).

can observe that for $w_{o}=0$ and a crack width of $1 \mathrm{~mm}$, shear stress is $4.5 \mathrm{MPa}$. For $w_{o}=1$, a shear stress of $0.3 \mathrm{MPa}$ is observed for a crack width of $1 \mathrm{~mm}$. The question of "how it is possible to transmit shear stress when crack width is $1 \mathrm{~mm}$ for $w_{o}=1$ ?" appears. The answer to this question is given in the next paragraph.

The crack opening path is shown in Fig. 5.16c. If the curve for $w_{o}=1$ is observed, it is possible to see that for a crack width value of $1 \mathrm{~mm}$, a slip value of $0.5 \mathrm{~mm}$ is reached. This slip value is the answer of the above question. For $w_{o}=0$ when crack width is $1 \mathrm{~mm}$, slip is more than $2 \mathrm{~mm}$. When we observe this behavior, it can be state that cracked concrete can transmit shear stress, even for a wide initial crack width, when slip displacement begins.

Normal stress evolution as a function of crack width comes in different shapes if the specimens with $w_{o}=0$ and $w_{o}=1 \mathrm{~mm}$ are compared, as shown in Fig. 5.16d. When $w_{o}=0 \mathrm{~mm}$, a clear bi-linear shape is found, as defined by three singular points. These points are initial confinement stress (of 0.6 MPa), the normal stress produced by precracking, and the normal stress developed during the push-off test. When $w_{o}=1 \mathrm{~mm}$, a curved-straight line is obtained. 
Now that the influence of the allowed initial crack width $\left(w_{o}\right)$ for plain concrete has been explained, and that the influence of $w_{o}$ for SFRC and RC is presented. In Fig. 5.17, the shear stress as a function of the slip displacement is presented. In this figure, SFRC (A4 specimen) and RC (S8 specimen) are shown in order to see the differences in shear behavior for both the $w_{o}$ values considered.

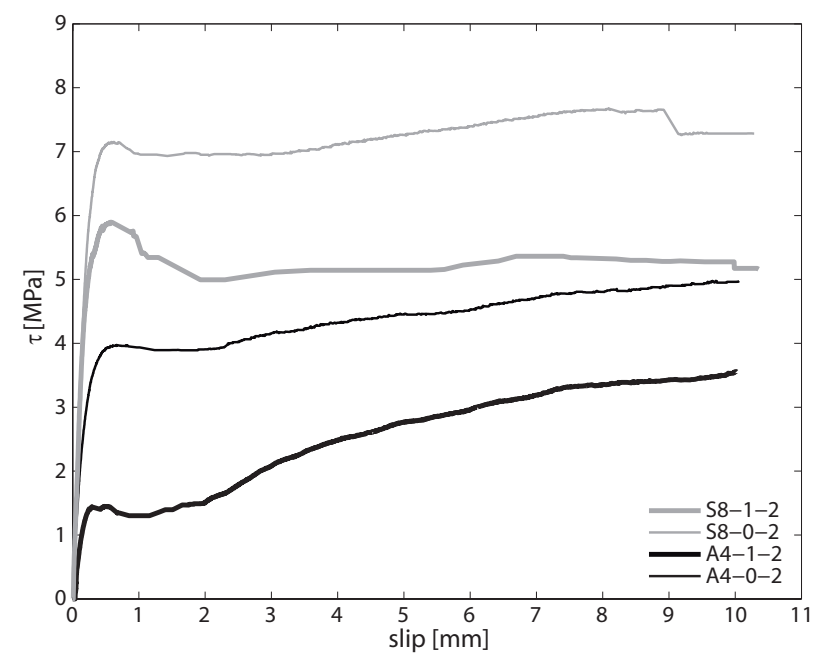

Fig. 5.17. Influence of $w_{o}$ on shear behavior for different shear reinforcement.

\subsubsection{Influence of fiber type}

In this section, the influence of fiber type on shear behavior is studied. Three different fiber types were used in the experimental program: RC-65/35 BN, RC$80 / 50 \mathrm{BN}$ and RC-80/30 BP. The same fiber amount $\left(40 \mathrm{~kg} / \mathrm{m}^{3}\right)$ was used to compare these three fiber types. The fiber type analysis was done by means of the shear stress-slip displacement curves, as shown in Fig. 5.18. In this figure, the dashed curves represent the allowed initial crack width of $1 \mathrm{~mm}\left(w_{o}=1\right)$, and the continuous line represents confined specimens $\left(w_{o}=0\right)$. 


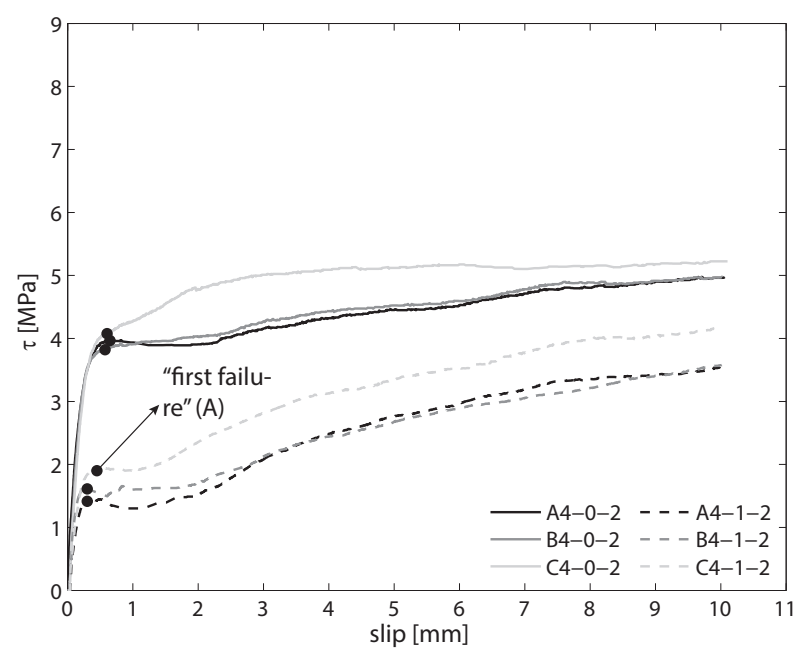

Fig. 5.18. Influence of fiber type on shear behavior.

For the confined conditions, no significant differences among the three fiber types (RC-65/35 BN, RC-80/50 BN and RC-80/30 BP) were observed. Thus the three fibers showed a "first failure" at $4 \mathrm{MPa}$ and $0.6 \mathrm{~mm}$ of slip, and the three slopes prior this point are also comparable. After this point, for RC-65/35 BN (A4-0-2), shear stress slightly dropped followed by an increase in shear stress for larger slip displacements, and the ultimate shear stress was around 5.0 MPa. For RC-80/50 BN (B4-0-2), non drop on shear stress is observed after the "first failure" point, and then a similar response to that obtained for (A4-0-2) is shown, which reached an ultimate shear stress of around $5 \mathrm{MPa}$. Finally, for RC-80/30 BP (C4-0-2), increasing shear stress values after the "first failure" of up to $5.2 \mathrm{MPa}$ at failure were obtained. The explanation for this behavior might be the larger amount of fiber; in other words, the number of fibers for RC-80/50 BN was 8100 fibers $/ \mathrm{kg}$, while it was 34000 fibers $/ \mathrm{kg}$ for RC-80/30 BP.

The behavior for the initially unconfined specimens $\left(w_{o}=1\right)$ showed different "first failure" points depending on the fiber type (see Fig. 5.18). Thus the highest shear stress value was found for RC-80/30 BP fiber (C4-1-2), at around $2 \mathrm{MPa}$, the lowest value $(1 \mathrm{MPa})$ went to specimen $\mathrm{A} 4-1-2(\mathrm{RC}-65 / 35 \mathrm{BN})$, and in middle value was for B4-1-2 (RC-80/50 BN) with 1.5 MPa. Then shear stress dropped for A4-1-2, while B4-1-2 and C4-1-2 remained constant. Between 1.5 and $2 \mathrm{~mm}$, shear stress began to increase to reach ultimate shear stress of 3.5 MPa for A4-1-2 and B4-1-2, and 4.1 MPa for C4-1-2. The fact that ultimate shear stress had similar values, regardless of fiber type, shows that macro-roughness is the shear transfer mechanism which governs this property for high slip displacement values. 


\subsubsection{Influence on amount of fibers}

Influence on amount of fibers was analyzed by two fiber types: the first type had a difference of $10 \mathrm{~kg} / \mathrm{m}^{3}$ (40 and $50 \mathrm{~kg} / \mathrm{m}^{3}$ ) for RC-65/35 BN, while the second difference was $30 \mathrm{~kg} / \mathrm{m}^{3}$ (40 and $70 \mathrm{~kg} / \mathrm{m}^{3}$ ) for RC-80/30 BP. As in previous sections, the analysis was done based on the average behavior from the results obtained thanks to the repetition of specimens. These behaviors are reported by the "Material id code" values, as it was indicated in Table 4.4. The first difference is presented in Fig. 5.19 for both confinement conditions (A4-0-2 and A5-0-2). When the initially confined condition was analyzed (see Fig. 5.19a), the influence of an increase in amount of fiber remained unclear. The "first failure" was detected between 3.0 MPa (A5-0-2) and 4.0 MPa (A4-0-2) of shear stress, then a sudden slip occurred until $2 \mathrm{~mm}$. After this point, both shear stress increased with similar slopes, and ultimate shear stress was around 4.5 MPa (A5-0-2) and 5.0 MPa (A4$0-2)$. The same trend was observed for the initially unconfined specimens (A4-1-2 and A5-1-2) (see Fig. 5.19b). In this case, the "first failure" was slightly higher for A5-1-2 than for A4-1-2. After this point, a sharper drop in shear stress was observed for A5-1-2. A sudden slip occurred to $2 \mathrm{~mm}$ for A4-1-2 and to $3 \mathrm{~mm}$ for A5-1-2, then shear stress increased until ultimate shear stress was reached. Shear strengths of 3.5 MPa for A4-1-2 and of 2.5 MPa for A5-1-2 were observed. 


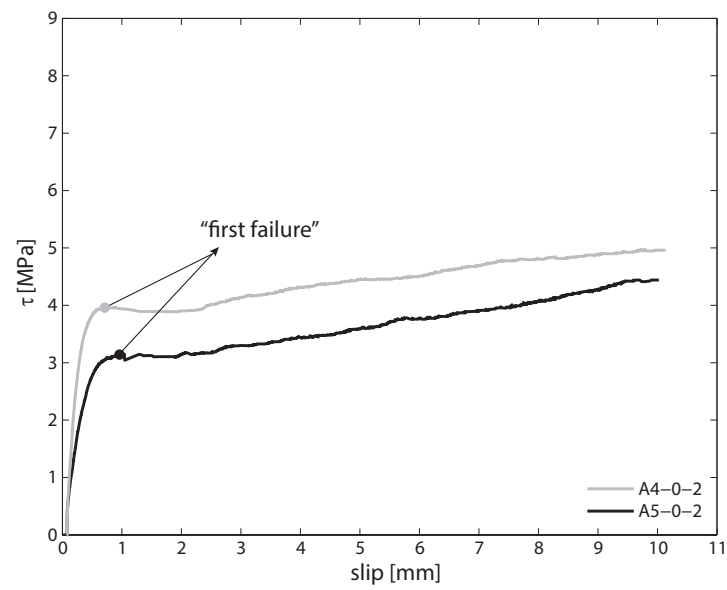

(a) Initially confined conditions

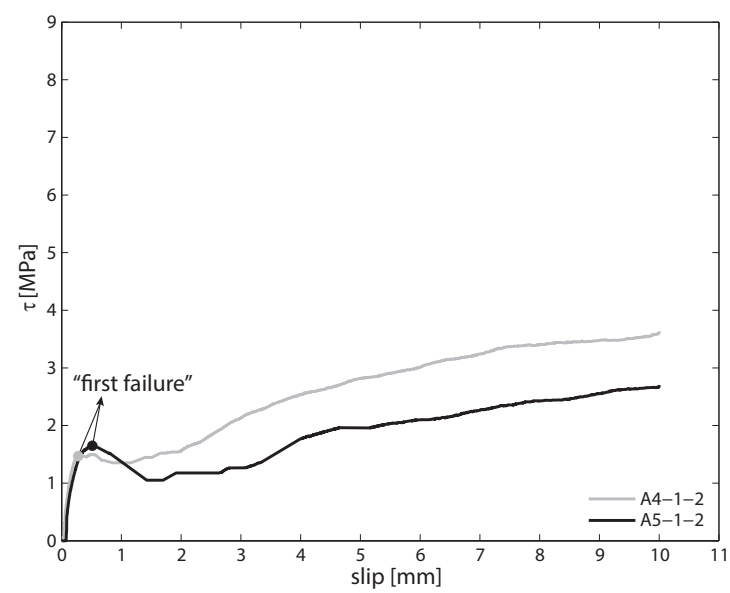

(b) Initially unconfined conditions

Fig. 5.19. Shear behavior for 40 and $50 \mathrm{~kg} / \mathrm{m}^{3}(\mathrm{RC}-65 / 35 \mathrm{BN})$.

In Fig. 5.20, the second couple 40 (C4) and $70(\mathrm{C} 7) \mathrm{kg} / \mathrm{m}^{3}$ are compared. The specimens under confined conditions (C4-0-2 and C7-0-2) (see Fig. 5.20a) showed a slight increase in shear stress at the "first failure", which rose from 4.2 to 5.5 $\mathrm{MPa}$ (in average values) when the amount of fiber increased. Under the failure conditions, the distance between both values reduced. The shear stress for $\mathrm{C} 4$ showed increased shear strength, while $\mathrm{C} 7$ remained constant. For the initially unconfined specimens (C4-1-2 and C7-1-2) (see Fig. 5.20b), similar behavior was observed. Shear stress increased when the amount of fiber increased at "first failure" from $2 \mathrm{MPa}$ in $\mathrm{C} 4$ to $3 \mathrm{MPa}$ in $\mathrm{C}$. After this point, $\mathrm{C} 7$ the shear stress curves showed no increment (or even drops), followed by a faster increase in slip displacement. C4 showed an increasing shear stress trend while slip increased, and at ultimate higher shear strength. 


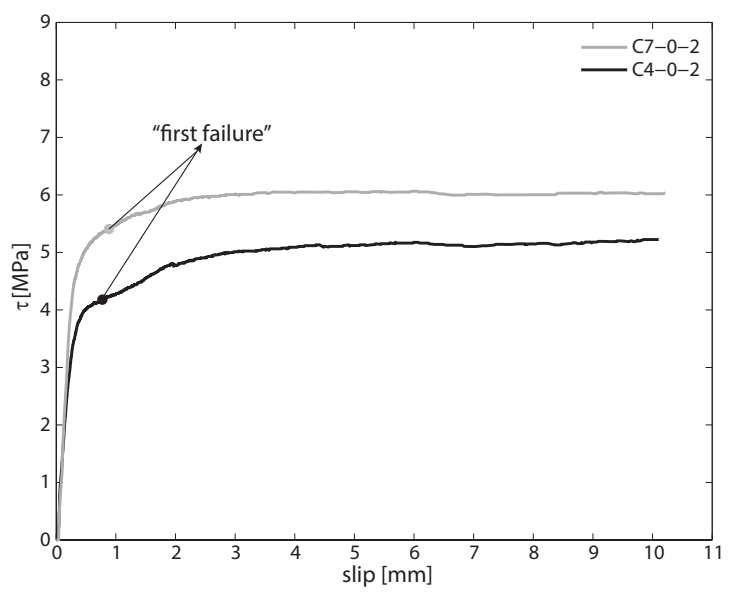

(a) Initially confine condition

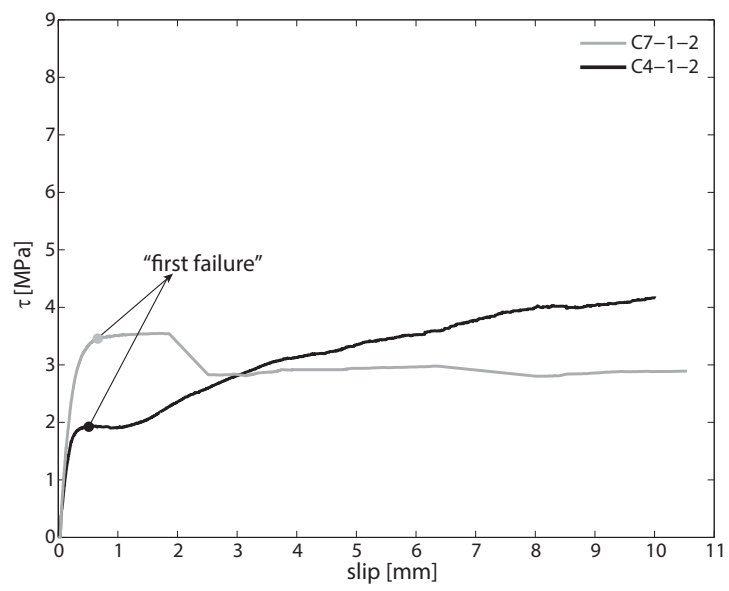

(b) Initially unconfined condition

Fig. 5.20. Shear behavior for 40 and $70 \mathrm{~kg} / \mathrm{m}^{3}$ (RC-80/30 BP).

\subsubsection{Influence of transverse reinforcement ( $\rho$ ratio)}

To analyze the influence of transverse reinforcement ( $\rho$ ratio) two stirrup diameters of $6 \mathrm{~mm}$ (S6) and $8 \mathrm{~mm}$ (S8) were used, as mentioned in Table 4.4. With these stirrups, a $\rho$ ratio of $0.44 \%$ and of $0.79 \%$ was obtained, respectively.

Under the initially confined conditions (see Fig. 5.21a) a clear difference was observed. The increment in the reinforcement ratio led to incremented shear stress. S8 behavior is characterized by a drop in shear stress after "first failure", a constant shear zone and then an increased branch with a tended slope. The S6 series gave lower shear stress values at "first failure", and shear stress increased after this point until failure was reached. Indeed under the failure conditions, both series showed a drop in shear stress. 
Under the initially unconfined conditions (see Fig. 5.21b), behavior was similar to the confined conditions. The main difference in this case was how clear the difference in shear stress was at "first failure". No significant difference in shear behavior was reported for different concrete strengths (see S6-1-2 and S6-1-5). Thus for the S6 series, this point was around 4.0 MPa, while the S8 series reached 6.0 MPa. Then a drop in shear stress was followed by a huge increment in slip. The S6-1-5 series showed an increasing trend in shear stress which, at failure, meant that shear strength was similar to the results of the S8-1-2 series. By observing these behaviors, it can be concluded for the S8 series that once yielding stress was reached, brittle failure by sliding took place. Similar behaviors have been reported in previous works by Nagle and Kuchma (2007). In the S6 series, behavior was slightly brittle than for the S8 series.

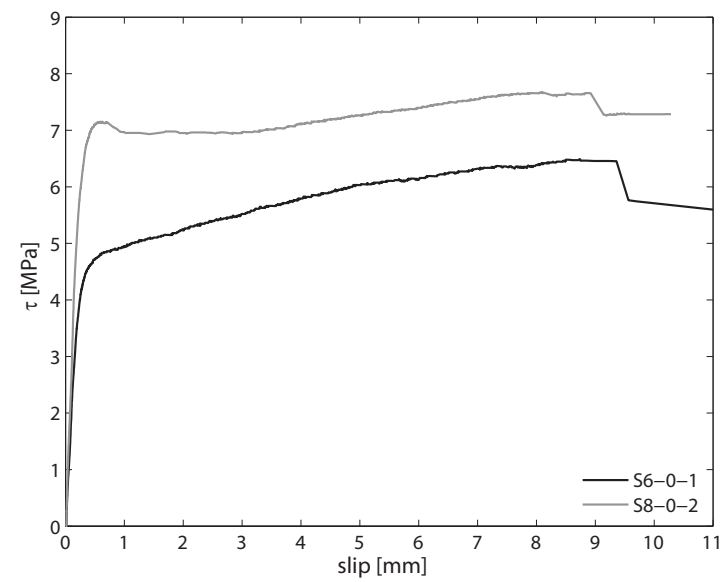

(a) Initially confined conditions

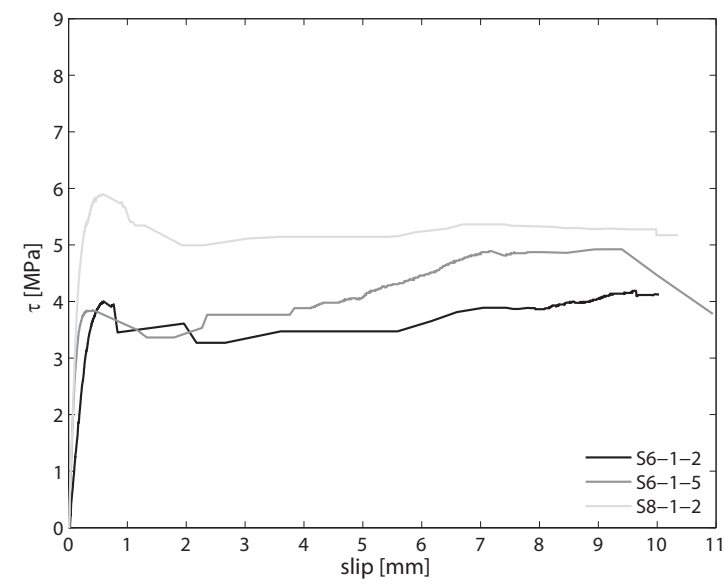

(b) Initially unconfined conditions

Fig. 5.21. Shear behavior for different shear reinforcement ratios (0.44 and $0.77 \%)$. 
Moreover, despite the brittle behavior and the crushed concrete covering of stirrups (see Fig. 5.22a) observed in the S8 series, the stirrups remained together as a single piece. In the S6 series, no crushing of concrete was observed when push-off finished (see Fig. 5.22b); usually 3 of the 4 stirrups were completely cut off (see Fig. 5.23b). In both series, the concrete surrounding the stirrups was crushed upside the stirrup in the ACTIVE part and downside the stirrup in the PASSIVE part, as seen in Fig. 5.23a. The same figure also shows the necking zone of the stirrup.

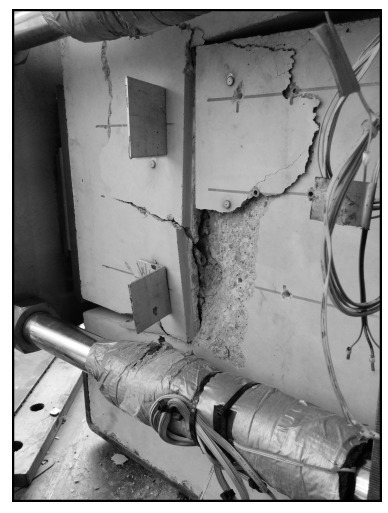

(a) S8 series

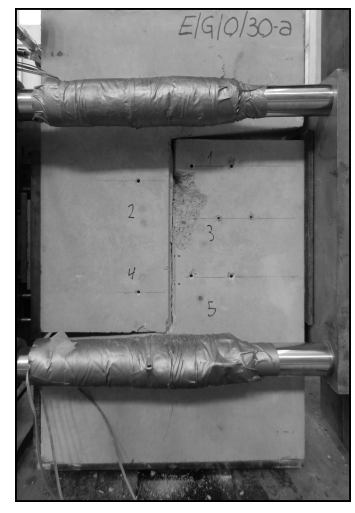

(b) S6 series

Fig. 5.22. Crushed concrete covering of stirrups.

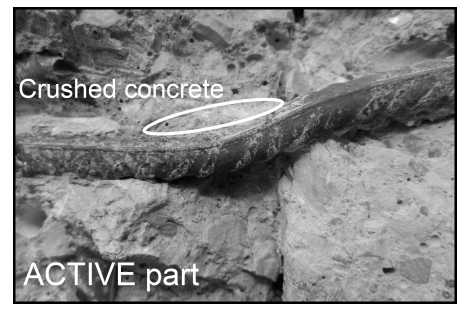

(a) S8 series

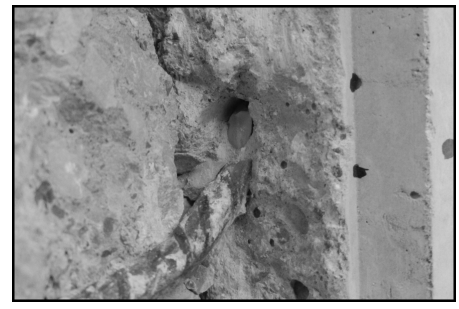

(b) S6 series

Fig. 5.23. Final aspect of stirrup.

\subsubsection{Influence of concrete strength and maximum aggre- gate size}

To analyze the influence of maximum aggregate size, two concrete mixtures with a similar concrete compressive strength, but with a different maximum aggregate size, were tested. The maximum size corresponded to $20 \mathrm{~mm}$ for mix 4 and 12 mm for mix 5, while concrete compressive strength was between 56 and $61 \mathrm{MPa}$. In this subsection, only the plain concrete specimens were analyzed in order to study the influence of maximum aggregate size to avoid the influence of the other parameters considered in the experimental program. 


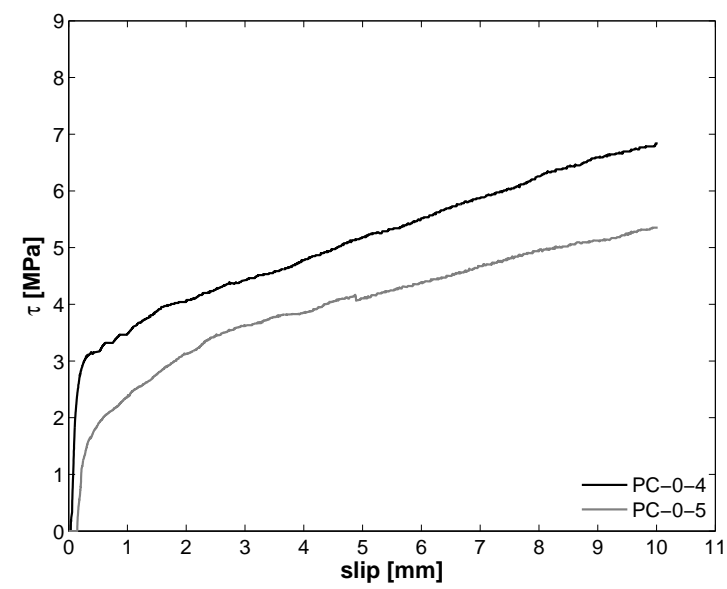

(a) Shear stress vs slip relationship

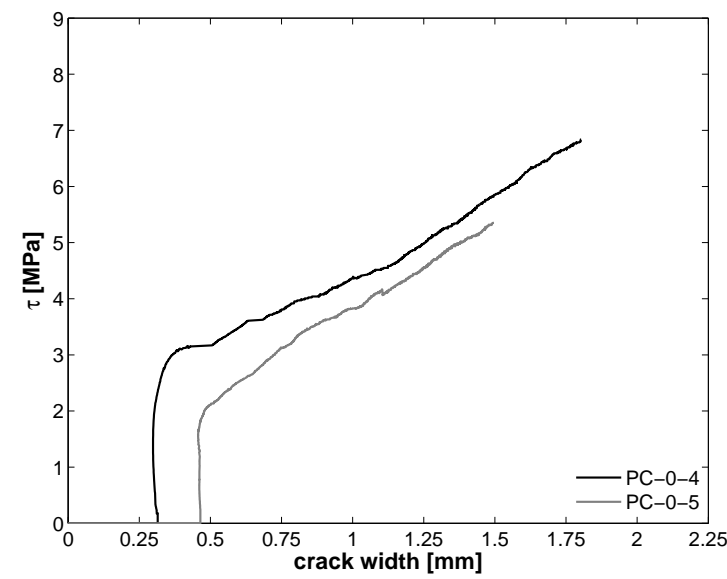

(b) Shear stress vs crack width relationship

Fig. 5.24. Influence of maximum aggregate size on the confined condition.

The shear behavior of these specimens is shown in Fig. 5.24. When the evolution of shear stress vs. slip was observed (see Fig. 5.24a), a significant difference was found in both cases. In PC-0-4, a steeper slope to 3.0 MPa was found first. Then a series of steps to 4.0 MPa were presented for a slip value of $2.0 \mathrm{~mm}$. After this point, a straight line was observed. Ultimate shear stress was around 7.0 MPa for a slip value of $10.0 \mathrm{~mm}$. In PC-0-5, a tri-linear behavior was noted. In the first part, with a steeper slope to $2.0 \mathrm{MPa}$ and $0.5 \mathrm{~mm}$ of slip, the next line had a less marked slope and went to $3.0 \mathrm{MPa}$ and $2.0 \mathrm{~mm}$ of slip. The last line had a less marked slope than the previous line, and went to $5 \mathrm{MPa}$ and $10 \mathrm{~mm}$ of slip. The fact that shear stress increased with increment slip indicates that macro-roughness is a major mechanism of shear transfer.

If shear stress evolution as a function of crack width is observed (see Fig. 5.24b), one possible explanation for this behavior can be found. The initial crack width 
for PC-0-4 was around $0.25 \mathrm{~mm}$, while in the PC-0-5 series, the initial crack width was twice that (close to $0.5 \mathrm{~mm}$ ). It is well-known that initial crack width was one of the most important variables in shear behavior. Therefore, higher shear stress values are found for lower crack width values. Thus, PC-0-5 showed the lowest shear stress values with the highest initial crack width value $(0.5 \mathrm{~mm})$. The figure also shows that while the test continued, the difference in shear stress became smaller.

The behavior, trends and scatters on shear strength explained in the previous paragraph were found for the initially unconfined conditions (see Fig. 5.26). This confirms that macro-roughness is affected by maximum aggregate size and that it is a major mechanism of shear stress transmission. All aggregate particles were broken when a concrete strength of $60 \mathrm{MPa}$ was studied (mixes 4 and 5). For this reason, a lower concrete compressive strength of $50 \mathrm{MPa}$ was used. In this case, specimens with thin aggregates slices were found when the push-off test finished, as shown in Fig. 5.25, where we can also see aggregates of different sizes pasted by the matrix.

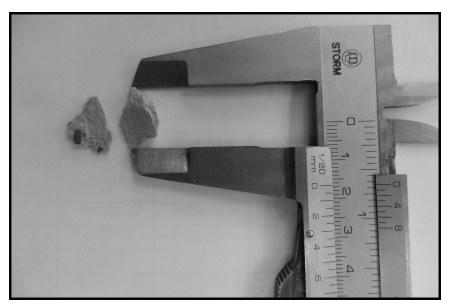

(a) Detail of aggregate with matrix added

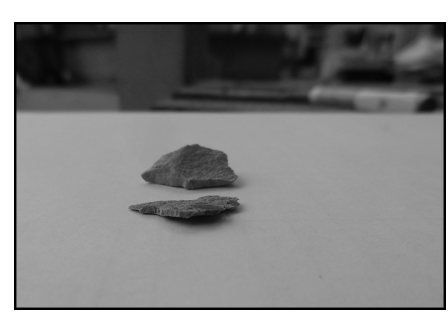

(b) Other view of the slices

Fig. 5.25. Sample of aggregate slice. 


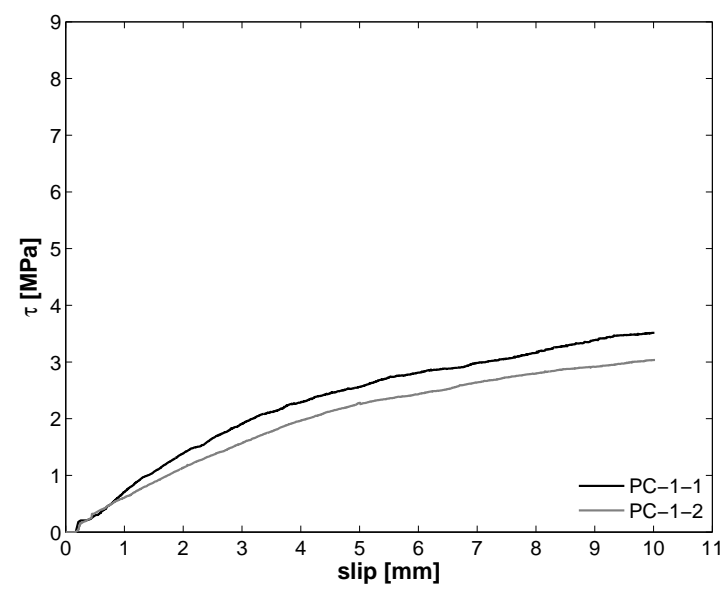

(a) Shear stress vs slip relationship

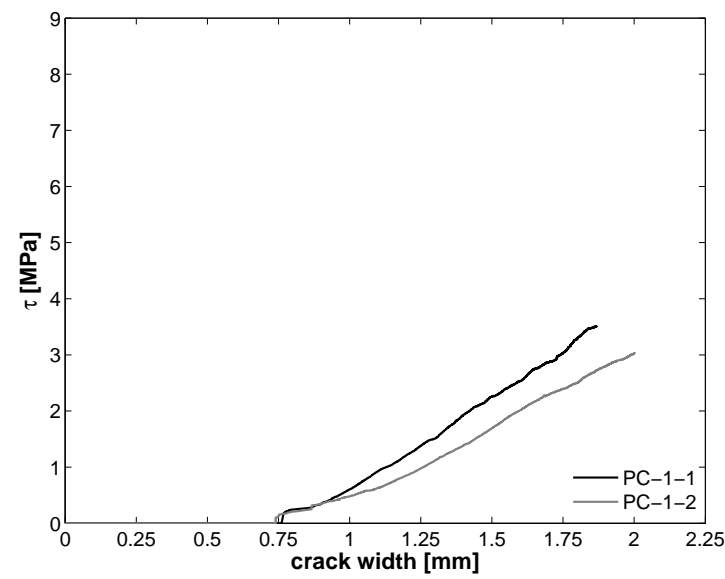

(b) Shear stress vs crack width relationship

Fig. 5.26. Influence of concrete strength on direct shear behavior.

\subsubsection{SFRC and RC comparison}

The results between the SFRC and RC push-off specimens are compared in this section. From the experimental results (sections 5.4.2, 5.4.3, and 5.4.4), we can see that the reinforced concrete (RC) specimens showed higher shear stress for small slip values. So to compare the shear behavior of RC and SFRC, a superposed figure was used. In this figure, shear stress as a function of crack width is presented in black, while the crack opening path is depicted in light gray (see Fig. 5.27). Thus, shear stress evolution and the in-plane shear displacements (crack width and slip) are seen in the same figure, which provides a general understanding of shear behavior in the same figure. 


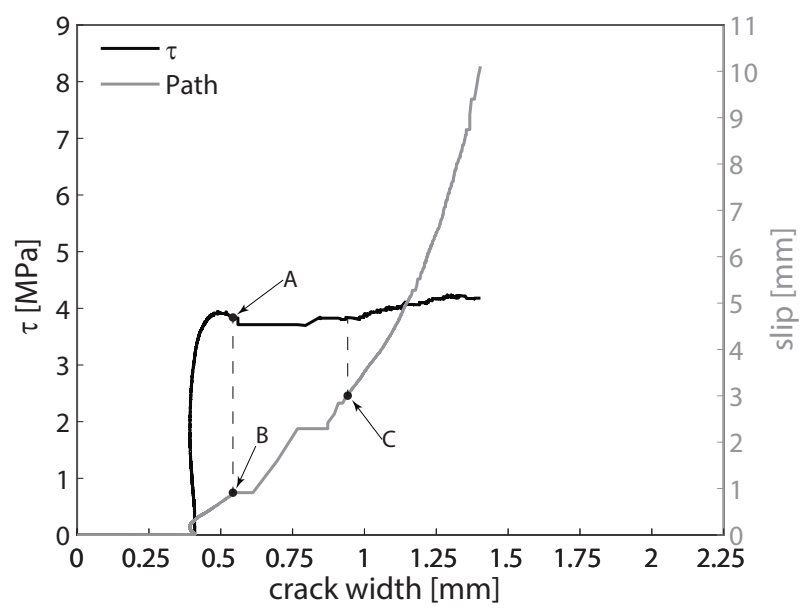

Fig. 5.27. General shear behavior of SFRC (A4-0-2a specimen).

By way of example, specimen A4-0-2a is presented in Fig. 5.27. Maximum shear stress is located before the "first failure", marked at point A on the black curve. Point A was around $4 \mathrm{MPa}$ and corresponded to a crack width of around $0.5 \mathrm{~mm}$. On the crack opening path (light gray color), this point A corresponded to $0.7 \mathrm{~mm}$ of slip, marked as Point B. After point A, a small drop in shear stress is occurred followed by an increment in crack width. The kinematics of crack (see light gray) shows that before Point B, both crack width and slip increased together. Then crack width and slip increased by steps until point $\mathrm{C}$. It can be seen that a large increment in slip displacement took placed between point $\mathrm{B}(0.7 \mathrm{~mm})$ and Point C $(3.0 \mathrm{~mm})$. After Point C, the shear stress (black color) increases at small rate until failure as a result of the combined effect of pull-out of some steel fibers and shear friction.

In Fig. 5.28, two comparisons were made by means of the aforementioned figure. First, shear behavior for high reinforced levels, which means $\rho=0.79 \%$ (S8 series) and $V_{f}=0.89 \%$ (C7 series, thicker line) (see Fig. 5.28a). In this figure, the initially confined conditions are represented, where we can see that steel fiber reinforced concrete (SFRC) presented lower shear stress, but also more ductile behavior. This ductility was due to the fiber pull-out from the matrix, represented by steps. In Fig. $5.28 \mathrm{~b}$, the same materials, but the initially unconfined conditions, are presented. With this condition, it is possible to see more clearly that when reinforced concrete reaches point $\mathrm{A}$, a slight failure mode is shown. In steel fiber reinforced concrete, a much more ductile behavior is shown. 


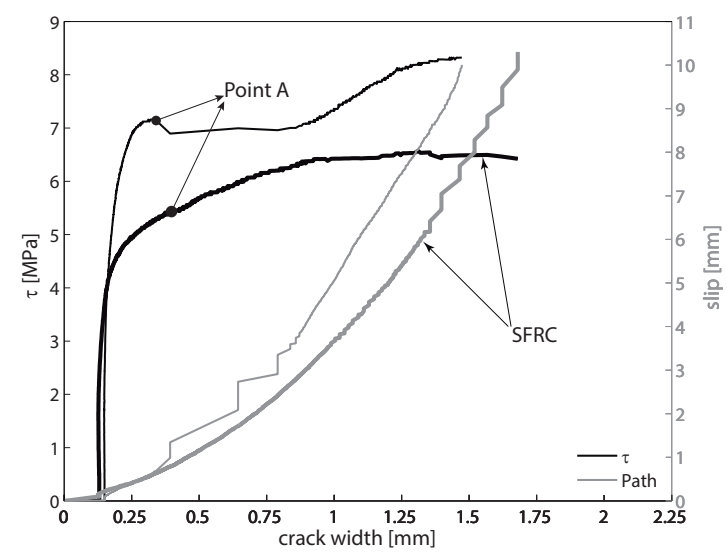

(a) Initially confined conditions (S8-0-2 and C7-0-2)

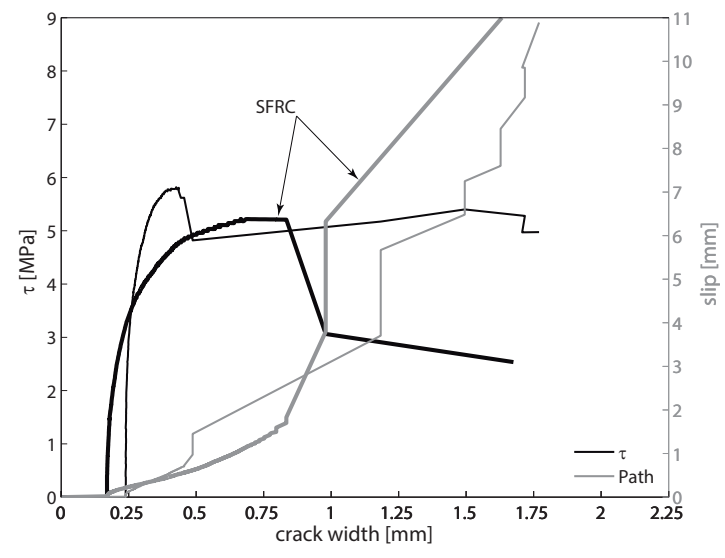

(b) Initially unconfined conditions (S8-1-2 and C7-1-2)

Fig. 5.28. Shear behavior for high reinforced levels.

\subsubsection{Roughness analysis}

Superficial roughness of the crack faces is one of the most influencing factors on shear behavior. This is due to the frictional forces developed as a result of the combined effect of normal force and this natural roughness.

Birkeland and Birkeland (1966), defined the friction coefficient as $\mu=\tan \theta$. This was because they idealized the natural roughness of the failure plane along $\mathrm{m}-\mathrm{m}$ (see Fig. 5.29) as fine sawtooth ramps with a slope of $\tan \theta$. In other words, the friction coefficient is a nondimensional number which expresses (in a qualitative manner) the roughness of this shear plane. 

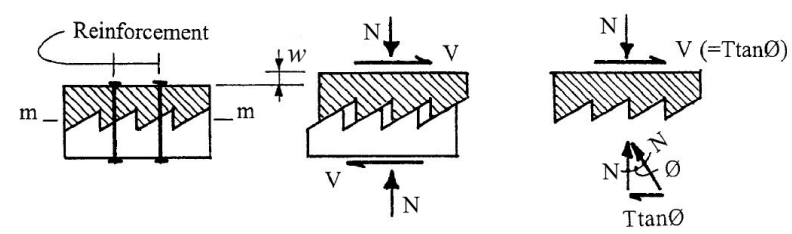

Fig. 5.29. Hypothesis of the shear friction theory.

Several shear friction theories have been applied to date for different friction coefficient $(\mu)$ values based on the superficial treatment of the potential failure plane. For instance, if concrete is cast monolithically, the friction coefficient at failure takes a value of 1.4 according to ACI318-08 (2008)-08. Table 5.15 shows the values of the friction coefficient applied by different authors.

Table 5.15. Values of friction coefficient used by different authors.

\begin{tabular}{llll}
\hline \multirow{2}{*}{ Author (year) } & \multicolumn{2}{l}{ Concrete } & \\
\cline { 2 - 4 } & Monolithic & Art. Roughned & Ord. Contruction \\
\hline Birkeland (1966) & 1.7 & 1.4 & $0.8-1$ \\
Mast (1968) & 1.4 & 1 & 0.7 \\
Mattock (1972) & 0.8 & & \\
Mattock (1976) & 0.8 & & \\
Walraven (1980) & 0.5 & $0.878 * f_{c}^{0.406}$ & \\
Walraven (1987) & 0.66 & & \\
Mau and Hsu (1988) & 0.573 & & \\
Loov ans Patnaik (1994) & 0.8 & 1 & 0.7 \\
Mattock (2001) & 1.4 & 1 & 0.6 \\
ACI-318 (2011) & 1.4 & & \\
AASHTO (2012) & & \\
\hline
\end{tabular}

Table 5.15 shows higher scatter of results of the friction coefficient. The main reason is that all these values were obtained empirically. The idea used by the aforementioned authors to obtain the friction coefficient is simply explained by by merely applying eq. 5.10.

$$
\mu_{e}=\frac{V}{N}=\tan \theta
$$

The problem of this idea is that a non-real material property is applied to define the friction coefficient. This hypothesis was confirmed by Mansur, Vinayagam, and Tan (2008) who, based on statistical analyses of previous authors, concluded that the friction coefficient between cracks is independent of concrete strength and is equal to 0.55 .

Due to the superficial unevenness of the crack surface, crack width and slip are simultaneously produced. This behavior is known as shear dilatancy. Usually in push-off tests, slip displacement is much higher than crack width displacement. 
As a result, the true trajectory of the ACTIVE part of the specimen is not parallel to the shear plane. However the true trajectory is parallel at angle $i$ to the shear plane, as shown in Fig. 5.30. Considering the fiction coefficient along the true trajectory, the following relationship can be obtained.

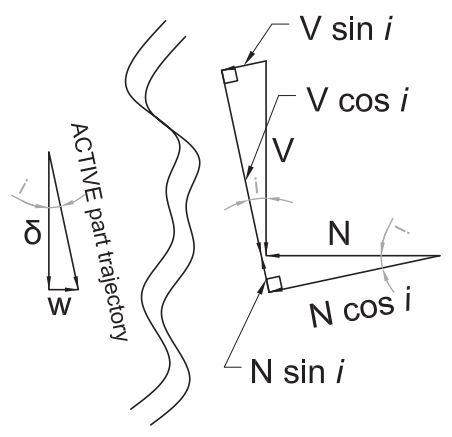

Fig. 5.30. Applied force at the crack interface.

$$
V \cos i-N \sin i=\mu_{b}(N \cos i+V \sin i)
$$

where $i$ is the ACTIVE part trajectory angle or roughness angle, and $\mu_{b}$ is the basic friction coefficient.

Dividing both sides of eq. 5.11 by the $N$ cosi equation, 5.12 is reached.

$$
\frac{V}{N}-\operatorname{tani}=\mu_{b}\left(1+\frac{V}{N} \cdot \tan i\right)
$$

Defining the friction coefficient along a true trajectory angle $\left(\mu_{i}\right)$, as the ratio between crack width increment $(\Delta w)$ and slip increment $(\Delta \delta)$, the following equation is obtained

$$
\mu_{i}=\frac{\Delta w}{\Delta \delta}=\operatorname{tani}
$$

Eqs. 5.10 and 5.13, and by solving the remaining equation for $\mu_{i}$, the following expression is obtained:

$$
\mu_{b}=\frac{\mu_{e}-\mu_{i}}{1+\mu_{e} \cdot \mu_{i}}
$$

Eq. 5.14 was first introduced in rock mechanics by Patton et al. (1966). Then in 1998, Fronteddu, Leger, and Tinawi (1998) applied eq. 5.14 to analyze the static and dynamic behavior of concrete lift. Fronteddu, Leger, and Tinawi (1998) also showed that eq. 5.14 indicates the friction coefficient, which involves interface geometrical component $i$, and a basic material property, basic friction angle $\phi_{b}$.

Fig. 5.31 shows the evolution of these three friction coefficients for plain concrete. For instance, under initially confined conditions (see Fig. 5.31a), the experimental friction coefficient was completely defined and its peak (2.2) was reached at 0.37 $\mathrm{mm}$ of slip, while for that slip value, the basic friction coefficient gave a value of 
0.27. After the peak, the experimental friction coefficient showed a transition to the residual frictional plateau at a slip value close to $6 \mathrm{~mm}$. The basic friction coefficient peaked at a sliding value of $2 \mathrm{~mm}$ and then remained constant, showing a plateau until the end of the test. This constant feature confirms that the basic friction coefficient reflect a material property more realistically.

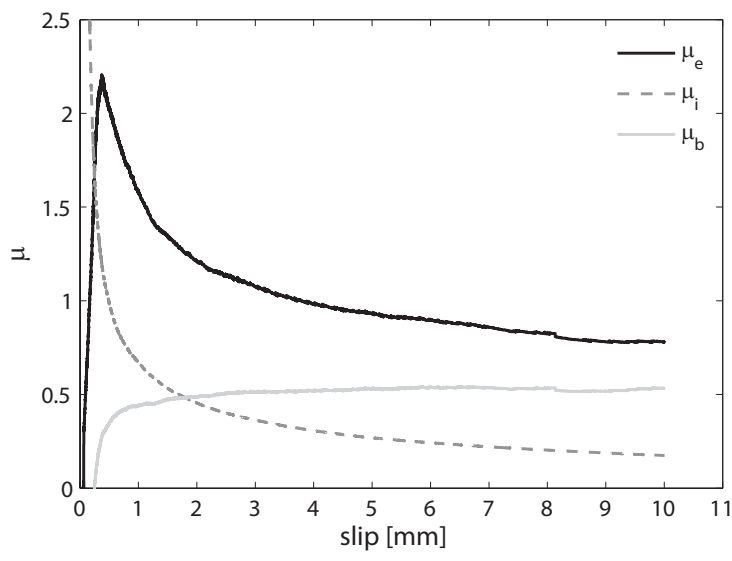

(a) Initially confined conditions (specimen PC-0-2a)

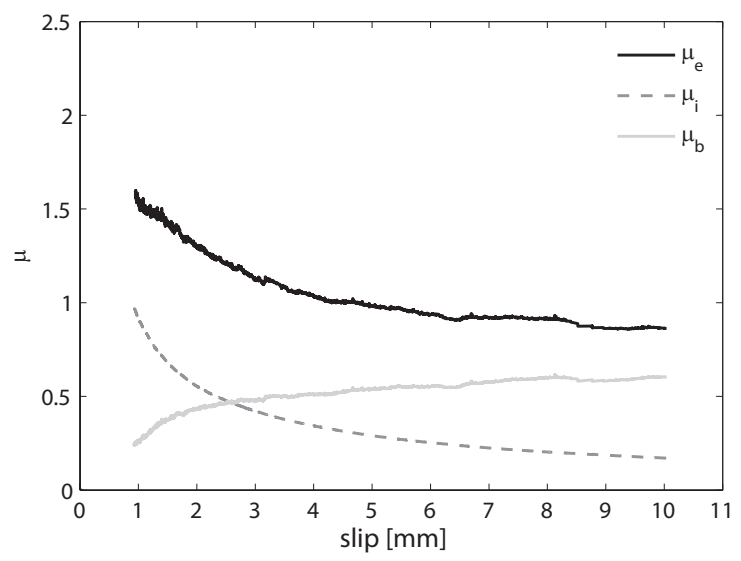

(b) Initially unconfined conditions (specimen PC-1-2b)

Fig. 5.31. Evolution of the friction coefficient in plane concrete.

Similar trends for the initially unconfined conditions were found (see Fig. 5.31b). In this figure, we can see that the three curves start close to $0.8 \mathrm{~mm}$ of slip. This is because an initial dilatancy is required before the restraint frame begins to confine and normal stress is developed. For this reason, the peak of the experimental friction coefficient was not detected, but the shear behavior of diagonal tension where crack width first opened and then sliding started was reproduced. The transition zone of the experimental friction coefficient finished close to $6 \mathrm{~mm}$ of 
slip and afterward the residual value was observed. The basic friction coefficient seemed to stabilized at around 0.55 at a slip value of $4 \mathrm{~mm}$. So it can be concluded that when $w_{o}=0$ the stabilizing of the basic friction coefficient was reached for higher values of slips. In any case under the failure conditions (UFC), both friction coefficients were found in the same trends of the initially confined specimens, where 0.57 was the average value of the basic friction coefficient in both cases.

Table 5.16 summarizes the evolution of the experimental $\left(\mu_{e}\right)$ and basic $\left(\mu_{b}\right)$ friction coefficients. The assessment of these friction coefficients was made at three points. The first point corresponded to the maximum value of $\mu_{e}$, and is defined as $\mu_{e, \max }$. At this point, the values of $\mu_{e}$, slip, $w, \tau, \sigma$, and $\mu_{b}$ are shown. The second point corresponded to $\mu_{b}=0$ because this coefficient is obtained from a mathematical expression (eq. 5.14), and negative values were first obtained. It must be pointed out that these negative values were negligible. In this part $\left(\mu_{b}=0\right)$, the values of slip, $w$, and the corresponding $\mu_{e}$ were given. The third point corresponded to the failure conditions (UFC), where the values of $\mu_{e}$ and $\mu_{b}$ are presented. By means of these three points, it was possible to assess the evolution of the friction coefficients during the push-off test.

In Table 5.16 we can see that for the initially confined conditions $\left(w_{o}\right)$, the peak of the experimental friction coefficient $\left(\mu_{e, \max }\right)$ was obtained. At this point, the significant values of displacements (slip and crack width) were given. Indeed if the ratio between slip and $w$ is calculated, the relationship is higher than 0.7. However, if the shear and normal stresses are seen, small values are given if compared with their values under the failure conditions. If the experimental and basic friction coefficients are compared with the value reported under failure conditions, it can be stated that while $\mu_{e}$ reached its maximum value, the basic friction coefficient was $50 \%$ of its maximum value.

For instance, if $\mathrm{PC}-0-2 \mathrm{a}$ is observed, $\mu_{b}$ is 0.28 when $\mu_{e, \max }$ is reached, while under failure conditions, $\mu_{b}$ is 0.53 . The experimental friction coefficient peak $\left(\mu_{e, \max }\right)$ was reached at an average slip value of $0.5 \mathrm{~mm}$, which corresponded to "first failure" (point A, see Fig. 5.27).

When the basic friction coefficient was zero $\left(\mu_{b}=0\right)$, experimental friction coefficient was on the ascending branch and reached $80 \%$ of its maximum value. At this point, the slip was approximately $60 \%$ of the "first failure" point. This means that when Point A was reached a combined effect of both friction coefficients took place.

The $\mu_{b}$ coefficient, did not show any degradation like the $\mu_{e}$ coefficient did, but it showed more stability during the push-off test. For this reason, the hypothesis that the basic friction coefficient represents the material property more accurately was confirmed. The failure conditions gave results with a lower scatter, and the basic friction coefficient was higher for the larger maximum aggregate size (PC-0-4a, PC-0-4b, PC-1-1a and PC-1-1b). 
Table 5.16. Values of friction coefficients at different sliding points (plain concrete).

\begin{tabular}{|c|c|c|c|c|c|c|c|c|c|c|c|}
\hline \multirow{2}{*}{ Specimen } & \multicolumn{6}{|c|}{$\mu_{e, \max }$} & \multicolumn{3}{|c|}{$\mu_{b}=0$} & \multicolumn{2}{|l|}{$\mathrm{AFC}$} \\
\hline & $\mu_{e}$ & slip & $w$ & $\tau$ & $\sigma$ & $\mu_{b}$ & slip & $w$ & $\mu_{e}$ & $\mu_{e}$ & $\mu_{b}$ \\
\hline PC-0-2a & 2.21 & 0.37 & 0.45 & 2.44 & 1.10 & 0.28 & 0.25 & 0.41 & 1.67 & 0.78 & 0.53 \\
\hline PC-0-2b & 1.84 & 0.49 & 0.51 & 2.27 & 1.24 & 0.27 & 0.31 & 0.47 & 1.52 & 0.67 & 0.46 \\
\hline PC-0-2c & 2.27 & 0.52 & 0.61 & 2.96 & 1.31 & 0.30 & 0.29 & 0.57 & 2.00 & 0.98 & 0.68 \\
\hline PC-0-4a & 1.70 & 0.34 & 0.43 & 2.20 & 1.29 & 0.14 & 0.25 & 0.39 & 1.61 & 1.17 & 0.77 \\
\hline PC-0-4b & 3.69 & 0.17 & 0.28 & 3.73 & 1.01 & 0.29 & 0.09 & 0.23 & 2.50 & 1.15 & 0.85 \\
\hline PC-0-5a & 0.87 & 2.34 & 0.78 & 2.62 & 3.02 & 0.41 & 0.76 & 0.55 & 0.72 & 0.73 & 0.54 \\
\hline PC-0-5b & 2.46 & 0.37 & 0.36 & 2.71 & 1.10 & 0.43 & 0.20 & 0.33 & 1.65 & 0.97 & 0.69 \\
\hline PC-1-1a & \multicolumn{9}{|c|}{ No experimental data } & 0.96 & 0.63 \\
\hline PC-1-1b & \multicolumn{9}{|c|}{ No experimental data } & 0.83 & 0.58 \\
\hline PC-1-2a & \multicolumn{9}{|c|}{ No experimental data } & 0.83 & 0.54 \\
\hline PC-1-2b & \multicolumn{9}{|c|}{ No experimental data } & 0.86 & 0.60 \\
\hline PC-1-2c & \multicolumn{9}{|c|}{ No experimental data } & 0.88 & 0.57 \\
\hline PC-1-2d & \multicolumn{9}{|c|}{ No experimental data } & 0.80 & 0.52 \\
\hline PC-1-2e & \multicolumn{9}{|c|}{ No experimental data } & 0.90 & 0.57 \\
\hline & & & & & & & & & S.D. & $\begin{array}{l}0.88 \\
0.14\end{array}$ & $\begin{array}{l}0.60 \\
0.11\end{array}$ \\
\hline
\end{tabular}

When both friction coefficients were analyzed for steel fiber reinforced concrete, a slight increase in the average values was found. Thus, the average experimental friction coefficient for plain concrete was 0.88 , while the average value was 0.91 for SFRC. The same trend was reported for the basic friction coefficient, with an average value of 0.64 for SFRC and an average value of 0.64 for plain concrete. Given the standard deviation of the basic friction coefficient, we can state that it was almost the same in both cases, SFRC and PC, which re-confirmed once that the basic friction coefficient is a material property. Table 5.17, shows the evolution of these friction coefficients at different points during the push-off test for the SFRC specimens.

Interesting information can be obtained when calculating the basic friction coefficient by fiber type. This is shown in Table 5.18, where the average basic friction coefficient is shown at the ultimate state. Fiber amount seems to have no effect on the basic friction coefficient. This is shown by comparing A4 with A5, and C4 with $\mathrm{C} 7$. The aspect ratio $\left(l_{f} / d_{f}\right)$ had a clear effect on the basic friction coefficient. When the aspect ratio increased from 65 to 80 , a clear increase in the coefficient was observed. However, more tests are needed to guarantee the present experimental results. 
Table 5.17. Values of friction coefficients at different sliding points (SFRC).

\begin{tabular}{|c|c|c|c|c|c|c|c|c|c|c|c|}
\hline \multirow{2}{*}{ Specimen } & \multicolumn{6}{|c|}{$\mu_{e, \max }$} & \multicolumn{3}{|c|}{$\mu_{b}=0$} & \multicolumn{2}{|c|}{$\mathrm{UFC}$} \\
\hline & $\mu_{e}$ & slip & $w$ & $\tau$ & $\sigma$ & $\mu_{b}$ & slip & $w$ & $\mu_{e}$ & $\mu_{e}$ & $\mu_{b}$ \\
\hline $\mathrm{A} 4-0-2 \mathrm{a}$ & 3.32 & 0.40 & 0.43 & 3.54 & 1.07 & 0.50 & 0.19 & 0.39 & 2.12 & 0.79 & 0.59 \\
\hline $\mathrm{A} 4-0-2 \mathrm{~b}$ & 3.03 & 0.19 & 0.35 & 2.99 & 0.99 & 0.17 & 0.00 & 0.33 & -0.02 & 0.84 & 0.63 \\
\hline $\mathrm{A} 4-0-2 \mathrm{c}$ & 3.76 & 0.25 & 0.27 & 4.01 & 1.07 & 0.51 & 0.10 & 0.23 & 2.38 & 1.01 & 0.76 \\
\hline $\mathrm{A} 4-1-2 \mathrm{a}$ & \multicolumn{9}{|c|}{ No experimental data } & 0.82 & 0.52 \\
\hline$A 4-1-2 b$ & \multicolumn{9}{|c|}{ No experimental data } & 0.68 & 0.41 \\
\hline $\mathrm{A} 4-1-2 \mathrm{c}$ & \multicolumn{9}{|c|}{ No experimental data } & 0.93 & 0.61 \\
\hline A5-0-2a & 2.18 & 0.56 & 0.53 & 3.29 & 1.51 & 0.39 & 0.26 & 0.43 & 1.66 & 0.78 & 0.53 \\
\hline A $5-0-2 b$ & 2.00 & 0.61 & 0.56 & 2.57 & 1.29 & 0.38 & 0.30 & 0.49 & 1.63 & 0.76 & 0.54 \\
\hline A5-1-2a & \multicolumn{9}{|c|}{ No experimental data } & 0.92 & 0.65 \\
\hline A5-1-2b & \multicolumn{9}{|c|}{ No experimental data } & 0.98 & 0.66 \\
\hline A5-1-4a & \multicolumn{9}{|c|}{ No experimental data } & 0.89 & 0.57 \\
\hline A $5-1-4 b$ & \multicolumn{9}{|c|}{ No experimental data } & 0.90 & 0.61 \\
\hline B4-0-2a & \multicolumn{11}{|c|}{ No experimental data } \\
\hline B4-0-2b & 2.73 & 0.36 & 0.38 & 2.95 & 1.08 & 0.42 & 0.17 & 0.34 & 1.99 & 0.83 & 0.63 \\
\hline B4-0-2c & 3.65 & 0.27 & 0.28 & 3.49 & 0.96 & 0.54 & 0.11 & 0.23 & 2.15 & 0.85 & 0.64 \\
\hline B4-1-2a & \multicolumn{9}{|c|}{ No experimental data } & 0.93 & 0.63 \\
\hline B4-1-2b & \multicolumn{9}{|c|}{ No experimental data } & 0.99 & 0.68 \\
\hline B4-1-2c & \multicolumn{9}{|c|}{ No experimental data } & 1.07 & 0.76 \\
\hline $\mathrm{C} 4-0-2 \mathrm{a}$ & 3.63 & 0.31 & 0.30 & 4.03 & 1.11 & 0.59 & 0.12 & 0.26 & 2.20 & 1.06 & 0.82 \\
\hline $\mathrm{C} 4-0-2 \mathrm{~b}$ & 2.87 & 0.33 & 0.36 & 3.07 & 1.07 & 0.43 & 0.17 & 0.33 & 1.96 & 0.86 & 0.65 \\
\hline $\mathrm{C} 4-0-2 \mathrm{c}$ & 3.42 & 0.26 & 0.23 & 3.38 & 0.99 & 0.63 & 0.10 & 0.18 & 1.78 & 1.01 & 0.77 \\
\hline C4-1-2a & \multicolumn{9}{|c|}{ No experimental data } & 0.95 & 0.66 \\
\hline $\mathrm{C} 4-1-2 \mathrm{~b}$ & \multicolumn{9}{|c|}{ No experimental data } & 1.08 & 0.74 \\
\hline $\mathrm{C} 4-1-2 \mathrm{c}$ & \multicolumn{9}{|c|}{ No experimental data } & 1.03 & 0.70 \\
\hline $\mathrm{C} 7-0-2 \mathrm{a}$ & 4.92 & 0.25 & 0.27 & 4.61 & 0.94 & 0.63 & 0.01 & 0.23 & -0.05 & 1.01 & 0.74 \\
\hline $\mathrm{C} 7-0-2 \mathrm{~b}$ & 3.55 & 0.33 & 0.32 & 4.01 & 1.13 & 0.58 & 0.13 & 0.29 & 2.21 & 1.00 & 0.76 \\
\hline $\mathrm{C} 7-0-2 \mathrm{c}$ & 4.39 & 0.26 & 0.17 & 4.21 & 0.96 & 0.99 & 0.11 & 0.13 & 1.15 & 1.06 & 0.76 \\
\hline $\mathrm{C} 7-1-2 \mathrm{a}$ & \multicolumn{9}{|c|}{ No experimental data } & 0.79 & 0.52 \\
\hline $\mathrm{C} 7-1-2 \mathrm{~b}$ & \multicolumn{9}{|c|}{ No experimental data } & 1.06 & 0.75 \\
\hline $\mathrm{C} 7-1-2 \mathrm{c}$ & \multicolumn{9}{|c|}{ No experimental data } & 0.81 & 0.59 \\
\hline & & & & & & & & & & 0.91 & $\overline{0.64}$ \\
\hline & & & & & & & & & S.D. & 0.11 & 0.10 \\
\hline
\end{tabular}

Table 5.18. Basic friction coefficient for different steel fibers types and amounts.

\begin{tabular}{llllll}
\hline & A4 & A5 & B4 & C4 & C7 \\
\hline mean & 0.58 & 0.59 & 0.67 & 0.72 & 0.69 \\
S.D. & 0.12 & 0.06 & 0.05 & 0.07 & 0.11 \\
\hline
\end{tabular}




\section{Chapter 6}

\section{Conclusions}

This $\mathrm{PhD}$ thesis presents an extensive experimental campaign during which more than 50 push-off specimens were tested. Part of this campaign was used to design, develop and calibrate an improvement, or "upgrade", of the traditional pushoff test by using a restraint frame capable of controlling crack width. Having completed this stage several tests with different concretes were done. The aim was to test if different shear behaviors can be detected from a qualitative point of view. More tests are required to determine how the parameters studied herein affect the shear transfer mechanisms of cracked concrete.

\subsection{Main conclusions}

Since most of this thesis intended to present the test methodology, a decision was made to present the conclusions in two groups. The first group includes the conclusions drawn on the testing methodology, while the second group offers the conclusions reached from the parameters studied in the experimental program.

\subsubsection{About the test methodology}

The main objective of this thesis was to present an improvement of the push-off test methodology in order to better understand the behavior of cracked concrete. In other words, this thesis mostly provides guidelines to set up a complete methodology with a view to studying the behavior of cracked concrete from the very first 
specimen casting stage to the very final stage, in which the experimental results are interpreted. Special insight into the different experimental test stages (precracking and push-off) is provided.

- The push-off test upgrade presented in this thesis begins with the specimen. Two types of modifications were made in the formworks. These modifications allowed perfectly defined pair of notches on the specimen to be produced during its casting. So, it was not necessary to saw a specimen after casting. Another major modification was the inclusion of eight connector links in the specimens. These connector links were used to fix the restraint frame to the specimen.

- The restraint frame presented relatively substantial horizontal stiffness $\left(k_{h}\right)$ to control crack width in both the precracking and push-off stages. Thus it can be stated that a test done under crack control conditions was satisfactorily carried out.

- The implementation of the ball bearing allowed a considerable reduction in vertical restraint frame stiffness $\left(k_{v}\right)$. Thus the frictional forces between the specimen and the restraint frame were reduced as much as possible, and most of the applied force in the push-off test went through the crack.

- This combination of high $k_{h}$ and low $k_{v}$, allowed a push-off test to be carried out for higher slip displacement values, and no secondary effects due to testing procedures were introduced. The $10 \mathrm{~mm}$ threshold reached during this test allowed us to study shear friction in cracks beyond the traditional limits reported by other researchers. Indeed a significant contribution of macro-roughness to shear strength was found for slip values higher than 2-3 $\mathrm{mm}$.

- The fact that the shear plane was confined prior to carrying out the precracking phase revealed that the influence of the handling process required to move the specimen between both stages can be satisfactorily controlled.

- A sufficiently precise mechanical system to fix different allowed initial crack widths $\left(w_{o}\right)$ was designed. $w_{o}$ allowed specimens to be test under different initial confinement conditions, which enabled us to observe how this confinement affected shear transfer mechanisms.

- The implementation of two discrete measurement techniques guaranteed traceability in the relative positions of the two blocks, ACTIVE and PASSIVE, in the handling process. These two techniques were experimentally validated and showed good accuracy.

- A simplified model to assess shear transfer through the restraint frame was developed. With this assessment and the total loading applied, the real shear stress transferred by the crack was calculated. From the experimental results, the stress transmitted by the restraint frame was $10 \%$ in average, in the ultimate state. 
- Another finding was that the difference between the total shear stress and real shear stress transmitted by the crack was large when the ball bearing mechanism was blocked. This resulted in a shear stress overestimation of 32 $\%$ with a slip value of only $2 \mathrm{~mm}$.

- The experimental results, obtained from more than 50 specimens, revealed that the repeatability in the testing methodology presented in this thesis was good.

- Based on previous conclusions, we can state that the push-off test upgrade presented herein made the analysis of cracked concrete under direct shear conditions possible. It was possible to control the effects of the restraint frame on the specimen, which enabled the real behavior of the shear transfer mechanisms in the crack to be isolated. For this reason, the present methodology is proposed as a standard experimental test to analyze crack behavior under direct shear conditions.

\subsubsection{Studying the parameters in the experimental program}

After defining the final test procedure, an extensive experimental program was run and the experimental results were analyzed. The following conclusions were drawn:

- Depending on the allowed initial crack width $\left(w_{o}\right)$, when $w_{o}=0$, the influence of both shear strength mechanisms (aggregate interlock and macroroughness) was observed. Under these conditions, when the aggregate interlock mechanism began to fail, macro-roughness was responsible for the shear transfer mechanism.

- Depending on the type of steel fibers analyzed, when $w_{o}=0$, no significant differences among the three fiber types studied were observed; RC-65/35 $\mathrm{BN}, \mathrm{RC}-80 / 50 \mathrm{BN}$ and RC-80/30 BP. However when $w_{o}=1$, and before the restraint frame began to confine the specimen, different behaviors were detected according to fiber type.

- Depending on the amount of steel fibers, if the amount of fiber increased, shear stress also increased. This increment became more evident when the increase in the amount of fiber rose from 10 to $30 \mathrm{~kg} / \mathrm{m}^{3}$. Initial confinement $w_{o}$ did not seem to affect this increment.

- Depending on the shear reinforcement ratio, the increment in the reinforcement ratio led to an increase shear stress. This increment did not seem to be influenced by the initial confinement $w_{o}$ values.

- Depending on maximum aggregate size, the increment in maximum aggregate particle size led to an increment in shear stress. This behavior was observed for both the initial confinement conditions $\left(w_{o}=0\right.$ and $\left.w_{o}=1\right)$. The influence of concrete strength remained unclear. 
- In order to compare SFRC and RC, a superposed plot of shear stress vs. the crack width relationship and slip displacement vs. crack width was used. The analysis reveled, that RC specimens showed greater shear stress until the first failure if compared with the SFRC specimens. However when the stirrups reached the yield stress, brittle failure was observed. The SFRC showed less shear stress, but fibers gave more ductile failure.

- It has been reported that the basic friction coefficient $\left(\mu_{b}\right)$ accurately represents the macro-roughness of the crack interfaces. Having reached its plateau, this coefficient, remained constant during the push-off test. At failure, an increase in this friction coefficient when the maximum aggregate size increased was also reported. Finally, when using the steel fibers of the aspect ratio, which equalled 80, the basic friction coefficient gave higher values if compared with the steel fibers with an aspect ratio of 65 .

\subsection{Recommendations for further research}

To conclude the $\mathrm{PhD}$ thesis, some further recommendations based on the experimental results are made. These recommendations are presented following the criteria used in the main conclusions.

\subsubsection{About the methodology}

- To develop a system that allows the strain gauge to be recorded while specimen handling is being carried out between the precracking and push-off phases.

- To introduce an active confinement system that allows real crack width control.

\subsubsection{About cracked concrete behavior}

- To identify the effects of micro-roughness and macro-roughness. For this purpose, different shapes and roughnesses of the crack plane should be studied to see how they affect crack behavior.

- To analyze the influence of initial confinement $w_{o}$ on a wide range of possibilities, such as 0, 1, 2, $3 \mathrm{~mm}$. Thus, shear behavior can be analyzed from completely confined to unconfined conditions.

- To enlarge the data-base of the confined push-off test by means of a large experimental campaign. This experimental program has to be designed to assess the parameters that must be taken into account for the structural design. 
- To introduce new study variables, such as type of aggregate (river gravel), inclination of reinforcement at different angles, etc.

- To study the superficial crack aspect prior to and after push-off to justify the degree of degradation of the experimental friction coefficient.

- To use the experimental results to calibrate a mathematical model that allows the study of the kinematics of the crack, especially in SFRC. 


\section{References}

ACI318-05 (2005). Building Code Requirements for Structural Concrete and Commentary. American Concrete Institute.

ACI318-08 (2008). Building Code Requirements for Structural Concrete and Commentary. American Concrete Institute.

ACI318-11 (2011). Building Code Requirements for Structural Concrete and Commentary. American Concrete Institute.

Ahmad, S. H., A. Khaloo, and A. Poveda (1986). "Shear capacity of reinforced high-strength concrete beams". In: ACI Journal Proceedings 83.2, pp. 297-305.

Ahmed, L. and A. Ansell (2010). "Direct shear strength of high-strength fibre concrete". In: Magazine of Concrete Research 62.5, pp. 379-390.

ASCE-ACI326 (1962). Shear and Diagonal Tension: Report of the Joint ASCEACI Committee on Shear and Diagonal Tension. American Society of Civil Engineers.

ASCE-ACI544 (2008). Guide for Specifying, Proportioning, and Production of Fiber Reinforced Concrete. American Concrete Institute.

ASTM (2012). Standard Test Method for Flexural Performance of Fiber-Reinforced Concrete (Using Beam With Third-Point Loading). Cement Standard and Concrete Standard.

Banthia, N et al. (2014). "Fiber synergy in Hybrid Fiber Reinforced Concrete (HyFRC) in flexure and direct shear". In: Cement and Concrete Composites 48, pp. $91-97$.

Barr, B (1987). "Compact shear test specimens for FRC materials". In: Composites 18.1, pp. 54-60.

Barragan, B. et al. (2006). "Shear failure of steel fiber-reinforced concrete based on push-off tests". In: ACI materials journal 103.4, pp. 251-257.

Birkeland, P. W. and H. W. Birkeland (1966). "Connections in precast concrete construction". In: Journal of the American Concrete Institute 63.3, pp. 345-368. 
Boulekbache, B. et al. (2012). "Influence of yield stress and compressive strength on direct shear behaviour of steel fibre-reinforced concrete". In: Construction and Building Materials 27.1, pp. 6-14.

Bulletin 55, fib (2010). Model Code 2010 : first complete draft. Vol. 1.318 pages, p. 288.

Bulletin 57, fib (2010). Shear and punching shear in RC and FRC elements. edited by Minelli F. and Plizzari, G.

Bulletin 65, fib (2012). Model Code 2010: Final Draft. Vol. 1. 350 pages, p. 288.

Bulletin 66, fib (2012). Model Code 2010: Final Draft. Vol. 2. 370 pages, p. 370.

Calixto, J. (2002). "Shear Behavior fo Reinforced Concrete Beams with the Addition of Short Steel Fibers". In: ACI Special Publication 207, pp. 449-466.

Carmona, S. and M. Cabrera (2009). "Comportamiento al corte de hormigones reforzado con fibras de acero". In: Revista ingeniería de construcción 24.1, pp. 74 94.

Casanova, P. and P. Rossi (1997). "Can steel fibers replace transverse reinforcements in reinforced concrete beams?" In: ACI materials journal 94.5, pp. 341354.

Choi, K.-K., H.-G. Park, and J. K. Wight (2007). "Shear Strength of Steel FiberReinforced Concrete Beams without Web Reinforcement". In: ACI Structural Journal 104.1, pp. 12-22.

Collins, M. P. (1978). "Towards a rational theory for RC members in shear". In: Journal of the Structural Division 104.4, pp. 649-666.

Committee-426, ed. (1973). The Shear Strength of Reinforced Concrete Members. Journal of the Structural Division, pp. 1091-1187.

Conforti, A. (2013). "Shear behavior of deep and wide-shallow beams in fiber reinforced concrete". PhD thesis. University of Brescia, Italy.

Cuenca, E. (2012). "On shear behavior of structural elements made of steel fiber reinforced concrete". PhD thesis. Universitat Politècnica de València (Spain).

Cuenca, E. and P. Serna (2010a). "Shear behavior of self-compacting concrete and fiber reinforced concrete beams". In: 6th International RILEM symposium on self-compacting concrete SCC2010, Montreal, Canada.

Cuenca, E. and P. Serna (2010b). "Shear behavior of self-compacting concrete and fiber-reinforced concrete push-off specimens". In: Design, Production and Placement of Self Consolidating Concrete. Springer, pp. 429-438.

Cuenca, E. and P. Serna (2010c). "Respuesta frente a cizallamiento en probetas tipo Z fabricadas con HACs de diferente estructura granular". In: 2 Congreso Ibérico sobre Hormigón Autocompactante. Guimaraes, 1 y 2 de julio de.

Cuenca, E. and P. Serna (2010d). "Shear behavior and mode of failures analysis of different structural elements made with fiber reinforced concrete". In: 8th fib PhD symposium in Kgs. Lyngby, Denmark.

Desnerck, P, G De Schutter, and L Taerwe (2009). "Shear friction of reinforced self-compacting concrete members". In: ACI Special Publication 261, pp. 133 144.

Dinh, H. H (2009). "Shear Behavior of Steel Fiber Reinforced Concrete Beams Subjected to Monotonic Loading". PhD thesis. University of Michigan. 
Dinh, H. H. and J. K. Parra-Montesinos G. J and; Wight (2010). "Shear Behavior of Steel Fiber-Reinforced Concrete Beams without Stirrup Reinforcement". In: ACI Structural Journal 107.5, pp. 597-606.

EHE-08 (2008). Instrucción de Hormigón Estructural (in spanish). Ministerio de Fomento, p. 702.

Elzanaty, A. H., A. H. Nilson, and F. O. Slate (1986). "Shear capacity of reinforced concrete beams using high-strength concrete". In: ACI Journal Proceedings 83.2, pp. $290-296$.

ENSIDESA (1982). Prontuario Ensidesa: manual para cálculo de estructuras metálicas. Ensidesa.

Eurocode-2 (2004). Design of Concrete Structures - Part 1-1: General Rules And Rules for Building. 225 pages.

FIBRE REINFORCED CONCRETE: Challenges and Opportunities. 8th RILEM Internation Symposium (BEFIB 2012) (2012). RILEM Publications, p. 314.

Frénay, J. W, H. W. Reinhardt, and J. C Walraven (1991a). "Time-Dependent Shear Transfer in Cracked Concrete: Part I". In: Journal of Structural Engineering 117.10, pp. 2900-2918.

Frénay, J. W., H. W Reinhardt, and J. C Walraven (1991b). "Time-Dependent Shear Transfer in Cracked Concrete: Part II". In: Journal of Structural Engineering 117.10, pp. 2919-2935.

Fronteddu, L., P. Leger, and R. Tinawi (1998). "Static and dynamic behavior of concrete lift joint interfaces". In: Journal of structural engineering 124.12, pp. $1418-1430$.

Haskett, M. et al. (2010). "The shear friction aggregate interlock resistance across sliding planes in concrete". In: Magazine of Concrete Research 62.12, pp. 907924.

Haskett, M. et al. (2011). "Evaluating the shear-friction resistance across sliding planes in concrete". In: Engineering Structures 33.4, pp. 1357-1364.

Hassan, A., K. Hossain, and M Lachemi (2008). "Behavior of full-scale self consolidating concrete beams in shear". In: Cement and Concrete Composites 30.7, pp. $588-596$.

Hatano, H. et al. (2011). "Shear reinforcement of RC members using post reinforcing bars". In: Proceedings of the Japan Concrete Institute 33.2, pp. 13691374.

Hofbeck, J., I. Ibrahim, and A. H. Mattock (1969). "Shear transfer in reinforced concrete". In: ACI Journal 66.2, pp. 119-128.

Houde, J. and M. S Mirza (1974). "A Finite Element Analsis of Shear Strength of Reinforced Concrete Beams". In: ACI Special Publication 42, pp. 103-128.

Imam, M. and L. Vandewalle (2000). "Role of Fibers in Controlling Failure Modes of High-Strength Concrete Beams". In: ACI Special Publication 193, pp. 503515.

Issa, M. a. et al. (Jan. 2003). "Fractal dimension - a measure of fracture roughness and toughness of concrete". In: Engineering Fracture Mechanics 70.1, pp. 125137.

JSCE-SF6 (1990). Method of Test for Shear Strength of Steel Fiber Reinforced Concrete. Japan Society of Civil Engineers, Tokyo, pp.67-69. 
Juárez, C. et al. (2007). "The diagonal tension behavior of fiber reinforced concrete beams". In: Cement and Concrete Composites 29.5, pp. 402-408.

Kahn, L. F. and A. D Mitchell (2002). "Shear friction tests with high-strength concrete". In: ACI Structural Journal 99.1, pp. 98-103.

Khaloo, A. R. and N. Kim (1997). "Influence of concrete and fiber characteristics on behavior of steel fiber reinforced concrete under direct shear". In: $A C I$ Materials Journal 94.6, pp. 592-600.

Kim, Y., D. Trejo, and M. Hueste (2007). "Shear characteristics of self-consolidating concrete for precast prestressed concrete members". In: ACI Special Publication 247, pp. 53-65.

Kim, Y. H. et al. (2010). "Shear Characteristics and Design for High-Strength Self-Consolidating Concrete". In: Journal of Structural Engineering 136.August, pp. $989-1000$.

Lim, E. et al. (2011). "Shear transfer in fibre-reinforced lightweight concrete". In: Magazine of Concrete Research 63.1, pp. 13-20.

Loov, R. E. and A. K. Patnaik (1994). "Horizontal shear strength of composite concrete beams with a rough interface". In: PcI Journal 38.1, pp. 48-69.

Lucas, W, D. J. Oehlers, and M. Ali (2011). "Formulation of a shear resistance mechanism for inclined cracks in RC beams". In: Journal of Structural Engineering 137.12, pp. 1480-1488.

Lucas, W. et al. (2012). "The FRP reinforced shear-friction mechanism". In: $A d$ vances in Structural Engineering 15.4, pp. 615-624.

Majdzadeh, F., S. M. Soleimani, and N. Banthia (2006). "Shear strength of reinforced concrete beams with a fiber concrete matrix". In: Canadian Journal of Civil Engineering 33.6, pp. 726-734.

Mansur, M. A., T. Vinayagam, and K Tan (2008). "Shear Transfer across a Crack in Reinforced High-Strength Concrete". In: Journal of Materials in Civil Engineering 20, pp. 294-302.

Mast, R. F. (1968). "Auxiliary reinforcement in concrete connections". In: Journal of the Structural Division 94, pp. 1485-1504.

Mattock, A. H. (2001). "Shear friction and high-strength concrete". In: ACI Structural Journal 98.1, pp. 50-59.

Mattock, A. H. (1968). Diagonal tension cracking in concrete beams with axial forces. Department of Civil Engineering, University of Washington.

Mattock, A. H. and N. M. Hawkins (1972). "Shear transfer in reinforced concreterecent research". In: PCI Journal 1.April, pp. 55-75.

Mattock, A. H., W. Li, and T. Wang (1976). "Shear transfer in lightweight reinforced concrete". In: Precast/prestressed concrete institute. journal 21.1, pp. 20 39.

Mattock, A. H. (1974). "Shear transfer in concrete having reinforcement at an angle to the shear plane". In: ACI Special Publication 42, pp. 17-42.

Mau, S. and T. Hsu (1988). Influence of concrete strength and load history on the shear friction capacity of concrete members comment.

Meda, A. et al. (2005). "Shear behaviour of steel fibre reinforced concrete beams". In: Materials and Structures 38.3, pp. 343-351.

Mirsayah, A. A. and N. Banthia (2002). "Shear strength of steel fiber-reinforced concrete". In: ACI Materials Journal 99.5, pp. 473-479. 
Mitchell, D. and M. P. Collins (1974). "Diagonal compression field theory-a rational model for structural concrete in pure torsion". In: ACI Journal Proceedings 71.8 , pp. 396-408.

Mohamed, M. E. et al. (2012). "Influence of Roughness, Cohesion and Friction on the Interface Shear Strength of Composite Concrete-to-Concrete Bond". In: APSEC-ICCER 2012: Joint Conference of the 8th Asia Pacific Structural Engineering $\&$ Construction Conference (APSEC) and 1st International Conference on Civil Engineering Conference (ICCER), pp. 137-143.

Mphonde, A. G. and G. C Frantz (1984). "Shear tests of high-and low-strength concrete beams without stirrups". In: ACI Journal Proceedings 81.4, pp. 350357.

Nagle, T. and D. Kuchma (2007). "Shear transfer resistance in high-strength concrete girders". In: Magazine of Concrete Research 59.8, pp. 611-620.

Nawy, E. (2009). Reinforced Concrete: A Fundamental Approach. Prentice Hall international series in civil engineering and engineering mechanics. Pearson Prentice Hall.

Okamura, H. and K. Maekawa (1991). "Nonlinear analysis and constitutive models of reinforced concrete". In: Gihodo, Tokyo, p. 182.

Otter, D. E. and A. E. Naaman (1988). "Properties of Steel Fiber Reinforced Concrete under Cyclic Load". In: ACI Materials journal 85.4, pp. 254-261.

Padmarajaiah, S. and A. Ramaswamy (2001). "Behavior of fiber-reinforced prestressed and reinforced high-strength concrete beams subjected to shear". In: ACI Structural Journal 98.5, pp. 752-761.

Parra-Montesinos, G. J. (2006). "Shear strength of beams with deformed steel fibers". In: Concrete international-detroit- 28.11, p. 57.

Patton, F. D. et al. (1966). "Multiple modes of shear failure in rock". In: 1st ISRM Congress. International Society for Rock Mechanics.

Paulay, T and P. Loeber (1974). "Shear transfer by aggregate interlock". In: $A C I$ Special Publication 42, pp. 1-15.

Rahal, K. N. (2011). "Shear-Transfer Strength of Reinforced Concrete". In: ACI Structural Journal 107, pp. 419-426.

Rajagopalan, K. and P. M Ferguson (1968). "Exploratory shear tests emphasizing percentage of longitudinal steel". In: ACI Journal Proceedings 65.8, pp. 634638.

Rao, G. A. and A. S. Rao (2009). "Toughness indices of steel fiber reinforced concrete under mode II loading". In: Materials and structures 42.9, pp. 11731184 .

Reinhardt, H. W and J. C Walraven (1982). "Cracks in concrete subject to shear". In: Journal of the Structural Division 108.1, pp. 207-224.

Sagaseta, J and R. Vollum (2011). "Influence of aggregate fracture on shear transfer through cracks in reinforced concrete". In: Magazine of Concrete Research 63.2, pp. 119-137.

Santos, P. and E. N. Júlio (2013). "A state-of-the-art review on roughness quantification methods for concrete surfaces". In: Construction and Building Materials 38, pp. 912-923. 
Serna, P. (1984). "Étude de la contribution des fibres métalliques a l'amélioratlon du comportement du béton au cisaillement". PhD thesis. l'École Nationale des Ponts et Chaussées.

Shear, A.-A. C. . on and Torsion (1998). Recent Approaches to Shear Design of Structural Concrete. Vol. 124. Journal of Structural Engineering, pp. 1375-1417.

Sneed, L (2013). Lightweight Concrete Modification Factor for Shear Friction. Tech. rep. Missouri University of Science and Technology.

Susetyo, J. (2010). "Fibre reinforcement for shrinkage crack control in prestressed, precast segmental bridges". PhD thesis. University of Toronto.

Swamy, R. and H. Bahia (1985). "The effectiveness of steel fibers as shear reinforcement". In: Concrete International 7.3, pp. 35-40.

Swamy, R., R Jones, and T. Chiam (1987). "Shear Transfer in Steel Fiber Reinforced Concrete". In: ACI Special Publication 105, pp. 565-592.

Tassios, B. T. P. and E. N. Vintzeleou (1987). "Concrete-to-concrete friction". In: Journal of structural engineering 113.4, pp. 832-849.

UNE-EN12350-8 (2011). Testing fresh concrete. Part 8: Self-compacting concrete. Slump-flow test. European Committee for Standardization.

UNE-EN12390-3 (2009). Testing hardened concrete. Part 3: Comporessive strength of test specimens. European Committee for Standardization.

UNE-EN12390-6 (2010). Testing hardened concrete. Part 6: Tensile splitting strength of specimens. European Committee for Standardization.

UNE-EN14651 (2005). Test method for metallic fiber concrete. Measuring the flexural tensile strength (limit of proportionally (LOP), residual). European Committee for Standardization.

Valle, M. and O. Buyukozturk (1993). "Behavior of Fiber Reinforced High-Strength Concrete under Direct Shear". In: ACI Materials Journal 90.2, pp. 122-133.

Vandewalle, L. (2000). "Cracking behaviour of concrete beams reinforced with a combination of ordinary reinforcement and steel fibers". In: Materials and Structures 33.3, pp. 164-170.

Vecchio, F. J. (2000a). "Analysis of shear-critical reinforced concrete beams". In: ACI Structural Journal 97.1, pp. 102-110.

Vecchio, F. J. (2000b). "Disturbed stress field model for reinforced concrete: formulation". In: Journal of Structural Engineering 126.9, pp. 1070-1077.

Vecchio, F. J. and M. P. Collins (1986). "The modified compression-field theory for reinforced concrete elements subjected to shear". In: ACI Journal Proceedings 83.2, pp. 219-231.

Vecchio, F. J. and D. Lai (2004). "Crack Shear-Slip in Reinforced Concrete Elements". In: Journal of Advanced Concrete Technology 2.3, pp. 289-300.

Vondran, G. (1991). "Applications of steel fiber reinforced concrete". In: Concrete international 13.11, pp. 44-49.

Walraven, J. C. (1981). "Fundamental Analysis of Aggregate Interlock". In: Sructural Division. ASCE 107, pp. 2245-2270.

Walraven, J. C. (1978). Mechanics of Shear Transfer in Cracks in Concrete - A Survey of Literature. Tech. rep. Delf University, Stevin Laboratory report no. 5-78-12.

Walraven, J. C., B. Belletti, and R. Esposito (2012). "Shear capacity of normal, lightweight, and high-strength concrete beams according to Model Code 2010. I: 
Experimental results versus analytical model results". In: Journal of Structural Engineering 139.9, pp. 1593-1599.

Walraven, J. C., J. Frenay, and A. Pruijssers (1987). "Influence of concrete strength and load history on the shear friction capacity of concrete members". In: PCI journal 32.1, pp. 66-84.

Walraven, J. C. and H. W. Reinhardt (1981). "Concrete mechanics. Part A: Theory and experiments on the mechanical behavior of cracks in plain and reinforced concrete subjected to shear loading". In: HERON 82, p. 68.

Walraven, J. C. and J Stroband (1994). "Shear friction in high-strength concrete". In: ACI Special Publication 149, pp. 311-330.

Walraven, J. C., E Vos, and H. Reinhardt (1979). "Experiments on shear transfer in cracks in concrete-Part I: Description of results". In: Delft University of Technology, Report 1.5-79, p. 3.

Walraven, J. C. (1980). "Aggregate Interlock: A Theorical and Experimental Analysis". PhD thesis. Delf University.

Wright, J. K. and J. G. MacGregor (2009). Reinforced Concrete: Mechanics and Design. Pearson Education, New Jersey, The USA.

Xiao, J., H. Xie, and Z. Yang (2012). "Shear transfer across a crack in recycled aggregate concrete". In: Cement and Concrete Research 42.5, pp. 700-709.

Zhang, T, D. Oehlers, and P Visintin (2014). "Shear Strength of FRP RC Beams and One-Way Slabs without Stirrups". In: Journal of Composites for Construction 18.

Zhang, T. et al. (2014). "Presliding shear failure in prestressed RC beams. II: Behavior". In: Journal of Structural Engineering 10. 


\section{Annex A}

\section{Results of the push-off phase}

In the following figures the experimental behavior for all specimens are reported. These figures are presented according to the order used in Table 5.4. Also, the average behavior of each type of material is shown, using "Material" as name according to Table 4.4. This average behavior is shown in black color for all figures. For instance, for specimens of the second part A4-0-2a, A4-0-2b and A4-0-2c, the material name "A4-0-2" is used.

In these figures the average values of shear displacements crack width $(w)$ and slip (slip) are used. The measurements at both sides of the specimen individually did not show any systematical difference and exhibited low scatter. It must be pointed out that for the shear stress of all specimens reported in the following figures have been corrected according of the procedure explain in detail in subsection 5.3.1.

The following rules are applied to present the figures. Only two figures by page are presented, so for each material two pages are needed. In the first page, shear stress as a function of slip and shear stress as a function of crack width are presented. the second page is used to present the crack opening path and the normal stress as a function of crack width. 


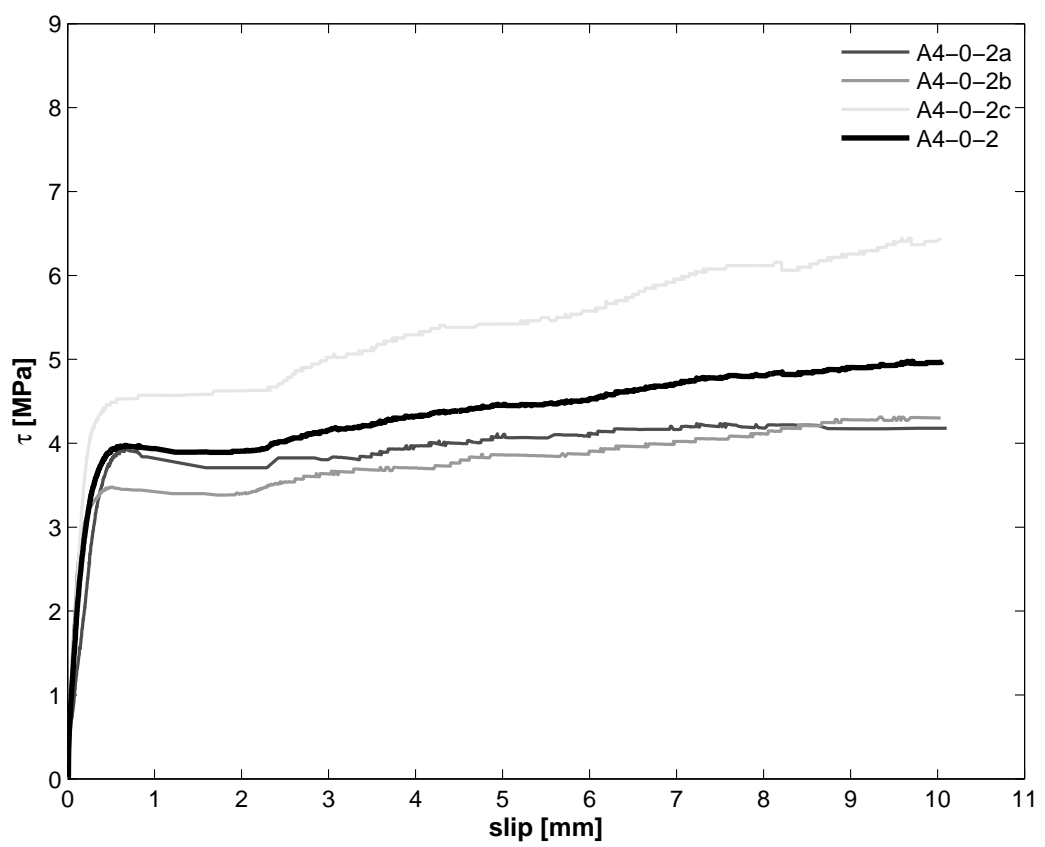

(a) Shear stress - slip relationship

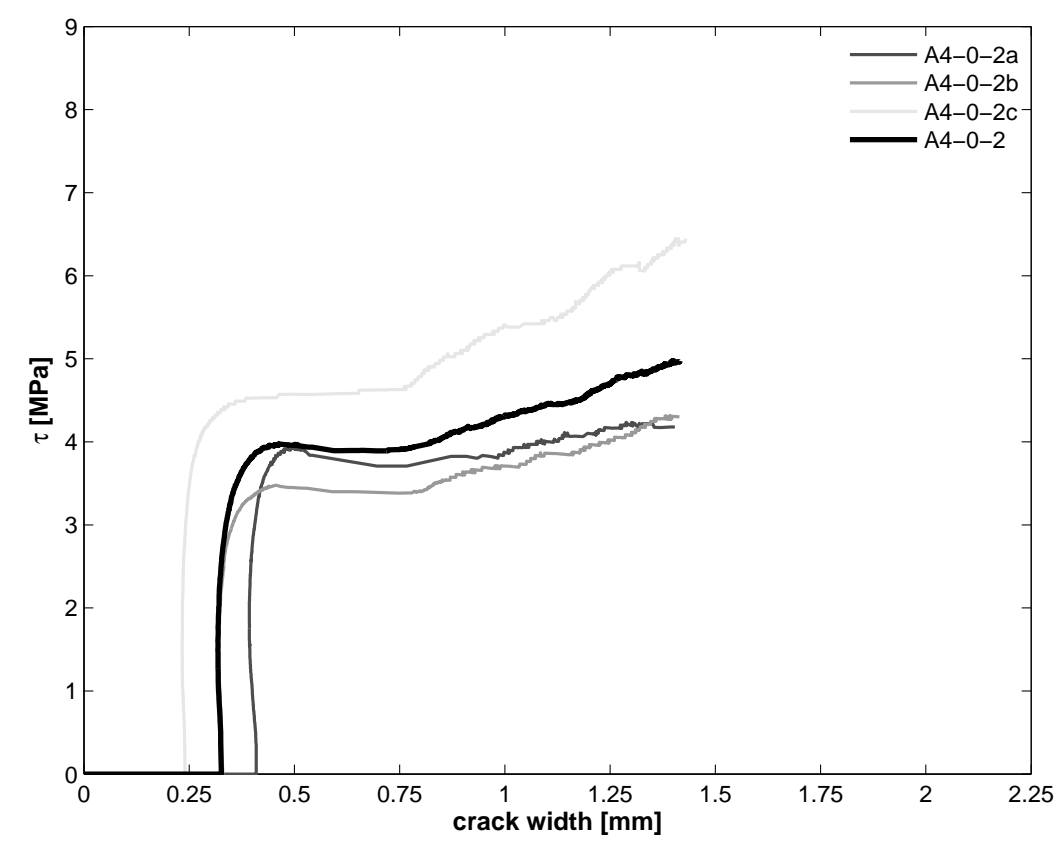

(b) Shear stress - crack width relationship

Fig. A.1. Shear behavior for confined specimens $\left(w_{o}=0\right)$, Material A4-0-2. 


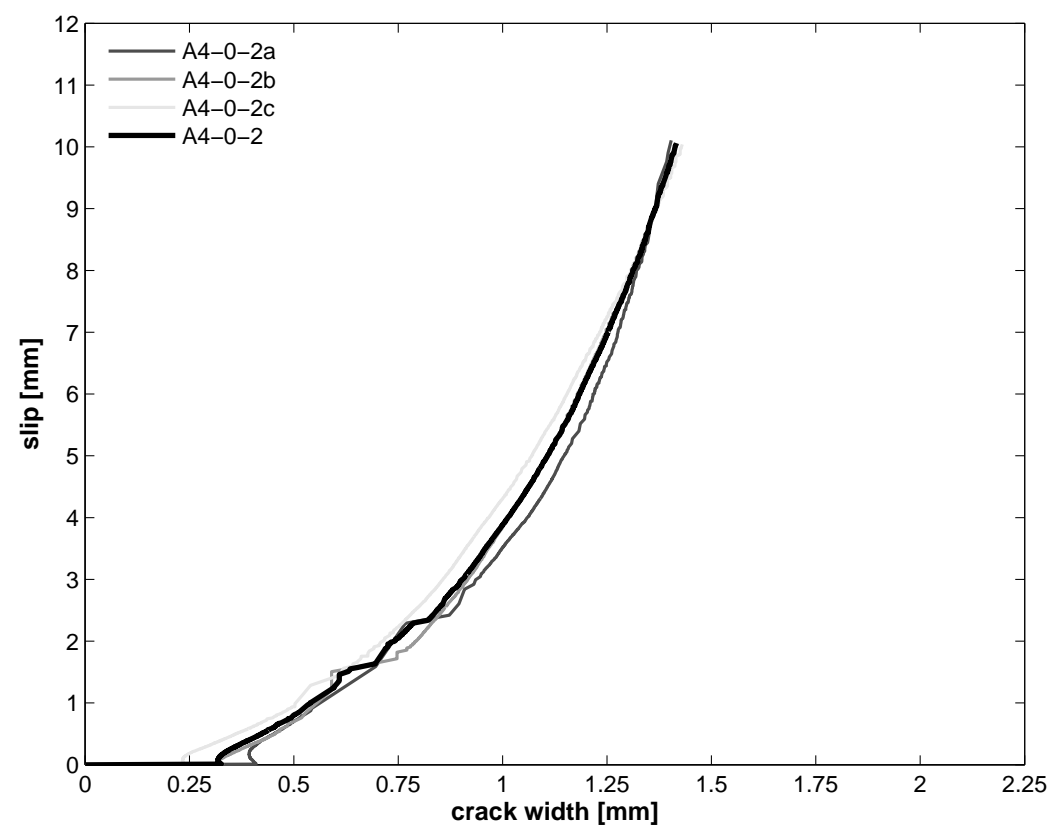

(a) Crack opening path relationship

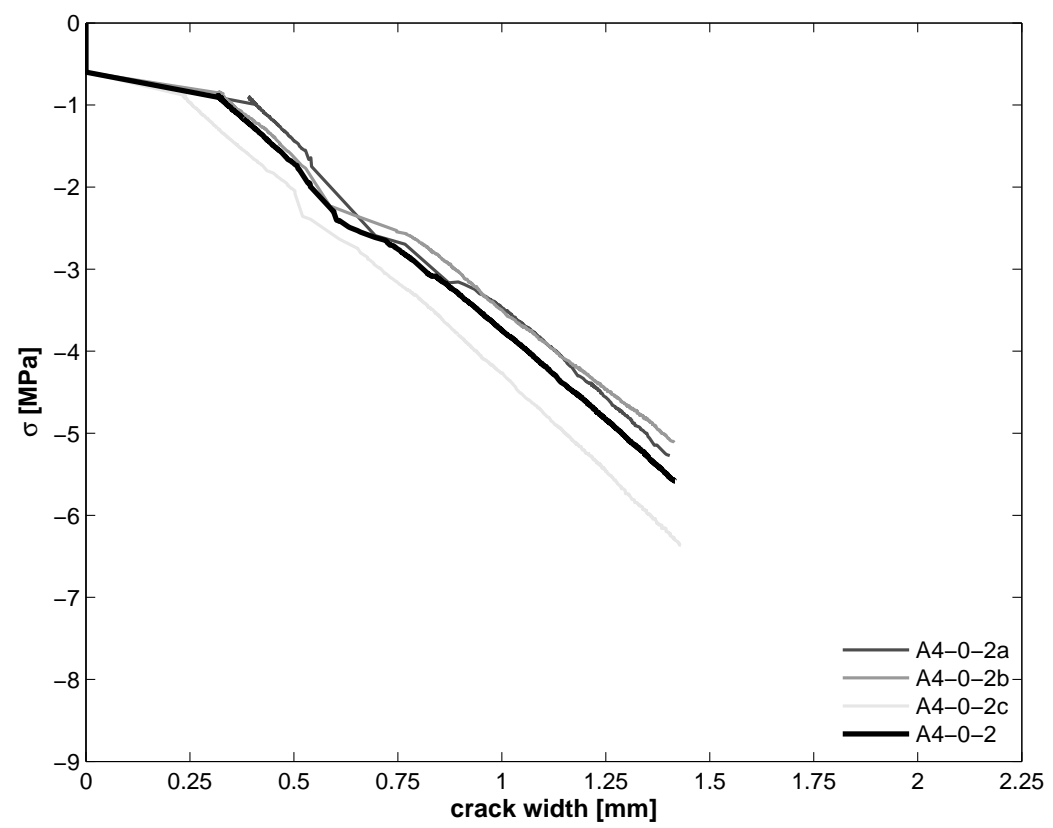

(b) Normal stress - crack width relationship

Fig. A.2. Shear behavior for confined specimens $\left(w_{o}=0\right)$, Material A4-0-2 (continued). 


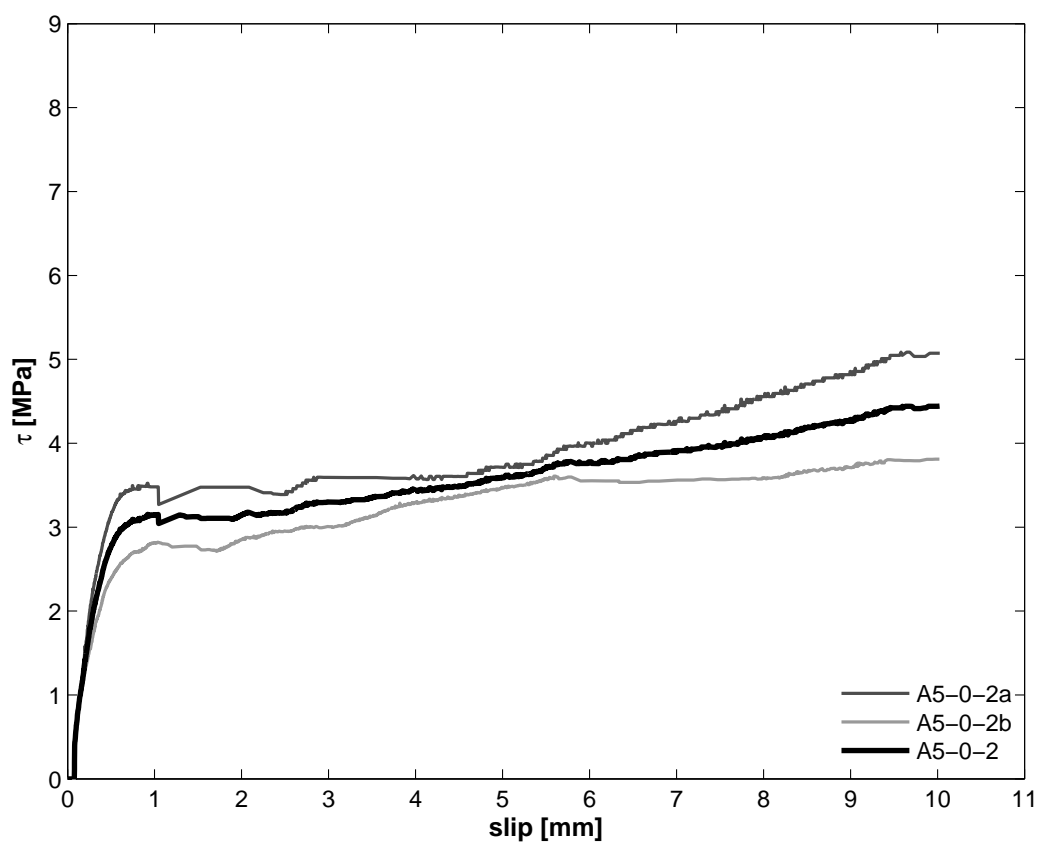

(a) Shear stress - slip relationship

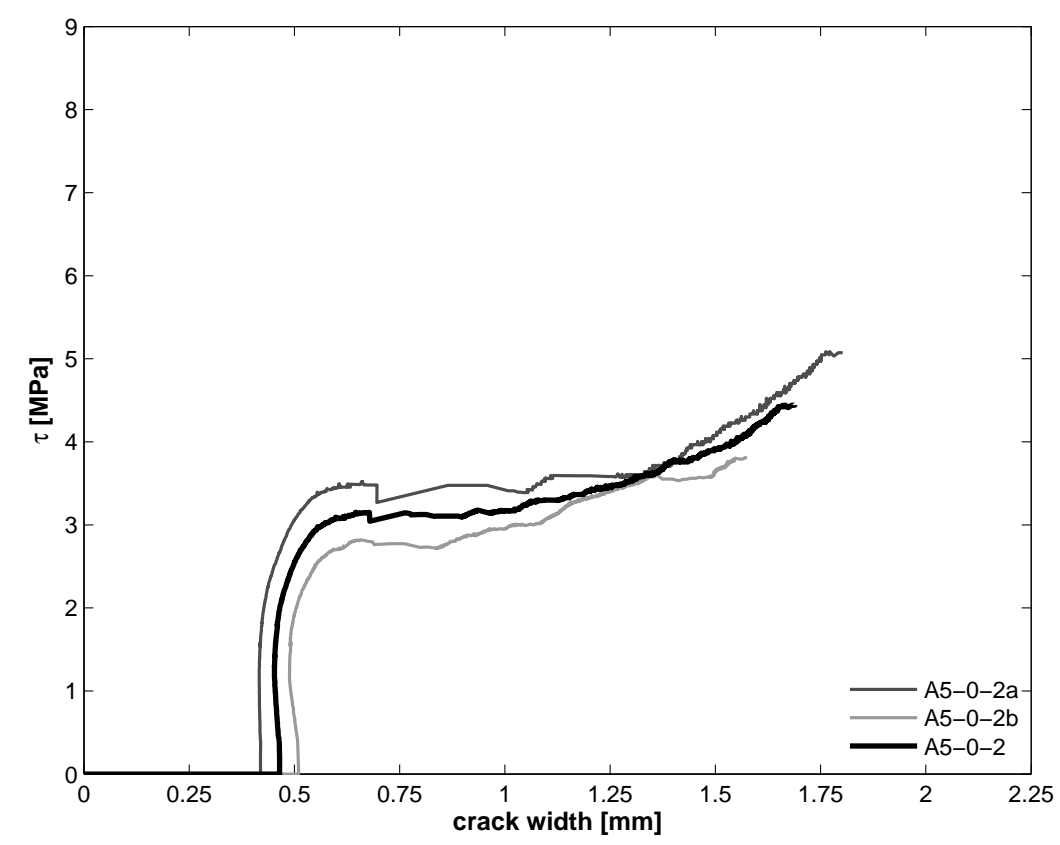

(b) Shear stress - crack width relationship

Fig. A.3. Shear behavior for confined specimens $\left(w_{o}=0\right)$, Material A5-0-2. 


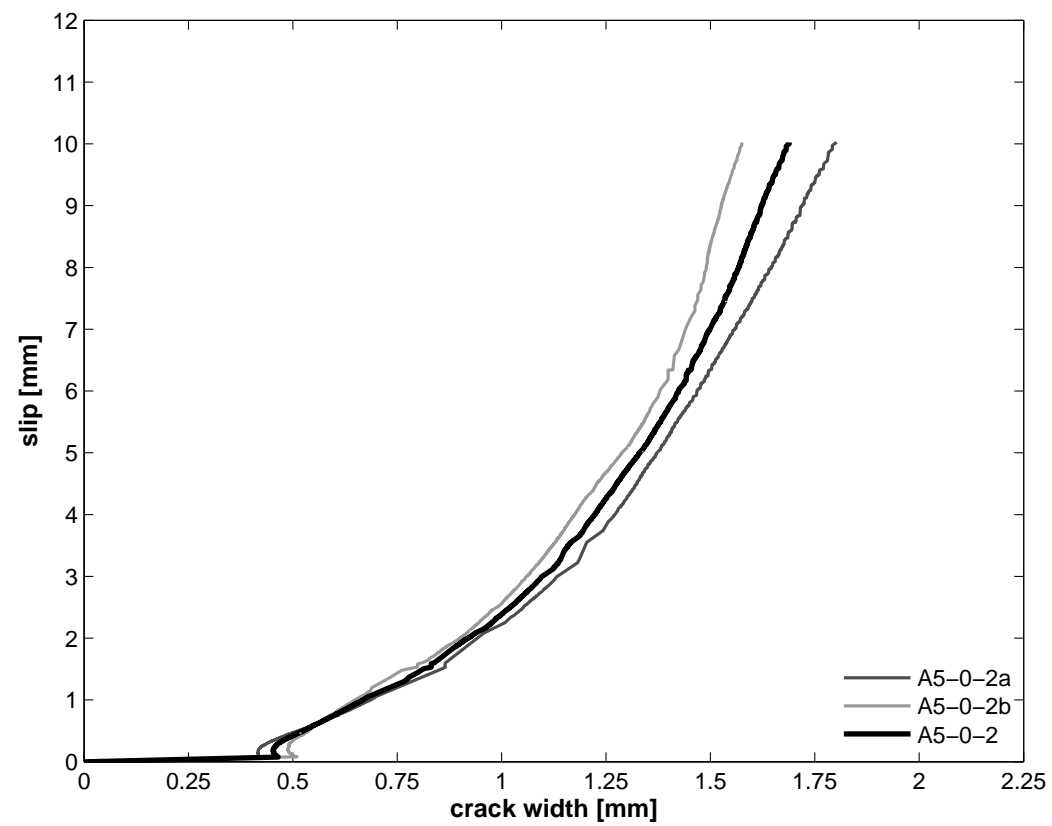

(a) Crack opening path relationship

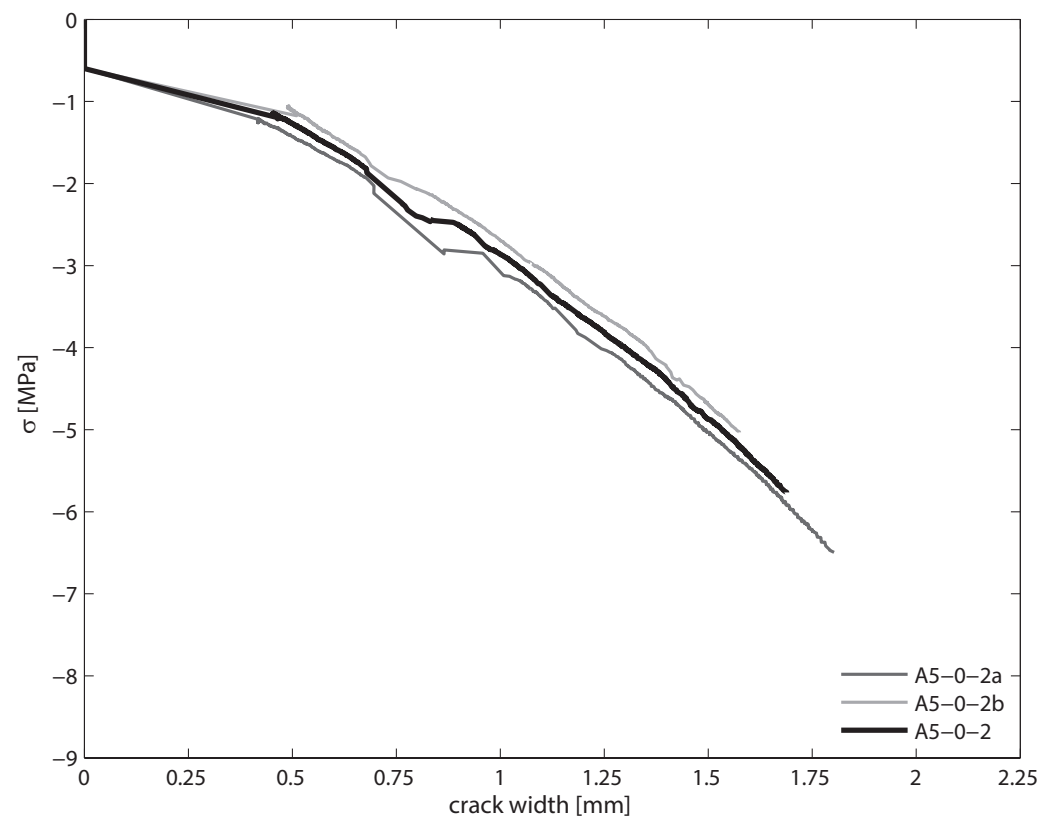

(b) Normal stress - crack width relationship

Fig. A.4. Shear behavior for confined specimens $\left(w_{o}=0\right)$, Material A5-0-2 (continued). 


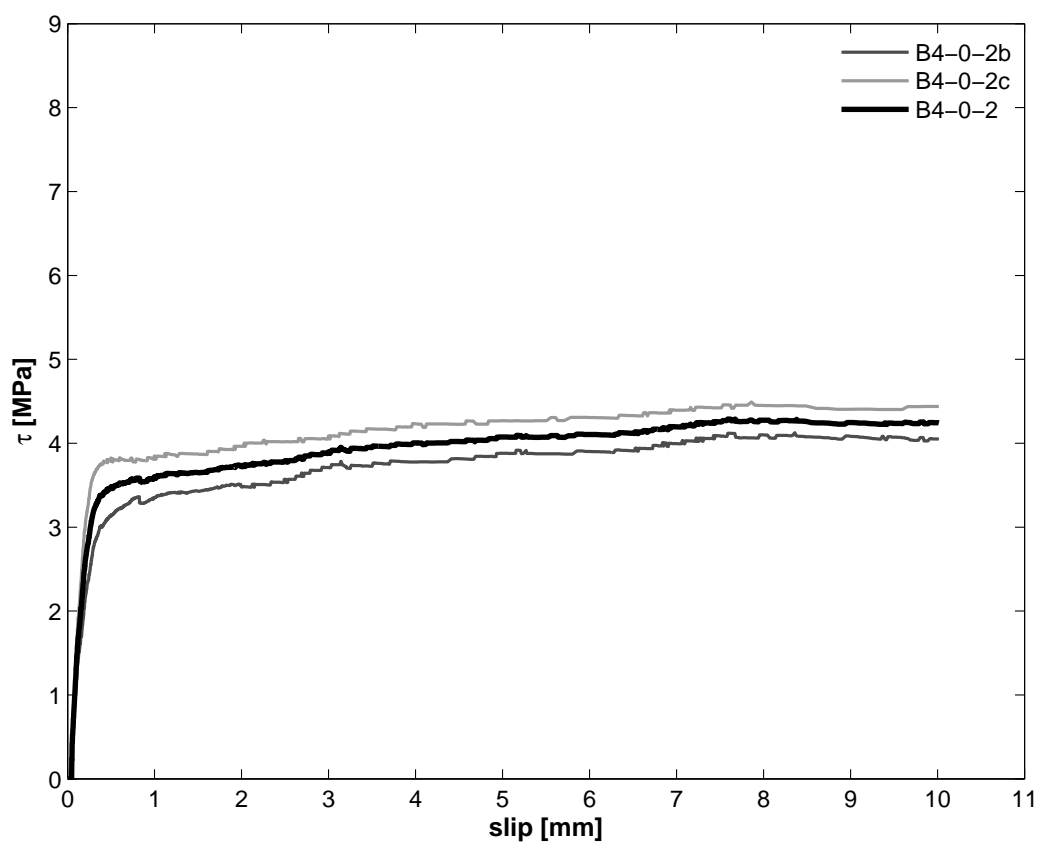

(a) Shear stress - slip relationship

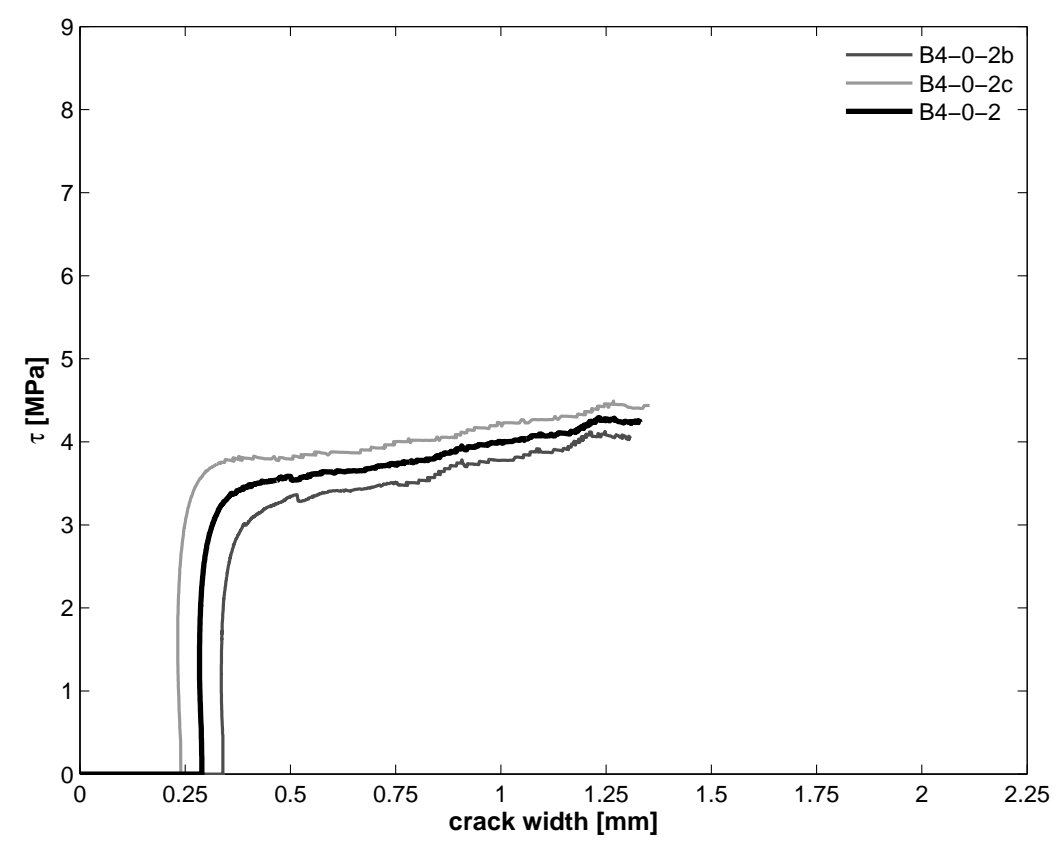

(b) Shear stress - crack width relationship

Fig. A.5. Shear behavior for confined specimens $\left(w_{o}=0\right)$, Material B4-0-2. 


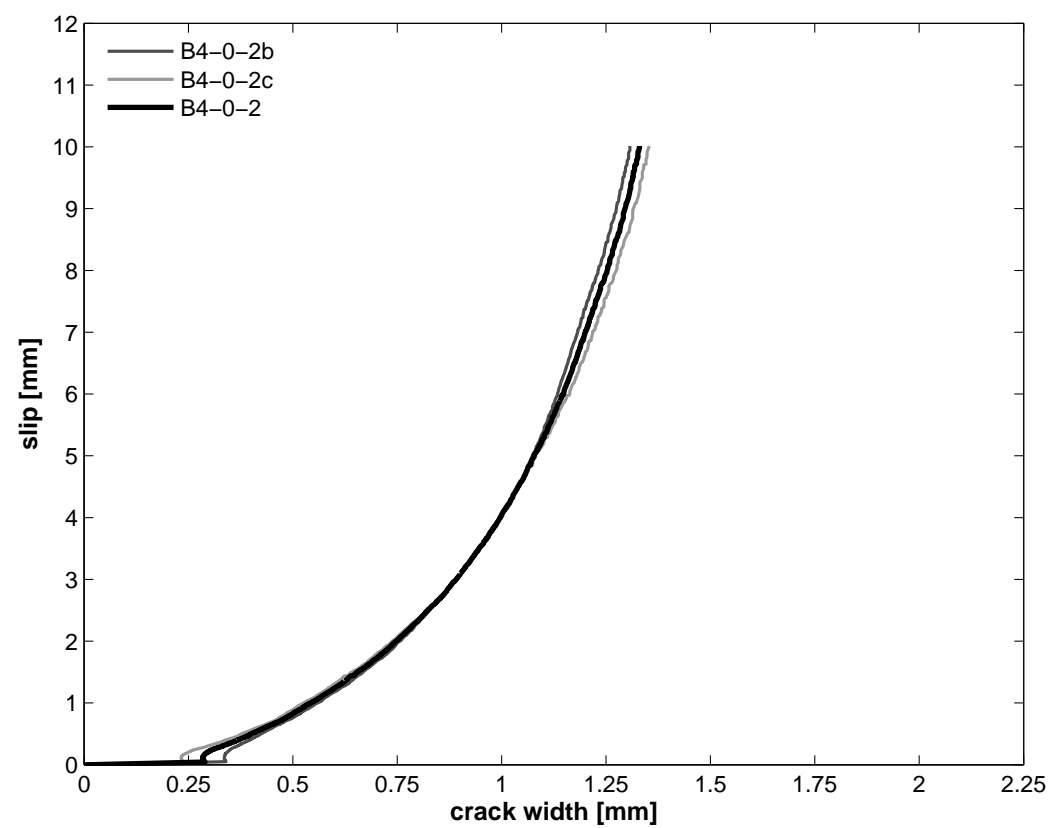

(a) Crack opening path relationship

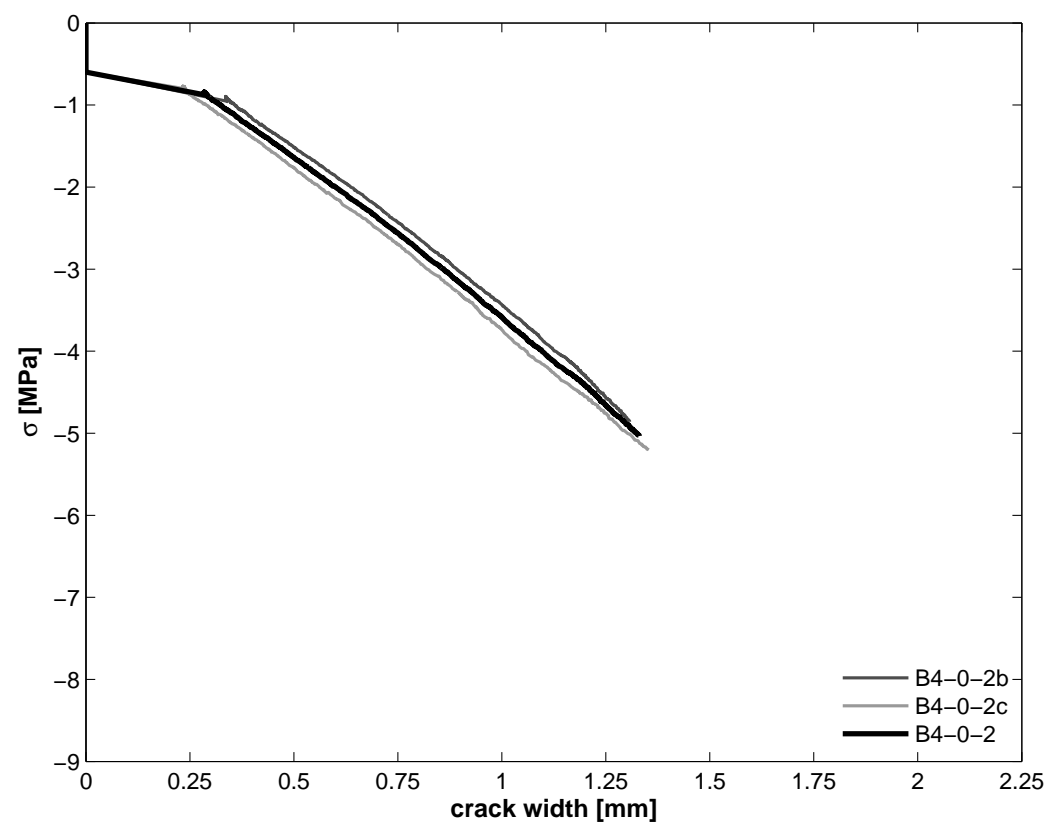

(b) Normal stress - crack width relationship

Fig. A.6. Shear behavior for confined specimens $\left(w_{o}=0\right)$, Material B4-0-2 (continued). 


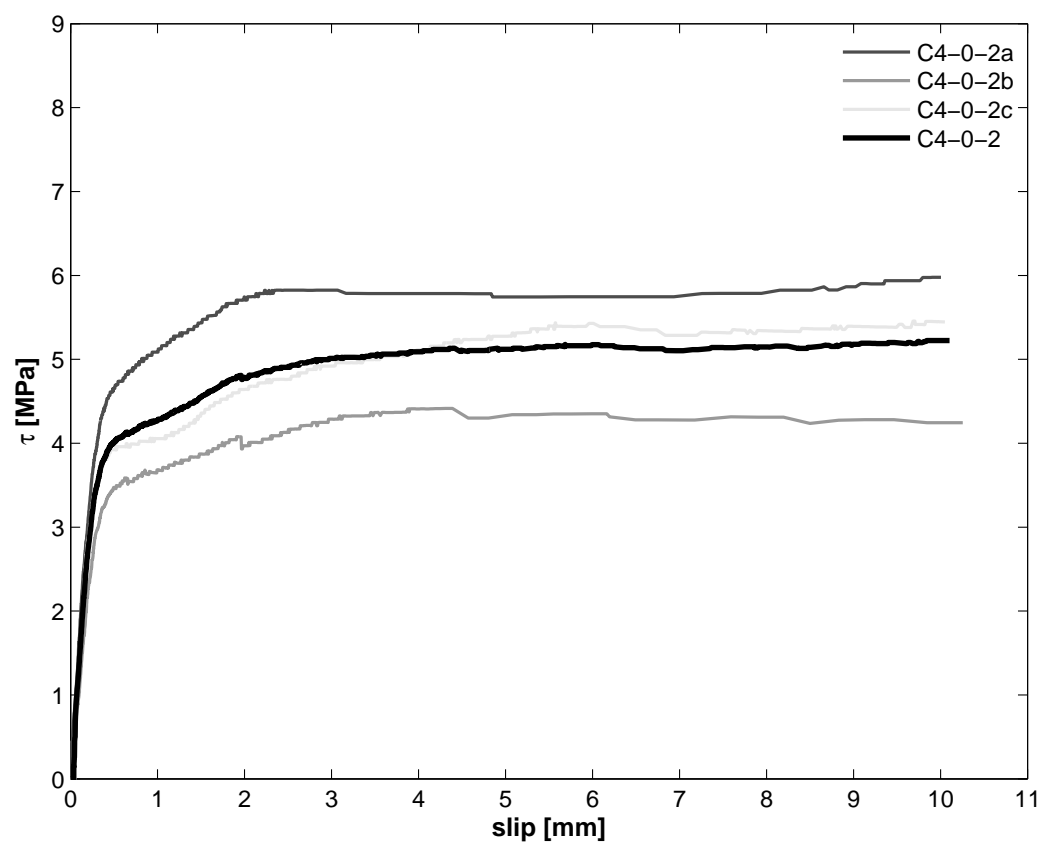

(a) Shear stress - slip relationship

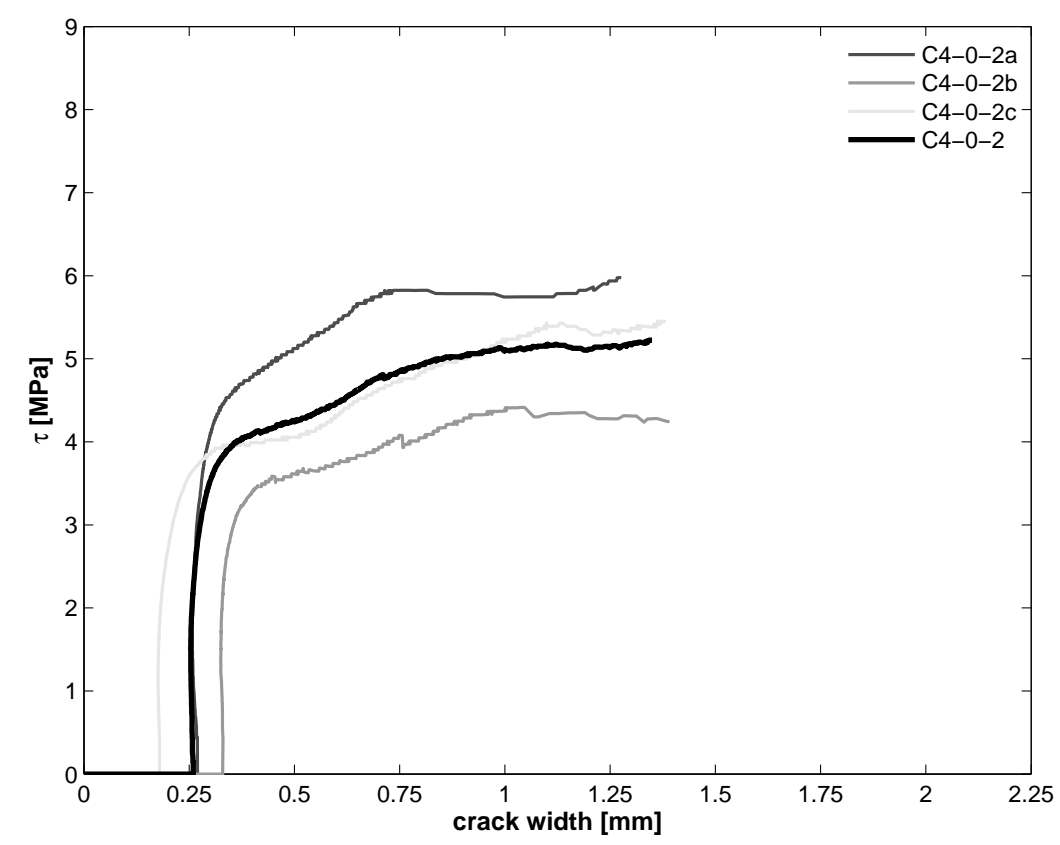

(b) Shear stress - crack width relationship

Fig. A.7. Shear behavior for confined specimens $\left(w_{o}=0\right)$, Material C4-0-2. 


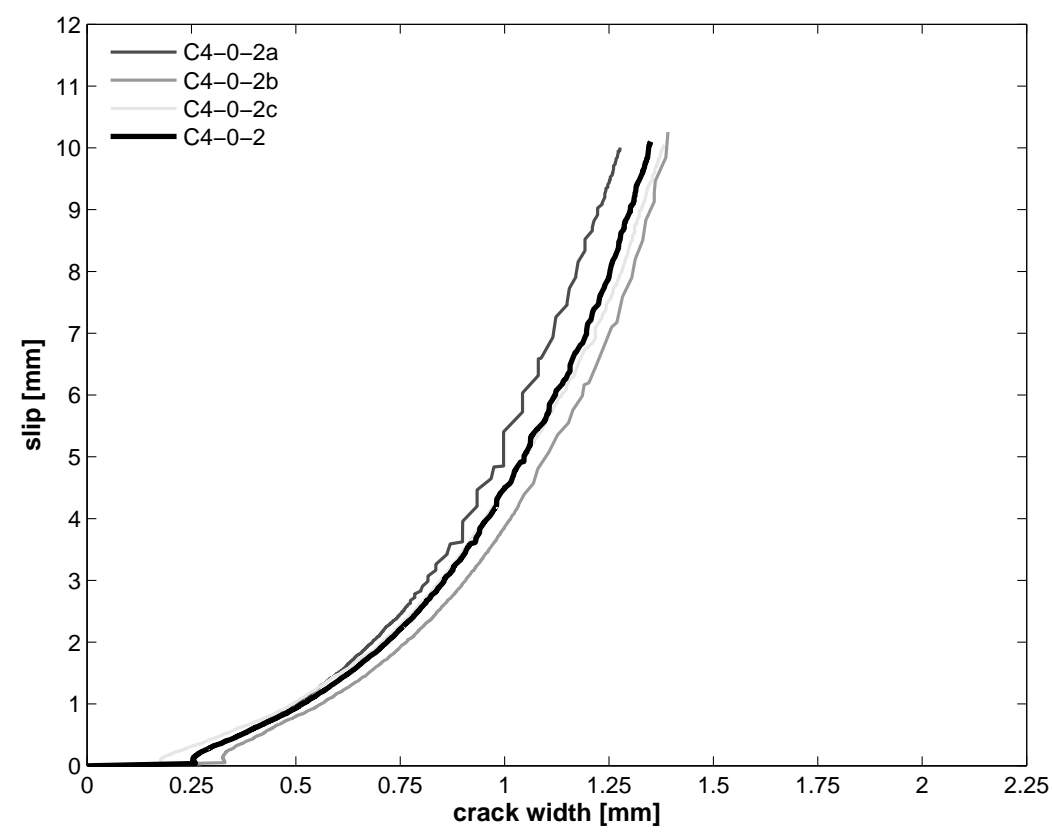

(a) Crack opening path relationship

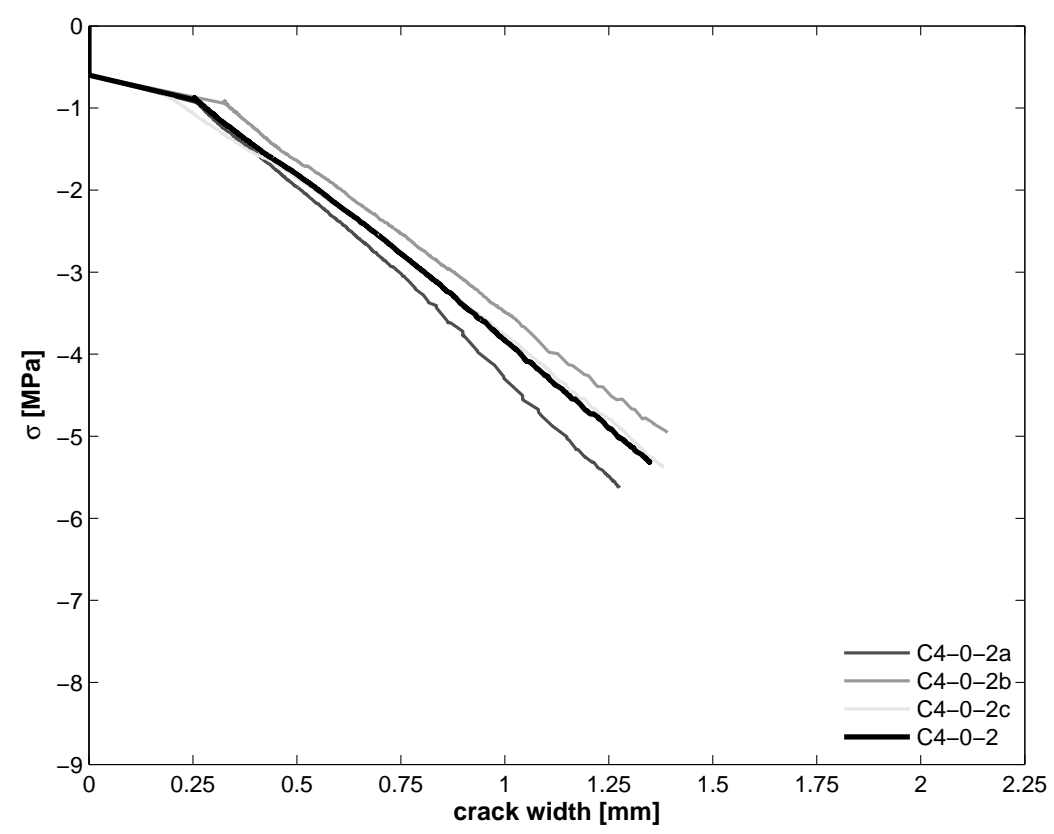

(b) Normal stress - crack width relationship

Fig. A.8. Shear behavior for confined specimens $\left(w_{o}=0\right)$, Material C4-0-2 (continued). 


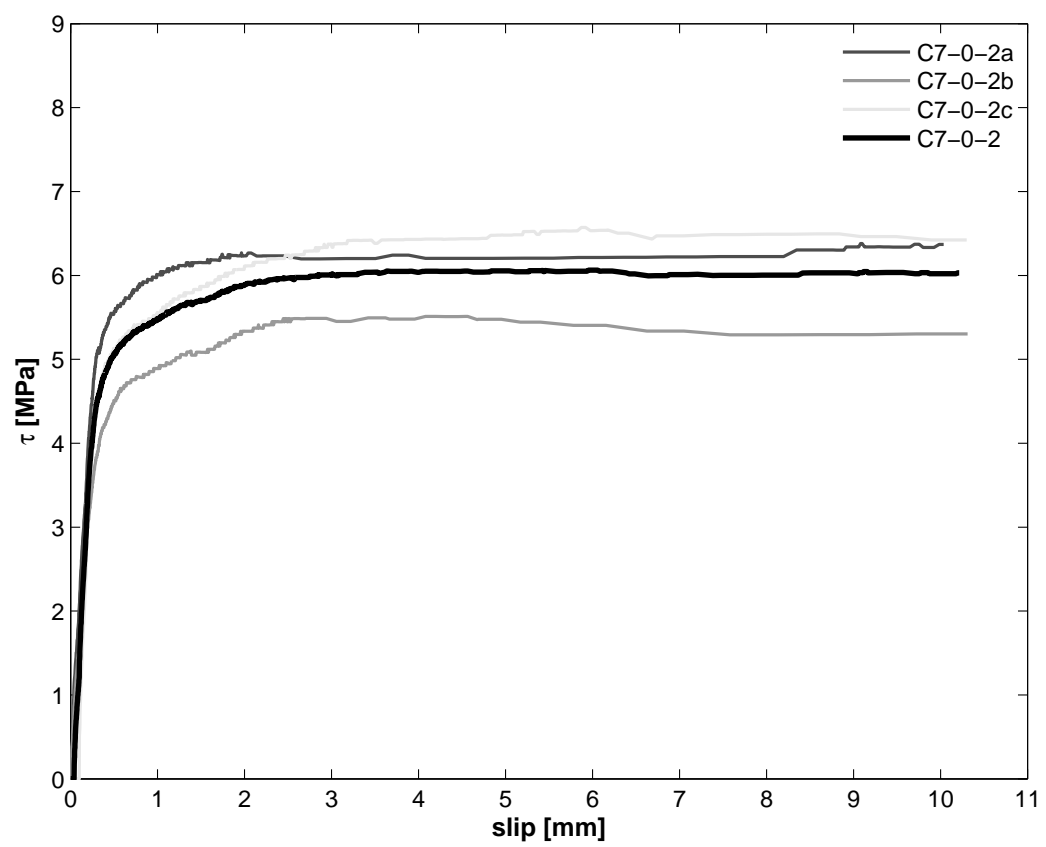

(a) Shear stress - slip relationship

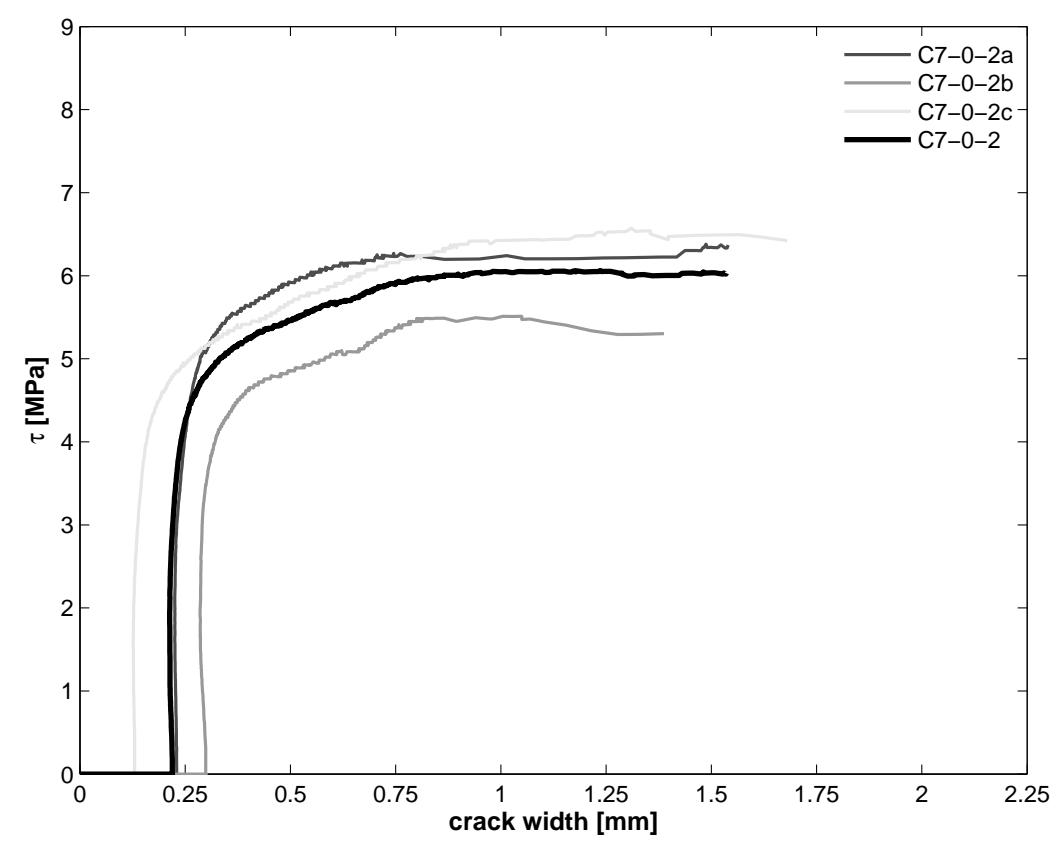

(b) Shear stress - crack width relationship

Fig. A.9. Shear behavior for confined specimens $\left(w_{o}=0\right)$, Material C7-0-2. 


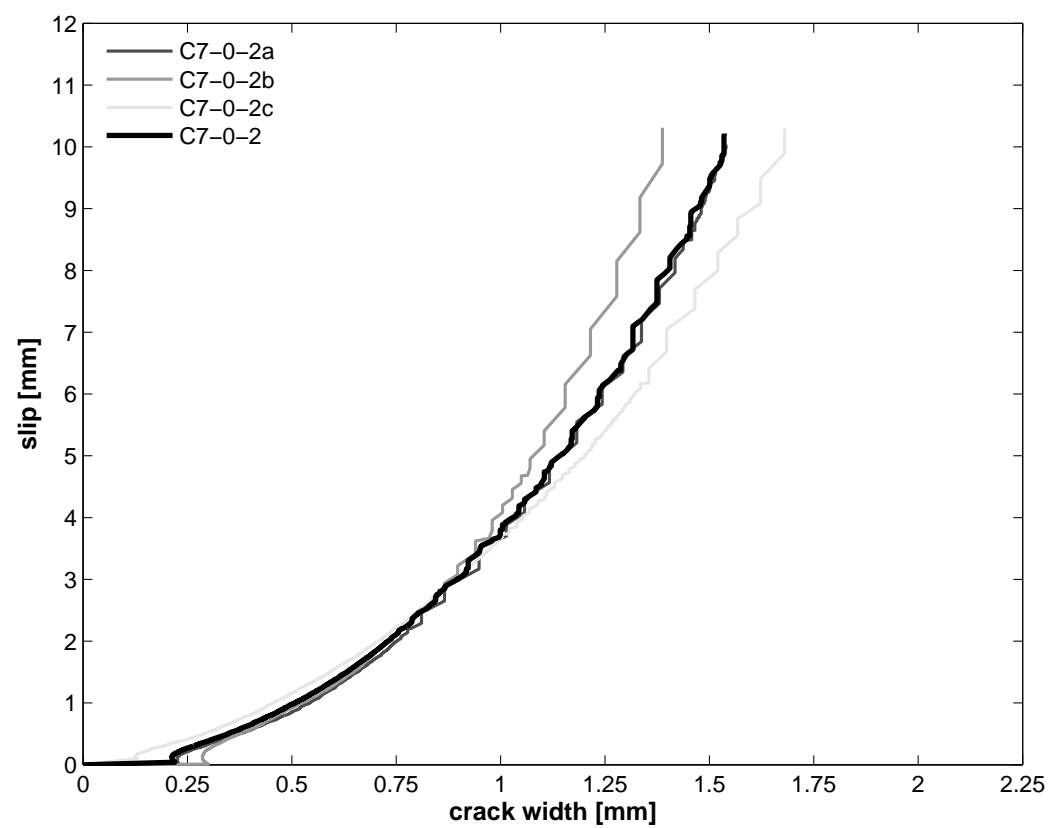

(a) Crack opening path relationship

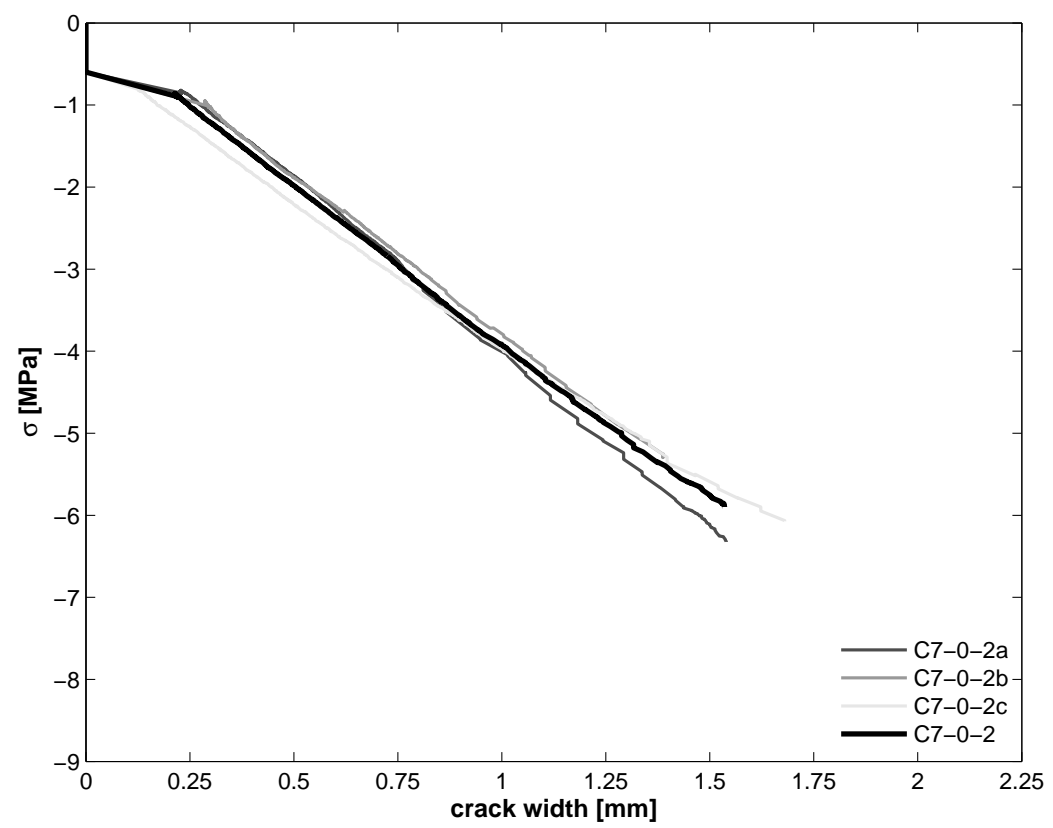

(b) Normal stress - crack width relationship

Fig. A.10. Shear behavior for confined specimens $\left(w_{o}=0\right)$, Material C7-0-2 (continued). 


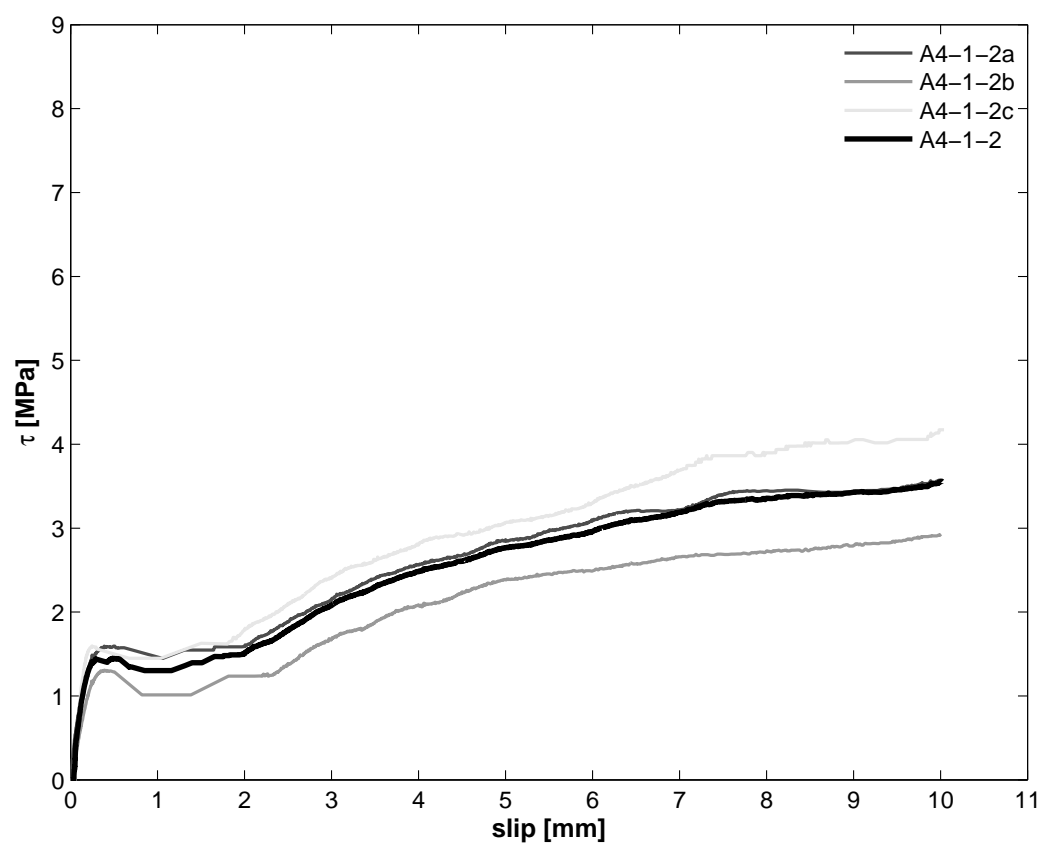

(a) Shear stress - slip relationship

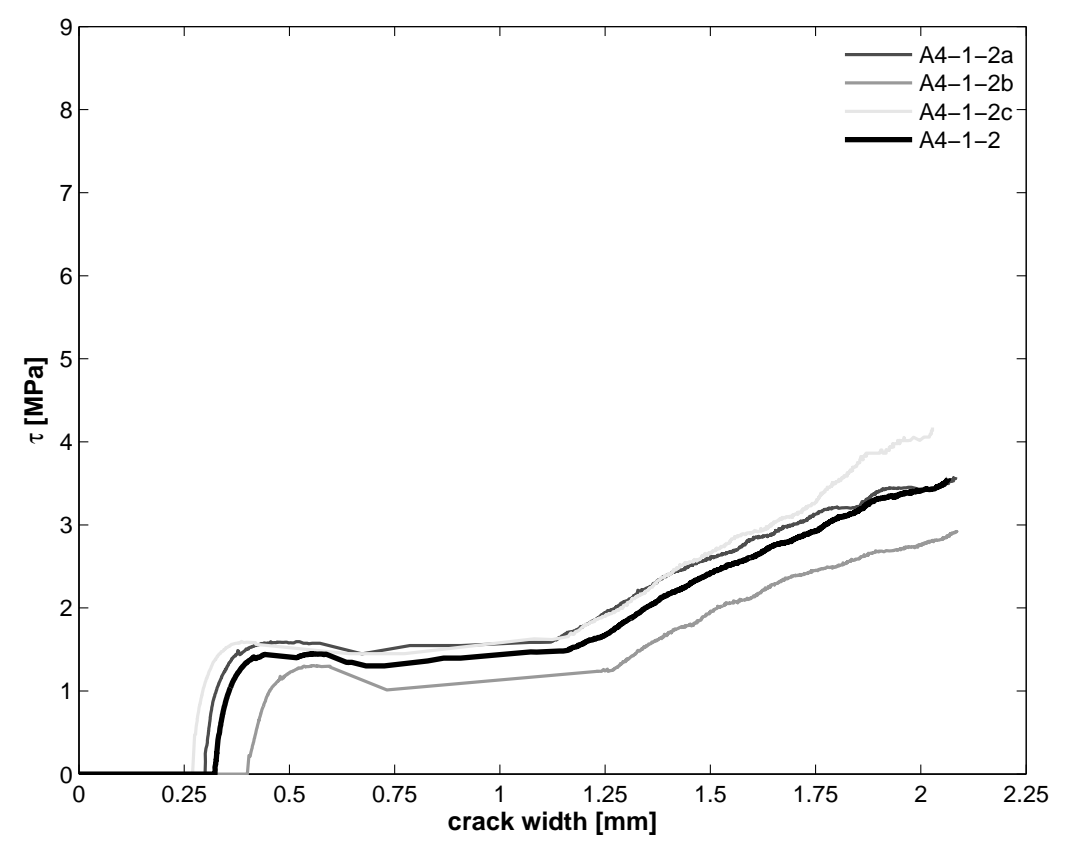

(b) Shear stress - crack width relationship

Fig. A.11. Shear behavior for confined specimens $\left(w_{o}=1\right)$, Material A4-1-2. 


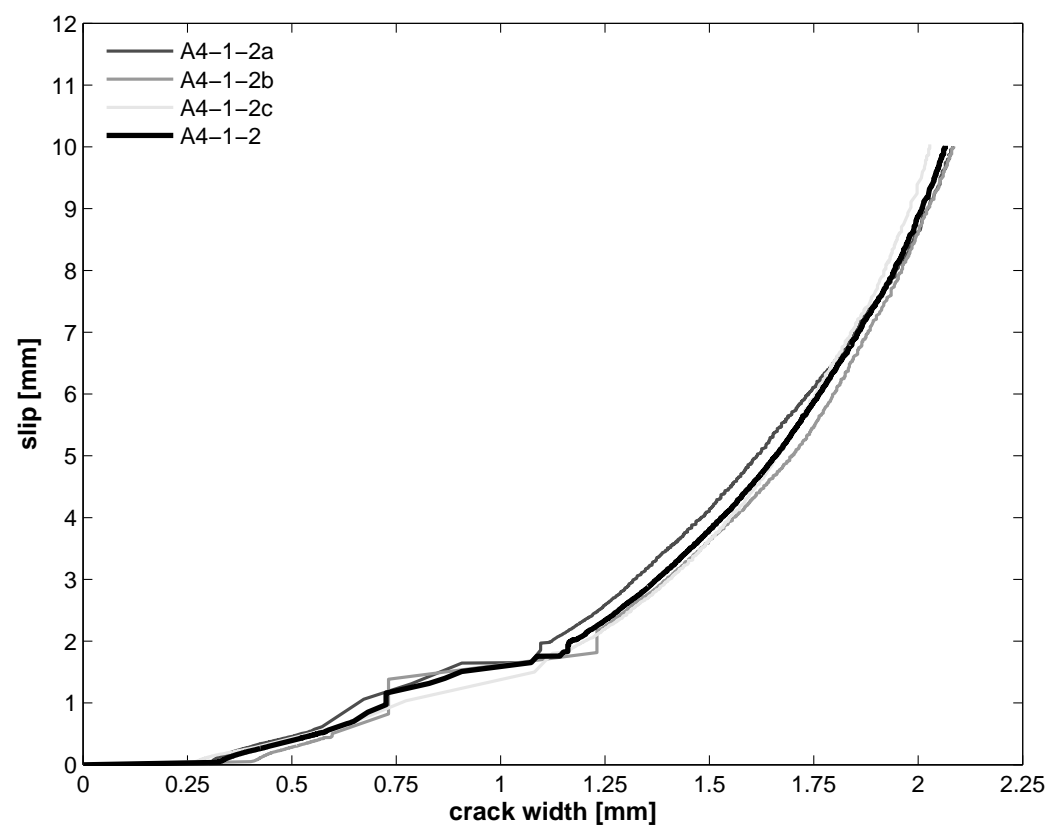

(a) Crack opening path relationship

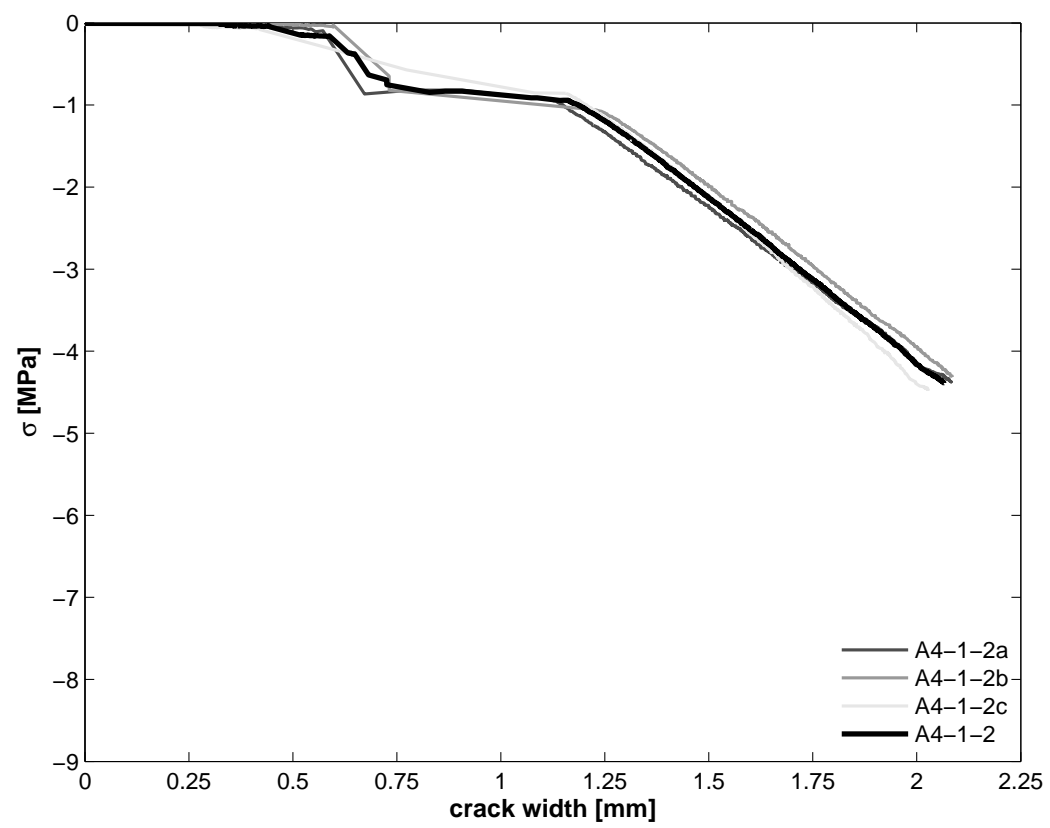

(b) Normal stress - crack width relationship

Fig. A.12. Shear behavior for confined specimens $\left(w_{o}=1\right)$, Material A4-1-2 (continued). 


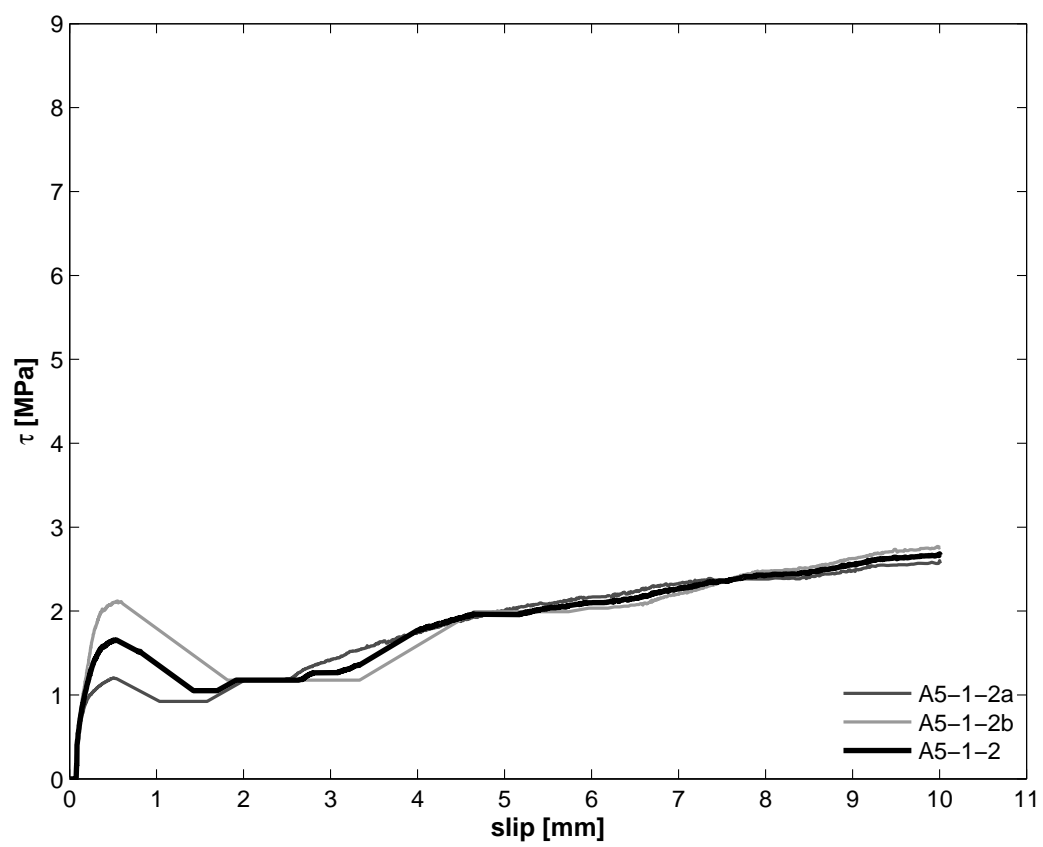

(a) Shear stress - slip relationship

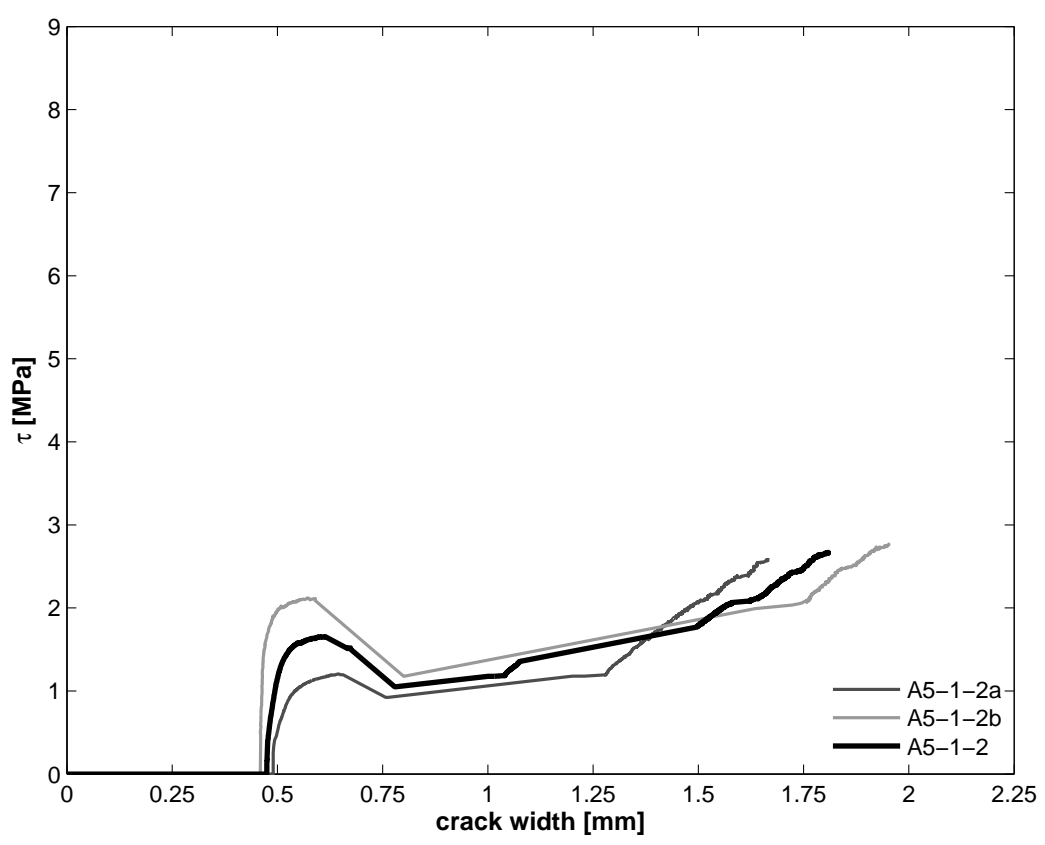

(b) Shear stress - crack width relationship

Fig. A.13. Shear behavior for confined specimens $\left(w_{o}=1\right)$, Material A5-1-2. 


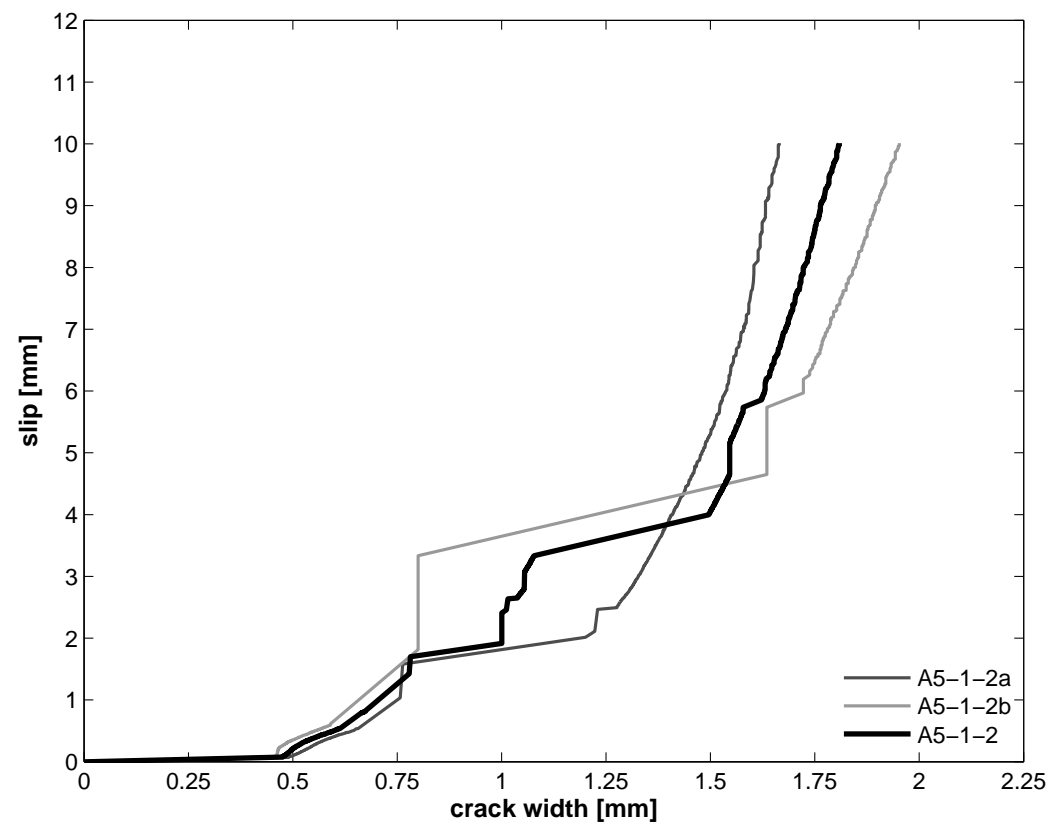

(a) Crack opening path relationship

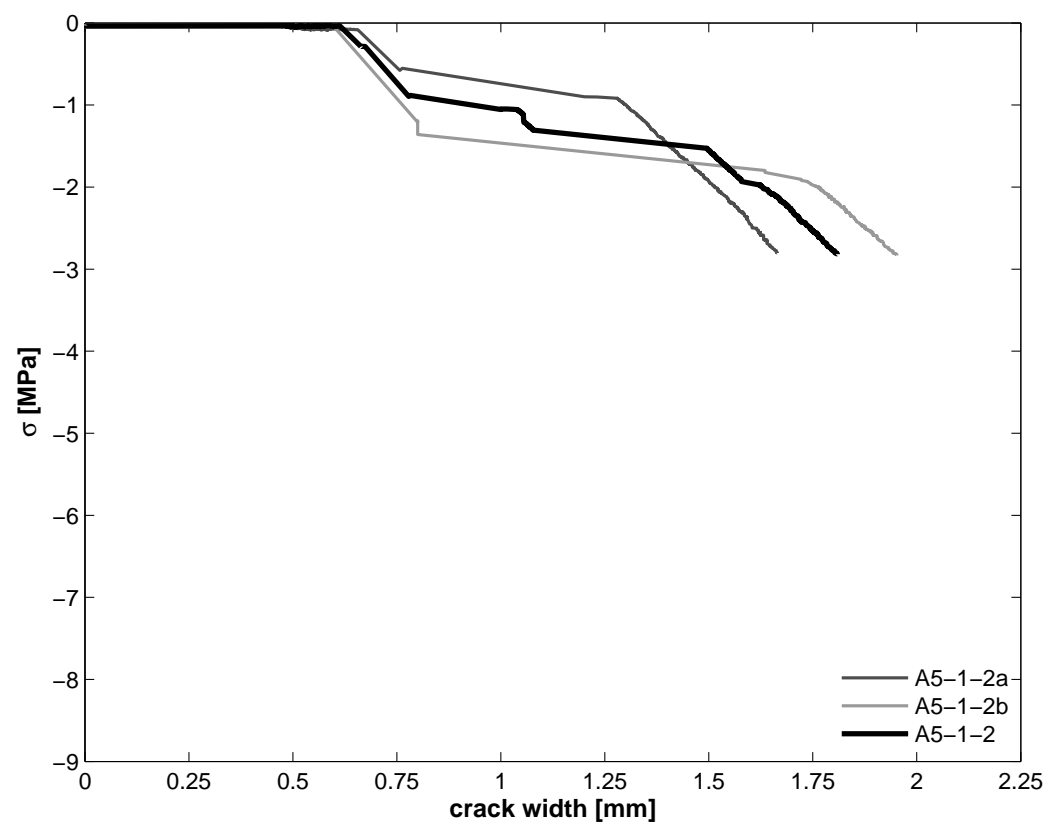

(b) Normal stress - crack width relationship

Fig. A.14. Shear behavior for confined specimens $\left(w_{o}=1\right)$, Material A5-1-2 (continued). 


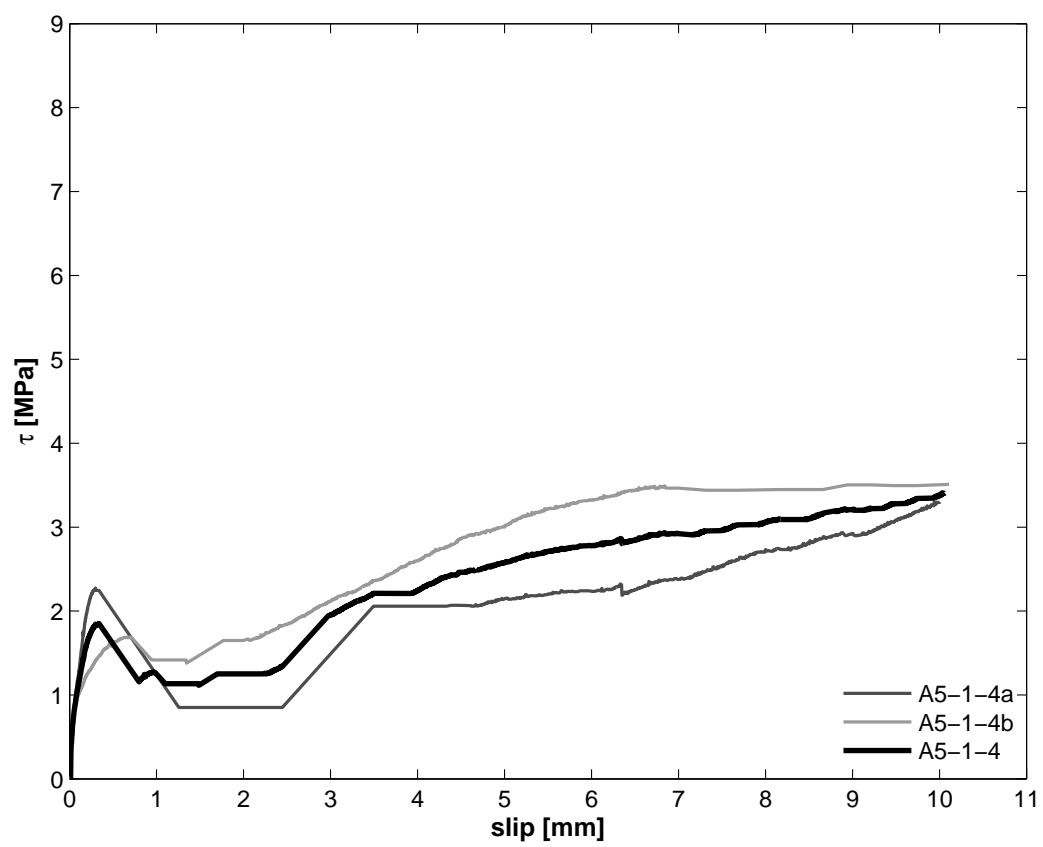

(a) Shear stress - slip relationship

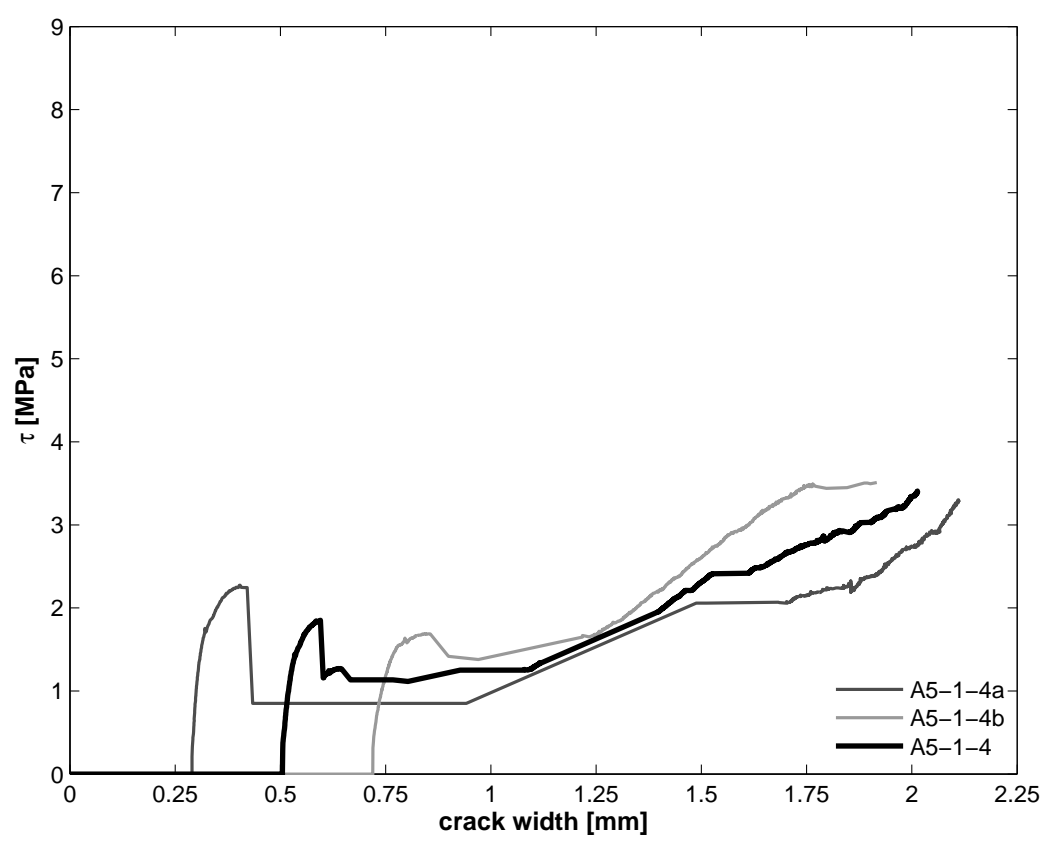

(b) Shear stress - crack width relationship

Fig. A.15. Shear behavior for confined specimens $\left(w_{o}=1\right)$, Material A5-1-4. 


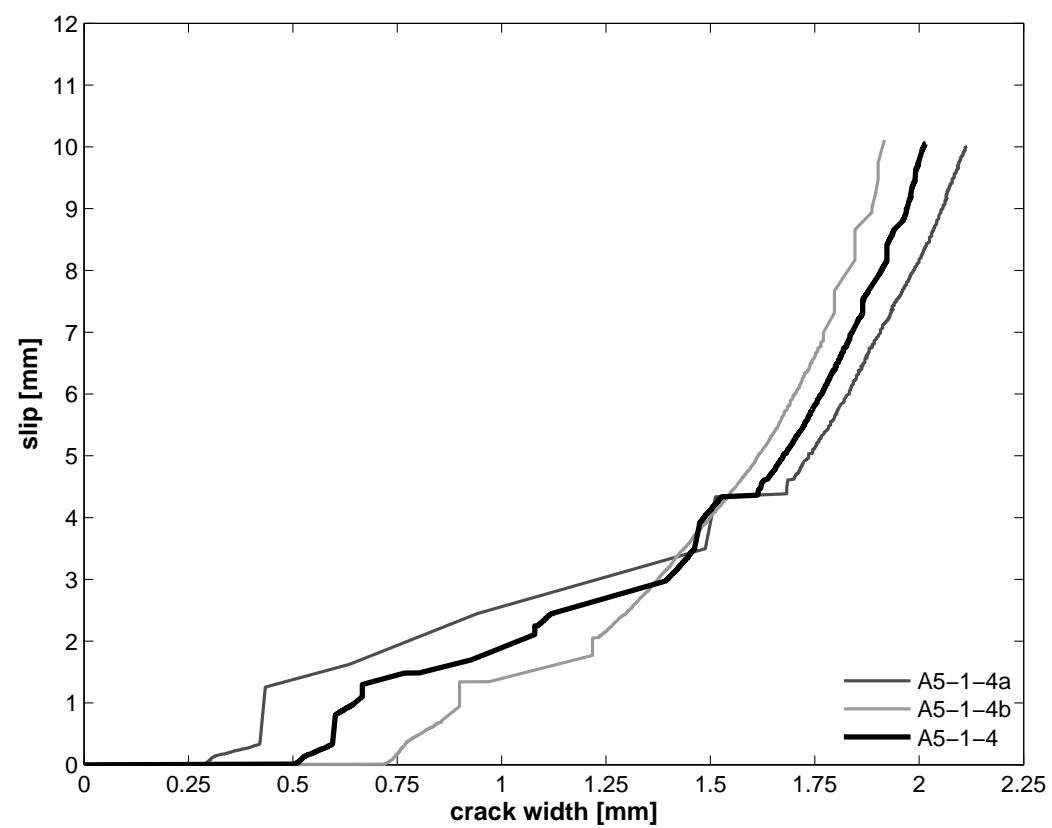

(a) Crack opening path relationship

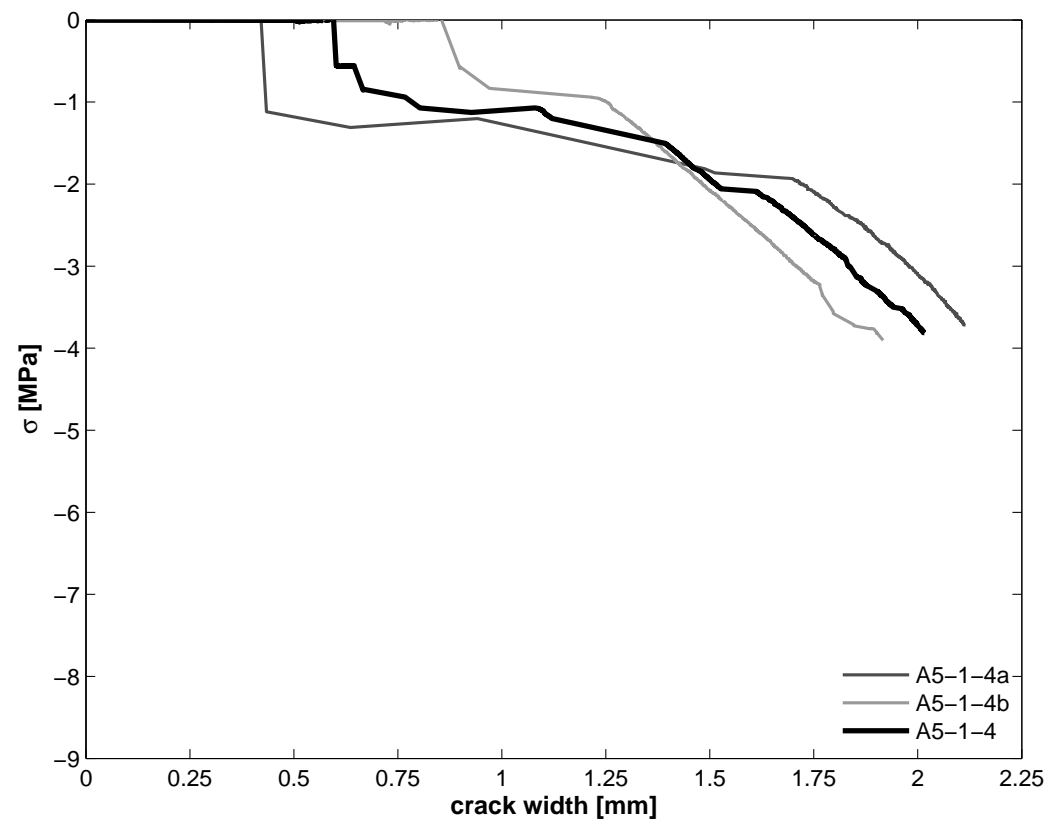

(b) Normal stress - crack width relationship

Fig. A.16. Shear behavior for confined specimens $\left(w_{o}=1\right)$, Material A5-1-4 (continued). 


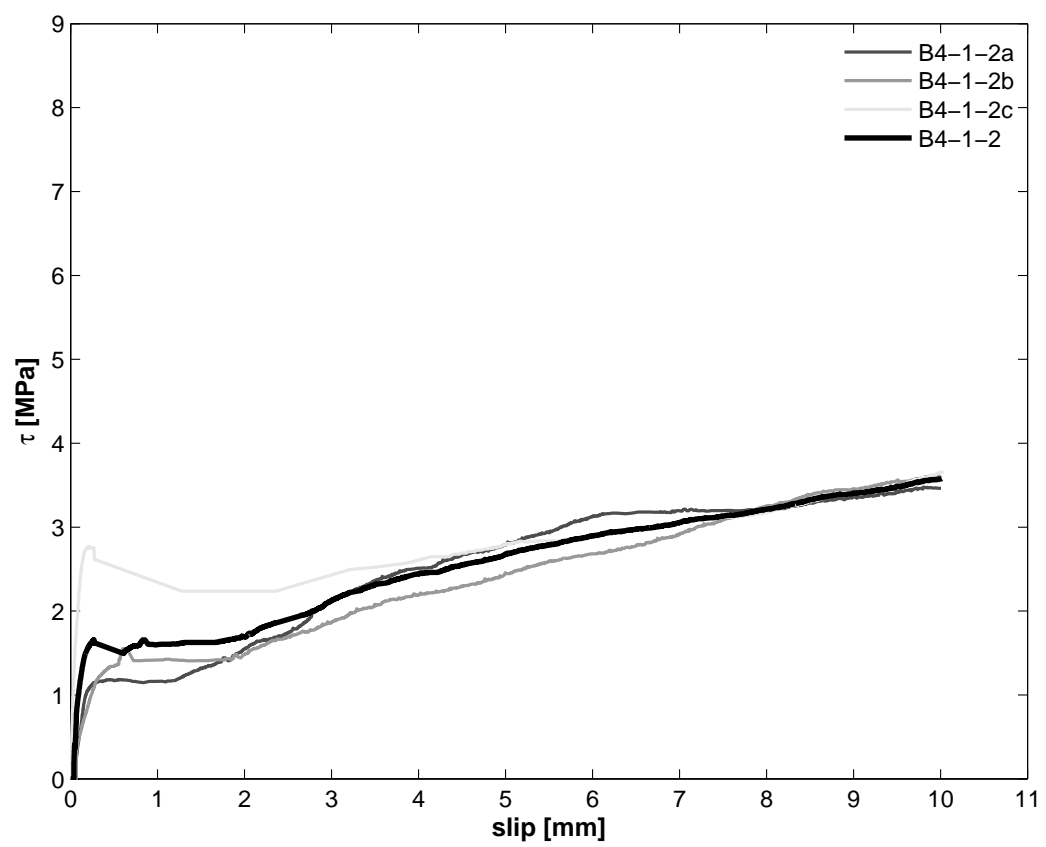

(a) Shear stress - slip relationship

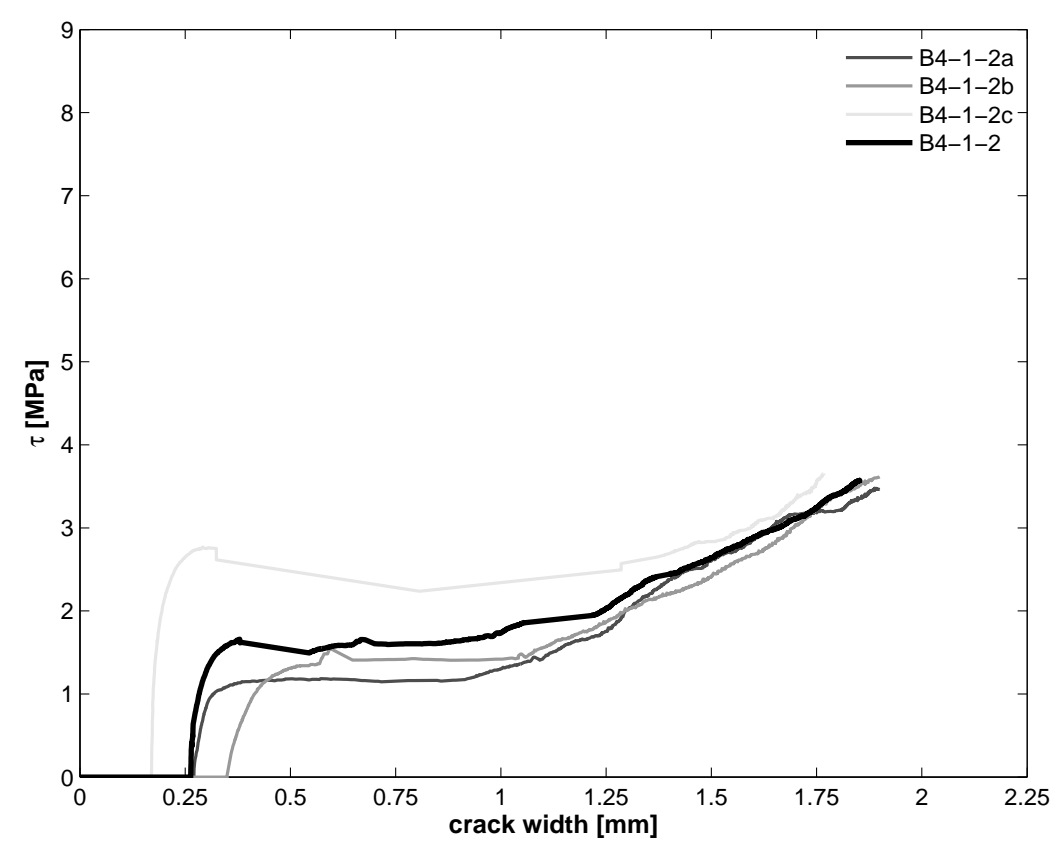

(b) Shear stress - crack width relationship

Fig. A.17. Shear behavior for confined specimens $\left(w_{o}=1\right)$, Material B4-1-2. 


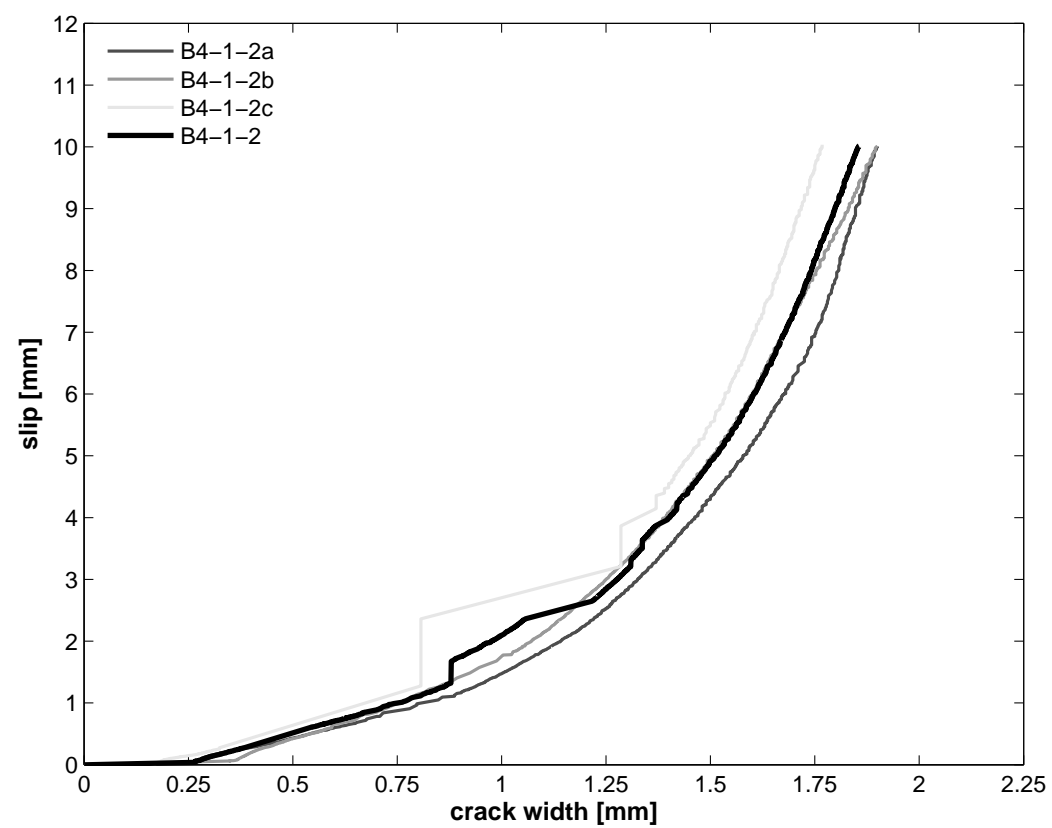

(a) Crack opening path relationship

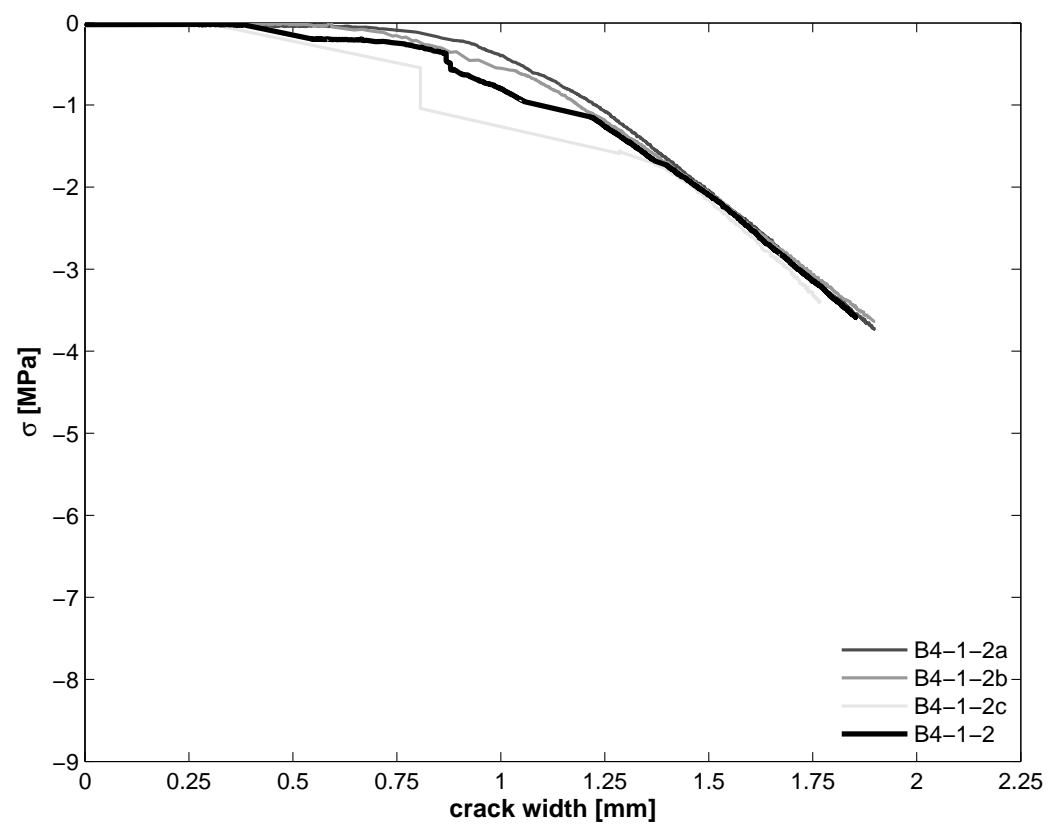

(b) Normal stress - crack width relationship

Fig. A.18. Shear behavior for confined specimens $\left(w_{o}=1\right)$, Material B4-1-2 (continued). 


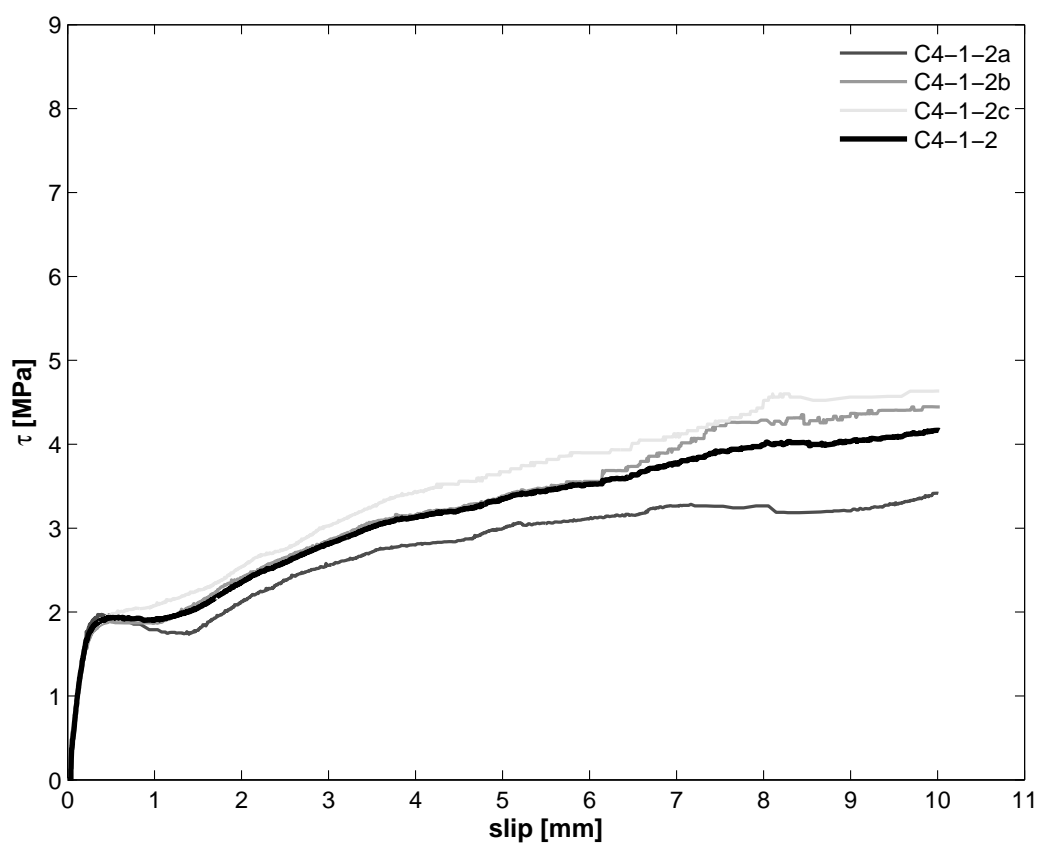

(a) Shear stress - slip relationship

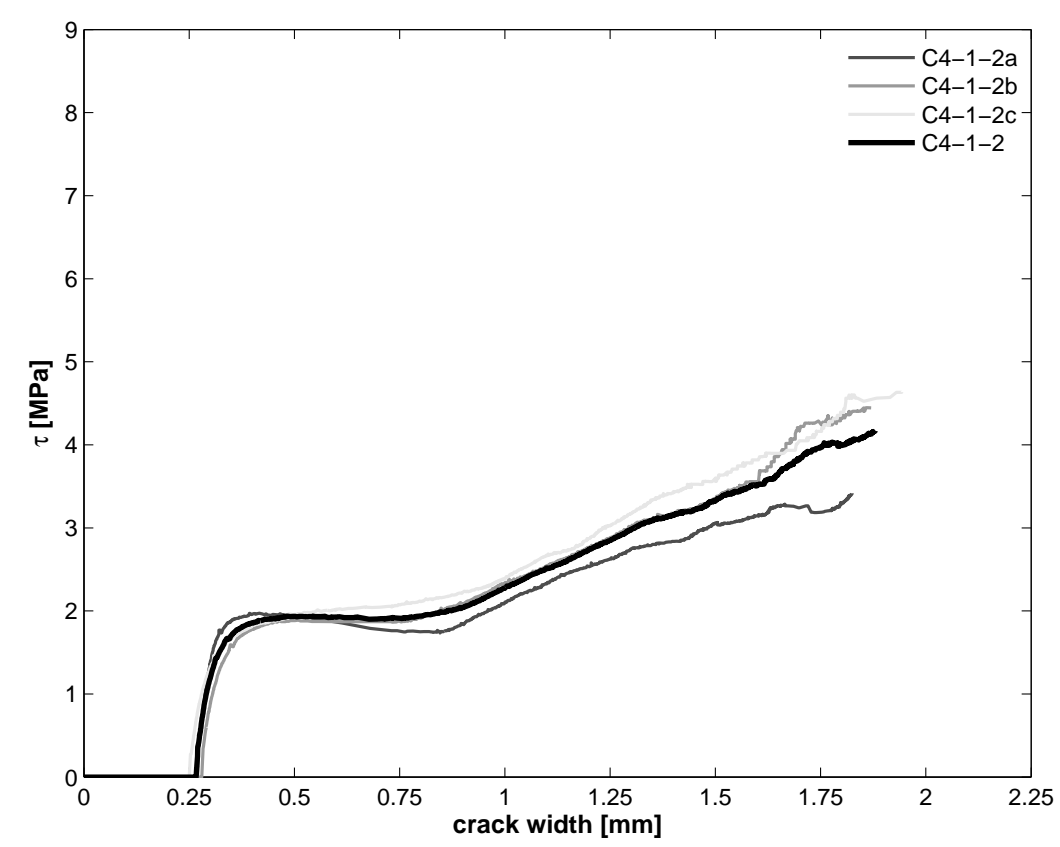

(b) Shear stress - crack width relationship

Fig. A.19. Shear behavior for confined specimens $\left(w_{o}=1\right)$, Material C4-1-2. 


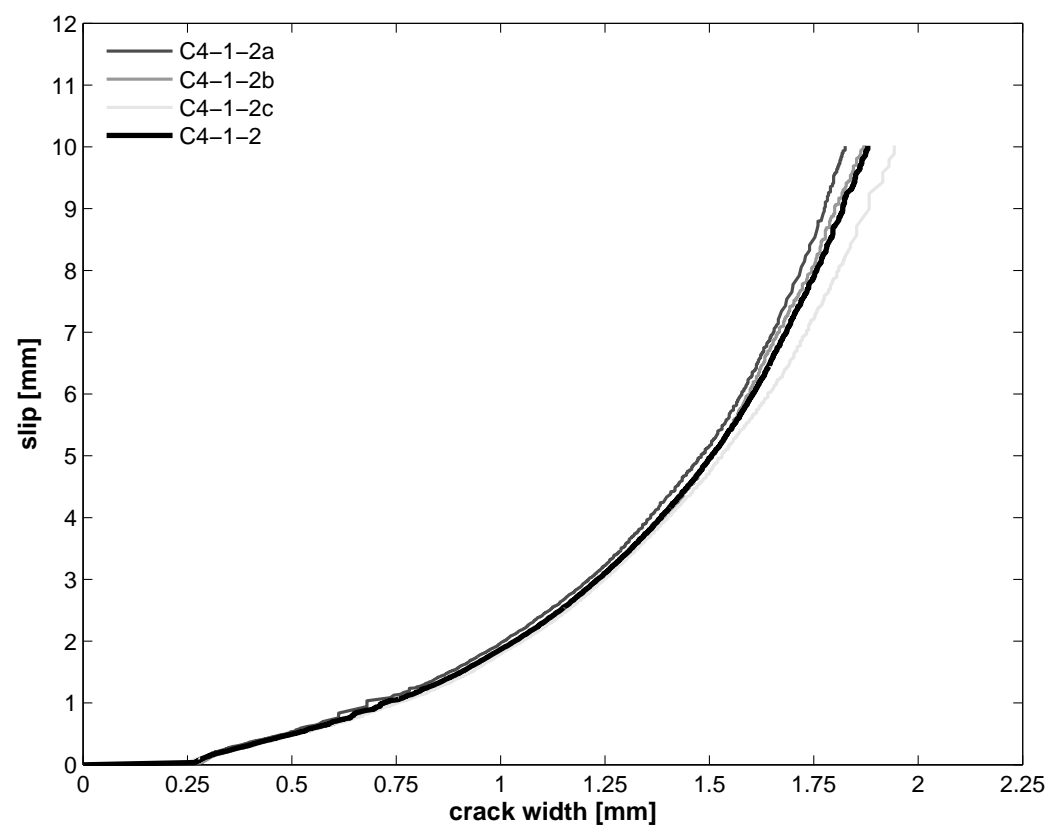

(a) Crack opening path relationship

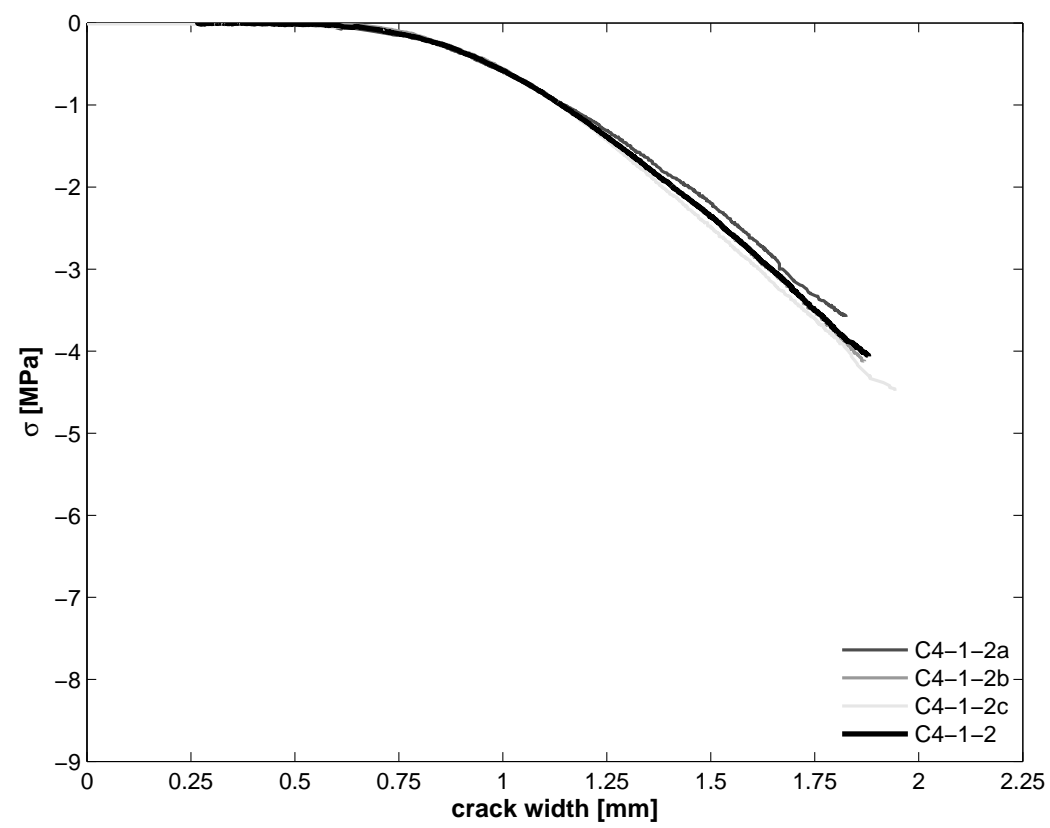

(b) Normal stress - crack width relationship

Fig. A.20. Shear behavior for confined specimens $\left(w_{o}=1\right)$, Material C4-1-2 (continued). 


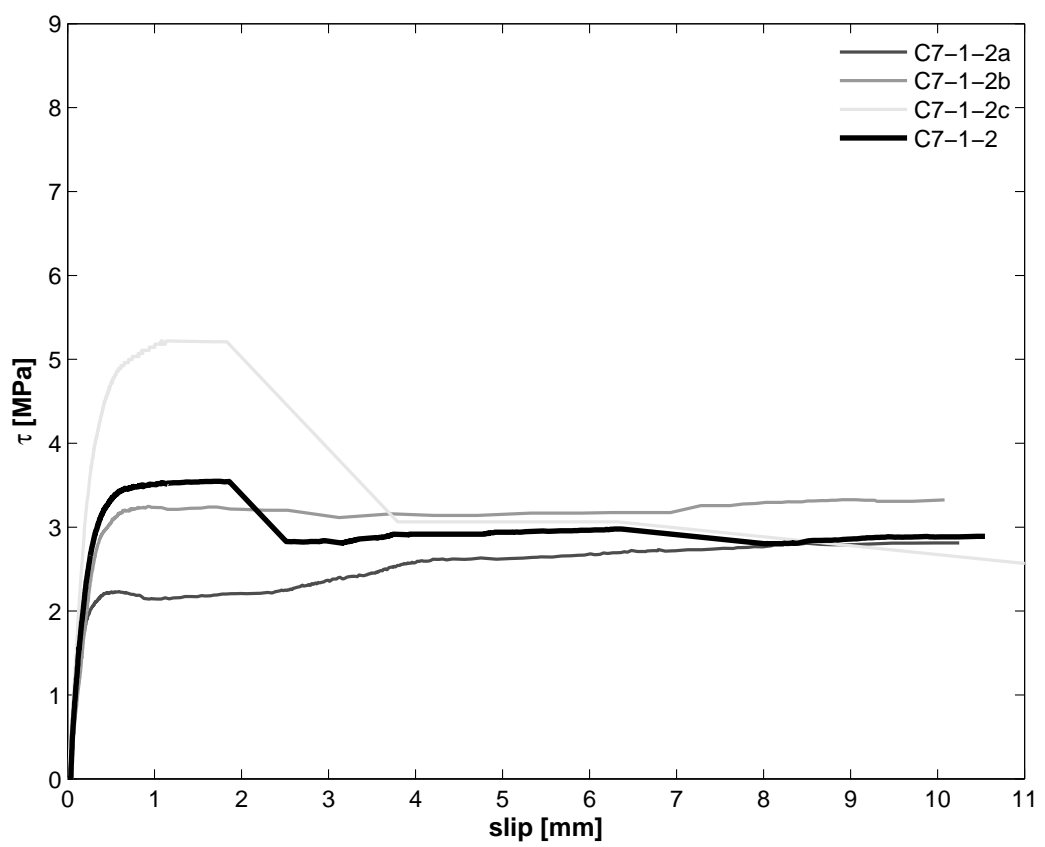

(a) Shear stress - slip relationship

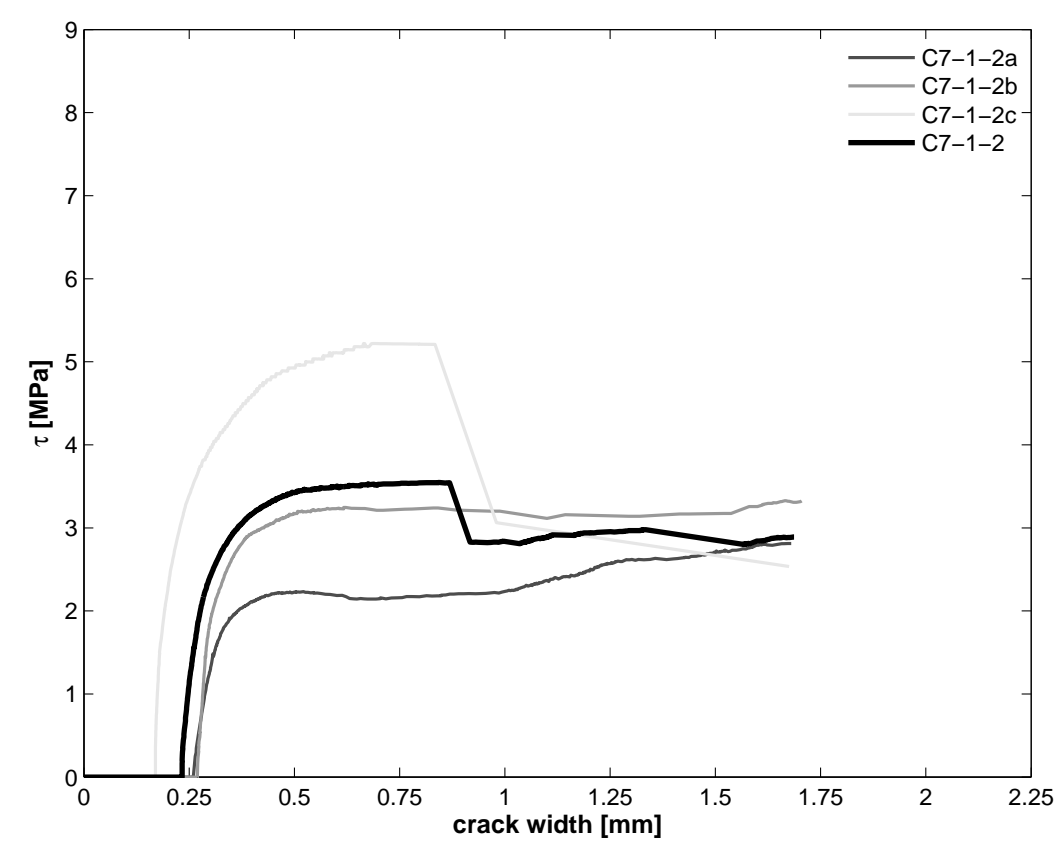

(b) Shear stress - crack width relationship

Fig. A.21. Shear behavior for confined specimens $\left(w_{o}=1\right)$, Material C7-1-2. 


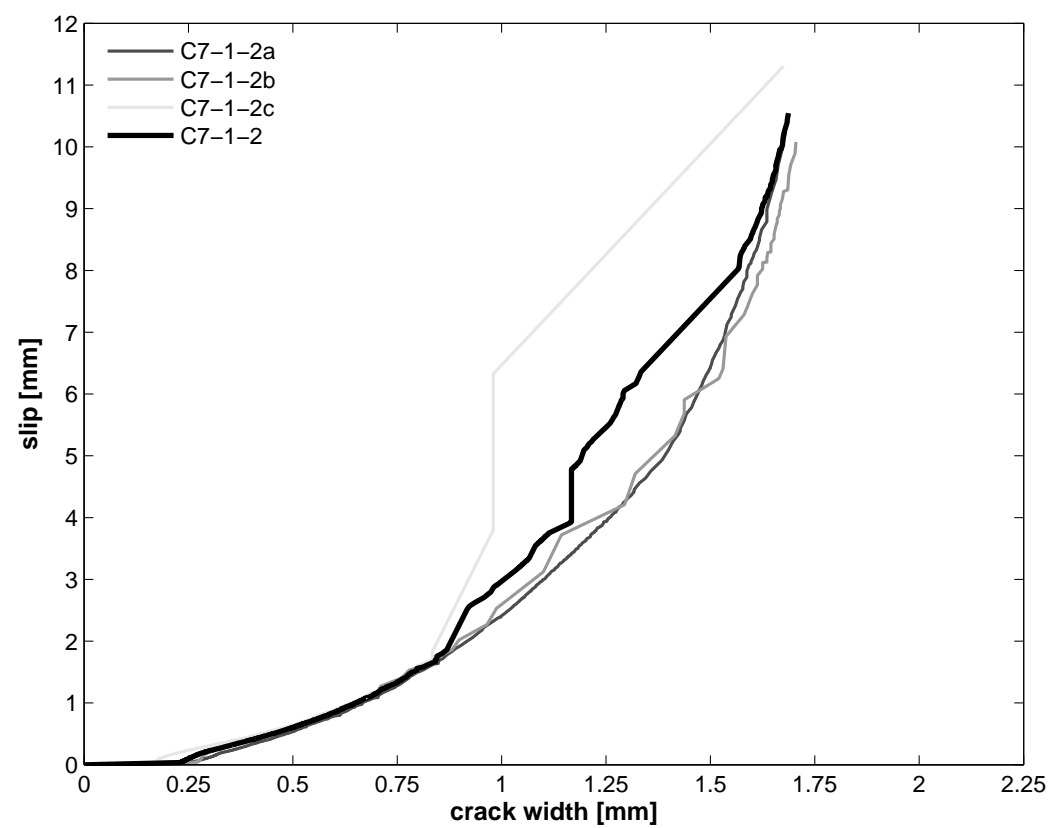

(a) Crack opening path relationship

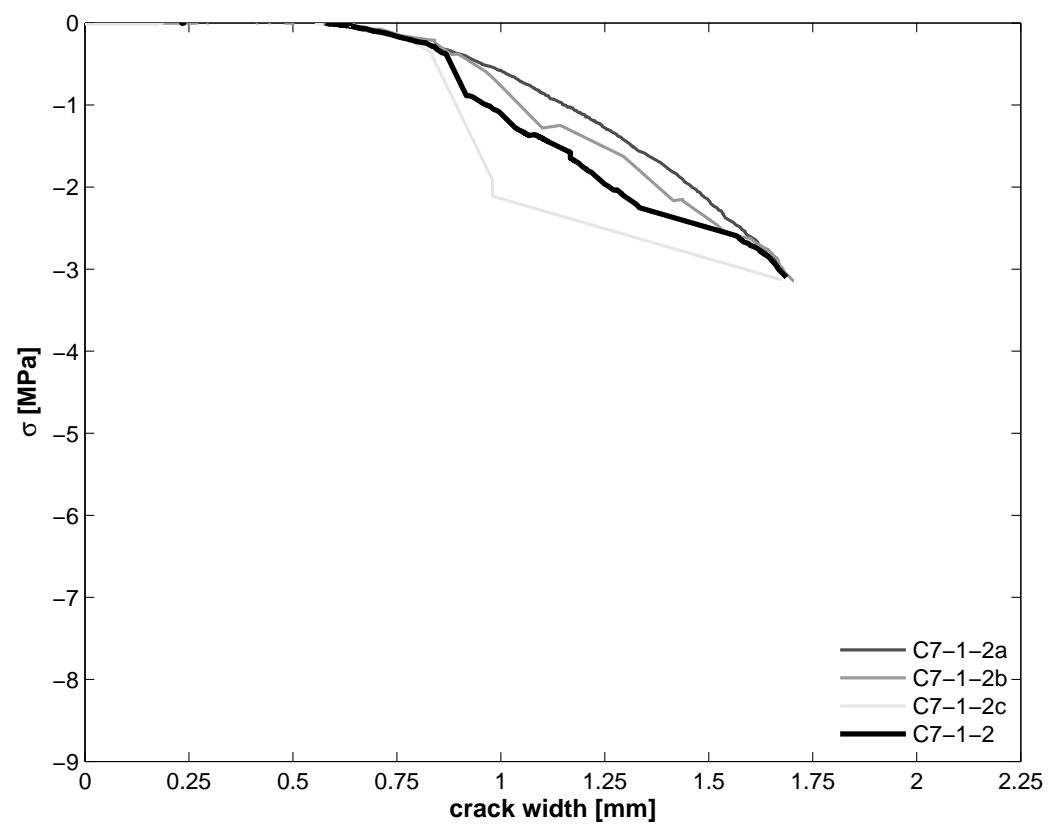

(b) Normal stress - crack width relationship

Fig. A.22. Shear behavior for confined specimens $\left(w_{o}=1\right)$, Material C7-1-2 (continued). 


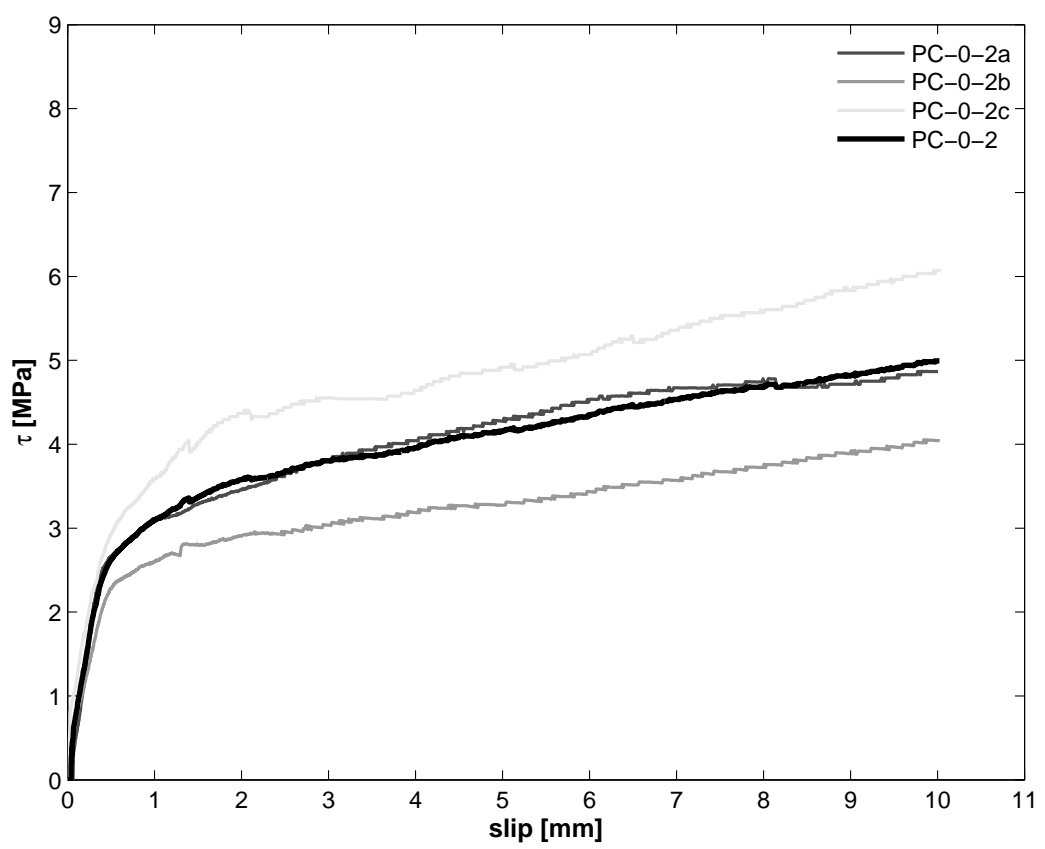

(a) Shear stress - slip relationship

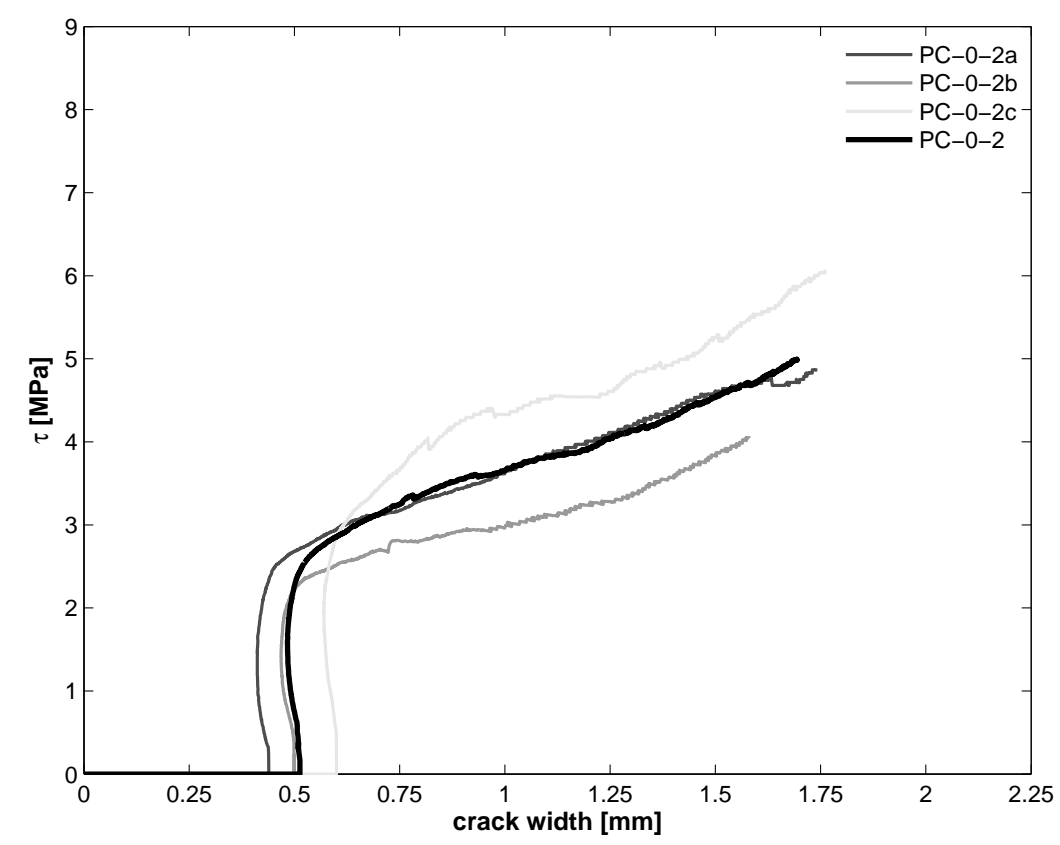

(b) Shear stress - crack width relationship

Fig. A.23. Shear behavior for confined specimens $\left(w_{o}=0\right)$, Material PC-0-2. 


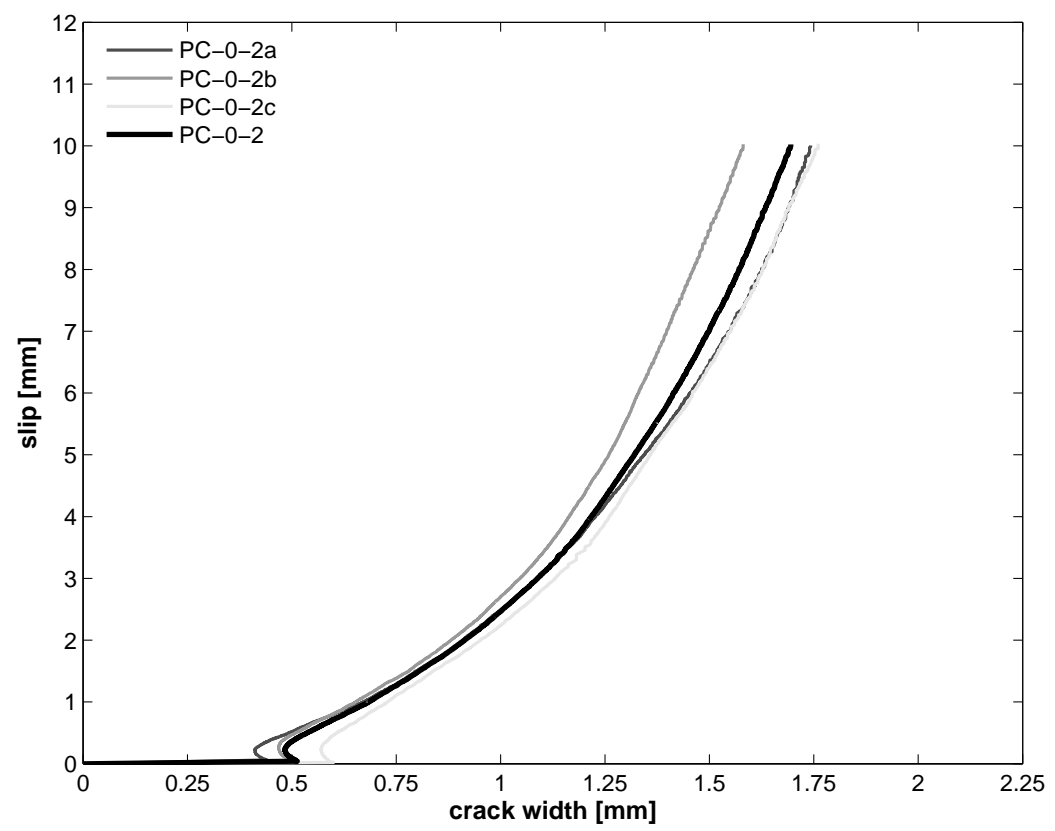

(a) Crack opening path relationship

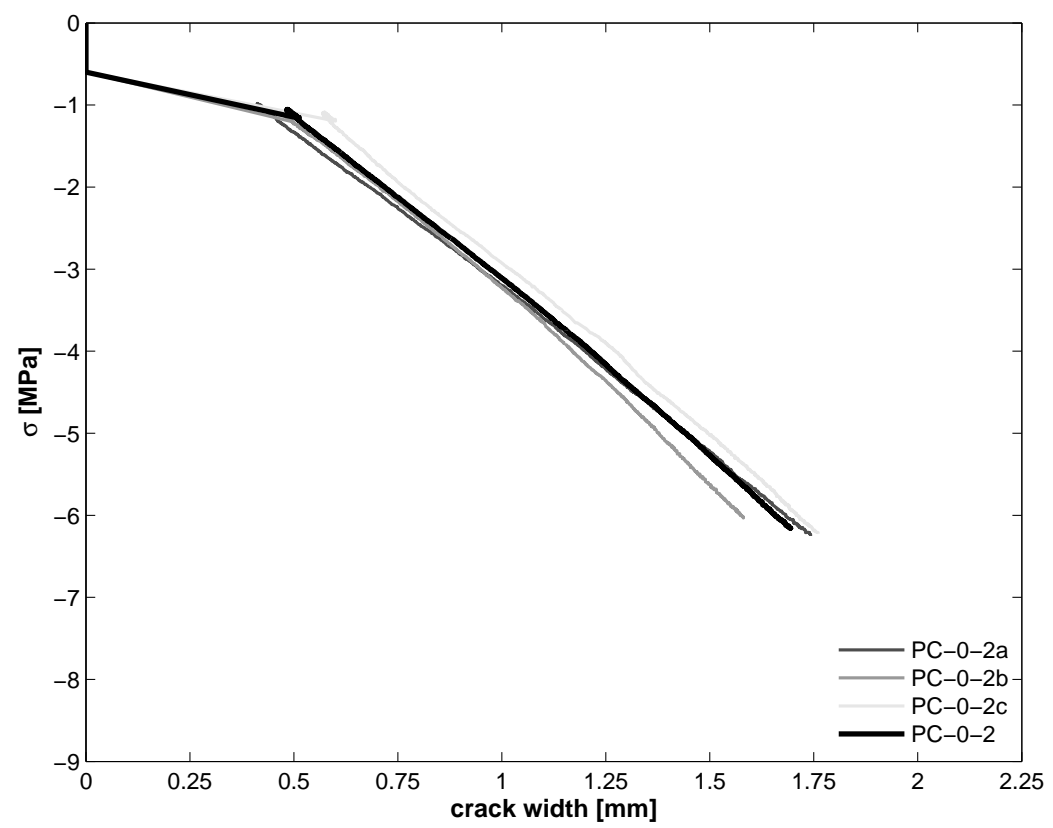

(b) Normal stress - crack width relationship

Fig. A.24. Shear behavior for confined specimens $\left(w_{o}=0\right)$, Material PC-0-2 (continued). 


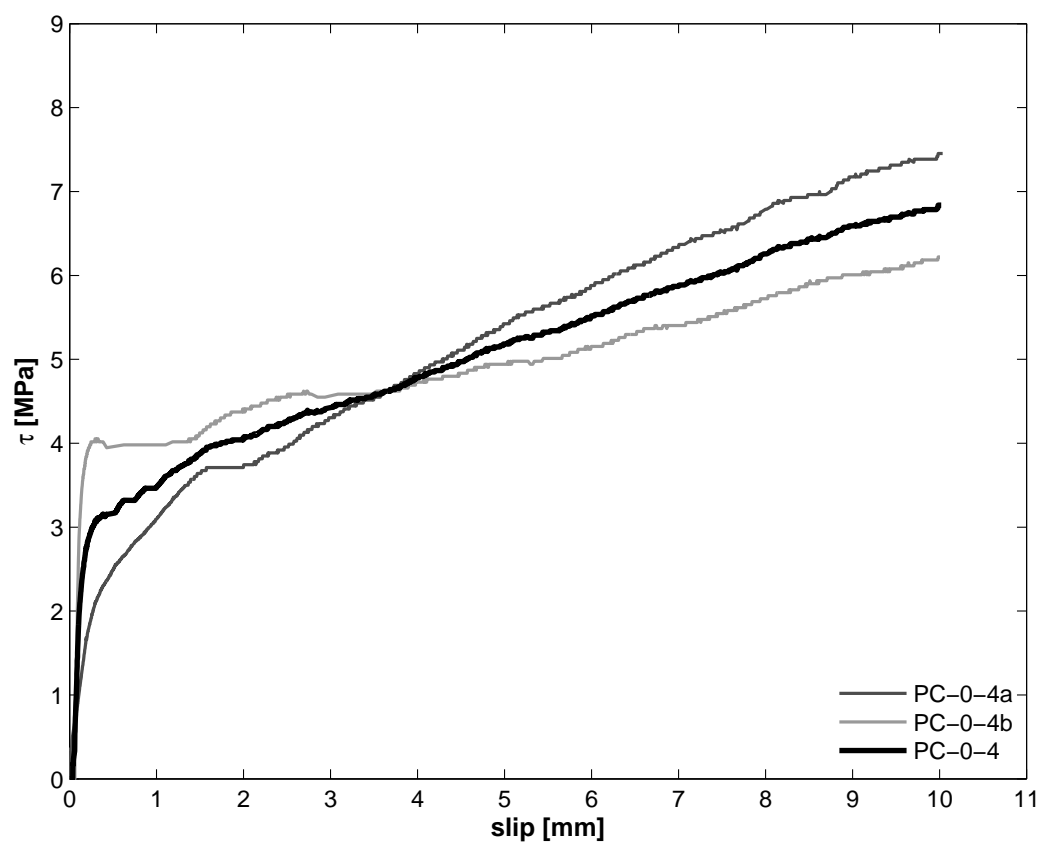

(a) Shear stress - slip relationship

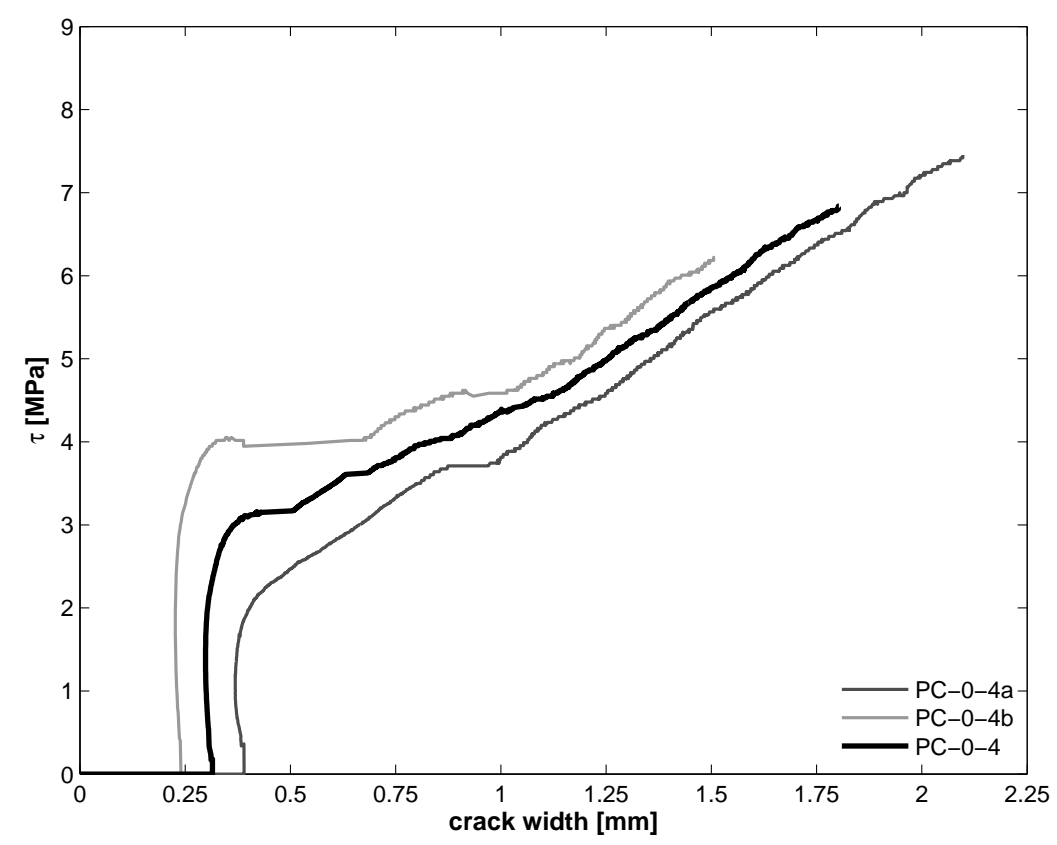

(b) Shear stress - crack width relationship

Fig. A.25. Shear behavior for confined specimens $\left(w_{o}=0\right)$, Material PC-0-4. 


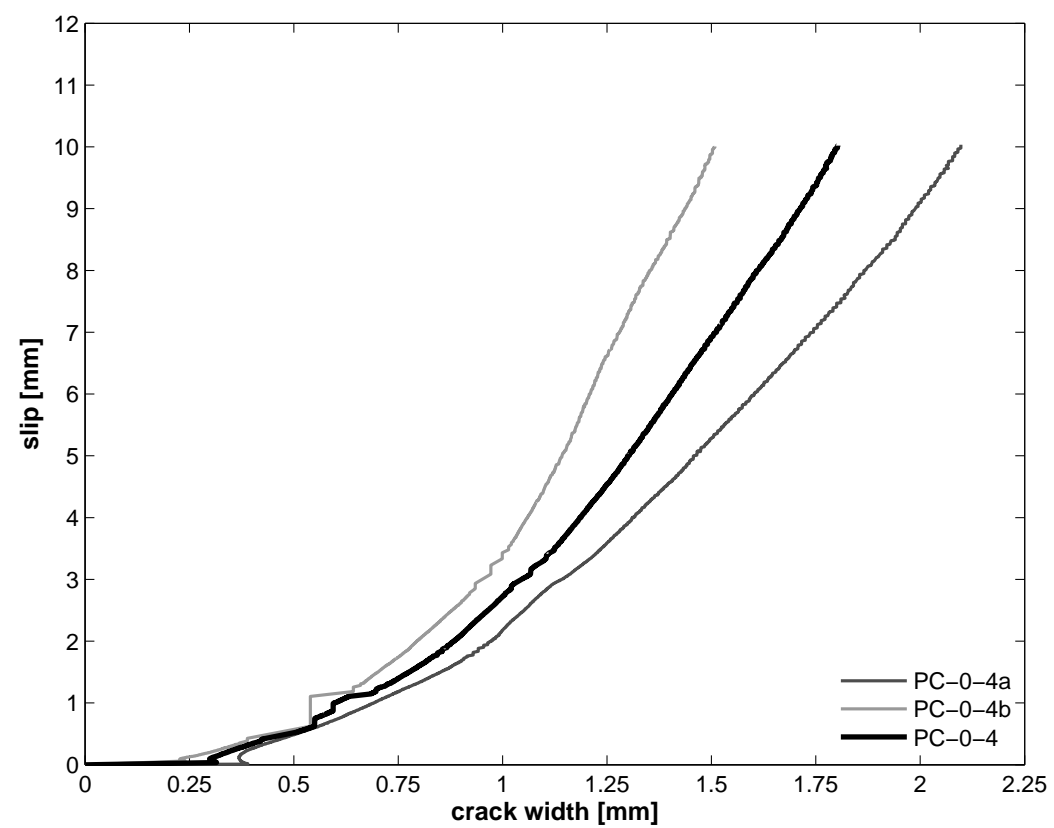

(a) Crack opening path relationship

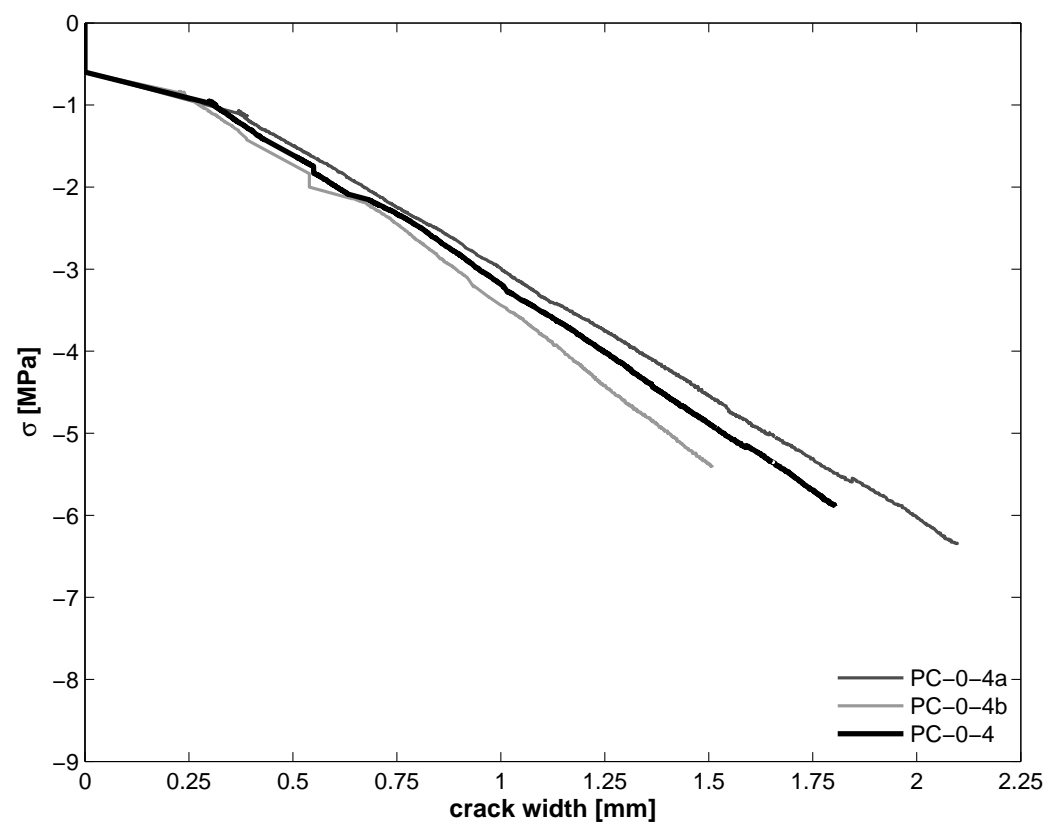

(b) Normal stress - crack width relationship

Fig. A.26. Shear behavior for confined specimens $\left(w_{o}=0\right)$, Material PC-0-4 (continued). 


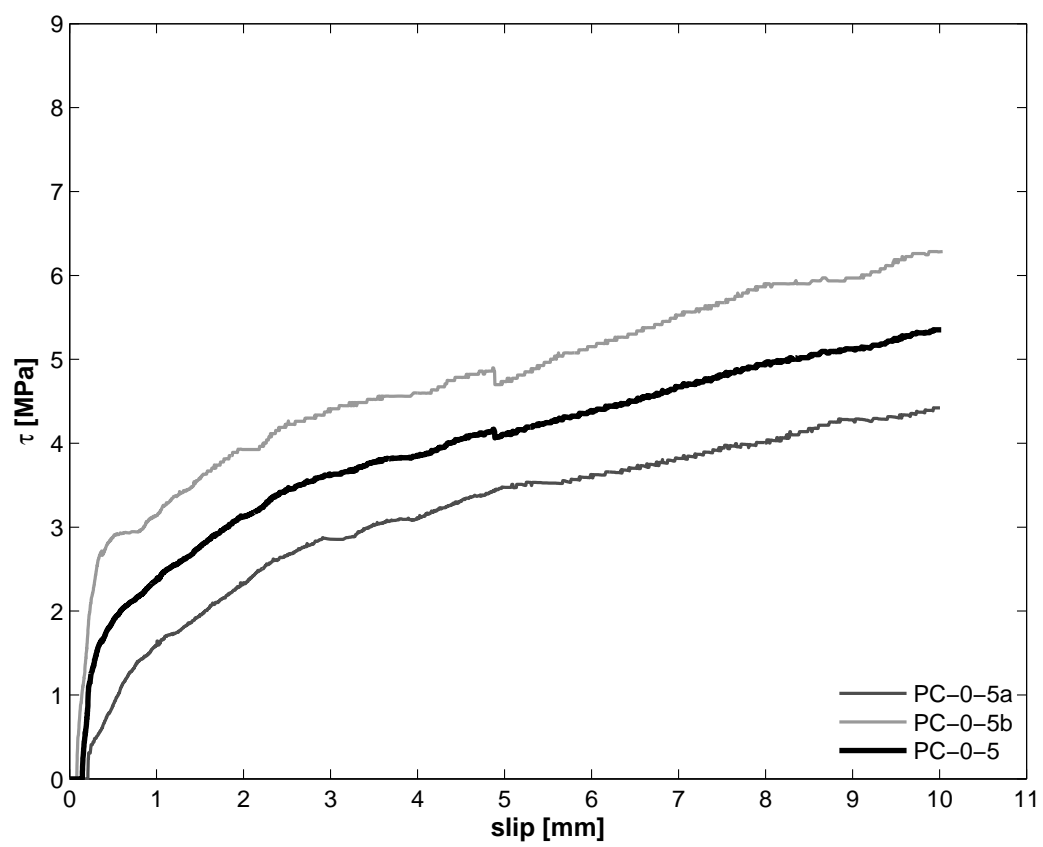

(a) Shear stress - slip relationship

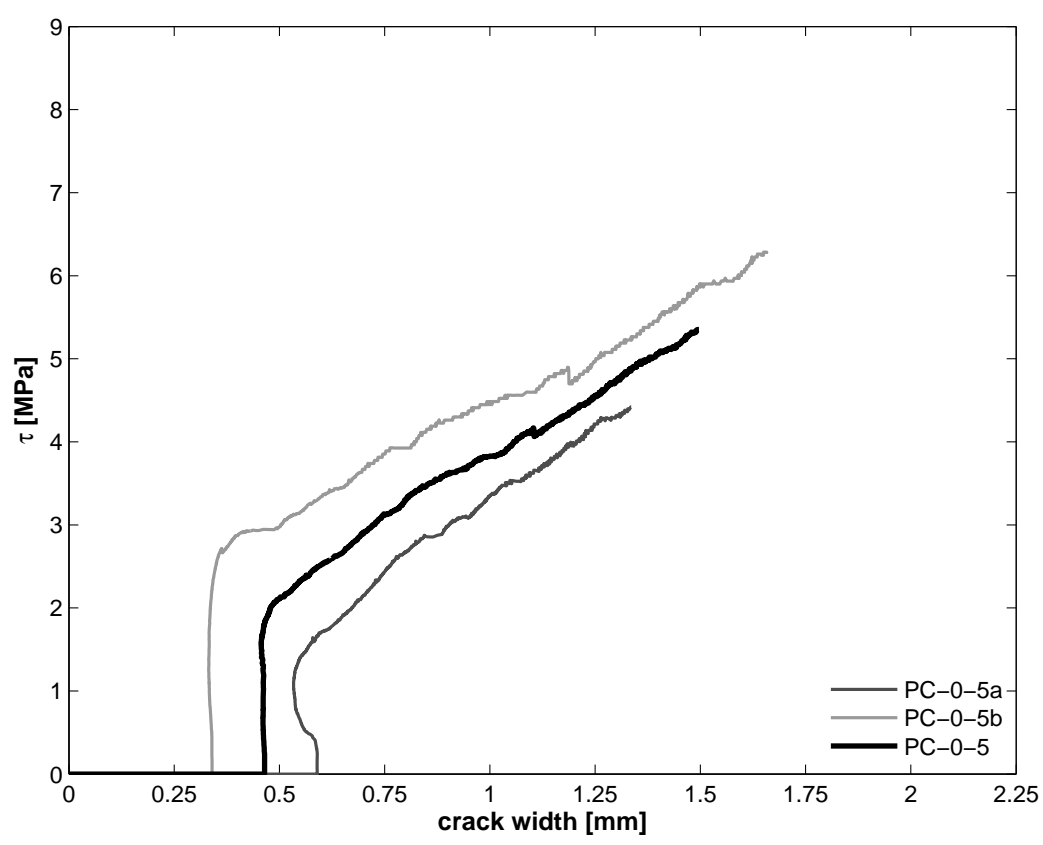

(b) Shear stress - crack width relationship

Fig. A.27. Shear behavior for confined specimens $\left(w_{o}=0\right)$, Material PC-0-5. 


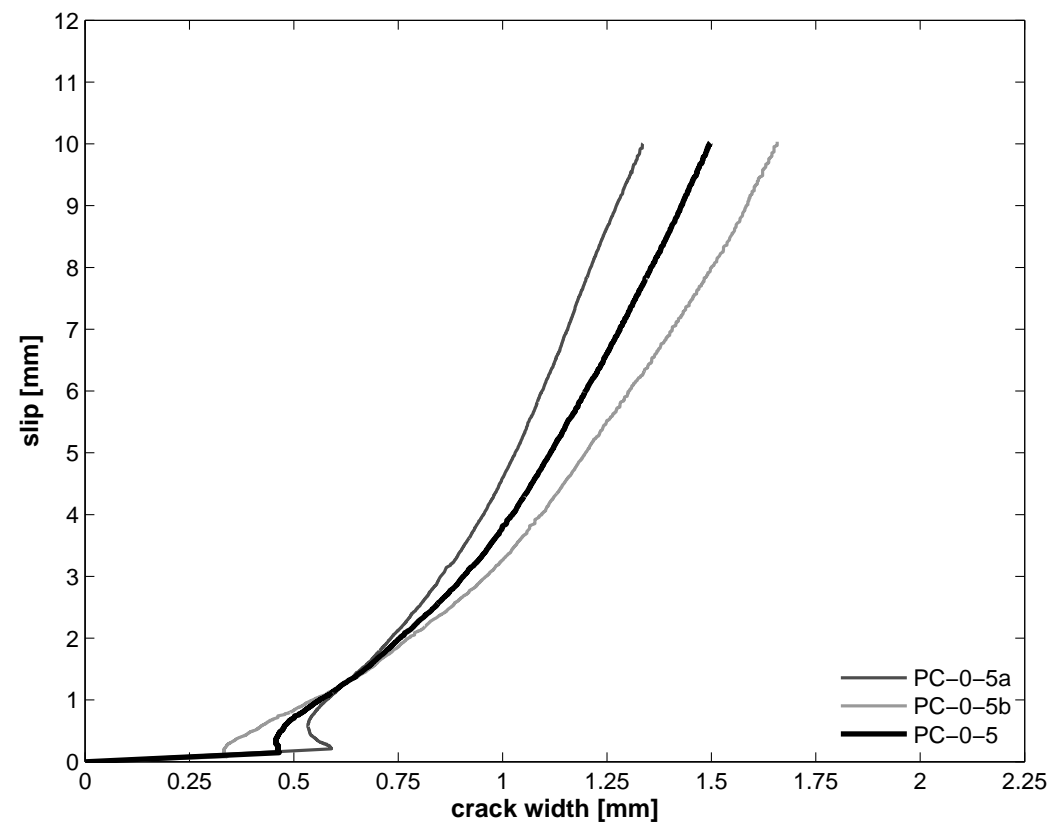

(a) Crack opening path relationship

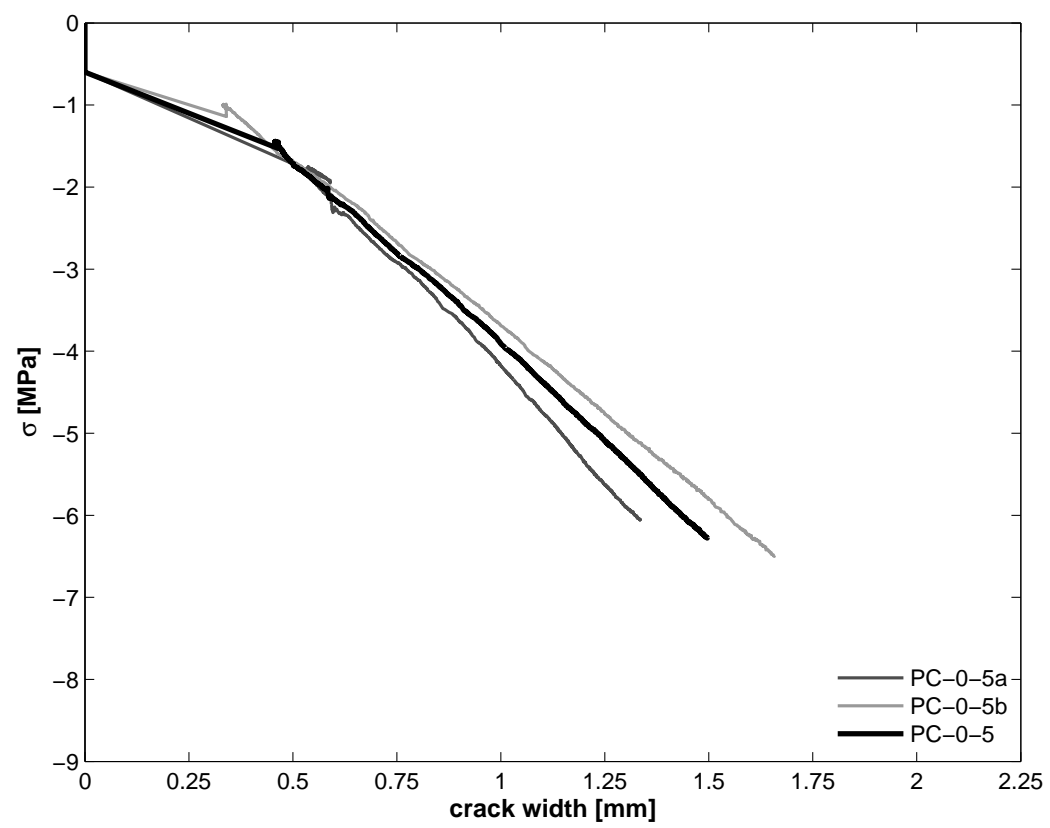

(b) Normal stress - crack width relationship

Fig. A.28. Shear behavior for confined specimens $\left(w_{o}=0\right)$, Material PC-0-5 (continued). 


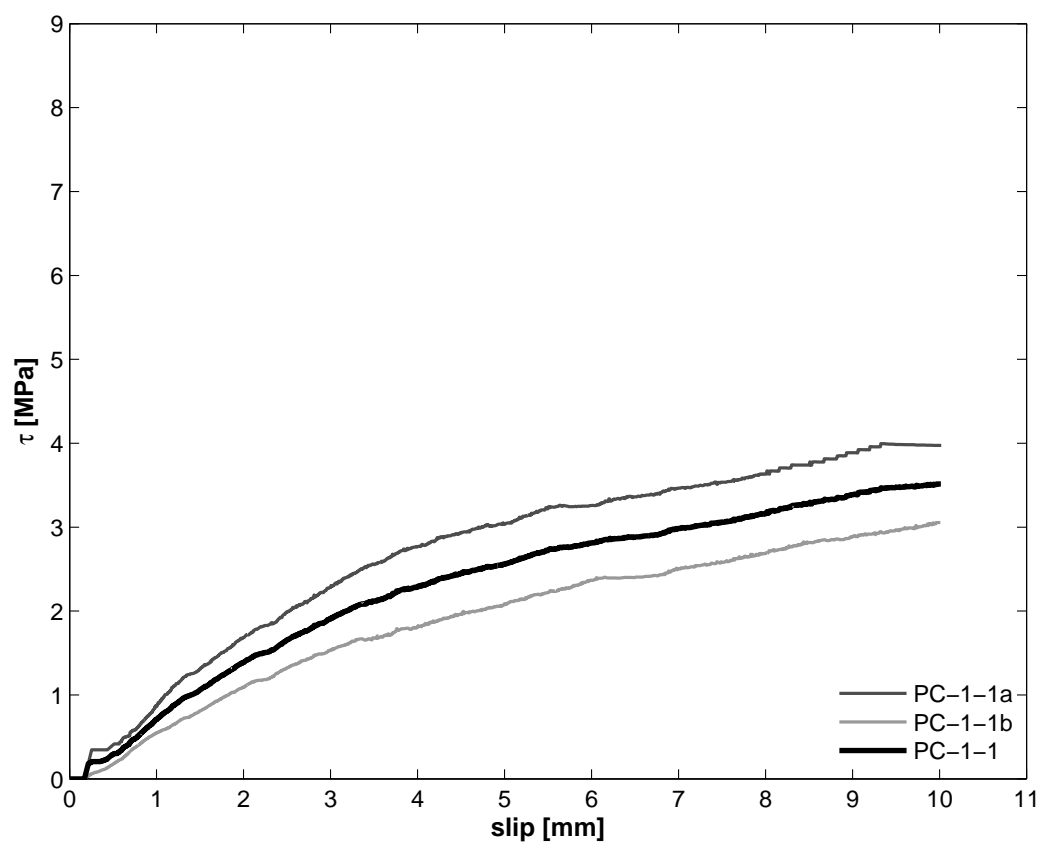

(a) Shear stress - slip relationship

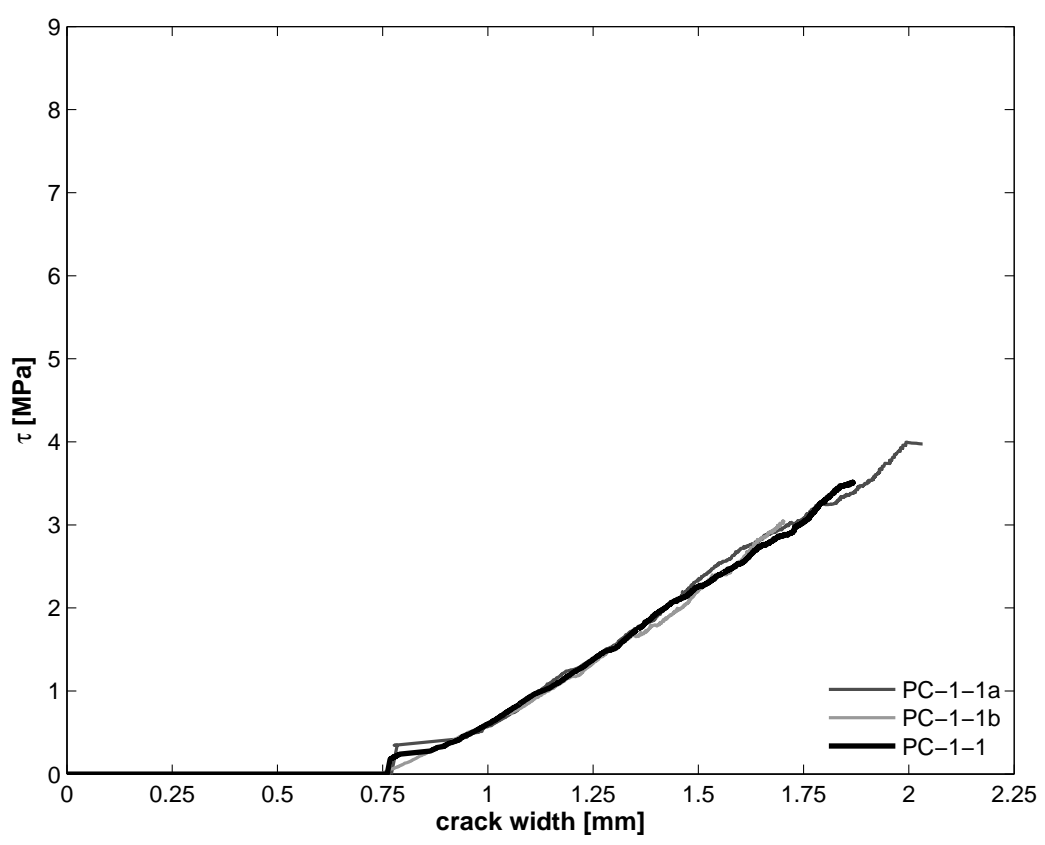

(b) Shear stress - crack width relationship

Fig. A.29. Shear behavior for confined specimens $\left(w_{o}=1\right)$, Material PC-1-1. 


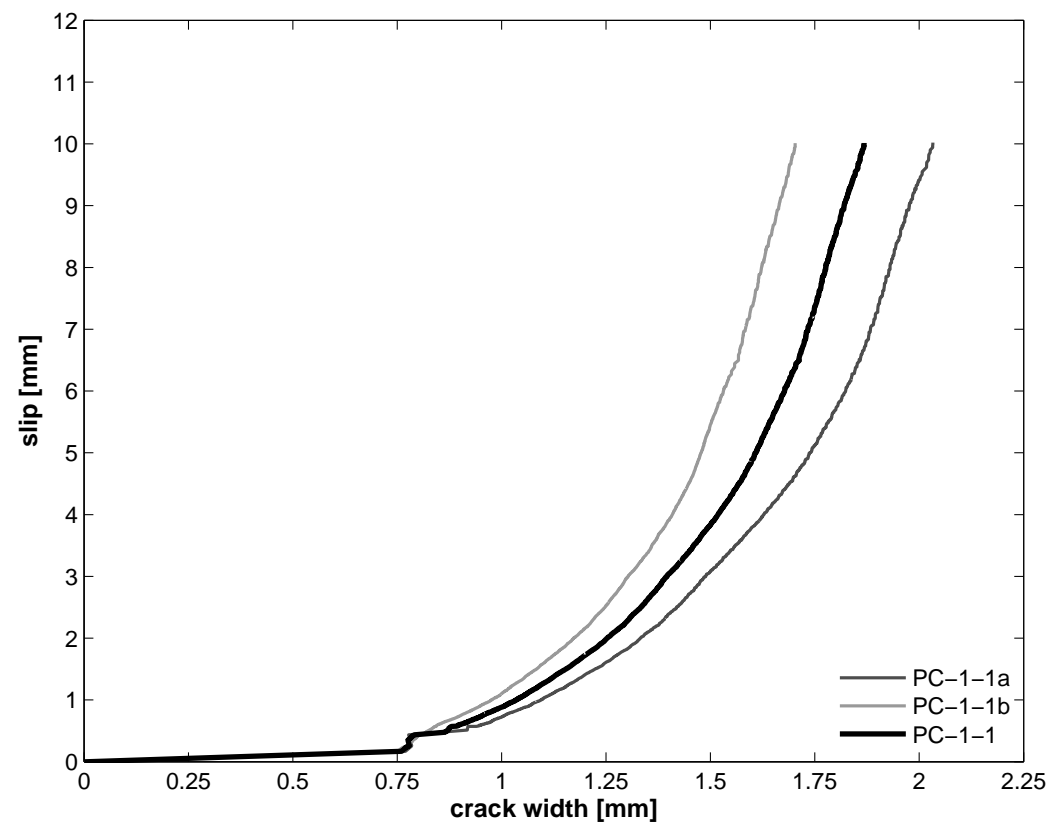

(a) Crack opening path relationship

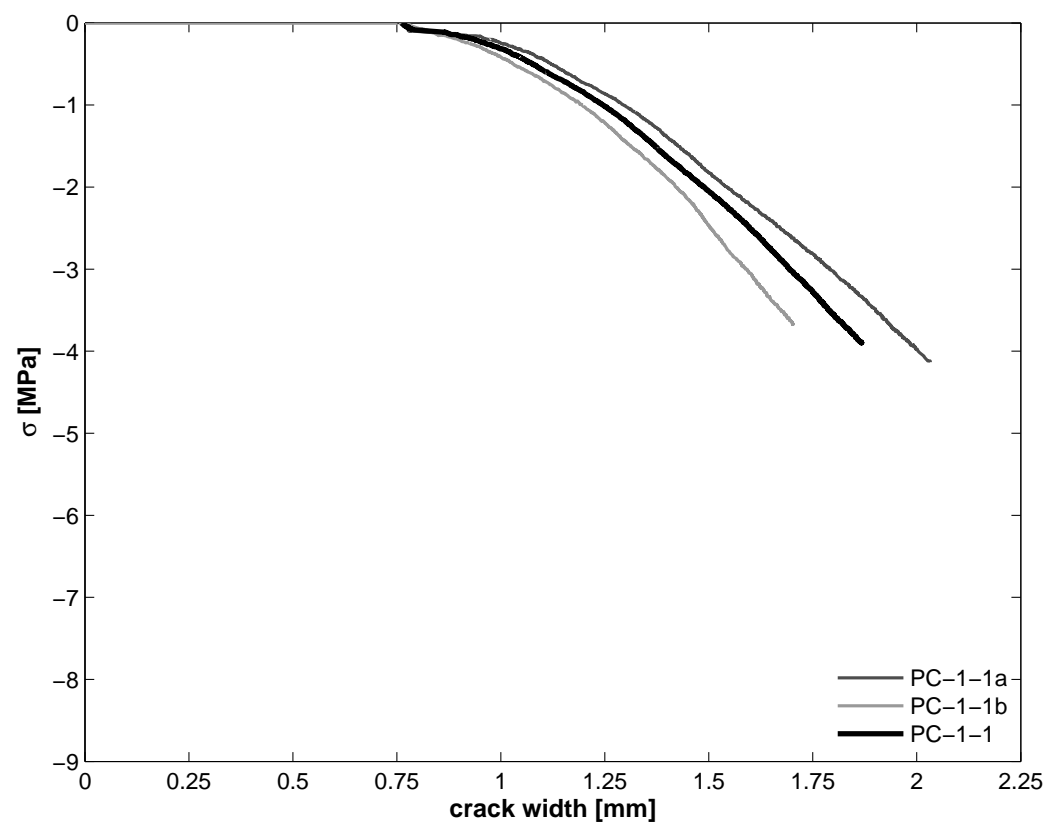

(b) Normal stress - crack width relationship

Fig. A.30. Shear behavior for confined specimens $\left(w_{o}=1\right)$, Material PC-1-1 (continued). 


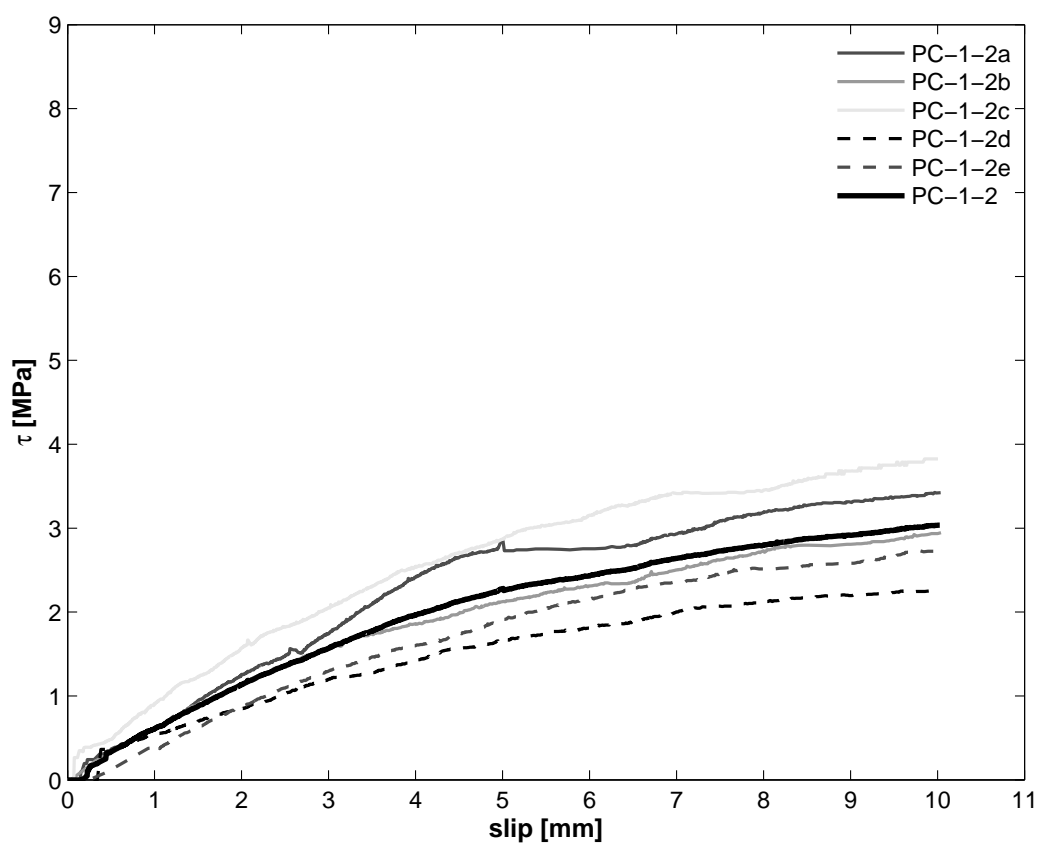

(a) Shear stress - slip relationship

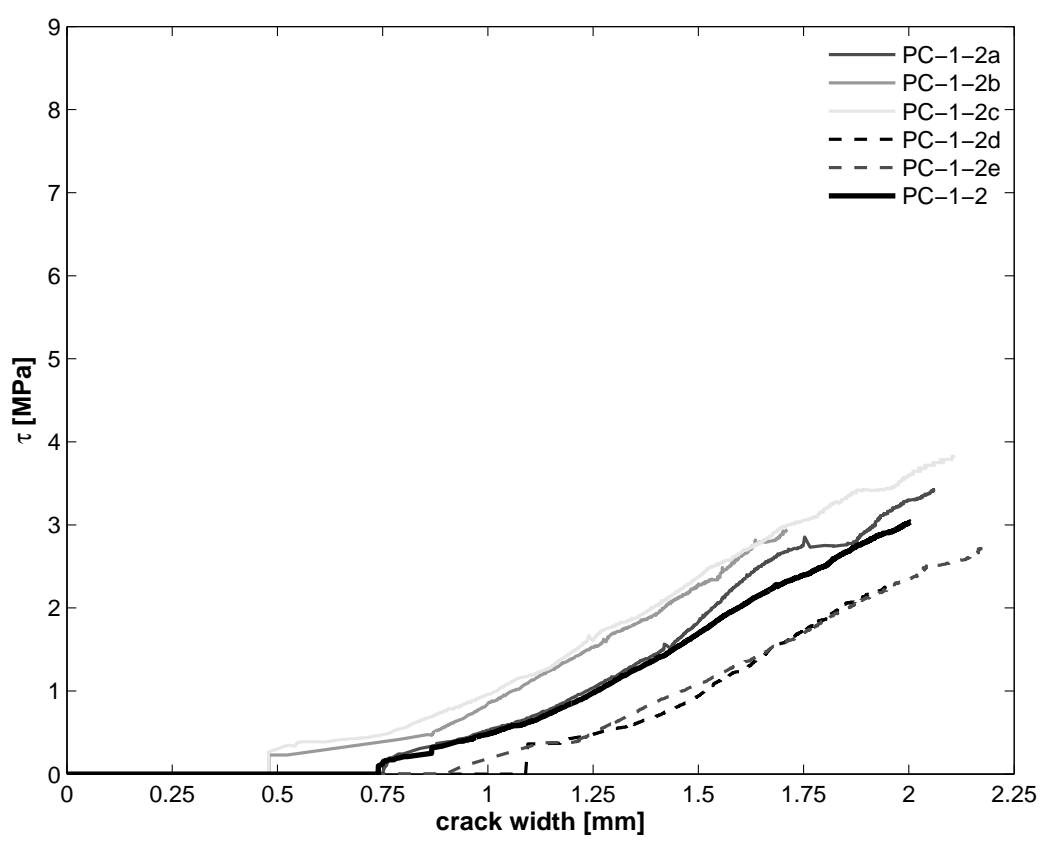

(b) Shear stress - crack width relationship

Fig. A.31. Shear behavior for confined specimens $\left(w_{o}=1\right)$, Material PC-1-2. 


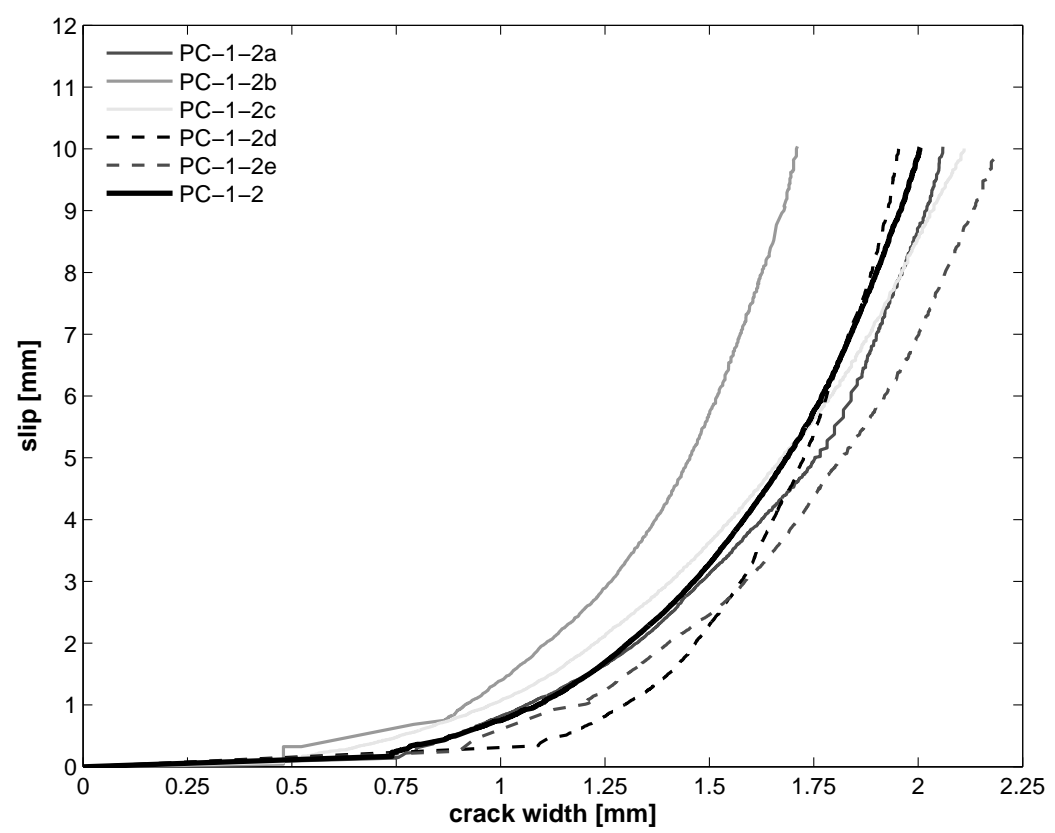

(a) Crack opening path relationship

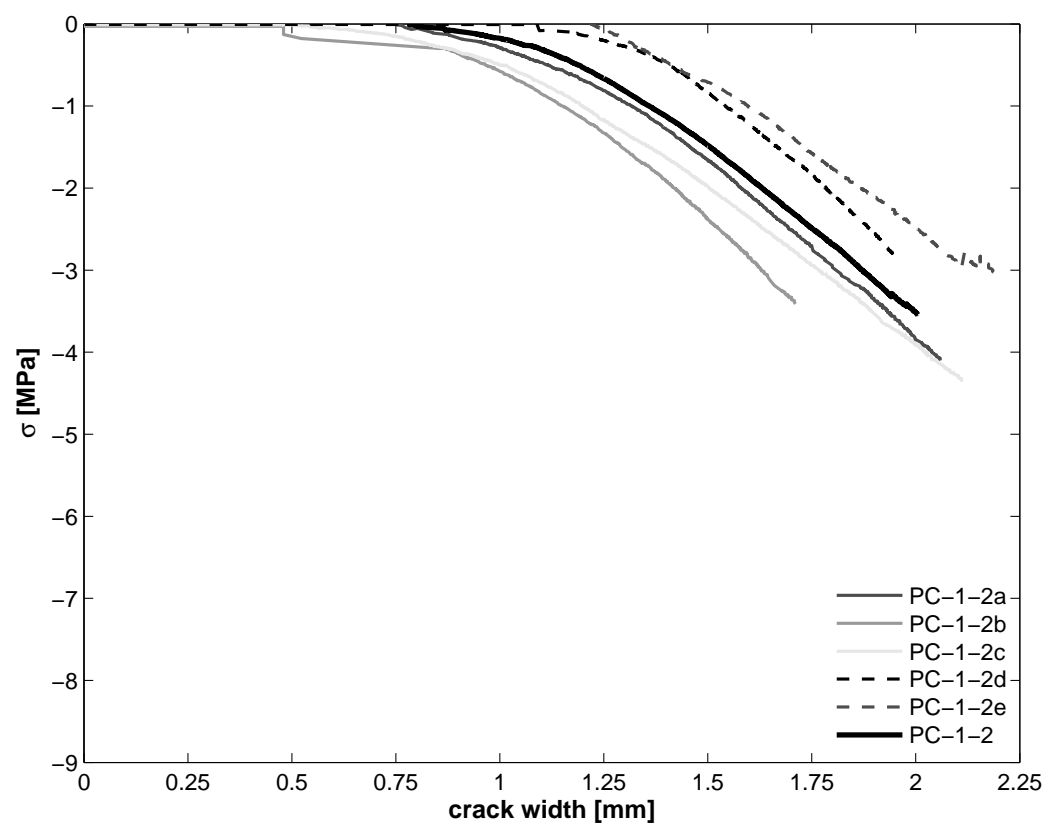

(b) Normal stress - crack width relationship

Fig. A.32. Shear behavior for confined specimens $\left(w_{o}=1\right)$, Material PC-1-2 (continued). 


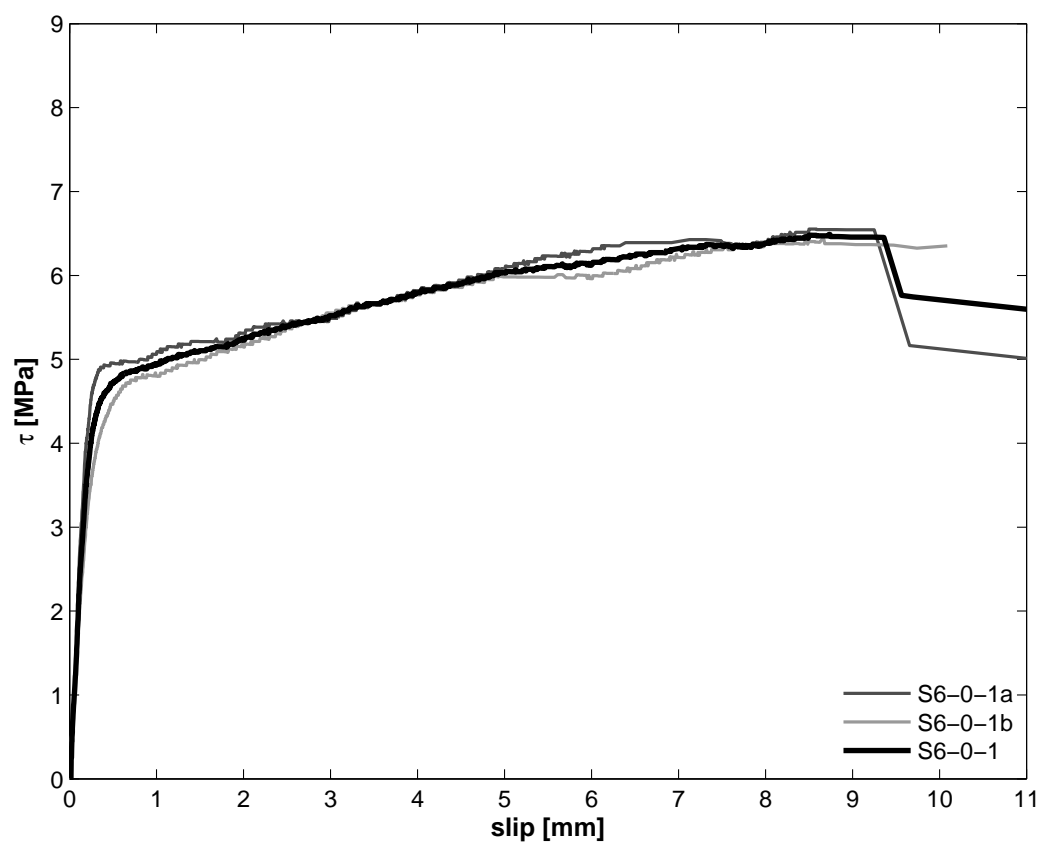

(a) Shear stress - slip relationship

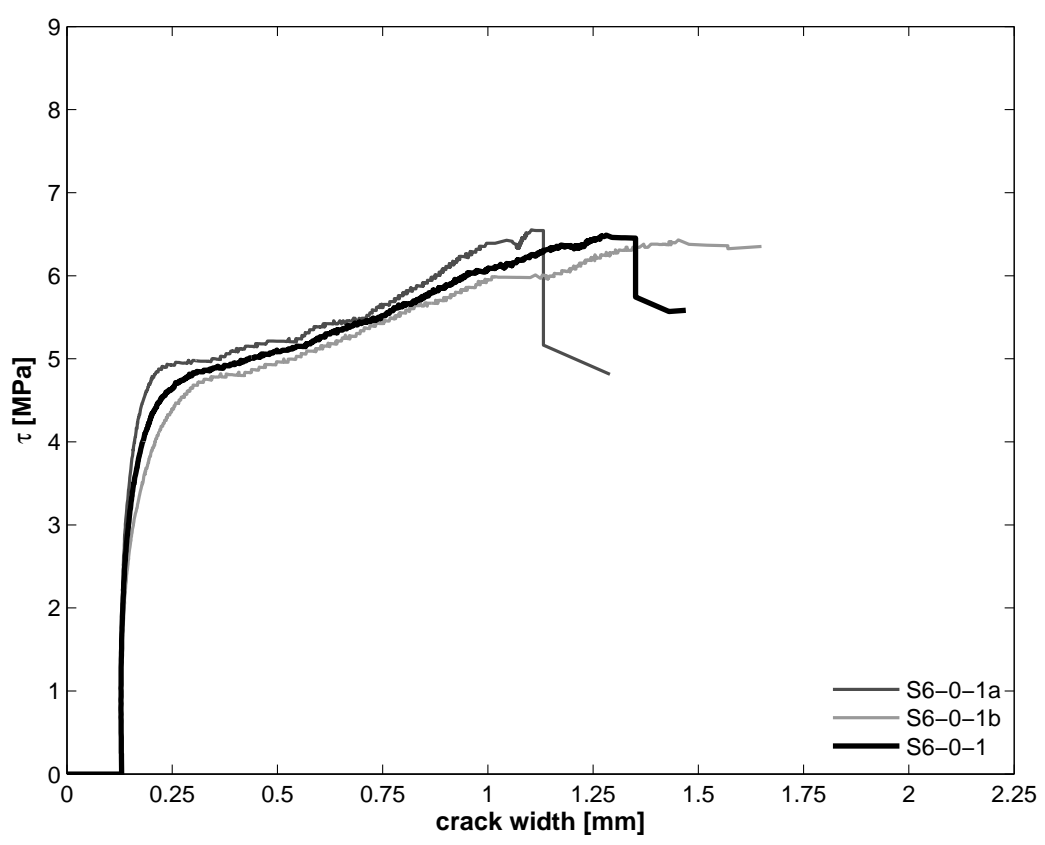

(b) Shear stress - crack width relationship

Fig. A.33. Shear behavior for confined specimens $\left(w_{o}=0\right)$, Material S6-0-1. 


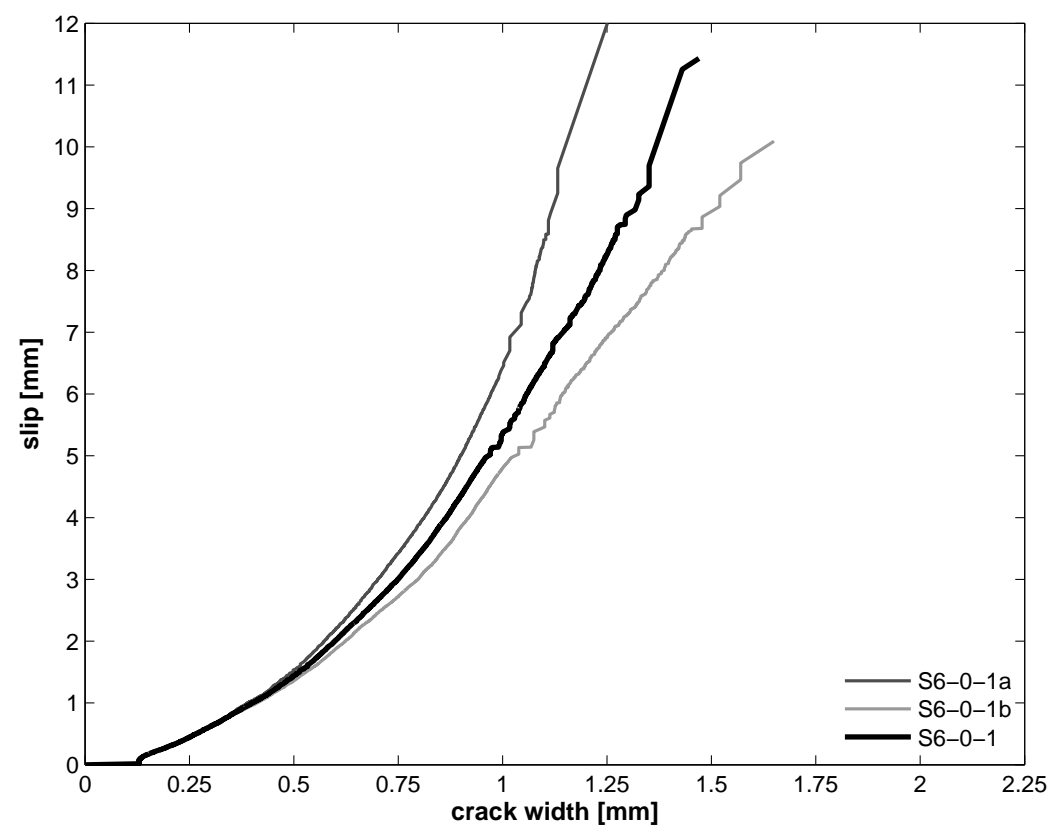

(a) Crack opening path relationship

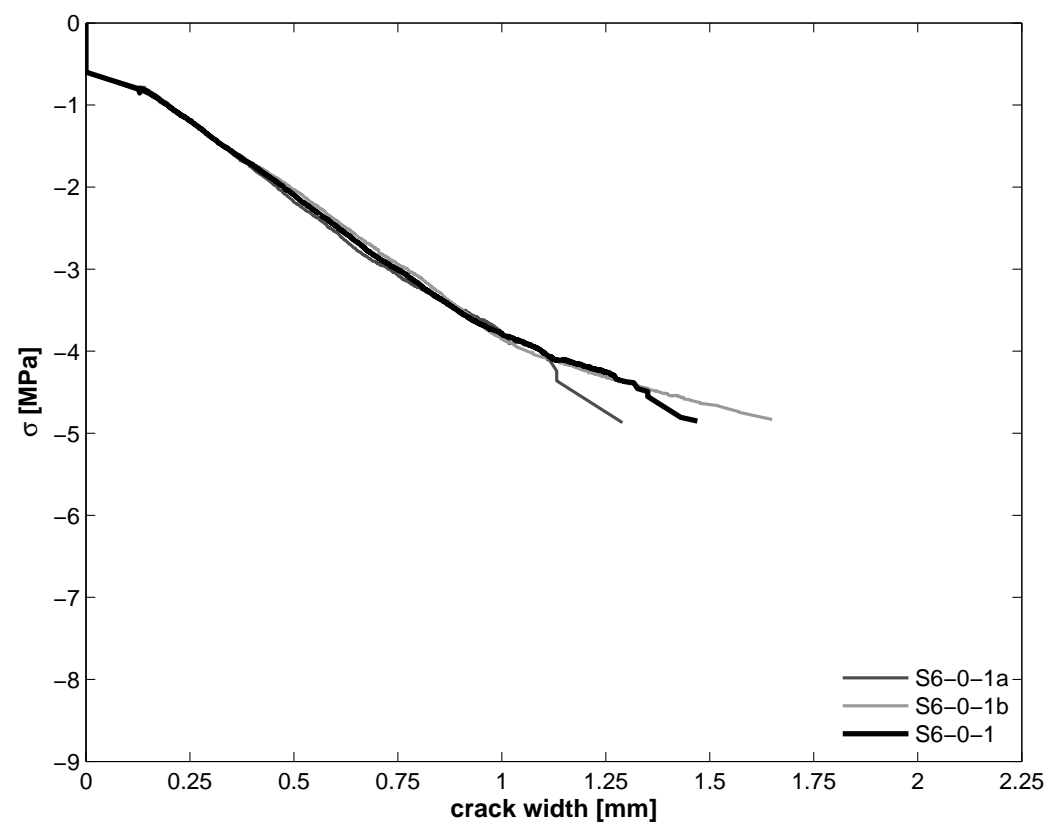

(b) Normal stress - crack width relationship

Fig. A.34. Shear behavior for confined specimens $\left(w_{o}=0\right)$, Material S6-0-1 (continued). 


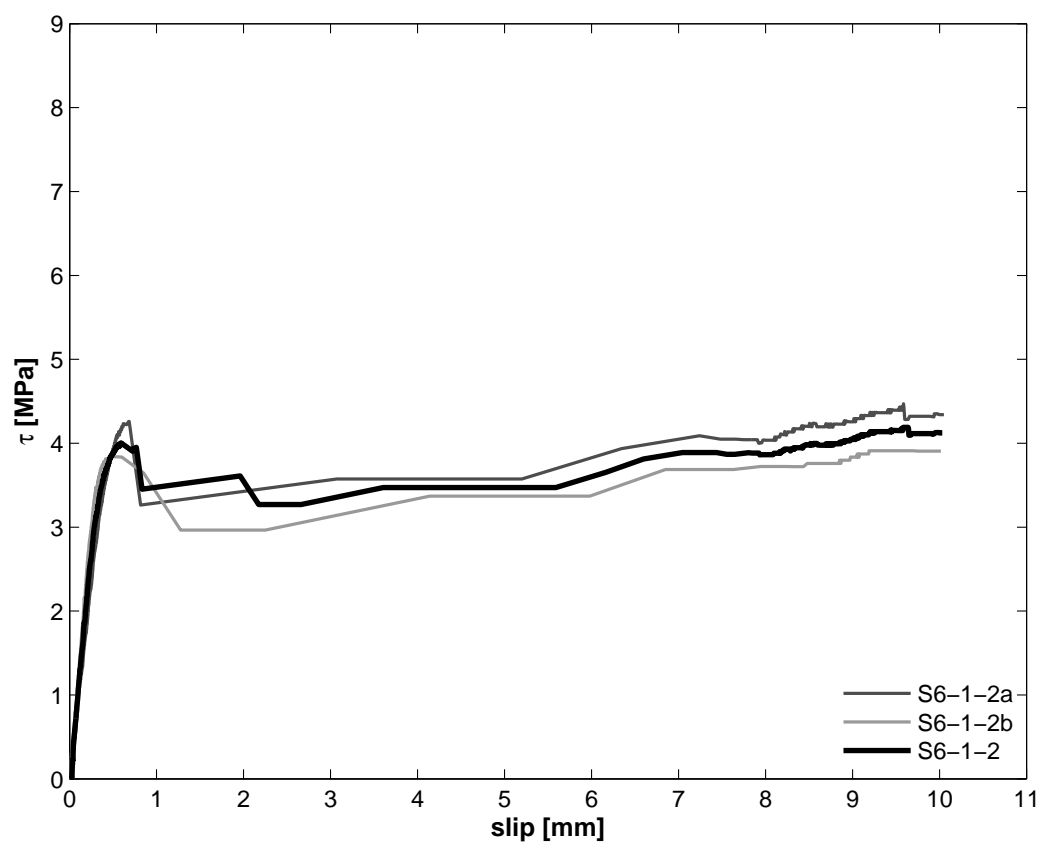

(a) Shear stress - slip relationship

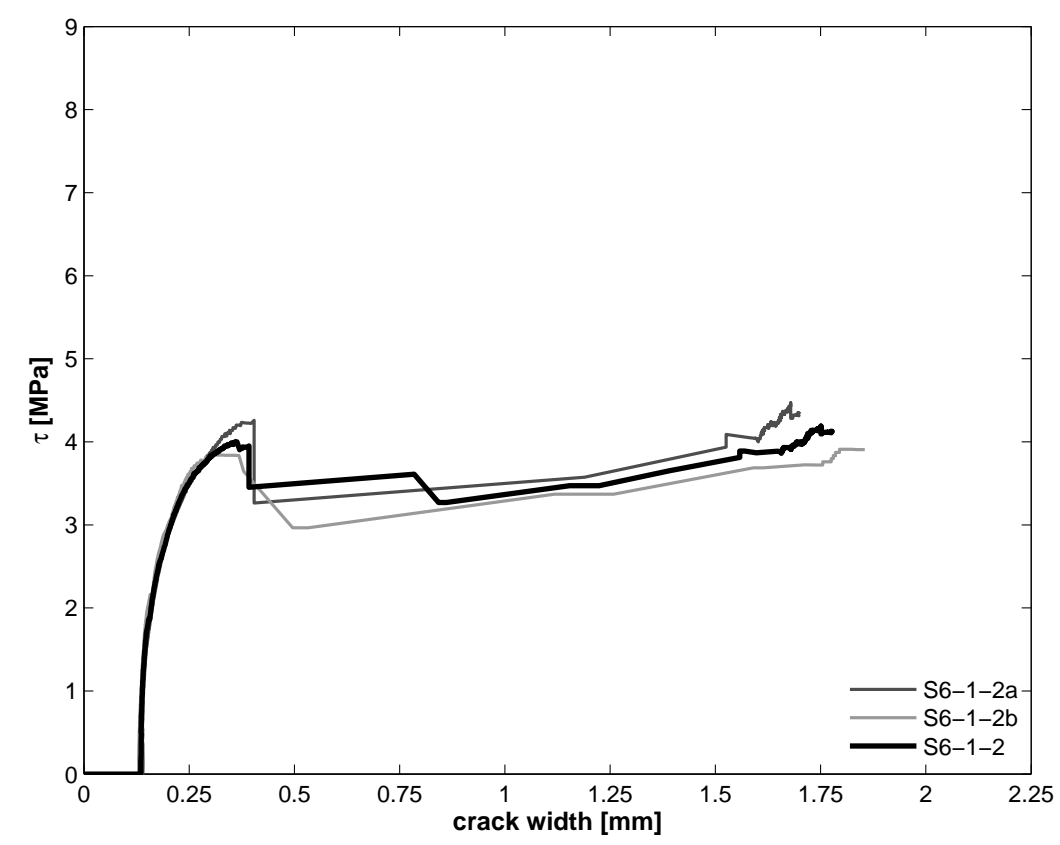

(b) Shear stress - crack width relationship

Fig. A.35. Shear behavior for confined specimens $\left(w_{o}=1\right)$, Material S6-1-2. 


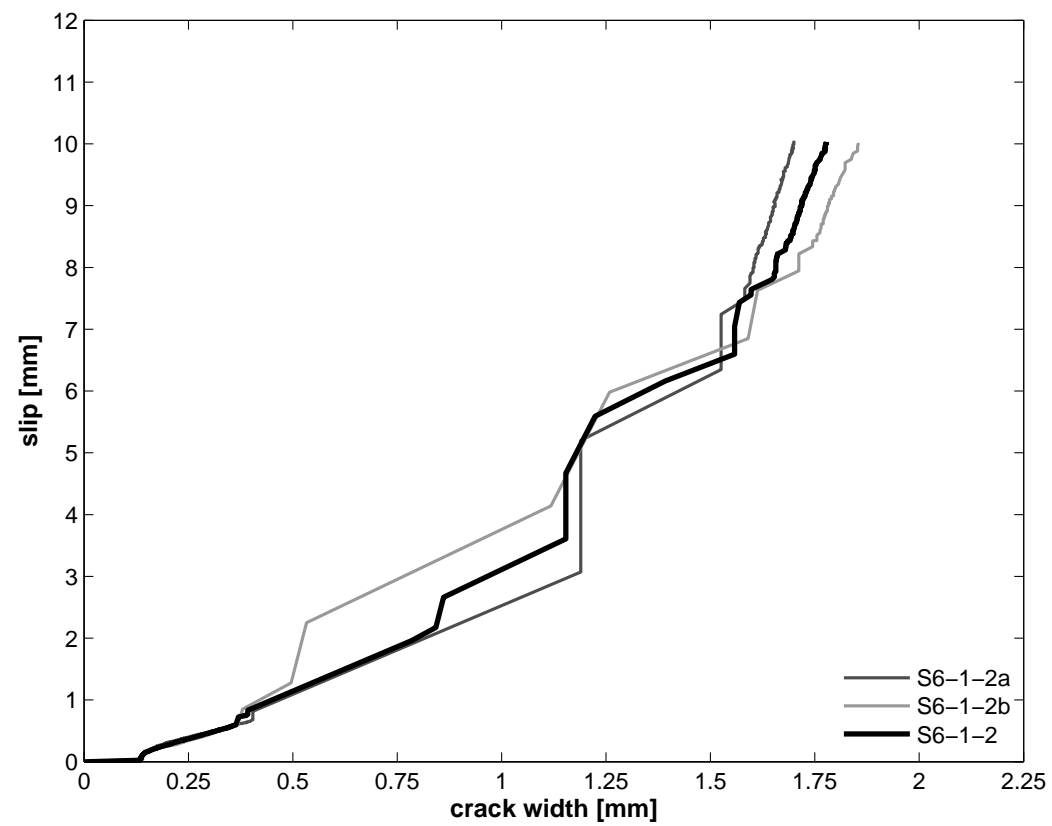

(a) Crack opening path relationship

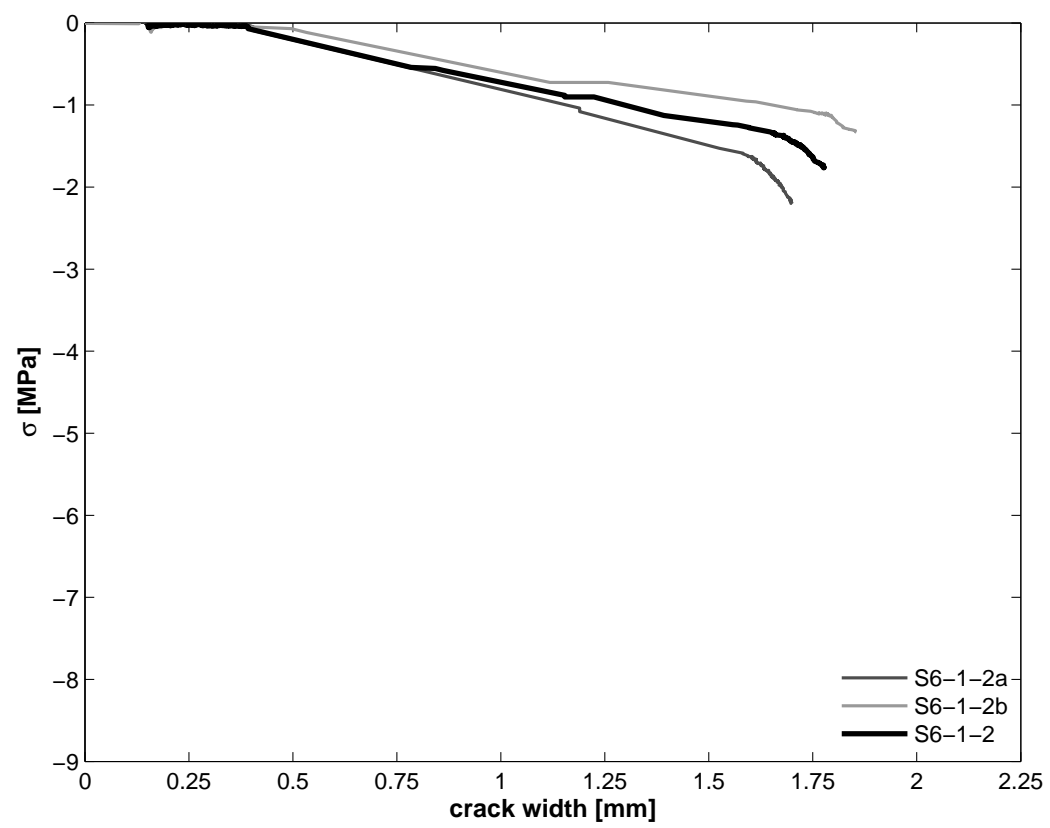

(b) Normal stress - crack width relationship

Fig. A.36. Shear behavior for confined specimens $\left(w_{o}=1\right)$, Material S6-1-2 (continued). 


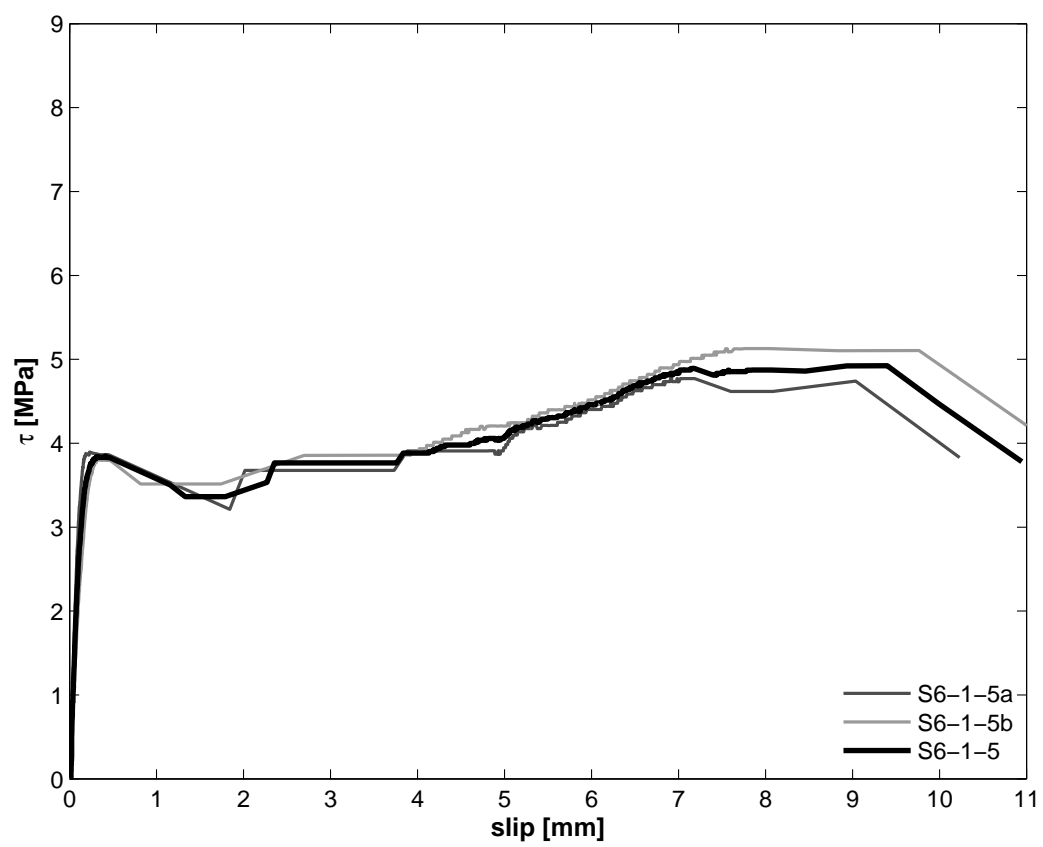

(a) Shear stress - slip relationship

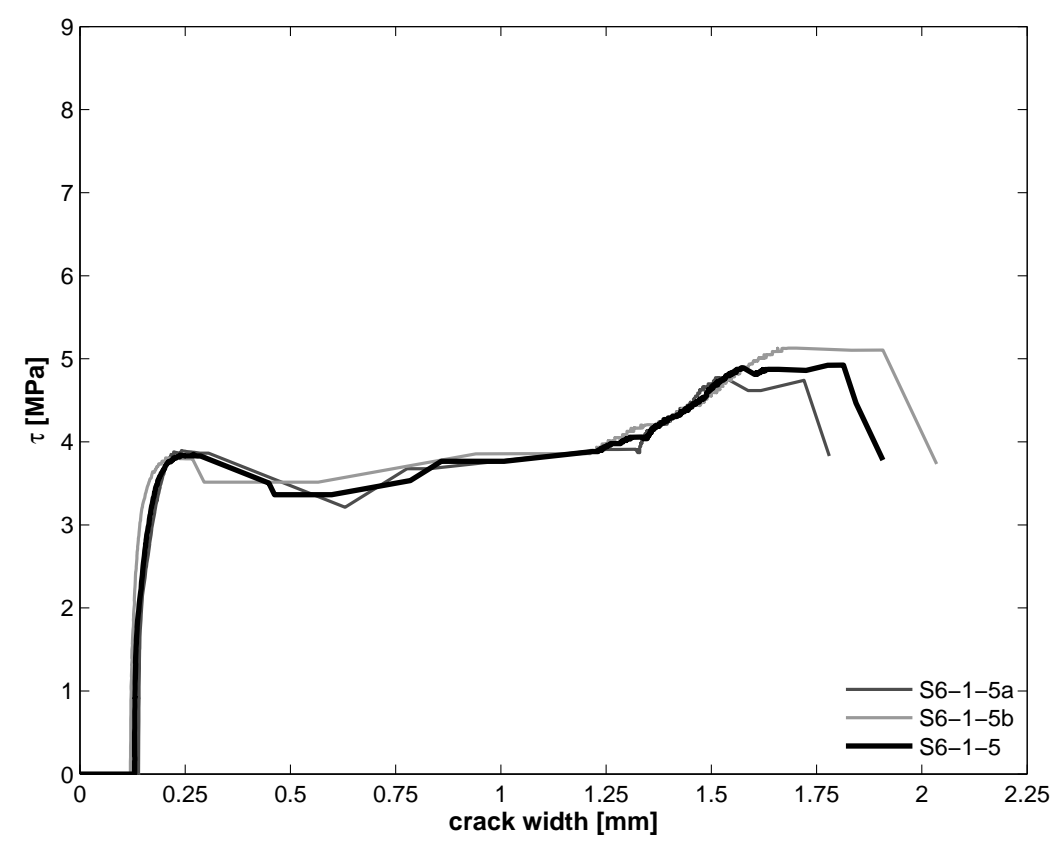

(b) Shear stress - crack width relationship

Fig. A.37. Shear behavior for confined specimens $\left(w_{o}=1\right)$, Material S6-1-5. 


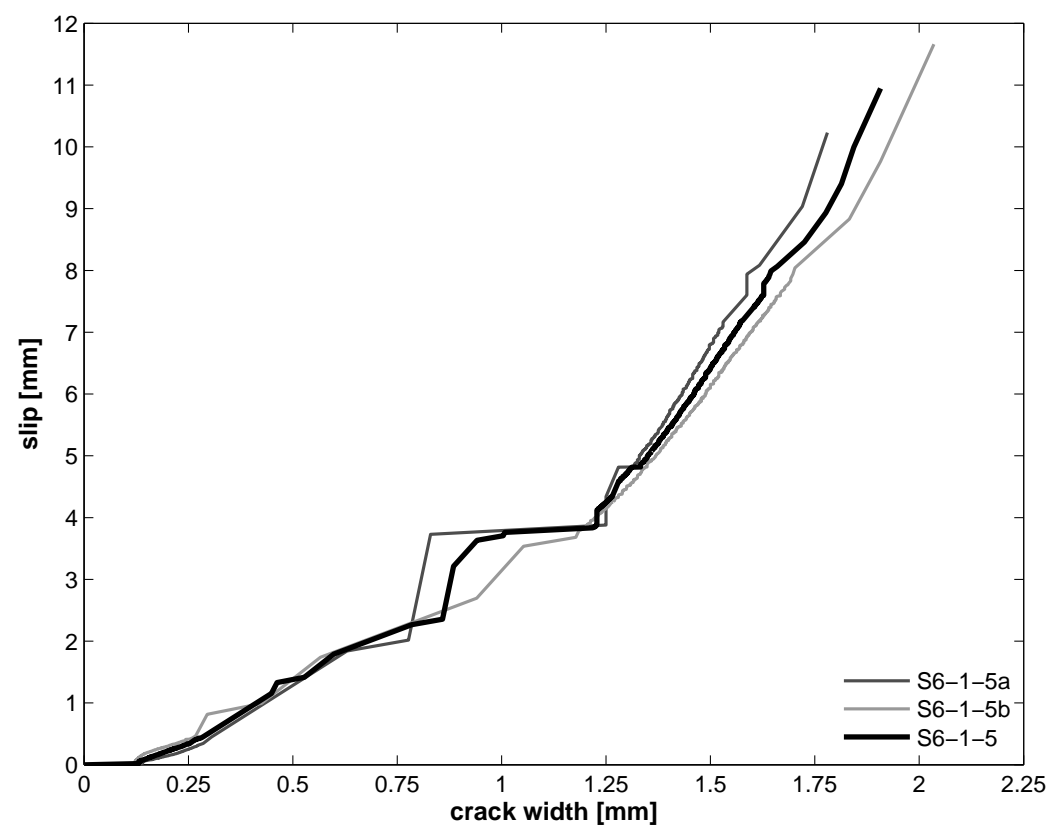

(a) Crack opening path relationship

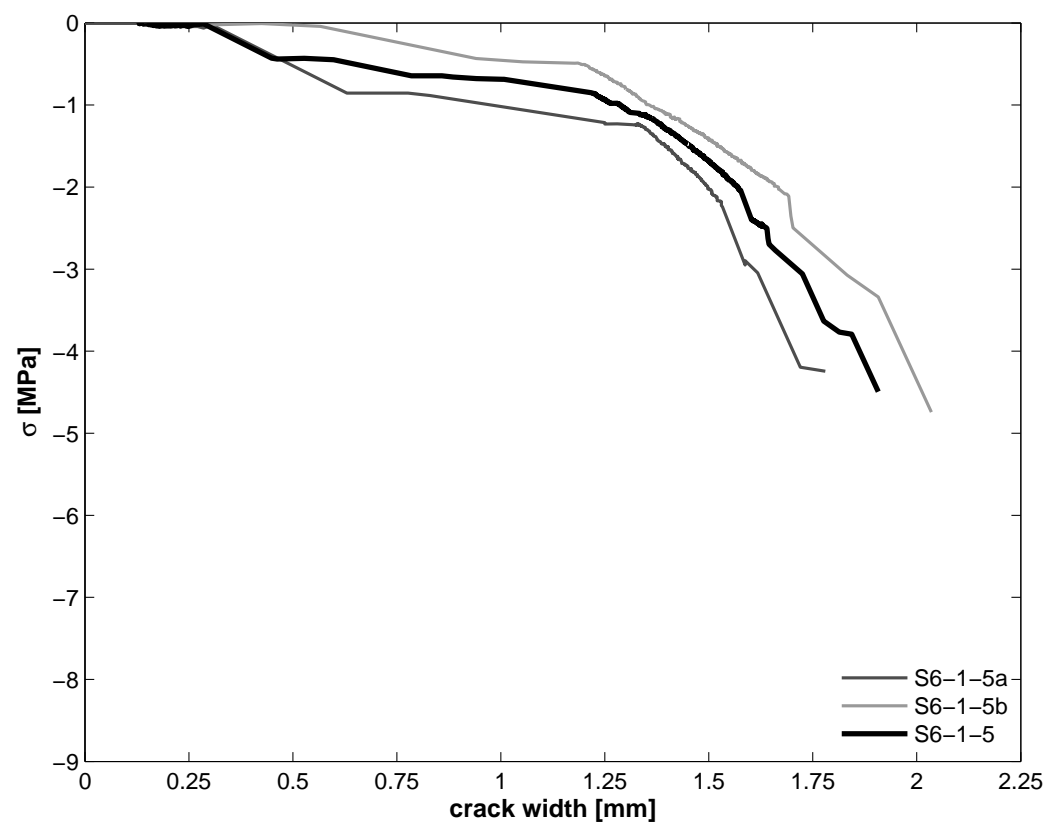

(b) Normal stress - crack width relationship

Fig. A.38. Shear behavior for confined specimens $\left(w_{o}=1\right)$, Material S6-1-5 (continued). 


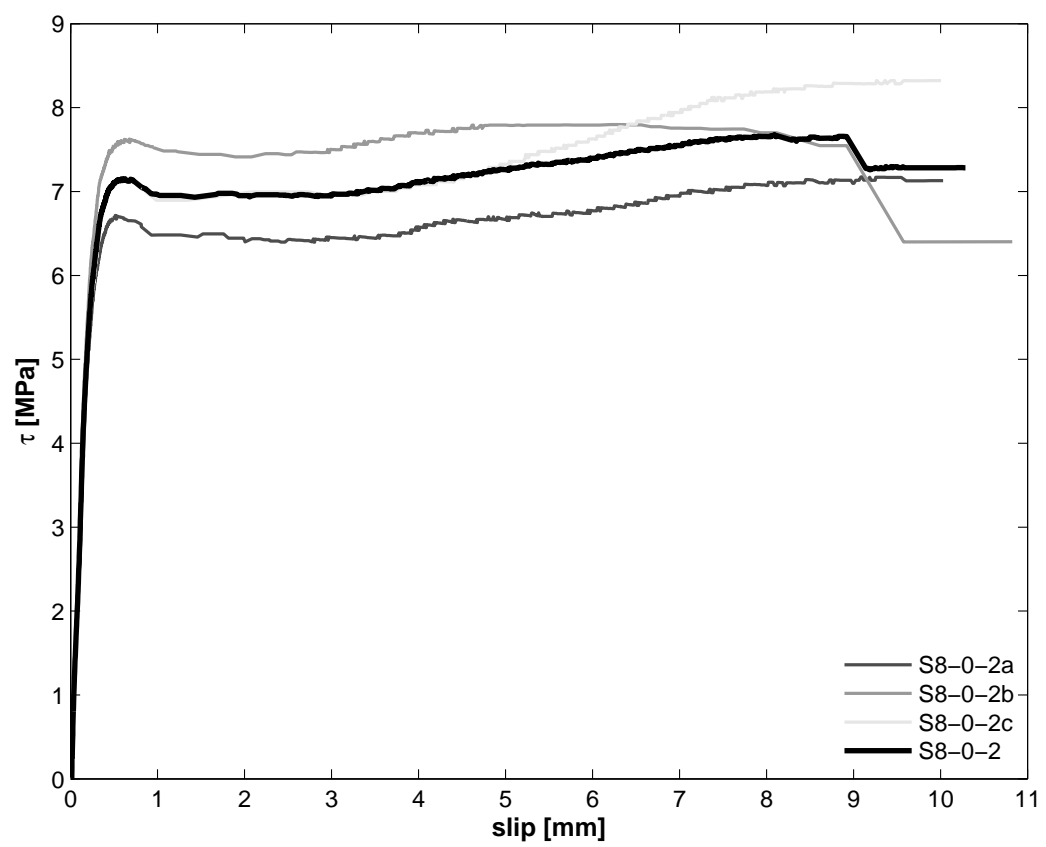

(a) Shear stress - slip relationship

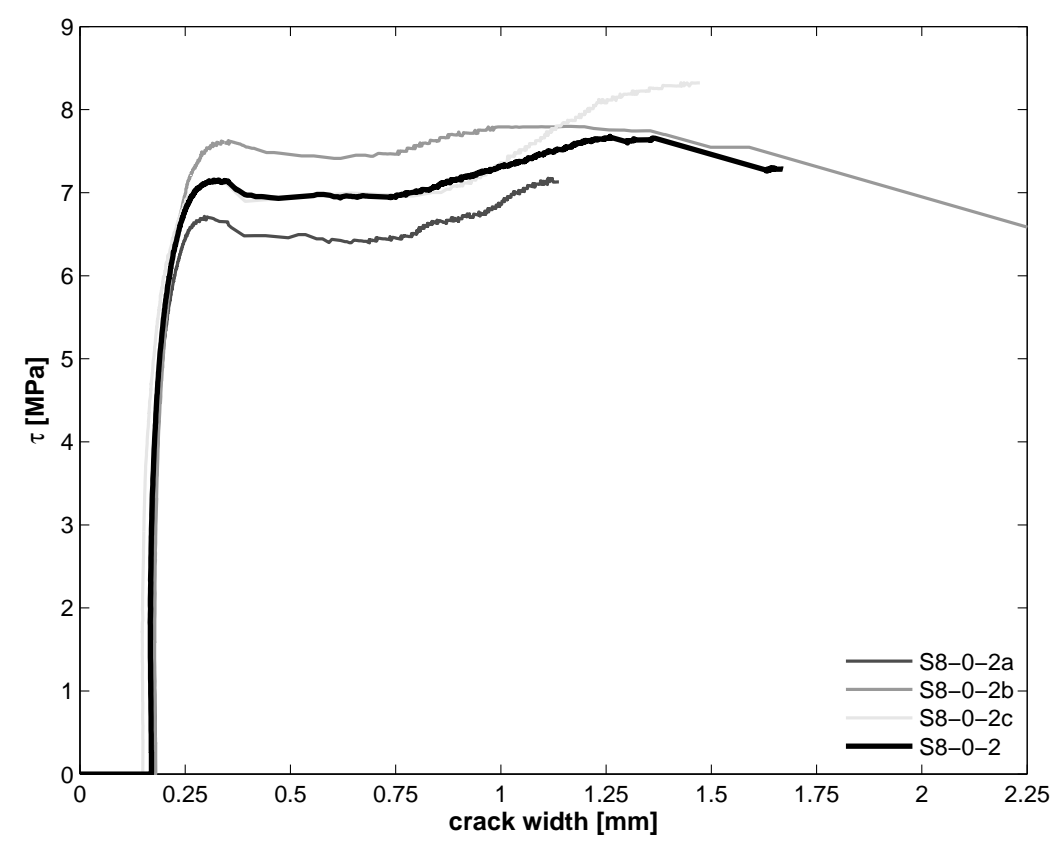

(b) Shear stress - crack width relationship

Fig. A.39. Shear behavior for confined specimens $\left(w_{o}=0\right)$, Material S8-0-2. 


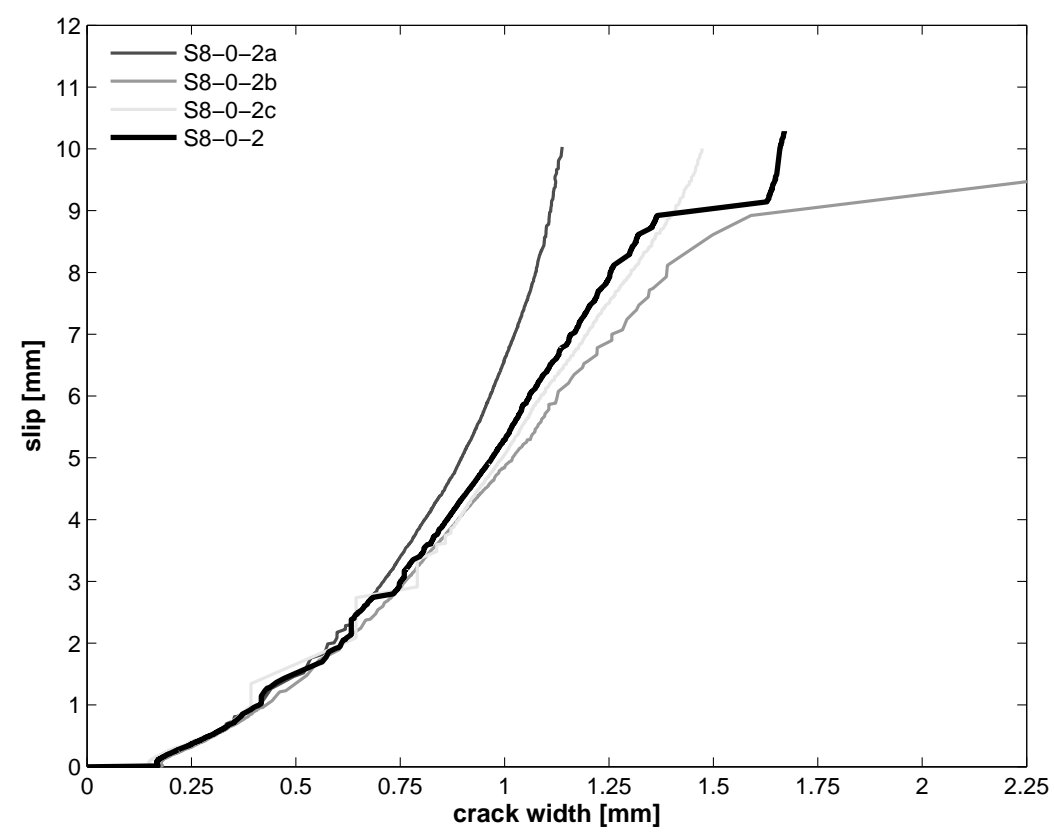

(a) Crack opening path relationship

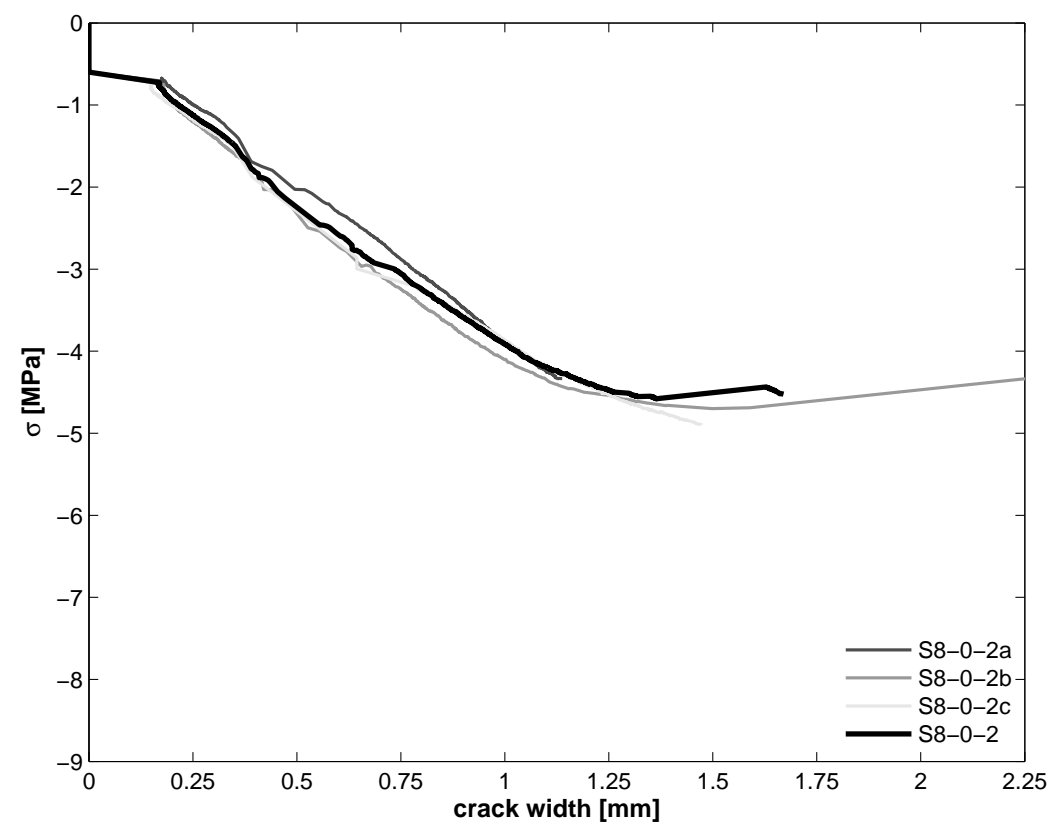

(b) Normal stress - crack width relationship

Fig. A.40. Shear behavior for confined specimens $\left(w_{o}=0\right)$, Material S8-0-2 (continued). 


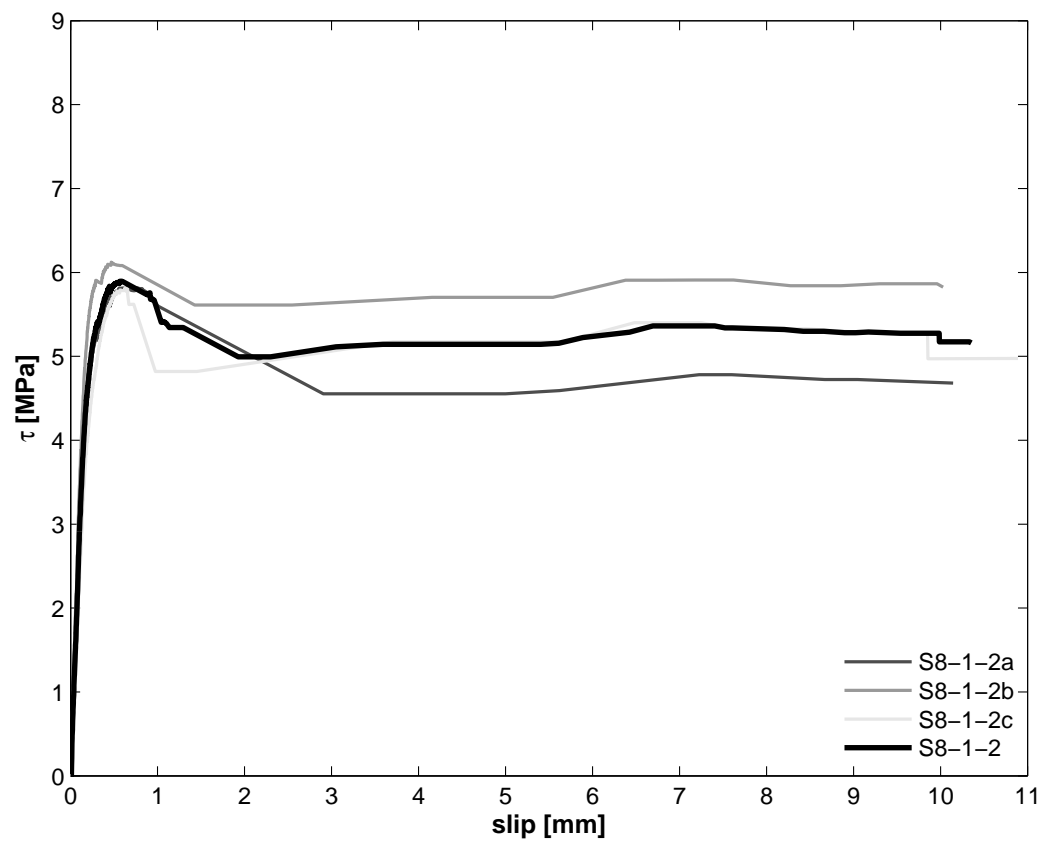

(a) Shear stress - slip relationship

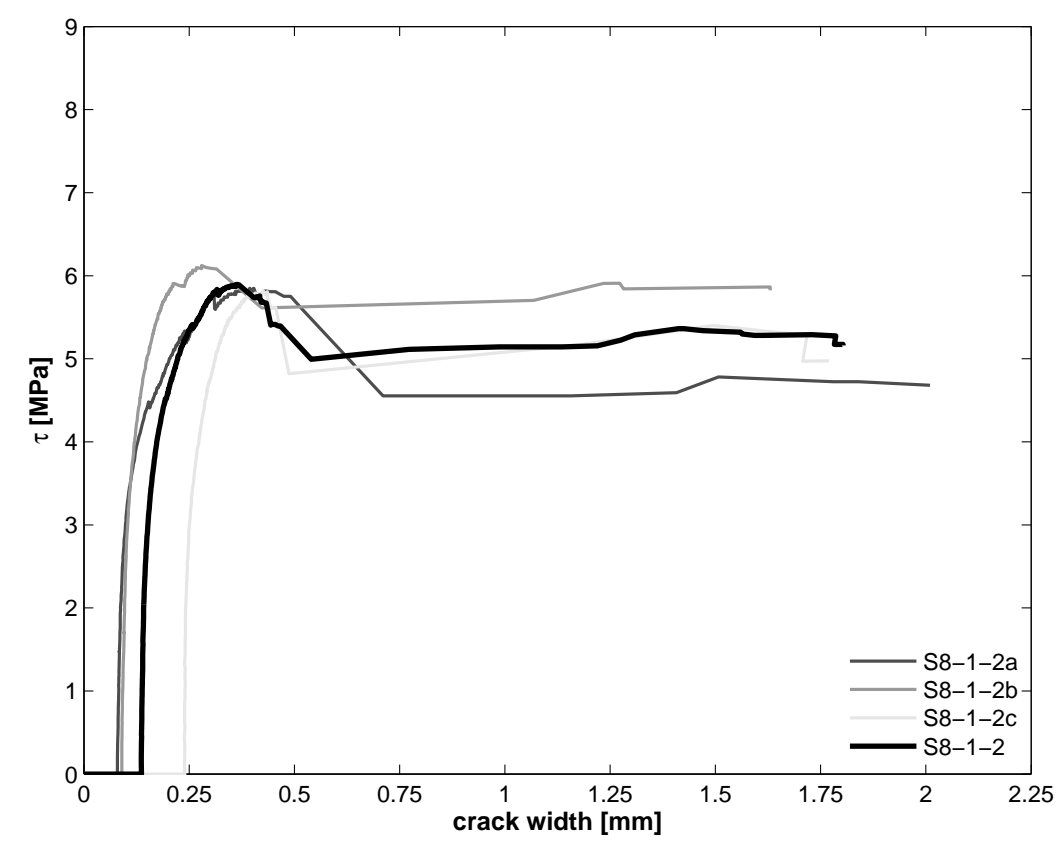

(b) Shear stress - crack width relationship

Fig. A.41. Shear behavior for confined specimens $\left(w_{o}=1\right)$, Material S8-1-2. 


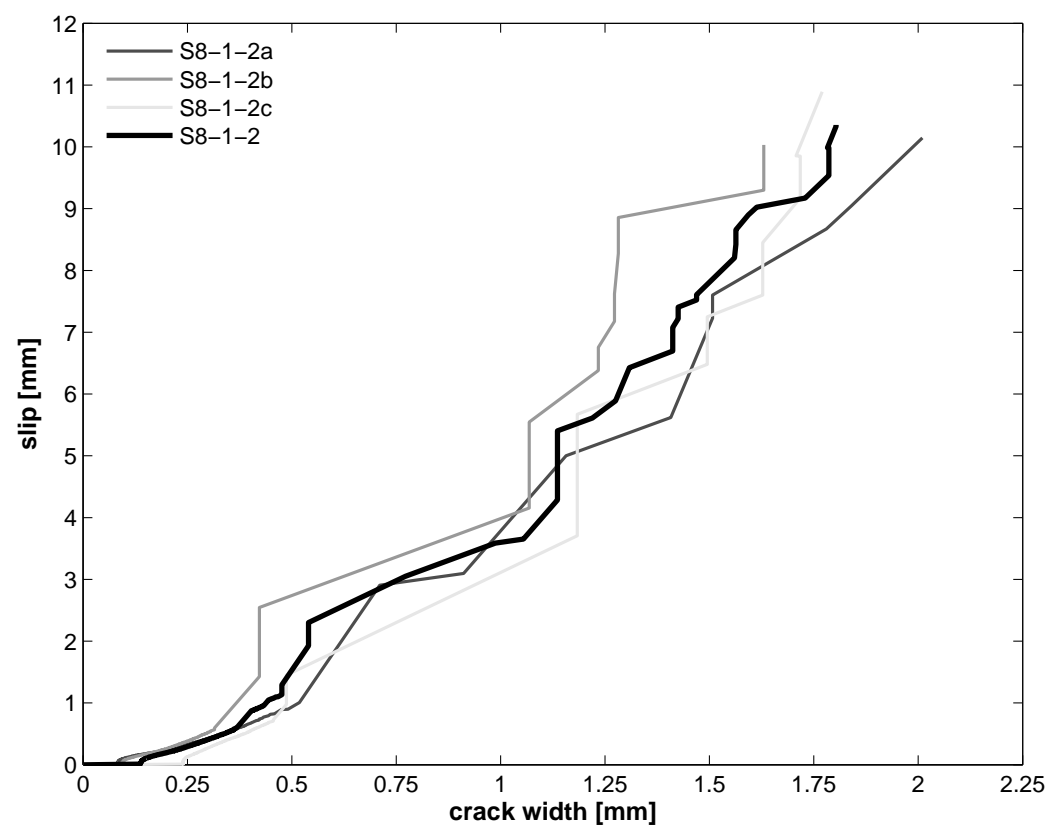

(a) Crack opening path relationship

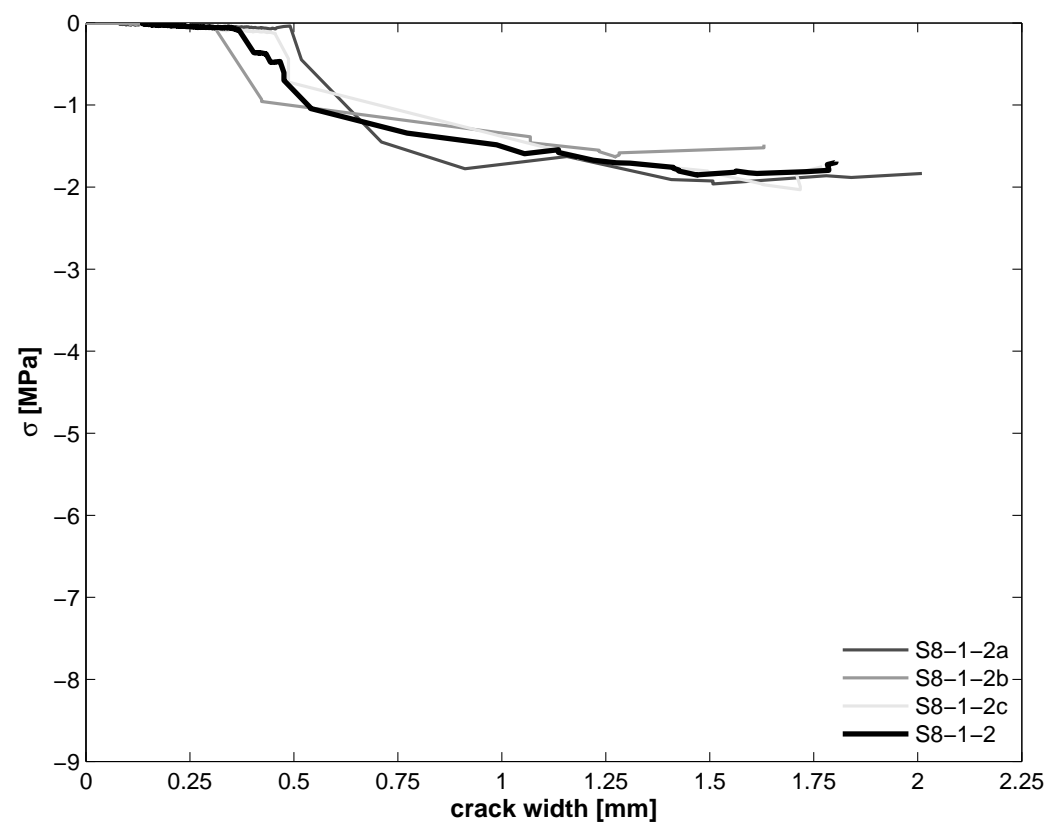

(b) Normal stress - crack width relationship

Fig. A.42. Shear behavior for confined specimens $\left(w_{o}=1\right)$, Material S8-1-2 (continued). 